\title{
A QUANTITATIVE DECISION MODEL TOWARDS MAXIMIZING ORGANIZATIONAL SUSTAINABILITY
}

\author{
by
}

\section{Fikret Korhan Turan}

B.S. in Industrial Engineering, Bogazici University, 2005

M. S. in Industrial Engineering, University of Pittsburgh, 2006

\author{
Submitted to the Graduate Faculty of \\ the Swanson School of Engineering in partial fulfillment \\ of the requirements for the degree of \\ Doctor of Philosophy
}

University of Pittsburgh 


\section{UNIVERSITY OF PITTSBURGH SWANSON SCHOOL OF ENGINEERING}

This dissertation was presented

by

Fikret Korhan Turan

It was defended on

November 18, 2009

and approved by

Aaron M. Swoboda, Mellon Post-Doctoral Fellow, Department of Economics, Carleton College

Bryan Norman, Associate Professor, Department of Industrial Engineering Jayant Rajgopal, Associate Professor, Department of Industrial Engineering Dissertation Co-Directors:

Mary E. Besterfield-Sacre, Associate Professor, Department of Industrial Engineering Kim LaScola Needy, Professor and Department Head, Department of Industrial Engineering, University of Arkansas 
Copyright (C) by Fikret Korhan Turan

2010 


\title{
A QUANTITATIVE DECISION MODEL TOWARDS MAXIMIZING ORGANIZATIONAL SUSTAINABILITY
}

\author{
Fikret Korhan Turan, PhD \\ University of Pittsburgh, 2010
}

In today's rapidly changing global world, the sustainability of an organization depends not only upon its financial performance, but also upon its environmental and social performance. It is suggested that policy makers, and corporate and engineering managers integrate economic, environmental and social objectives i.e., the triple bottom line (TBL) into their overall strategic plan and consider these objectives in their decision making. Investment planning and capital budgeting decisions play a critical role in aligning an organization with its economic, environmental and social strategic objectives. This research introduces a new decision making tool that integrates both financial and non-financial performance measures into the process of investment planning and capital budgeting via the TBL. It makes use of stakeholder theory for group decision making, analytic network process (ANP) as a decision support tool and stochastic linear programming to create an optimal investment portfolio. This new tool evaluates and prioritizes a set of projects and creates a long-term balanced investment portfolio based upon the perspectives and priorities of the stakeholder groups and decision makers. It can assist decision makers with developing and making proactive decisions which support the strategy of their organization with respect to economic, environmental and social issues, ensuring the sustainability of their organization in the future. To create a sustainability culture both in academia and business environment, and to encourage communities for sustainable development, a real life application of the developed tool is provided through coordination with Sustainable Pittsburgh and Cranberry Township business leaders. 


\section{TABLE OF CONTENTS}

PREFACE ...................................................................................................................................... XIV

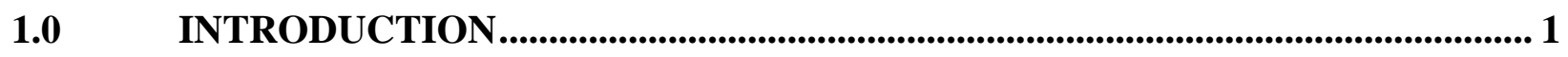

$2.0 \quad$ MOTIVATION.................................................................................................................. 3

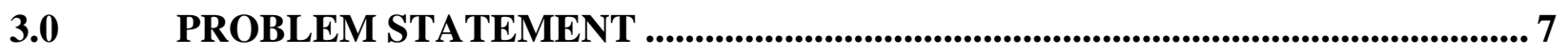

4.0 RESEARCH QUESTIONS ................................................................................................ 15

5.0 PERFORMANCE MANAGEMENT AND ORGANIZATIONAL SUSTAINABILITY ................................................................................................................ 18

5.1 PERFORMANCE MANAGEMENT AND COST MANAGEMENT ........... 18

5.2 MANAGING ORGANIZATIONAL SUSTAINABILITY ............................. 20

6.0 COMPONENTS OF PROPOSED MANAGEMENT TOOL ............................... 22

6.1 STAKEHOLDER THEORY ................................................................................. 22

6.2 TRIPLE BOTTOM LINE AND SUSTAINABILITY INDEX SYSTEM .... 24

6.3 ANALYTIC HIERARCHY PROCESS (AHP) METHODOLOGY ............ 26

6.4 ANALYTIC NETWORK PROCESS (ANP) METHODOLOGY ................. 28

6.5 STOCHASTIC LINEAR PROGRAMMING .................................................... 30

6.5.1 Deterministic Linear Programs................................................................................. 30

6.5.2 Stochastic Linear Programs ..................................................................................... 31

6.5.3 Two-Stage Stochastic Linear Program with Fixed Recourse ....................... 32

7.0 DEVELOPMENT OF THE PROPOSED MANAGEMENT TOOL ..................... 34 


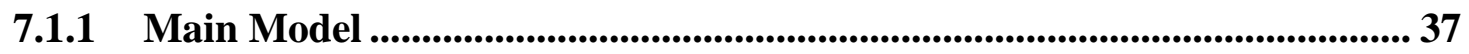

7.1.2 Subnetworks................................................................................................. 39

7.2 PROPOSED MULTI-STAGE STOCHASTIC LINEAR PROGRAM ........ 41

7.3 DEMONSTRATION OF THE PROPOSED MANAGEMENT TOOL....... 47

7.3.1 Determination of Stakeholders.............................................................. 48

7.3.2 Triple Bottom Line Sustainability Index System........................................ 49

7.3.3 Analytic Hierarchy Process (AHP) ...................................................... 49

7.3.4 Three-Stage Stochastic Linear Program ............................................ 50

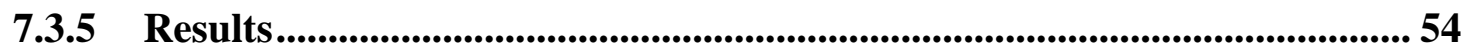

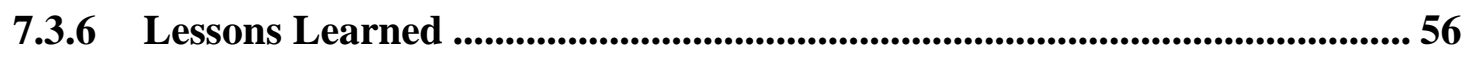

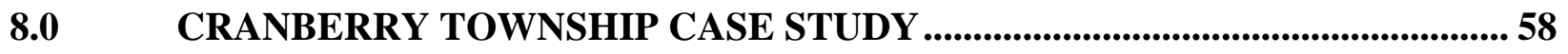

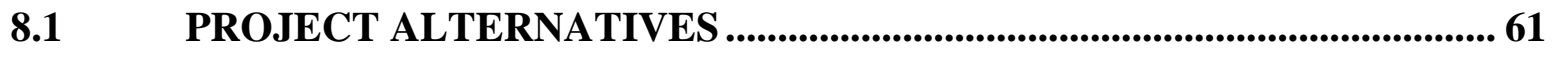

8.2 SUSTAINABILITY PERFORMANCE CRITERIA SET ........................... 63

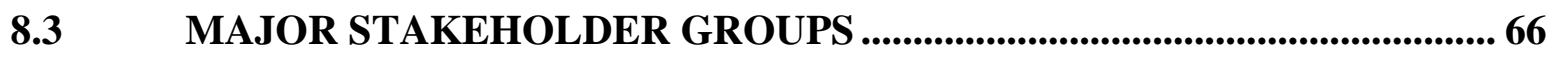

D.4 DEVELOPMENT OF ANP MODEL .....................................................69

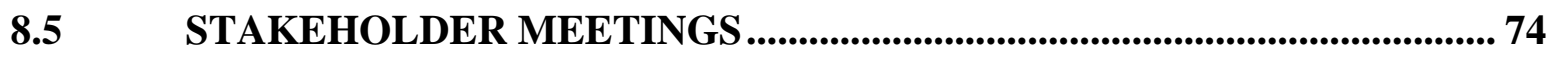

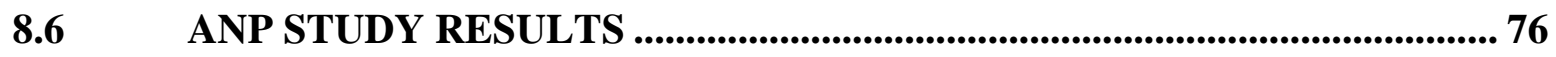

8.7 FINANCIAL ANALYSIS OF PROJECT ALTERNATIVES..................... 82

8.7.1 Project 1 - Building a Compost Facility (Compost)...................................... 84

8.7.2 Project 2 - Purchasing Alternative Fuel Vehicles for Cranberry Township Fleet (Alternative Fuel) ........................................................................ 90

8.7.3 Project 3 - Purchasing Renewable Energy Certificates (RECs)................. 96

8.7.4 Project 4 - Implementing Public Transportation System (Transit) .......... 98 
8.7.5 Project 5 - Achieving Gold status of LEED Certification for Municipal Center (LEED).

8.8 CREATING AN OPTIMAL BALANCED INVESTMENT PORTFOLIO115

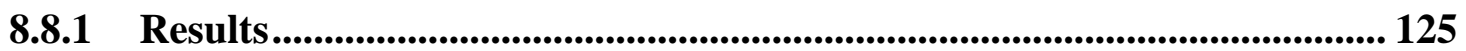

8.8.2 Sensitivity Analysis .................................................................................... 131

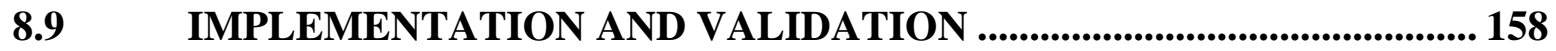

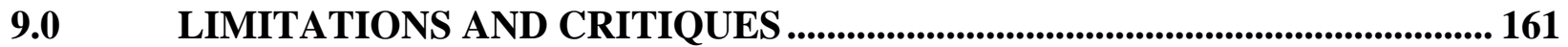

10.0 SUMMARY OF MAJOR RESEARCH FINDINGS ........................................... 164

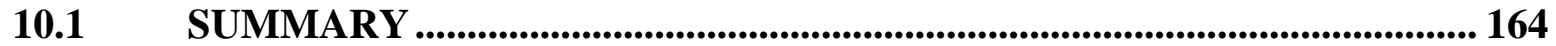

10.2 CONTRIBUTION FROM AN ACADEMIC PERSPECTIVE .................... 167

10.3 CONTRIBUTION FROM DECISION MAKER'S PERSPECTIVE......... 168

11.0 FUTURE RESEARCH DIRECTIONS ....................................................... 170

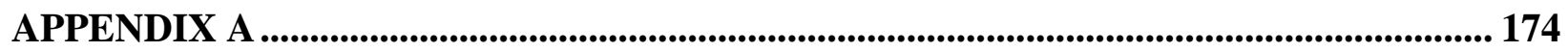

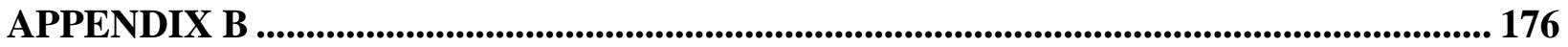

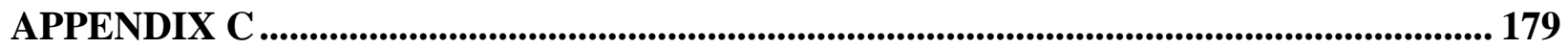

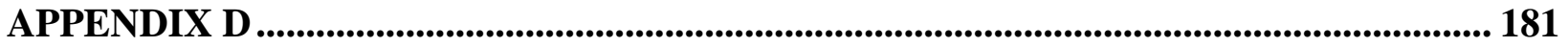

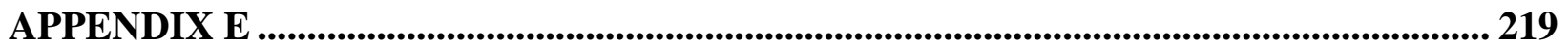

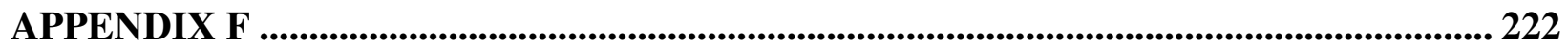

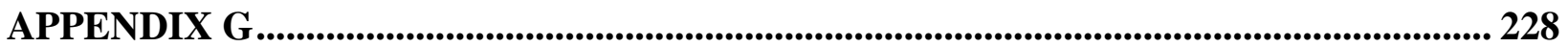

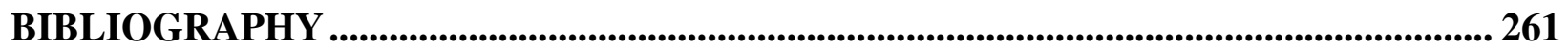




\section{LIST OF TABLES}

Table 1: AHP fundamental scale of absolute numbers $($ Saaty,1994) .......................................... 28

Table 2: Common issues in the U.S. electric utility industry and the related project alternatives (Turan et al., 2008) 36

Table 3: Internal rate of returns (IRRs) of project alternatives during recession and boom times48

Table 4: Overall weights of the project alternatives based on the perspectives of three stakeholder groups 53

Table 5: SRR values of the project alternatives (calculated by using the overall weights shown in Table 4) 53

Table 6: Model results for several K values 55

Table 7: Detailed time allocation for a typical stakeholder meeting (See Appendix D.2 for comparison sets) 75

Table 8: Information related to the stakeholder meetings ........................................................... 76

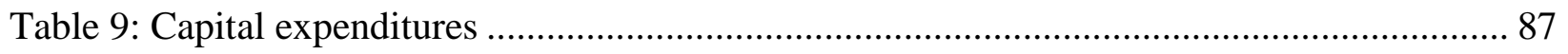

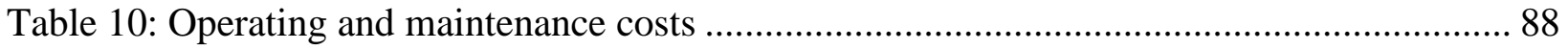

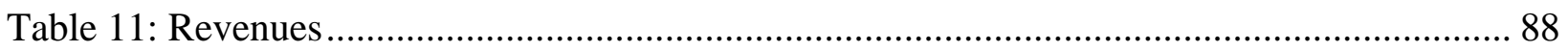

Table 12: Internal rate of return (IRR) of building a compost facility in Cranberry Township (Project 1) for worst case, most probable and best case scenarios

Table 13: Extra investment required to purchase alternative fuel vehicles and related savings obtained on fuel cost if the alternative fuel vehicles are preferred

Table 14: Internal rate of return (IRR) of purchasing alternative fuel vehicles for Cranberry Township fleet (Project 2) for worst case scenario. 
Table 15: Internal rate of return (IRR) of purchasing alternative fuel vehicles for Cranberry Township fleet (Project 2) for most probable scenario.

Table 16: Internal rate of return (IRR) of purchasing alternative fuel vehicles for Cranberry Township fleet (Project 2) for best case scenario 96

Table 17: Cost of purchasing PA wind RECs (Adapted from Mehalik et. al, 2008)................. 97

Table 18: Cost of purchasing national wind RECs (Adapted from Mehalik et. al, 2008)........... 98

Table 19: Capital expenditures (Adapted from the CAT Study) .......................................... 100

Table 20: Conceptual bus transportation system around Cranberry Township and related route specific capital cost, operating cost and revenue information 102

Table 21: Internal rate of return (IRR) of implementing a bus transportation system around Cranberry Township (Project 4) for worst case, most probable and best case scenarios 104

Table 22: Advantages and disadvantages of intensive and extensive green roofs (Adapted from Dinsdale et al., 2006) 107

Table 23: Cost statistics of the implementation and certification processes for 14 LEED certified existing buildings (Adapted from Leonardo Academy, Inc., 2008) ..... 112

Table 24: Internal rate of return (IRR) of achieving Gold status of LEED certification for the Municipal Center (Project 5) for worst case, most probable and best case scenarios 115

Table 25: Annual internal rate of returns (IRRs) of five project alternatives 116

Table 26: Three-years compounded internal rate of returns (IRRs) of five project alternatives 117

Table 27: Normalized overall weights (OWs) of the five project alternatives 118

Table 28: Sustainability rate of returns (SRRs) of the five project alternatives 118

Table 29: Scenario probabilities 121

Table 30: Probabilities assigned to each stakeholder perspective (i.e., $P_{j}$ values) $\ldots . . . \ldots \ldots \ldots . . . . . . . .122$

Table 31: Limits on total minimum and maximum investment amounts 124

Table 32: Limits on minimum and maximum investment amounts at each period..... 125

Table 33: Model results for several K values 126 
Table 34: Analysis of Model 1 results for $b=\$ 7,000,000$

Table 35: Investment strategies proposed by investment portfolios 1, 2 and 3 .

Table 36: Three-year internal rate of return (IRR) values of Project 3 (Financial) assumed for the worst case, most probable case and best case scenarios 133

Table 37: Assumed sustainability rate of return (SRR) values for Project 3 (Financial) ..... 133

Table 38: Limits on minimum and maximum investment amounts on Project 3 (Financial) .... 133

Table 39: Model 2 results when initial wealth is $\$ 283,000$ 135

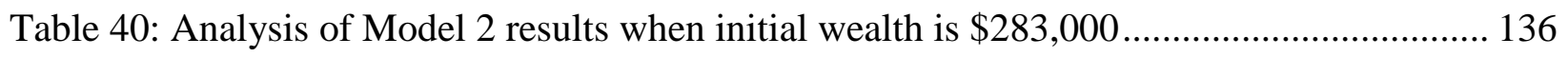

Table 41: Model 2 results when initial wealth is $\$ 5,000,000$............................................. 136

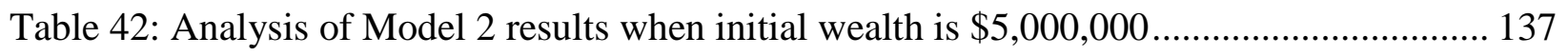

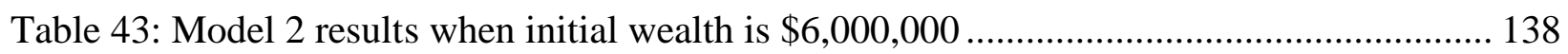

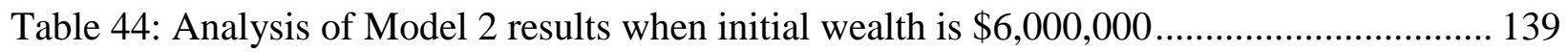

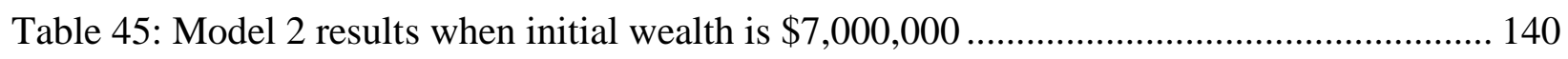

Table 46: Analysis of Model 2 results when initial wealth is $\$ 7,000,000 \ldots \ldots \ldots \ldots \ldots \ldots \ldots \ldots \ldots \ldots . . . . . . . . . . . . . . .141$

Table 47: Model 2 results when initial wealth is $\$ 7,350,000$............................................ 142

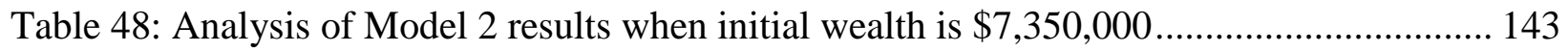

Table 49: Model 2 results when initial wealth is $\$ 7,478,000$............................................ 144

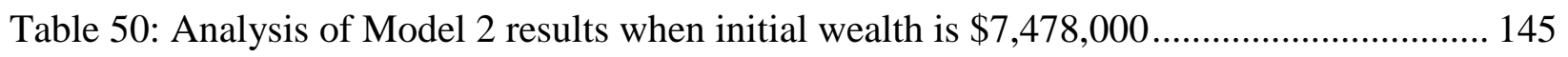

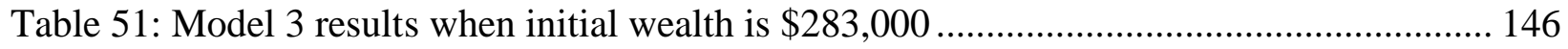

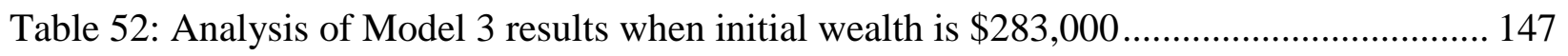

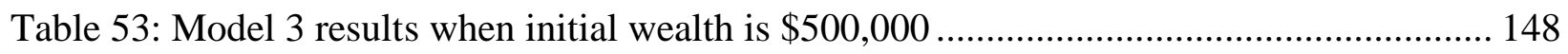

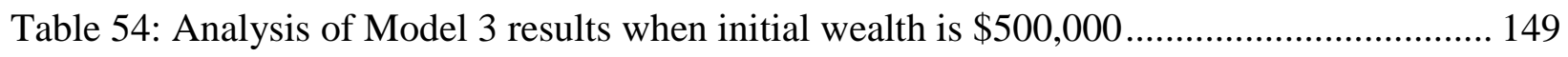

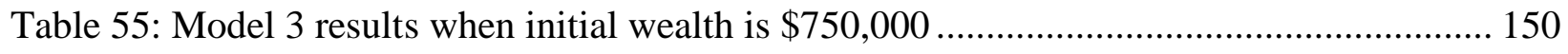

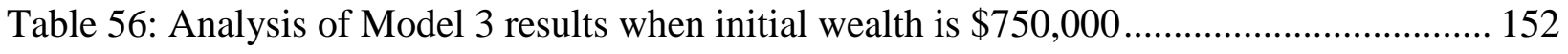


Table 57: Model 3 results when initial wealth is $\$ 953,000$

Table 58: Analysis of Model 3 results when initial wealth is $\$ 953,000$. 154

Table 59: Model 4 results when initial wealth is $\$ 500,000$...... 156

Table 60: Analysis of Model 4 results when initial wealth is $\$ 500,000$. 158 


\section{LIST OF FIGURES}

Figure 1: Characteristics of sustainable development principles....................................... 8

Figure 2: Triple bottom line framework and sustainability index system ............................. 26

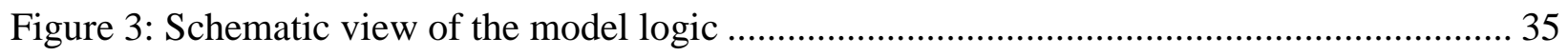

Figure 4: ANP Main Model - Hierarchy of strategic criteria and BOCR model ....................... 38

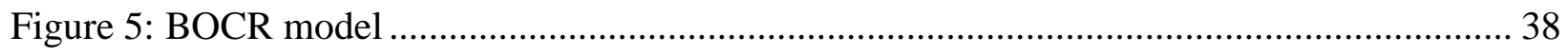

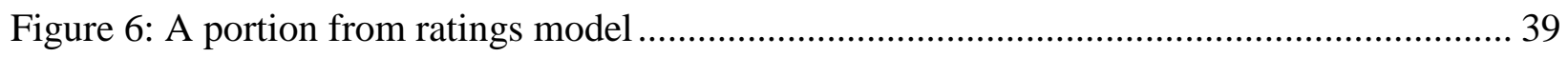

Figure 7: Subnetwork for economic benefits ............................................................... 40

Figure 8: The AHP model and hierarchy of criteria, sub-criteria, attributes and alternatives ...... 52

Figure 9: Investment portfolios on Financial (F) Value - Sustainability (S) Value graph.......... 56

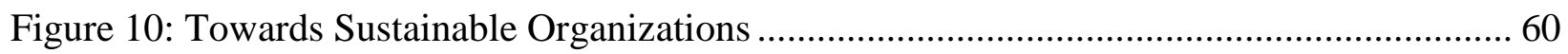

Figure 11: Final ANP model for Cranberry Township sustainability.................................... 69

Figure 12: Final Results of ANP study taken with Cranberry Township management............... 77

Figure 13: Final Results of ANP study taken with UPMC-Passavant................................... 78

Figure 14: Final Results of ANP study taken with Cranberry Township Homeowner's

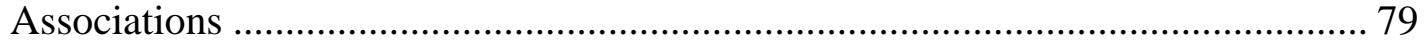

Figure 15: Final Results of ANP study taken with Cranberry Township employees ................. 80

Figure 16: Final Results of ANP study taken with Cranberry Township Chamber of Commerce 81

Figure 17: Modular green roof systems (Weston Solutions, Inc., 2009) ................................ 106 
Figure 18: Tree of scenarios for the three periods 120

Figure 19: Investment portfolios on Financial (F) Value - Sustainability (S) Value graph....... 127

Figure 20: Model 2 results on Financial (F) Value - Sustainability (S) Value graph when initial wealth is $\$ 283,000$ 135

Figure 21: Model 2 results on Financial (F) Value - Sustainability (S) Value graph when initial

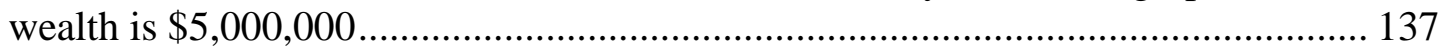

Figure 22: Model 2 results on Financial (F) Value - Sustainability (S) Value graph when initial wealth is $\$ 6,000,000$. 139

Figure 23: Model 2 results on Financial (F) Value - Sustainability (S) Value graph when initial wealth is $\$ 7,000,000$. 141

Figure 24: Model 2 results on Financial (F) Value - Sustainability (S) Value graph when initial wealth is $\$ 7,350,000$ 143

Figure 25: Model 2 results on Financial (F) Value - Sustainability (S) Value graph when initial wealth is $\$ 7,478,000$. 145

Figure 26: Model 3 results on Financial (F) Value - Sustainability (S) Value graph when initial wealth is $\$ 283,000$ 147

Figure 27: Model 3 results on Financial (F) Value - Sustainability (S) Value graph when initial wealth is $\$ 500,000$. 149

Figure 28: Model 3 results on Financial (F) Value - Sustainability (S) Value graph when initial wealth is $\$ 750,000$ 151

Figure 29: Model 3 results on Financial (F) Value - Sustainability (S) Value graph when initial wealth is $\$ 953,000$ 154

Figure 30: Model 4 results on Financial (F) Value - Sustainability (S) Value graph when initial wealth is $\$ 500,000$ 157 


\section{PREFACE}

I gratefully thank my academic advisors Dr. Kim LaScola Needy and Dr. Mary Besterfield-Sacre for their guidance, inspiration, and positive feedback throughout my graduate study at the University of Pittsburgh. Especially, I would like to express my deepest gratitude to Dr. Needy since she believed me, trusted me, and gave her continuous support throughout my graduate study not only as an advisor but also as a mentor. I feel I am really lucky since as a graduate student I had the opportunity to work with two great advisors who never hesitate to share the experience that they have gained in years with me faithfully.

I am also grateful to my dissertation committee members Dr. Jayant Rajgopal, Dr. Bryan Norman and Dr. Aaron Swoboda for their to-the-point comments and valuable suggestions. They played one of the most important roles in the completion of this dissertation.

Many thanks to Dr. Matthew Mehalik, Sustainable Pittsburgh, Mr. John Trant and Cranberry Township community for collaborating with me in the Cranberry Township Sustainability case study. It was really a pleasure and great experience for me to work with them.

I also would like to thank Dr. Robert Ries, Ankit Bansal and RT 254 research team members since I had the opportunity to develop my communication and research skills, and broaden my perspective by working together with them in the Construction Industry Institute (CII) project. 
My special thanks extend to all Industrial Engineering faculty members for their devotion to the education and development of their students. Special thanks to Dr. Andrew Schaefer for his helpful directions and advice, particularly in the first year of my study.

Also, I would like to mention wonderful staff of the Pitt IE department for providing their support and help to all faculty and students. I would like to express special thanks to Richard Brown and Angela Koval for sharing my art related e-mails with the faculty and students.

I am very grateful to all my friends not only at the Pitt IE department but also around Pittsburgh. I would like to thank Nur O. and Osman Y. Ozaltin, Murat Kurt, Burhaneddin Sandikci, Sakine Batun, Zeynep Erkin, Mustafa Baz, Erkut Sonmez, Halil Bayrak, Gorkem Saka, Zeynep Gozde Icten, Isil Ondes, Anil Yilmaz, Andrej Savol, Natalie Scala, Gillian Nicholls, Tuba Pinar Yildirim, Sebnem and Nuri Mehmet Gokhan, Natalie and Eugene Phillips, Aycil Cesmelioglu, John (Jay) P. Newton, Alp Sekerci, Anil Yilmaz, Sepehr Nemati Proon, Mehmet C. Demirci, Yonca and Levent Yilmaz, Cem Yolcu, Yu Wang, Lizhi Wang, Guiping Hu, Tolga Esat Ozkurt, Kadir Diri, Natasa Vidic, Rob Koppenhaver, Ozlem Arisoy, Erin Claypool, Erdem Erdirik, Akram Kamrani, Andy Trapp, Shengnan Wu, Ozgun Ekici, Vusal Babashov, Guvenc Degirmenci, M. Yasin Ulukus, and Serdar Karademir for sharing an exciting and joyful life with me.

Finally, I devote this dissertation to my dear parents Huriye and Ekrem Turan, and my sister Nedret Turan who have always given me their endless love, encouragement and unconditional support throughout my life. 


\subsection{INTRODUCTION}

As we begin the $21^{\text {st }}$ Century, it is evident that the world is rapidly changing. In today's high technology environment, while it is possible to easily purchase a product from another country, it is also possible to be adversely impacted by global warming propagated by the carbon emissions from manufacturers in other countries. In recent years, as environmental problems and their impact on nature, people and economies have been understood by policy makers, corporate and engineering managers, these stakeholders have started to look for new and contemporary management tools. Mainly, they have focused on developing management tools that will provide an insight into the best decisions leading to sustainable development in the changing world.

In this context, a new management tool that integrates both financial and non-financial performance measures including environmental and social, into the process of project portfolio management, investment planning and capital budgeting decisions via the triple bottom line (TBL) framework is proposed. This tool makes use of stakeholder theory for group decision making, analytic network process (ANP) as a decision support tool and stochastic linear programming to create an optimal investment project portfolio. In summary, it evaluates and prioritizes a set of projects by considering their impacts on different stakeholder groups such as shareholders, suppliers, employees, customers, non-governmental organizations (NGOs), financial partners, regulators, public authorities, community, etc., and creates an optimal balanced investment project portfolio based on that prioritization throughout a predetermined 
planning horizon. More specifically, it answers the question "Which projects should be selected, at what point should these projects be selected, and to what level should an organization invest in these projects to improve or even maximize its sustainability?" 


\subsection{MOTIVATION}

The word sustainability remains ambiguous although it has been used frequently by many people. The World Commission on Environment and Development (1987) defines sustainability as "economic development that meets the needs of the present generation without compromising the ability of future generations to meet their own needs." This definition is considered as the starting point of defining sustainability. At the organizational level, Dyllick and Hockerts (2002) define corporate sustainability as "meeting the needs of a firm's direct and indirect stakeholders without compromising its ability to meet the needs for future stakeholders as well." In general, corporate sustainability is defined as a "business approach that creates long-term shareholder value by embracing opportunities and managing risks deriving from the developments in three sustainability dimensions - economic, environmental and social" (Dow Jones Sustainability Indexes, 2008). In that sense, in today's competitive, complex and dynamic business environment, corporate sustainability is one of the major concerns of policy makers, and corporate and engineering managers since it enables an entity to build and maintain the longterm satisfaction of stakeholders.

Although sustainable development practices seem to be inconsistent with the short-term economic objectives of an organization, it can be understood that they are essential considerations when the long-term economic success and satisfaction of the stakeholders of the organization are considered. For instance, a study conducted by Switzerland's Bank Sarasin in 
2002 shows that the fluctuation in the share prices of companies that adopt environmentally and socially compatible business practices is lower than the fluctuation in the share prices of other companies which are in the same industry (Plinke, 2002). Similarly, by taking Tobin's $q$ (a ratio comparing the market value of a company's stock with the value of a company's equity book value developed by James Tobin in 1969) as the proxy for firm value, Lo and Sheu (2007) find a significantly positive relationship between corporate sustainability and business' market value. Additionally, recent environmental problems such as global climate change and the increased awareness of society with regard to environmental and social issues compel policy makers, and corporate and engineering managers to implement sustainable development practices in their organizations.

Conventional management tools and performance measures driven by economic rationality and profit maximization are relatively inadequate and poor in today's global conditions since they not only isolate or ignore the environmental and social impacts of organizational activities, but also consider only the local concerns and lack a global thinking perspective. In today's business environment, it is relatively easy to identify companies which are considered to be "big polluters." For instance, during the last three years, serious environmental and social events have taken place in BP's U.S. facilities: In March 2005, the BP refinery in Texas City faced a tragic explosion and fire which took the lives of 15 people. After that, two more fires occurred in the plant in July and August 2005. In March 2006, Alaskan BP facilities reported that the largest ever oil spill in the state had resulted from failures in corroded transmission pipelines due to inadequate maintenance. BP's pollution problems continue as BP plans to invest in the massive refinery in Whiting, Indiana which is located outside of Chicago and is already considered a large polluter in the Midwest (Verschoor, 2007). As another 
illustration, ten large companies (American Electric Power, Southern Company, AES Corporation, Duke Energy, Tennessee Valley Authority, NRG Energy, Xcel Energy, Midamerican Energy Holdings, Progress Energy and Dominion Resources) generate more than one third of the 2.8 billion tons of carbon dioxide emitted each year by the U.S. electric power generators (Lavelle, 2007). Even if some companies have environmental and social concerns and add social responsibility projects to their corporate plans, often their attempts do not reach the desired level of success since their perspectives about environmental and social issues are local rather than global.

Although leading multinational companies such as the Shell Group, Bristol-Myers Squibb Company, Unilever, Baxter International Inc., and Ford Motor Company are exploring the use of sustainability and reporting to define and implement a new corporate role for sustainable development, one of the biggest barriers in adopting sustainable practices in the business environment is the lack of an overarching management tool that will combine the three dimensions of sustainability - economic, environmental and social - with the organization's overall strategy. (For further information about specific company examples, refer to their websites as cited in the Bibliography section.) Managers question how to implement a strategy to encourage organizational sustainability when there are many competing and conflicting organizational constraints and numerous barriers to implementation (Epstein and Roy, 2001). In contrast to conventional management approaches, organizational sustainability management requires the integration of both financial aspects and non-financial strategic success factors, including environmental and social, into the management system of a company. For this reason, the primary motivation behind this research is to satisfy the need for a management tool that will assist decision makers with developing and making proactive decisions, which will support the 
strategy of their organization with respect to economic, environmental and social issues, ensuring the sustainability of their organization. This research develops one of the first sustainability optimization models that integrate both the qualitative and quantitative aspects of the decision into the managerial decision-making process. It can be used to create an optimal balanced investment portfolio by explicitly considering the future uncertainty which is not an aspect of previous models.

This dissertation is organized in the following way. First, the problem and related major research questions are presented. Second, background information is given about management and organizational sustainability, stakeholder theory, the TBL sustainability index system, analytic hierarchy process (AHP) and ANP, and stochastic linear programming. The proposed management tool and its assumptions are then discussed, followed by an illustration using the U.S. electric utility industry. A real life application of the tool is provided by working with Sustainable Pittsburgh and Cranberry Township. Sustainable Pittsburgh is a non-for-profit organization aimed at bringing sustainable solutions to communities and businesses by integrating economic prosperity, social equity, and environmental quality, and affecting decision-making in the Pittsburgh region (www.sustainablepittsburgh.org). Cranberry Township is a suburb located north of the City of Pittsburgh (www.twp.cranberry.pa.us). The business leadership of this township started a journey to develop a sustainable community for its residents. As a result of this effort, the provided application presents an example collaboration of academia, government and non-for-profit sector. Finally, major contributions, extensions and limitations of the research are explained and future research directions are provided. 


\subsection{PROBLEM STATEMENT}

The main problem studied in this research is to examine how policy makers, and corporate and engineering managers should implement sustainable development principles into the managerial decision making process so that they can increase or even maximize the degree of (economic, environmental and social) sustainability of their organizations under rapidly changing global conditions. Before trying to find a solution to this complex decision problem, it is first necessary to analyze it in a broader manner and understand carefully its characteristics, namely strategic importance, multiple stakeholders, subjectivity, multiple objectives and decision makers, uncertainty and high amount of risk, interdisciplinary, time constraint, quantification difficulty and interdependency shown in Figure 1. To better understand the complexity of this problem, the following discussion provides brief explanations and descriptive examples about these characteristics. 


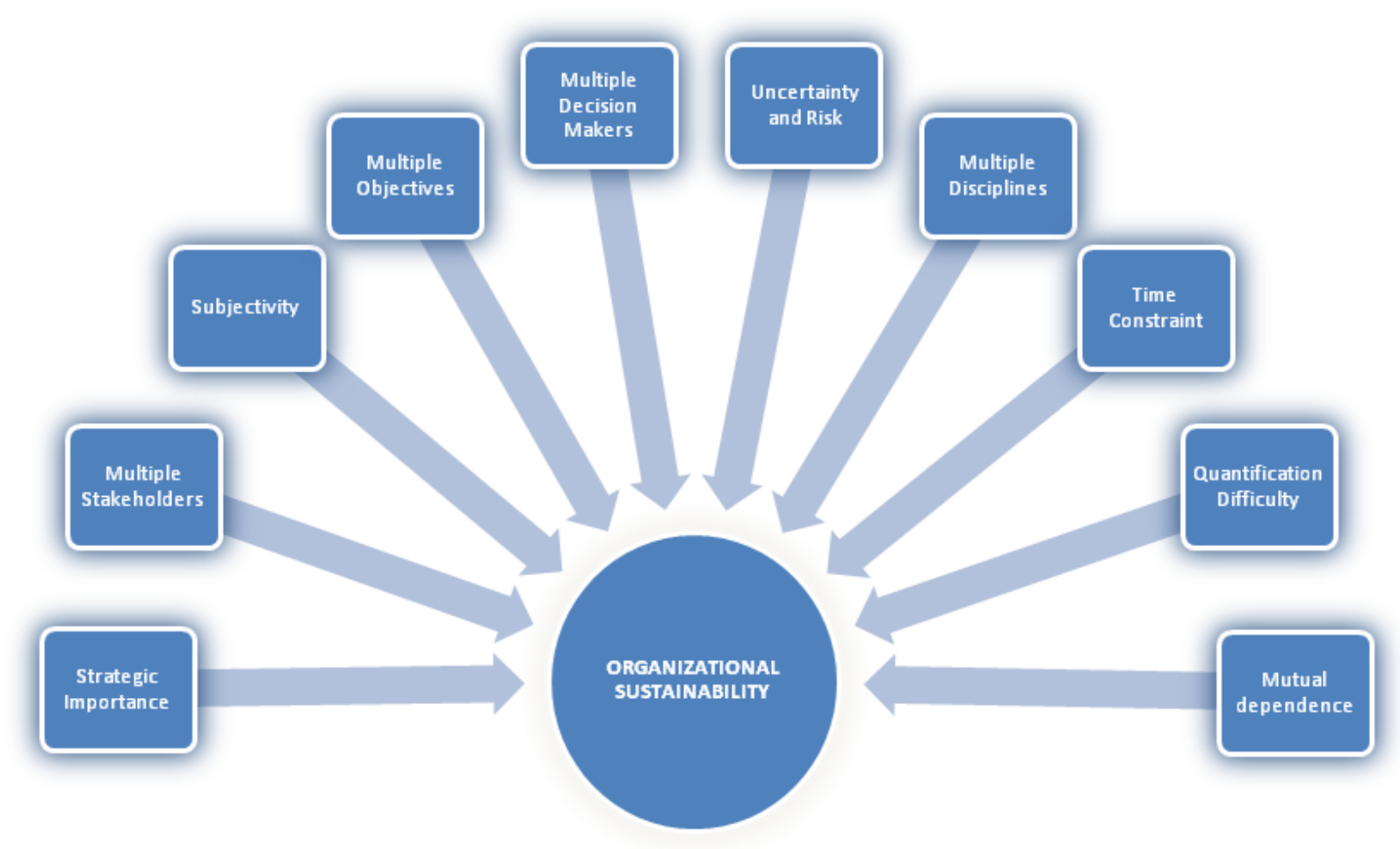

Figure 1: Characteristics of sustainable development principles

Strategic Importance: In the complex business environment of the current technology era, policy makers, and corporate and engineering managers should not only focus on the economic results of their organization's activities, but also consider the environmental and social impacts of these activities. They should develop sustainability plans and set objectives to guarantee both the short-term and long-term economic, environmental and social (i.e., TBL) sustainability of their organizations. In addition, they should be able to measure and monitor the degree of sustainability of their organizations at any time. For instance, in the 1990s although the Ford Motor company tried to improve the fuel economy performance of their vehicles due to the increased public concern on climate change, managers of the company faced difficulty in not only crafting a strategy, but also in determining how to implement a strategy that would balance 
the economic, environmental and social needs of both the company and society (Epstein and Roy, 2001). On the other hand, there are companies that are quite successful in setting sustainable development strategies. For instance, Interface Inc. implements a successful sustainable development strategy in its core business of floor carpeting. Rather than selling its carpets which are generally discarded after their useful life to its customers, Interface Inc. prefers to lease its carpets so that they can take them back after use and recycle them. As a result of this strategy, their customer satisfaction is increased as the customers receive high levels of service without concerns about post-consumer waste, and the company benefits through higher levels of customer retention and more efficient use of recycled material (Epstein and Roy, 2001; Interface Inc.).

Multiple Stakeholders: Although shareholders are often perceived as the most powerful and dominant stakeholder group, today's business has shown that at any particular time other stakeholder groups are crucial to the sustainability of an organization. For instance, protests and boycotts performed by NGOs such as Greenpeace International, Americares, World Wildlife Fund (WWF) International, Reporters Without Borders, Amnesty International, Oxfam International, etc. have compelled policy makers, and corporate and engineering managers to rethink critical decisions impacting the environment and society. For example, in 2005 Shell suspended its $\$ 1.1$ billion gas and oil pipeline work in Sakhalin, Russia due to the intense criticisms and protests from indigenous people, Russia's Green Party and Liberal Democratic Party, as well as Pacific Environment, Sakhalin Environment Watch, Rainforest Action Network, Global Response, Friends of the Earth, CEE Bankwatch and Greenpeace (Macalister, 2005; McGhie, 2005; Sakhalinsk, 2005). This shows that a real indicator of the success of an organization is how much it is successful in building and maintaining long-term, durable and 
high quality relationships with all types of its stakeholders, not only the shareholders, but also the suppliers, employees, customers, NGOs, financial partners (banks, insurance companies, etc.), regulators and public authorities, local, national and international community, and even new generations. In that sense, to minimize potential future problems with various stakeholder groups and related costs that organizations may face, it is necessary to behave in a proactive manner and take actions to effectively integrate stakeholder groups into the managerial decision making process. For instance, in addition to measuring the reactions of its stakeholders, The Cooperative Bank determines seven strategic groups or stakeholders on which its success depends (shareholders, customers, staff and their families, suppliers, local communities, national and international society, and past and future generations of co-operators) and uses specific indicators to assess and improve its relations with the strategic groups. While The Cooperative Bank regularly measures and tracks the satisfaction of its employees on salary, benefits and job security, they also perform frequent surveys to measure the satisfaction of their customers on service quality and convenience (The Cooperative Bank, 2001).

Subjectivity: Sustainability is a very complex and somewhat open to dispute and in recent years it is frequently discussed by people who have quite different backgrounds such as environmentalists, politicians, scientists and activists. This ambiguity in the notion of sustainability raises the question for whom and from what perspective an organization is sustainable. For example, often a shareholder's primary interest in sustainability is that the company's financial performance and profit rate are sustained; for employees it generally means that a company provides high wages, high quality working conditions and a variety of training opportunities, or while a company may be highly oriented in manufacturing green products, its customers, employees or the public may not be aware of the benefits of using these green 
products. This means that although a company seems quite sustainable from the perspective of one type of stakeholder group, it may not be perceived as sustainable from another stakeholder group's perspective. In the context of this research, the organizational sustainability is defined as building and maintaining the long-term satisfaction of stakeholders. For this reason, policy makers, and corporate and engineering managers should carefully evaluate the perceptions and views of all types of stakeholder groups in their managerial decision making process and be able to measure stakeholder-centered performance - the degree of stakeholder satisfaction and trust generated by the organizational activities - of their organizations (Ghoshal and Bartlett, 1999; Lev, 2001; Perrini and Tencati, 2006). For instance, Dow Chemical Company organizes panels in the communities in which it has facilities to obtain a clear view of how its actions are perceived and how it can improve its community relations (Epstein and Roy, 2001).

Multiple Objectives and Decision Makers: Implementing a sustainable development approach into the managerial decision making process involves the effective integration of the perceptions, views and expectations of all types of stakeholder groups. However, this will result in a different and most likely conflicting set of objectives for policy makers, and corporate and engineering managers. For instance, while one objective can be obtaining a high financial performance and profit rate to satisfy the shareholders, another objective can be low waste and carbon emission rates to satisfy the NGOs and environmental regulators. In order to create a reasonable balance among those different and most likely conflicting objectives, each stakeholder group should be perceived and considered as a different decision maker with a different perspective and background.

Uncertainty and High Amount of Risk: The world is continuously changing creating uncertainty and a degree of risk. A proactive approach to deal with this uncertainty is to take 
actions which would minimize the risks that an organization might face in the future. In order to achieve this, the uncertainties on the future availability of resources, state of the natural environment, needs and composition of future generations, state of financial markets and technological development should be considered before making managerial decisions.

Interdisciplinary: The implementation of sustainable development principles into the managerial decision making process and the creation of a sustainability-oriented organization requires an interdisciplinary approach. For instance, while accountants report the financial performance of an organization, conformance to the environmental regulations is usually the business of environmental engineers, ecologists and lawyers. Similarly, while companies usually make use of performance indicators such as philanthropic contributions, diversity data, wages and benefits, and health and safety records to assess the social performance, they have different types of performance indicators for their environmental performance assessment. For instance, Unilever focuses on Chemical Oxygen Demand, hazardous and non-hazardous waste, $\mathrm{SO}_{\mathrm{x}}$ (Oxides of Sulphur) emissions, energy consumption and water consumption to assess its environmental performance (Epstein and Roy, 2001). In that sense, while making their critical decisions, policy makers, and corporate and engineering managers should create environments which will provide collaboration between engineering fields and social sciences such as ecology, economy, psychology, political science, law, and ethical and cultural studies.

Time Constraint: An immediate transition to the creation of sustainability-oriented organizations seems to be a mandatory movement for policy makers, and corporate and engineering managers due to urgent business challenges such as corporate social responsibility reporting, crisis management, worker health and safety, unethical and fraudulent corporate behavior, global climate change, threats to biodiversity, pressures on biological systems, peaking 
of conventional oil supplies and increasing socio-economic inequality. For instance, most of the scientists claim that unless drastic actions are taken, the global warming problem will place a huge cost on the shoulders of the new generations. In his Stern Review, Nicholas Stern (2007) clearly and unambiguously mentions that it is necessary to make urgent, sharp and immediate reductions in greenhouse gas emissions. Although some of his assumptions are criticized by scholars, his report is one of the most remarkable studies on climate change since it explicitly points to the potential effects of climate change and global warming on the world economy. These concerns have resulted in stringent emissions regulations and controls including setting limitations on the amount of manufacturing process wastes and emissions released to the environment. In that sense, to comply with the new environmental regulations and adapt to the changing socio-economic conditions, policy makers, and corporate and engineering managers should readily adopt sustainable development principles in their organizations.

Quantification Difficulty: In the Strategic Importance subsection, it is mentioned that policy makers, and corporate and engineering managers should measure and monitor the degree of sustainability of their organizations at various points in time. Unfortunately, most of the traditional management tools lack performance measures for intangible assets such as human capital and know-how due to difficulty in quantifying those concepts (Bukowitz and Petrash, 1997; Ittner and Larcker, 1998). However, it should not be forgotten that an organization with more knowledgeable people leads to a more flexible organization with respect to future uncertainties, and hence a more sustainable organization.

Interdependency: One of the most important responsibilities of policy makers, and corporate and engineering managers is to make the interdependencies and links among the dimensions of sustainability (i.e., economic, environmental and social) transparent. For example, 
although at first glance some projects such as social responsibility, waste treatment and employee training projects seem to improve only the environmental and social sustainability of an organization, they also improve its economic sustainability as investments in the community, environment and human capital. William Nordhaus (2007) defines a well-designed policy as one that balances the economic costs of actions today with the economic and ecological benefits of the future. Because of this, policy makers, and corporate and engineering managers need to understand the impacts or effects of their actions on the various dimensions of sustainability.

In sum, building and maintaining organizational sustainability is an extremely complex decision problem that requires a comprehensive solution methodology. 


\subsection{RESEARCH QUESTIONS}

This research aims to investigate a new, contemporary management tool that implements sustainable development principles into the managerial decision making process with a purpose of increasing or even maximizing the degree of sustainability of an organization under rapidly changing global conditions. Since one of the major decisions made in an organization is investment decisions, specifically this research focuses on the development of a tool that can be used in investment planning and capital budgeting decisions by considering the following research questions:

1. How should policy makers and corporate and engineering managers decide how much to invest in a project or an activity so that they can improve or even maximize the sustainability of their organization in the future?

2. How should an organization deal with the trade-offs and risks among the financial, environmental and social impacts of its activities and projects on different stakeholder groups?

3. How can an investment project portfolio result in an optimal balance among the multiple characteristics of an organization (i.e., economic, environmental and social) and make the maximum contribution to the organization's overall sustainability? 
In addressing these research questions, several considerations logically follow as input including the characteristics described in the Problem Statement section involving stakeholder theory, the triple bottom line (TBL) framework, project portfolio management, investment planning, and capital budgeting. First, in addition to the shareholders, it is necessary to consider all the major stakeholder groups in today's global business environment and integrate their perceptions, views and expectations in to the decision making process. In that sense, the developed tool should be able to quantify and integrate stakeholder perspectives into investment planning and capital budgeting decisions so that the degree of sustainability of an organization perceived by different stakeholder groups (i.e., the organization's stakeholder-centered performance) can be measured and improved. (The term stakeholder-centered performance refers to the degree of stakeholder satisfaction and trust generated by organizational activities (Ghoshal and Bartlett, 1999; Lev, 2001; Perrini and Tencati, 2006).) However, to be able to measure and improve stakeholder-centered performance, it is necessary to determine a set of performance measures which should include not only the financial measures that are traditionally used in investment planning and capital budgeting decisions, but also the non-financial ones related to sustainability issues. To deal with these considerations, an extensive literature review is performed, and the previous related management tools, group decision making and decision analysis techniques found in the literature or used in practice are utilized in this research.

Furthermore, a mathematical program is developed which makes use of stakeholder perspectives as input in addition to financial data, and provides a long-term investment plan for a set of alternative projects. In that sense, the major contribution of this research is the development of a mathematical program that enables decision makers to integrate stakeholder perspectives into the investment planning and capital budgeting decisions as input. Each of the 
above considerations and research questions are subsequently explored in the following chapters, and Chapter 10 provides a summary of the research explaining how and to what extent they are addressed. 


\subsection{PERFORMANCE MANAGEMENT AND ORGANIZATIONAL SUSTAINABILITY}

This section analyzes the formation and development of management tools for organizational sustainability from an evolutionary perspective. It discusses how various areas such as strategic management, performance measurement, cost management and accounting systems have been developed, and relate to one another.

\subsection{PERFORMANCE MANAGEMENT AND COST MANAGEMENT}

Without accurate and comprehensive information, it would be difficult for decision makers to make correct and rational decisions for the future of their organizations. Therefore, measuring with a high level of accuracy costs and benefits of all types of organizational activities is a desirable aspect of an effective managerial decision making tool. However, in today's competitive and complex business environment many of the traditional management tools are relatively inadequate and lack this precision as they are built on financially-driven performance measurement systems. Aside from creating profit, sustainable company leaders need to consider other qualitative, non-financial aspects as references for their performance, such as quality of management, corporate governance structures, reputation, human capital management, 
stakeholder relations, environmental protection and corporate social responsibility (Lo and Sheu, 2007).

Researchers note that the concept of non-financial performance measures is not a new phenomenon. For example, General Electric was using non-financial performance measures such as productivity, employee attitudes, public responsibility, and the balance between the short-term and long-term goals in the 1950s (Eccles, 1991; Aschenbrennerová, 2007). Also, a number of theorists, Hopwood (1973), Parker (1979), Anthony (1984), Merchant (1985), Schoenfeld (1986), Eccles (1991), Maciariello and Kirby (1994) pointed to the importance of non-financial performance measures in their studies (Aschenbrennerová, 2007). In addition to these scholars, Thor not only explained the need for a family of performance measures to evaluate an organization's performance, but also proposed a methodology to create a family of performance measures as well as arrive at the optimal number and type of performance measures in a family (Thor, 1995).

However, up to 1992, there was no comprehensive and widely accepted management tool that integrated both financial and non-financial performance measures. Kaplan and Norton proposed the Balanced Scorecard (BSC) as a management tool that integrates both financial and non-financial performance measures in the translation of organizational strategy into action (Kaplan and Norton, 1992). The four perspectives of the BSC - financial, customer, internal business, and innovation and learning, enable an organization to build a connection between organizational strategy and operational activities.

Moreover, in the 1980s, as a result of environmental problems and increased awareness of society on environmental and social issues, environmental and social performance measures began to be considered within the set of non-financial performance measures. These measures 
typically focus on externalities. Externalities are the costs imposed by an entity as the by-product of its economic activity on third parties such as households and are often both non-monetary and difficult to quantify (Atkinson, 2000). These concepts were then extended by other scholars. For example, in order to improve environmental accounting and reporting practices, Atkinson proposed a full cost accounting system that takes into account external costs (Atkinson, 2000). In addition, after the 1997 publication of John Elkington's book Cannibals with Forks: The Triple

Bottom Line for the $21^{\text {st }}$ Century Business, the triple bottom line (TBL) accounting system became popular (Elkington, 1997).

\subsection{MANAGING ORGANIZATIONAL SUSTAINABILITY}

All of the developments previously mentioned (including the usage of non-financial performance measures in management, considerations of environmental and social costs, developments of full cost accounting and TBL accounting systems) have stimulated researchers to consider a comprehensive management tool for organizational sustainability. For instance, Figge et al. introduced the Sustainability Balanced Scorecard (SBSC) by considering the Balanced Scorecard (BSC) as a starting-point to incorporate the environmental and social aspects into the management system of an organization (Figge et al., 2002). To create the SBSC these authors proposed three different approaches and demonstrated them on a fictitious textile company as a case study. Additionally, Wang and Lin (2007) presented a quantitative model that makes use of the TBL accounting mechanism (Wang and Lin, 2007). As a support tool for managerial decisions, Wang and Lin proposed a sustainability optimization model which incorporates the environmental and social costs and values into the economic activities. In their sustainability 
optimization model, they made use of the TBL accounting framework, multi-criteria decision making (MCDM) methods and multi-attribute utility theory (MAUT). 


\subsection{COMPONENTS OF PROPOSED MANAGEMENT TOOL}

This section addresses the construction and development process of a management tool that can be used in making investment planning and capital budgeting decisions in order to improve organizational sustainability. First, it provides a brief overview of stakeholder theory, followed by a short summary of Elkington's triple bottom line (TBL) accounting framework and its extensions. After that, the analytic hierarchy process (AHP), analytic network process (ANP), and their advantages are discussed as multi-criteria decision making support tools. Finally stochastic linear programming and its applications are also summarized as a useful optimization tool for problems containing a high degree of uncertainty.

This research makes use of AHP/ANP methodology instead of utility theory, and stochastic linear programming for developing the optimization model which is a distinction from the work down by Wang and Lin (2007). By using stochastic linear programming, this research explicitly considers the uncertainty which is considered to be a major research contribution.

\subsection{STAKEHOLDER THEORY}

Since conventional management tools and performance measures are mostly built on the perspective of "shareholder satisfaction," they are usually driven by economic rationality and

profit maximization. To this end, they are relatively inadequate in today's global environment as 
they not only isolate or ignore the environmental and social impacts of organizational activities, but they also lack a global thinking perspective. In contrast, "stakeholder satisfaction" includes the consideration of other groups or entities that are affected by an organization's activities besides shareholders (Branco and Rodrigues, 2007). Stakeholder theory (originally known as "stakeholder theory of the firm") is a relatively new concept (Wilson, 2003). In 1984, it was first popularized by R. Edward Freeman's book "Strategic Management: A Stakeholder Approach" (Freeman, 1984). Madsen and Ulhøi (2001) define stakeholders as "individuals or groups with a legal, economic, moral and/or self-perceived opportunity to claim ownership, rights or interests in a firm and its past, present or future activities - or in parts thereof." Clarkson (1995) classifies stakeholders as primary and secondary. Primary stakeholders are the stakeholders without whose continuing and direct participation or input the organization cannot survive as a going concern (Madsen and Ulhøi, 2001). Owners, investors, employees, suppliers, customers and competitors are among the examples of primary stakeholders. Secondary stakeholders are those who in the past, present or future influence or might be influenced by the organization's activities without being directly engaged in transactions with the organization in question and thus are not essential for its survival (Madsen and Ulhøi, 2001).

Such a variety of stakeholder groups creates a challenge since each stakeholder group has different goals, priorities and expectations. Shareholders and investors expect a reasonable return on their investments; employees look for safe workplaces, competitive salaries and job security; customers demand high quality of goods and services at fair prices; local communities want community investment, and regulators dictate full compliance on regulations (Wilson, 2003). For this reason, stakeholder-centered performance, defined as the degree of stakeholder trust and the stakeholder satisfaction generated by the organizational strategy and behavior should be 
measured in order to build and maintain sustainable stakeholder relations (Perrini and Tencati, 2006). The sustainable stakeholder relations achieved by active advancement of communication and exchange of information positively influences the innovation, reputation and risk management and thus enhances the competitiveness of the organization. Finally, comprehensive and early consideration of stakeholder interests, priorities and expectations helps to predict potential future threats and enables decision makers to take early actions or switch to alternatives in a timely manner (Langer and Schön, 2003).

\subsection{TRIPLE BOTTOM LINE AND SUSTAINABILITY INDEX SYSTEM}

The triple bottom line (TBL) approach was developed by John Elkington in the 1980s as a platform to report and measure organizational performance with respect to the three dimensions of sustainability - economic, environmental and social (Elkington, 1997). (Sustainability in these dimensions can be defined as the long-term maintenance of economic, environmental and social resources for future generations, respectively.) By reporting and measuring not only financial performance but also the performance in environmental and social dimensions of sustainability, TBL helps to build and maintain the satisfaction of all types of stakeholders.

In recent years, the TBL approach has rapidly increased in popularity. For instance, the phrase "triple bottom line" occurs in 67 articles in the Financial Times in the years preceding June 2002 (Norman and MacDonald, 2004). A Google search shows that from 2002 to early 2005 the number of hits on the phrase "triple bottom line" rose from 15,600 to 187,000; and the current hit rate is 700,000 (Mirvis, 2007). Companies such as the Shell Group, AT\&T Inc., Dow Chemicals, British Telecom, Baxter International Inc., and Bristol-Myers Squibb Company have 
used TBL terminology in their press releases, annual reports and other documents (Norman and MacDonald, 2004). (For further information about specific company examples, refer to their websites as cited in the Bibliography section.) By examining the operations, quarterly and annual financial reports, health and safety reports, and interviews with the managers, employees, customers, suppliers of these companies, Wang and Lin (2007) developed a TBL sustainability index system to measure the sustainability performance of a company. This research makes use of Wang and Lin's TBL sustainability index system to integrate the financial and non-financial performance measures into the investment planning and capital budgeting process since it was developed by analyzing a variety of companies and industries. Wang and Lin's TBL sustainability index system provides an individual index set not only for the three dimensions of sustainability - economic, environmental and social, but also for the intersecting areas of these three main dimensions, namely eco-environmental, eco-social, socio-environmental and ecosocio-environmental. A visual representation of the Wang and Lin's TBL sustainability index system is given in Figure 2, and the individual indices and sub-indices of their TBL sustainability index system can be seen in Appendix A.

Although in this research, Wang and Lin's TBL sustainability index system is used to report and measure organizational performance, it should not be forgotten that the structure of the index system should be reviewed and examined periodically for logic, consistency and potential relationships among the indices. 


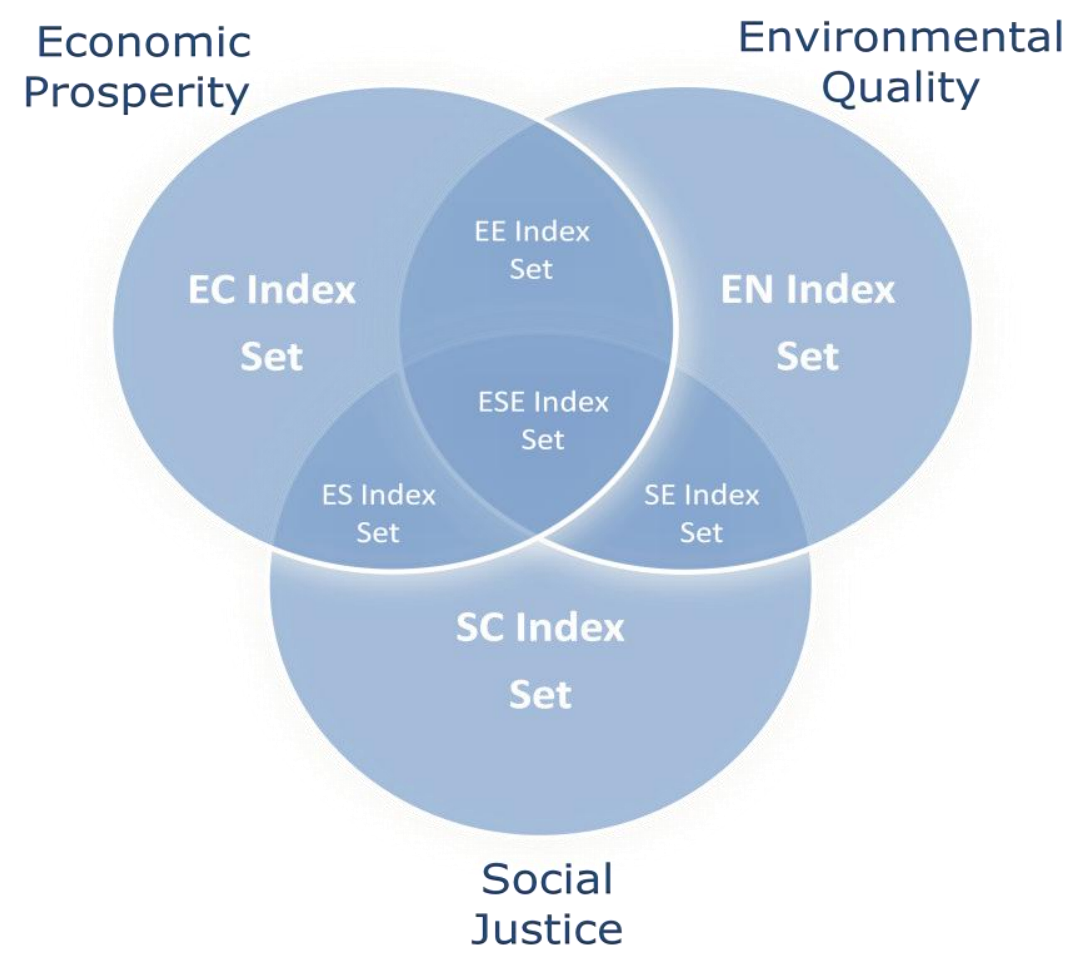

Figure 2: Triple bottom line framework and sustainability index system

(EC: Economic, EN: Environmental, SC: Social, EE: Eco-Environmental, ES: Eco-Social, SE:

Socio-Environmental, ESE: Eco-Socio-Environmental)

(Adapted from Wang and Lin, 2007)

\subsection{ANALYTIC HIERARCHY PROCESS (AHP) METHODOLOGY}

The analytic hierarchy process (AHP) was first introduced by Thomas L. Saaty in 1980 as a mathematical based decision support tool (Saaty, 1980). In general terms, AHP provides a framework that helps to model and solve multi-criteria decision making problems. The AHP methodology has four basic steps: Problem structuring, criteria and alternative prioritization, calculation of ranks and sensitivity analysis. 


\section{Problem Structuring}

As a first step, the multi-criteria decision making problem is framed in a hierarchical structure. The objective is placed at the top of the hierarchy, and, the criteria, sub-criteria and alternatives are located on respective lower levels of the hierarchy. Neither interaction nor dependency among and between the levels of this hierarchical structure is assumed.

\section{Criteria and Alternative Prioritization}

In the second step, the decision maker assigns relative weights to the objects by performing pairwise comparisons at each level of the hierarchy with respect to an immediate upper level attribute. These weights are assigned to all criteria, sub-criteria and alternatives. When assigning relative weights, a scale from one to nine is used where one represents no difference between the compared objects and nine represents that one object is significantly more important or dominant than the other one (Saaty, 1994). A schematic of the weighting scale is given in Table 1. The criteria and alternative prioritization process is redundant, leading to multiple comparisons of the same objects in order to check for consistency. An inconsistency ratio is calculated and examined by the decision makers to guide their decision making as they compare objects. Saaty (1994) recommends that an acceptable inconsistency ratio should be less than or equal to 0.1 . 
Table 1: AHP fundamental scale of absolute numbers (Saaty,1994)

\begin{tabular}{|c|l|}
\hline 1 & Equal importance \\
\hline 3 & Moderate importance of one over another \\
\hline 5 & Strong or essential importance \\
\hline 7 & Very strong or demonstrated importance \\
\hline 9 & Extreme importance \\
\hline $2,4,6,8^{*}$ & Intermediate values \\
\hline
\end{tabular}

*Reciprocals are used for inverse comparisons

\section{Calculation of Ranks}

In this step, all assigned relative weights are aggregated throughout the hierarchy, and overall weights for each alternative are calculated. This overall weight for each alternative represents its final priority and rank among the other alternatives.

\section{Sensitivity Analysis}

As a final step, a sensitivity analysis is performed in order to determine how the final rankings are affected by changes in the judgments throughout the process.

\subsection{ANALYTIC NETWORK PROCESS (ANP) METHODOLOGY}

Analytic Network Process (ANP), similar to Analytic Hierarchy Process (AHP), is a multicriteria decision making (MCDM) technique that enables a decision maker to prioritize a discrete set of alternatives based on his/her preferences. As mentioned, AHP is based on relative comparisons 
of the alternatives with respect to a certain goal and criteria set which are in a hierarchical structure (Saaty, 1980; Saaty, 1994) and the final product of an AHP study is the prioritization of the alternatives according to their contribution to the goal (Saaty, 1995). ANP is structured on the same basis as AHP; however, it differs from AHP in two ways. First, ANP does not assume that the alternatives, attributes and criteria are independent from each other. Their potential dependencies are handled through the feedback mechanism (Saaty, 2001; Saaty, 2005). Second, ANP has a network structure that is composed of subnetworks and submodels. The single hierarchical structure of AHP is constrained and inadequate, as the dependency and feedback mechanism are necessary for the decision making process (Saaty, 2001 and Saaty, 2005). In that sense, it can be said that ANP reflects the complexity of the decision in a more accurate way.

The first step in an ANP study is to build the problem as a network structure. Generally, an ANP network structure has four parts: (1) the main model, (2) the benefits, opportunities, costs and risks (BOCR) model, (3) the ratings model and (4) the subnetworks. The main model contains the goal node and it is connected to the BOCR model through the ratings model. In the ratings model, alternatives are assessed according to their contributions to the goal in terms of BOCR. The second step is to perform pairwise comparisons between the various criteria and alternatives. As with AHP, Saaty (2005) recommends that an acceptable consistency ratio (CR) should be less than or equal to 0.1 . If the CR exceeds 0.1 , pairwise comparisons should be repeated to ensure that the decision maker is consistent. Finally, the rankings of the alternatives are calculated and a sensitivity analysis is performed to observe the sensitivity of the final rankings to the changes in the judgments performed throughout the pairwise comparisons.

AHP and ANP are used in this research as a decision support tool because of their particular characteristics and advantages. They simplify complex problems because they provide 
a formal structure to describe a problem as well as a solution procedure comprised of simple calculations. Second, AHP and ANP are intuitive because they synthesize the judgments that reflect both the decision maker's knowledge and emotions and incorporates both qualitative and quantitative aspects into the decision making process. Third, AHP and ANP use the prioritization process to build consensus among multiple decision makers. Finally, user friendly commercial AHP/ANP software packages such as Expert Choice and Super Decisions are readily available.

\subsection{STOCHASTIC LINEAR PROGRAMMING}

Stochastic linear programming is a tool for optimization under uncertainty that has a variety of application areas including financial planning and control, capacity expansion, design for manufacturing, production planning, water management, etc. In this subsection, a brief summary is provided about stochastic linear programming and its basic concepts. Details can be found in

John R. Birge's book “Introduction to Stochastic Programming” (Birge, 1997).

\subsubsection{Deterministic Linear Programs}

In mathematical optimization, a deterministic linear program is often formulated as

$$
\text { Min } Z=c_{(n x 1)}^{T} x_{(n x 1)}
$$

S.t.

$$
\begin{gathered}
A_{(m x n)} x_{(n x 1)} \geq b_{(m \times 1)} \\
x_{(n x 1)} \geq 0
\end{gathered}
$$


where $x$ represents a vector of decisions, and $A, b$ and $c$ are assumed to be strictly known problem data since the model does not involve any uncertainty. The objective function of the model and its value is represented by $c^{T} x$ and $Z$, respectively and the set of feasible solutions is defined as $\{x \mid A x=b, x \geq 0\}$. In that sense, $x^{*}$ (the optimal solution) is a feasible solution such that $c^{T} x \geq c^{T} x^{*}$ for any feasible $x$ (Birge, 1997). Deterministic linear programs have a wide range of application areas both in academia and industry.

\subsubsection{Stochastic Linear Programs}

Stochastic linear programs are linear programs in which some problem data are uncertain and recourse programs are those in which some decisions or recourse actions can be taken after uncertainty is disclosed (Birge, 1997). In a stochastic linear program, the problem data which involves uncertainty is represented as random variables. It is assumed that probability distributions or densities are available for those random variables and their particular values are determined after a random experiment. Therefore, in a stochastic linear program the set of variables are divided into two groups: the variables whose values are determined before the random experiment, namely first-stage variables and the variables whose values are determined after the random experiment, namely second-stage variables. By convention, first-stage variables are represented by the vector $x$ whereas second-stage variables are represented by the vector $y$ or $y(\omega)$ or even $y(\omega, x)$, thus the sequence of events and realization of variables are

$$
x \rightarrow \xi(\omega) \rightarrow y(\omega, x)
$$

where $\xi(\omega)$ represents a realization of the random experiment (Birge, 1997). 


\subsubsection{Two-Stage Stochastic Linear Program with Fixed Recourse}

The two-stage stochastic linear program with fixed recourse is formulated as the following:

$\operatorname{Min} Z=c^{T} x+E_{\xi}\left[\min q(\omega)^{T} y(\omega)\right]$

S. t.

$$
\begin{gathered}
A x=b \\
T(\omega) x+W y(\omega)=h(\omega) \\
x \geq 0, y(\omega) \geq 0
\end{gathered}
$$

(Dantzig, 1955; Beale, 1955 and Birge, 1997).

In this formulation, first stage variables are represented by the $\left(n_{1} \times 1\right)$ vector $x$ and the sizes of matrices $c, b$ and $A$ are $\left(n_{1} \times 1\right),\left(m_{1} \times 1\right)$ and $\left(m_{1} \times n_{1}\right)$, respectively. In the second stage, based on the realization of random events $\omega \in \Omega$, the second stage problem data $q(\omega), h(\omega)$ and $T(\omega)$ are known, where $q(\omega)$ is $\left(n_{2} x l\right), h(\omega)$ is $\left(m_{2} \times 1\right)$ and $T(\omega)$ is $\left(m_{2} \times n_{1}\right)$ (Birge, 1997).

In addition to a deterministic term $c^{T} x$, the objective function of the above formulation contains the expectation of the second stage objective $q(\omega)^{T} y(\omega)$ taken over all realizations of the random event $\omega$. By using this notion, sometimes a deterministic equivalent program (DEP) can be created as the following:

$\operatorname{Min} Z=c^{T} x+\vartheta(x)$

S. t.

$$
\begin{aligned}
& A x=b \\
& x \geq 0
\end{aligned}
$$

where for a given realization $\omega$,

$$
\vartheta(x)=E_{\xi} Q(x, \xi(\omega))
$$




$$
Q(x, \xi(\omega))=\min _{y}\left\{q(\omega)^{T} y \mid W y=h(\omega)-T(\omega) x, y \geq 0\right\}
$$

In the DEP formulation, $\vartheta(x)$ is defined as the expected second stage value function (Birge, 1997).

This research utilizes a similar approach creating a multi-stage stochastic linear program whose details are discussed in the following section. 


\subsection{DEVELOPMENT OF THE PROPOSED MANAGEMENT TOOL}

The objective of the proposed management tool is to assist the policy makers, and corporate and engineering managers with making a good investment or capital budgeting decision that will provide the maximum improvement in their organization in terms of sustainability. Figure 3 presents the basic logic behind the proposed management tool. As mentioned, stakeholder priorities and expectations can vary. From the TBL perspective, these expectations and priorities are grouped under the categories of economic prosperity, environmental quality, social justice, eco-environmental, eco-social, socio-environmental and eco-socio-environmental aspects (as shown in Figure 2). Since each project that the organization implements has different impacts on different TBL sustainability indices ultimately affecting the stakeholders, the proposed management tool aims to relate the investment planning and capital budgeting decisions to the stakeholder expectations and priorities through the TBL sustainability framework analytic network process (ANP) as a decision support tool. 


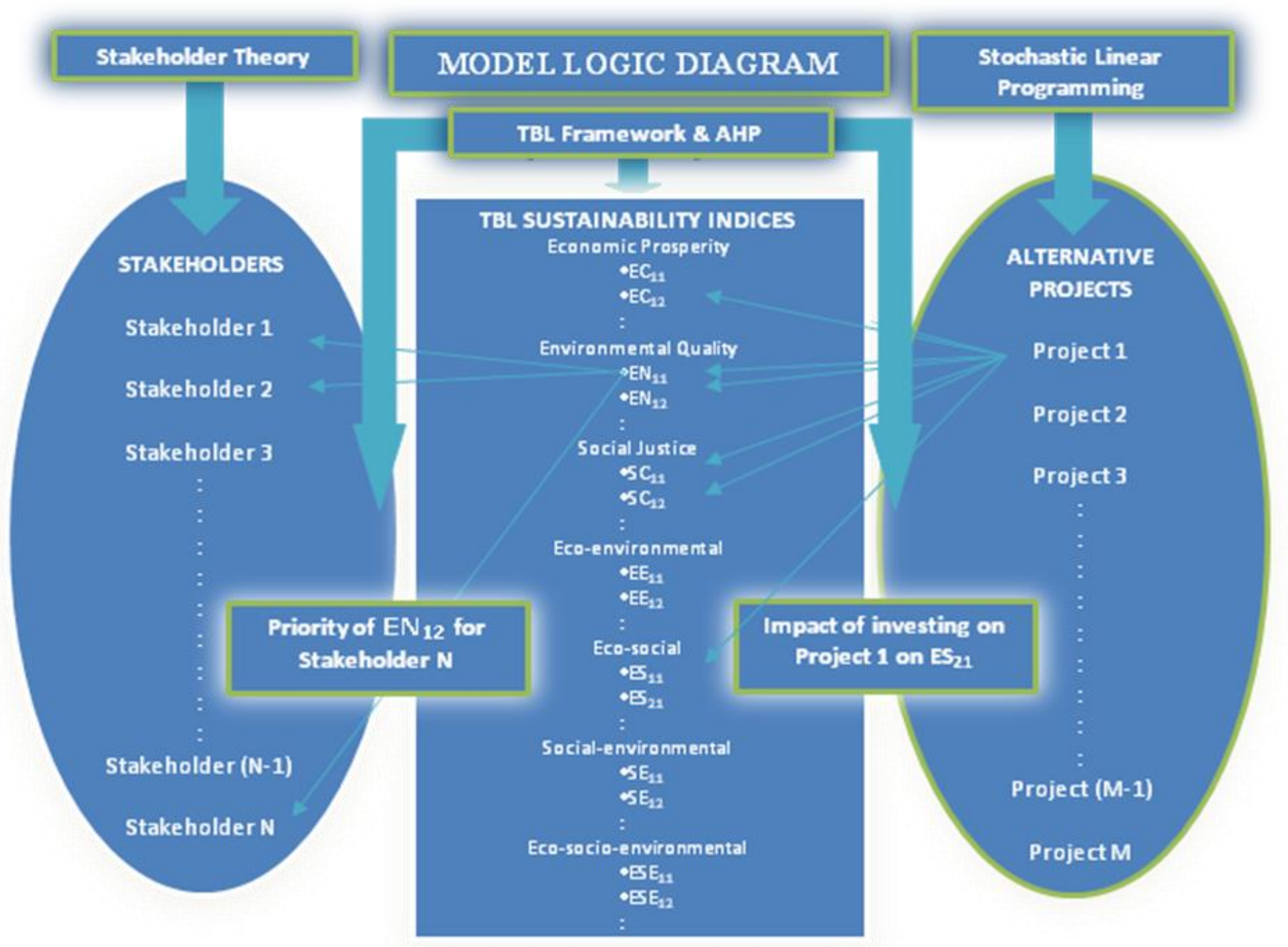

Figure 3: Schematic view of the model logic 


\subsection{PROPOSED ANP MODEL}

The development and demonstration of the proposed ANP model has several assumptions. The ANP model is considered to be an extension of the AHP model for organizational sustainability developed by Turan et al. (2008), for which further details are provided in Chapter 8 . Since the proposed ANP model is a generalized form of the AHP model, it is logical to provide the details of the ANP model first. Similar to the AHP model, the TBL (Elkington, 1997) sustainability index system developed in 2007 by Wang and Lin is used as the criteria and subcriteria set in the hierarchy of the ANP main model. No industry specific criterion is assumed. The proposed ANP model is demonstrated on the same illustrative example as Turan et al. (2008), which is based on the evaluation and prioritization of the project alternatives shown in Table 2. These alternatives consider the current trends and issues in the U.S. electric utility industry. The comparisons of the nodes and clusters in the main model are performed similarly to those comparisons in the AHP model of Turan, et al. (2008).

Table 2: Common issues in the U.S. electric utility industry and the related project alternatives

(Turan et al., 2008)

\begin{tabular}{|c|c|}
\hline $\begin{array}{c}\text { Major Issues in the U.S. Electric Utility } \\
\text { Industry }\end{array}$ & Related Project Alternatives \\
\hline Future Capacity Concerns & (1) Capacity Expansion Project \\
\hline Absence of Green Power & (2) Green Power Applications Project \\
\hline Emissions Control and Allowances & (3) Emissions Control Project \\
\hline Continued Financial Performance & $\begin{array}{c}\text { (4) Financial Performance Improvement } \\
\text { Project }\end{array}$ \\
\hline Aging Workforce & (5) Workforce Refreshment Project \\
\hline
\end{tabular}




\subsubsection{Main Model}

Figure 4 provides the ANP main model that was built using SuperDecisions, an AHP/ANP software package. As seen in the goal node, the objective of the main model is to maximize organizational sustainability. The connecting criteria cluster is comprised of the three main sustainability dimensions and their overlapping areas (i.e., economic prosperity, environmental quality, social justice, eco-environmental, eco-social, socio-environmental, eco-socioenvironmental). In turn, each node in the criteria cluster is connected to the nodes of the related subcriteria clusters. For instance, economic prosperity is connected to the nodes in the 1EC1, 2EC2, 3EC3 and 4EC4 subcriteria clusters. Due to space limitation, subcriteria cluster names and their nodes are labeled as 1EC1, 1EC11, etc. (also used by Wang and Lin (2007)). The exact names can be found in the related publication of Wang and Lin (2007). Additionally, the nodes of all subcriteria clusters are connected to the BOCR model through the ratings model, shown in Figures 5 and 6 respectively. 


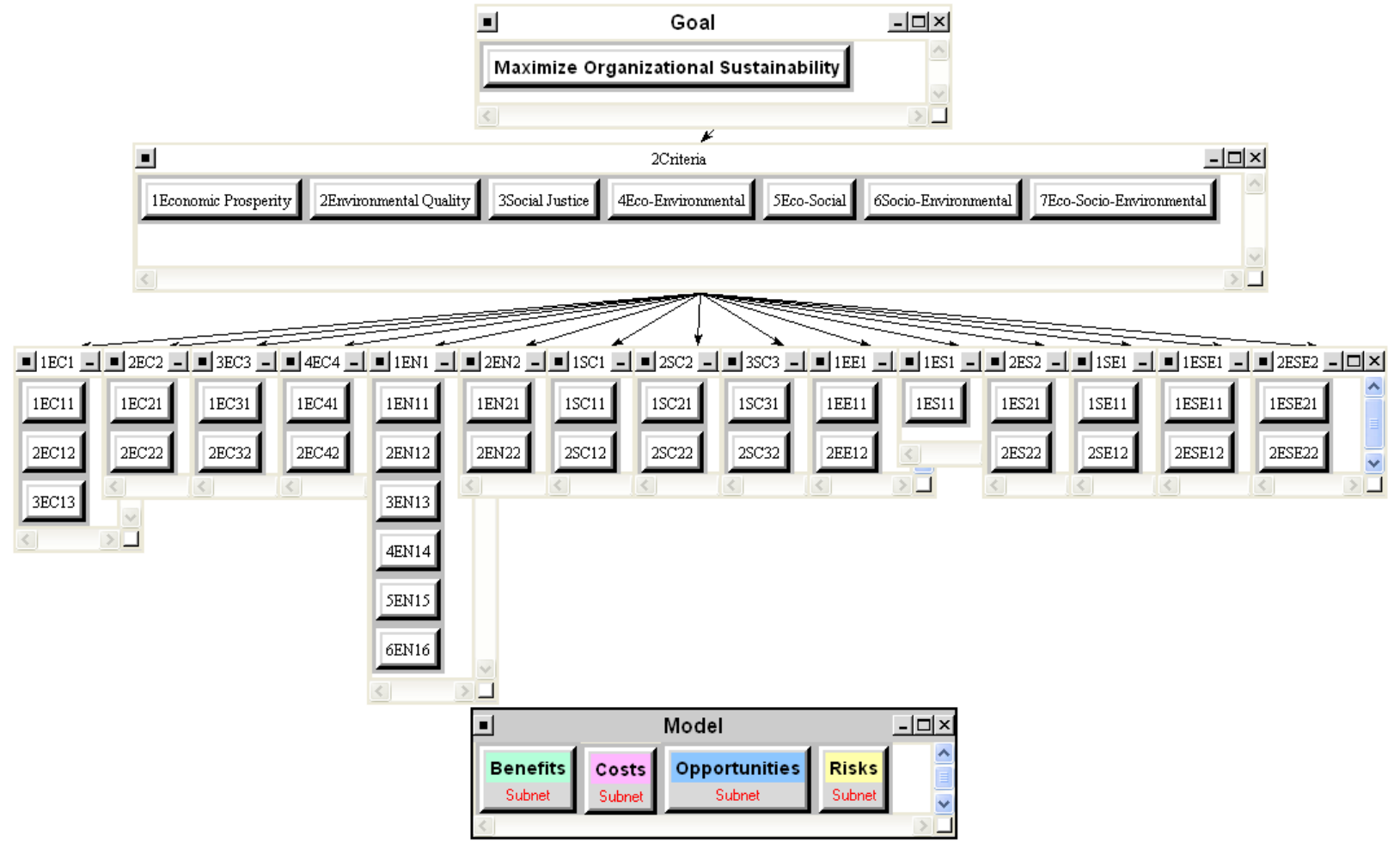

Figure 4: ANP Main Model - Hierarchy of strategic criteria and BOCR model

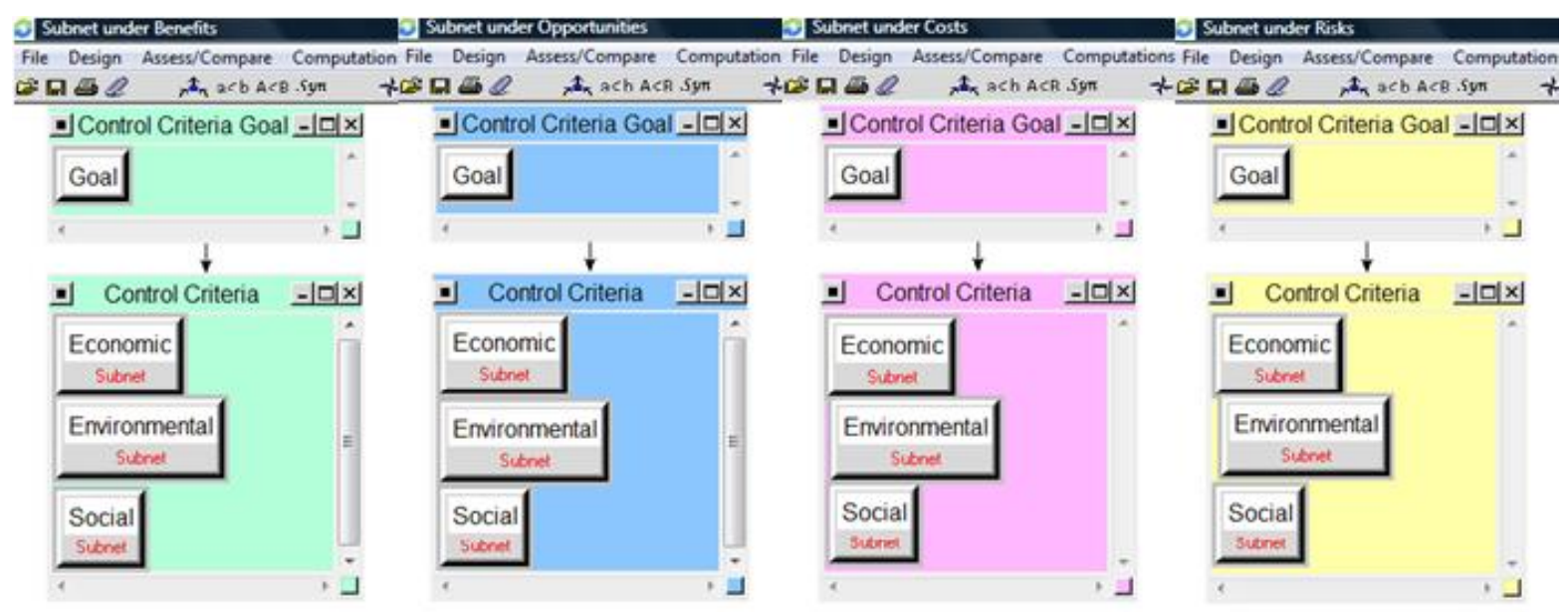

Figure 5: BOCR model 


\begin{tabular}{|c|c|c|c|c|c|c|c|c|c|}
\hline \multirow[t]{3}{*}{ File Edit View } & \multicolumn{9}{|c|}{ Calculations Help } \\
\hline & \multirow[b]{2}{*}{ Priorities } & \multirow[b]{2}{*}{$\begin{array}{l}1 \mathrm{ECC11} \\
0.009640\end{array}$} & \multirow[b]{2}{*}{\begin{tabular}{|l|l|}
$2 E C C 12$ \\
0.058628
\end{tabular}} & \multicolumn{6}{|c|}{ Super Decisions Ratings } \\
\hline & & & & $\begin{array}{l}3 E C 13 \\
0.023772\end{array}$ & \begin{tabular}{|l|l|}
$1 E E 11$ \\
0.012006
\end{tabular} & $\begin{array}{l}2 \mathrm{EEE} 12 \\
0.012006\end{array}$ & \begin{tabular}{|l|l} 
1EN11 \\
0.000860
\end{tabular} & \begin{tabular}{|l|l} 
2EN12 \\
0.003720
\end{tabular} & $\begin{array}{l}3 \text { EEN13 } \\
0.001706\end{array}$ \\
\hline Benefits & 0.292688 & $\mathrm{Hi}$ & $\mathrm{Hi}$ & $\mathrm{Hi}$ & Med & Med & $\mathrm{Fi}$ & $\mathrm{Hi}$ & $\mathrm{Hi}$ \\
\hline Opportunities & 0.230307 & Med & Med & Med & Lo & Lo & Med & Med & Med \\
\hline Costs & 0.272946 & $\mathrm{Hi}$ & $\mathrm{Hi}$ & $\mathrm{Hi}$ & Lo & Lo & Med & Med & Med \\
\hline Risks & 0.204059 & Med & Med & Med & Lo & Lo & $\mathrm{L}_{3}$ & Lo & Lo \\
\hline
\end{tabular}

Figure 6: A portion from ratings model

\subsubsection{Subnetworks}

As shown in Figure 5, under each node of the BOCR model, three subnetworks are delineated economic, environmental and social. To further illustrate, the economic benefits subnetwork under the benefits node is shown in Figure 7. It is composed of one alternatives cluster and nine stakeholder clusters - suppliers, employees, customers, media, NGO's, regulators and authorities, financial partners, community and others. The alternatives cluster contains the five project alternatives described in Table 2. The stakeholder clusters and their nodes are created by considering the typical stakeholders of a U.S. electric utility company. It is assumed that an electric utility company has four different potential suppliers - coal plants, hydroelectric and wind facilities, natural gas or oil plants and nuclear plants. Another perspective can be the communities that are potentially affected by the utilities' activities - categorized as local, national and global communities. 


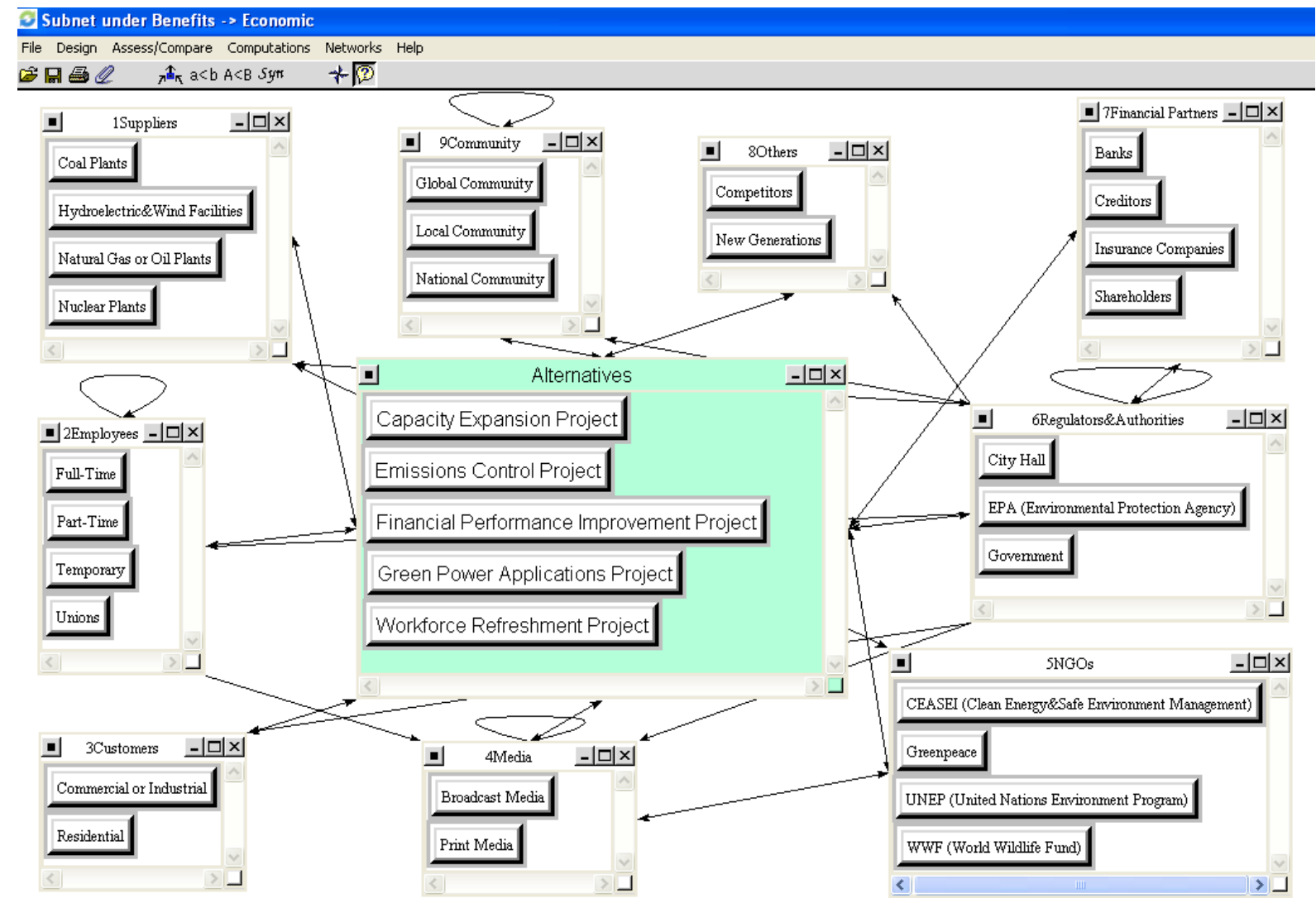

Figure 7: Subnetwork for economic benefits

The network in Figure 7 displays the various dependencies and feedback loops. For example, the priority of each project alternative is strongly related to the feedback that is obtained from each stakeholder group. Similarly, the impact of an alternative project on the global community is dependent on its impact on the national community which is also dependent on its impact on the local community. All feedbacks and dependencies in the subnetwork are represented by the two sided arrows and loops in Figure 7, respectively. 


\subsection{PROPOSED MULTI-STAGE STOCHASTIC LINEAR PROGRAM}

The general deterministic equivalent formulation of the proposed multi-stage stochastic linear program is as the following:

\section{Parameters:}

$N=$ Number of stakeholders

$M=$ Number of projects

$H=$ Number of stages (periods)

$b=$ Initial wealth (or initial available budget which will be invested in the projects)

$G=$ Target wealth at the end of $H$ periods

$r=$ Shortage penalty of missing the target wealth $G$ at the end of $H$ periods

$q=$ Surplus reward of surpassing the target wealth $G$ at the end of $H$ periods

$s_{t}=$ Economic state in period $t$ where $1 \leq t \leq H$

$\Omega=$ The set of all possible economic states in a period

Hence, the total number of scenarios for the $H$ periods planning horizon is equal to $[\mathrm{n}(\Omega)]^{H}$ where $\mathrm{n}(\Omega)$ represents the number of elements in $\Omega$.

$p\left(s_{t}\right)=$ Probability of experiencing a specific economic state in period $t$ where $1 \leq t \leq H$

$p\left(s_{1}, \ldots \ldots, s_{H}\right)=$ Probability of experiencing scenario $\left(s_{1}, \ldots \ldots, s_{H}\right)$ throughout the planning horizon

By assuming economic states are independent, $p\left(s_{1}, \ldots \ldots, s_{H}\right)$ is equal to $\left[p\left(s_{1}\right) \ldots \ldots p\left(s_{H}\right)\right]$.

$K=$ Sustainability coefficient

The value of the sustainability coefficient represents the orientation of an organization for sustainable development. A higher sustainability coefficient indicates higher investment on 
environment and society. The value of the sustainability coefficient can be determined by interviewing the decision maker and analyzing the model results which are obtained for several different $K$ values.

$\operatorname{IRR}\left(i, t, s_{1}, \ldots \ldots, s_{H}\right)=$ Internal rate of return of project $i$ for period $t$ of scenario $\left(s_{1}, \ldots \ldots\right.$, $\left.s_{H}\right)$ where $1 \leq i \leq M$ and $1 \leq t \leq H$

$L(i, 1)=$ Minimum investment amount on project $i$ in period 1 where $1 \leq i \leq M$

$U(i, 1)=$ Maximum investment amount on project $i$ in period 1 where $1 \leq i \leq M$

$L\left(i, t, s_{1}, \ldots . ., s_{H}\right)=$ Minimum investment amount on project $i$ in period $t$ of scenario $\left(s_{1}, \ldots \ldots, s_{H}\right)$ where $2 \leq t \leq H$

$U\left(i, t, s_{1}, \ldots \ldots, s_{H}\right)=$ Maximum investment amount on project $i$ in period $t$ of scenario $\left(s_{1}, \ldots \ldots, s_{H}\right)$ where $2 \leq t \leq H$

$\operatorname{SRR}\left(i, j, t, s_{1}, \ldots \ldots, s_{H}\right)=$ Sustainability rate of return of project $i$ predicted by stakeholder j for period $t$ of scenario $\left(s_{1}, \ldots \ldots, s_{H}\right)$ where $1 \leq i \leq M, 1 \leq j \leq N$ and $1 \leq t \leq H$

The sustainability rate of return $(S R R)$ concept is a notion which is borrowed from financial management and similar to the internal rate of return concept. It represents the rate of an organization's improvement in the three dimensions of sustainability (i.e., economic, environmental and social) as a percentage when a project is invested in. More specifically, it represents the rate of improvement in the criteria that are considered under the economic, environmental and social clusters of the ANP model. The rate of improvement for each project is calculated based on the perceptions of stakeholders on the contribution of each project to the organization's sustainability. Hence, a project may have several sustainability rates of returns depending on the stakeholder and economic conditions considered throughout the planning horizon. Specifically, $\operatorname{SRR}\left(i, j, t, s_{1}, \ldots \ldots, s_{H}\right)$ values are calculated by the following 2 steps: 
Step 1: Each stakeholder group is asked to rank $M$ projects by using the TBL sustainability framework and AHP/ANP methodology for each specific period $(t)$ and economic state $\left(s_{t}\right)$. For instance, an appropriate AHP/ANP study question may be "Which projects should the organization invest in to improve or even maximize its sustainability in period $t$ if an economic recession is expected to be in that period?" Hence, by performing $[H . \mathrm{n}(\Omega)]$ AHP/ANP studies for each stakeholder group, $[N . H . \mathrm{n}(\Omega)]$ overall weights $(O W)$ are determined for each project such that $\quad 0 \leq O W_{i j t}^{s_{t}} \leq 1$ for $1 \leq i \leq M, 1 \leq j \leq N, 1 \leq t \leq H$ and $s_{t} \in \Omega$.

Step 2: $\operatorname{SRR}\left(i, j, t, s_{1}, \ldots \ldots, s_{H}\right)$ values are calculated by normalizing and scaling the overall weights $(O W)$ with respect to the internal rate of return values of the projects. Hence, for each $\mathrm{j}=1, \ldots \ldots, \mathrm{N} ; \mathrm{t}=1, \ldots \ldots, \mathrm{H}$ and $s_{t} \in \Omega$ :

$$
{ }^{N} O W_{i j t}^{s_{t}}=\frac{O W_{i j t}^{s_{t}}}{\operatorname{Max}\left\{O W_{i j t}^{s_{t}}: 1 \leq i \leq M\right\}} \quad \text { (Normalization) }
$$

$\operatorname{SRR}\left(i, j, t, s_{1}, \ldots \ldots, s_{H}\right)$

$$
\begin{aligned}
& =\left[\frac{\operatorname{Max}\left\{\operatorname{IRR}\left(i, t, s_{1}, \ldots \ldots, s_{H}\right): 1 \leq i \leq M\right\}-\operatorname{Min}\left\{\operatorname{IRR}\left(i, t, s_{1}, \ldots \ldots, s_{H}\right): 1 \leq i \leq M\right\}}{\operatorname{Max}\left\{{ }^{N} O W_{i j t}^{s_{t}}: 1 \leq i \leq M\right\}-\operatorname{Min}\left\{{ }^{N} O W_{i j t}^{s_{t}}: 1 \leq i \leq M\right\}}\right] \times{ }^{N} O W_{i j t}^{s_{t}} \\
& +\left[\left(\operatorname{Min}\left\{\operatorname{IRR}\left(i, t, s_{1}, \ldots \ldots, s_{H}\right): 1 \leq i \leq M\right\}-\operatorname{Min}\left\{{ }^{N} O W_{i j t}^{s_{t}}: 1 \leq i \leq M\right\}\right)\right] \quad \text { (Scaling) }
\end{aligned}
$$

$P_{j}=$ Probability of experiencing the $S R R$ set which is predicted by stakeholder $j$ where $1 \leq j \leq N$ 


\section{Decision Variables:}

$x(i, 1)=$ Amount invested on project $i$ in period 1 where $1 \leq i \leq M$

$x\left(i, t, s_{1}, \ldots \ldots, s_{H}\right)=$ Amount invested on project $i$ in period $t$ of scenario $\left(s_{1}, \ldots \ldots, s_{H}\right)$

where $2 \leq i \leq M$ and $2 \leq t \leq H$

$w\left(s_{1}, \ldots \ldots, s_{H}\right)=$ Deficit or shortage amount if scenario $\left(s_{1}, \ldots \ldots, s_{H}\right)$ occurs

$y\left(s_{1}, \ldots \ldots, s_{H}\right)=$ Excess or surplus amount if scenario $\left(s_{1}, \ldots \ldots, s_{H}\right)$ occurs

\section{Objective Function:}

$\operatorname{Max} Z=F+[K \times S]$

Where

$$
\begin{aligned}
F & =\sum_{s_{H}} \ldots \ldots \sum_{s_{1}} p\left(s_{1}, \ldots \ldots, s_{H}\right)\left[-r w\left(s_{1}, \ldots \ldots, s_{H}\right)+q y\left(s_{1}, \ldots \ldots, s_{H}\right)\right] \\
S & =\sum_{s_{1}} p\left(s_{1}\right)\left[\sum_{j=1}^{N} P_{j}\left[\sum_{i=1}^{M} S R R\left(i, j, 1, s_{1}\right) x(i, 1)\right]\right] \\
& +\sum_{s_{2}} p\left(s_{2}\right) \sum_{s_{1}} p\left(s_{1}\right)\left[\sum_{j=1}^{N} P_{j}\left[\sum_{i=1}^{M} \operatorname{SRR}\left(i, j, 2, s_{1}, s_{2}\right) x\left(i, 2, s_{1}\right)\right]\right] \\
& : \\
& : \\
& : \\
& +\sum_{s_{H}} p\left(s_{H}\right) \ldots \ldots \sum_{s_{I}} p\left(s_{1}\right)\left[\sum_{j=1}^{N} P_{j}\left[\sum_{i=1}^{M} \operatorname{SRR}\left(i, j, H, s_{1}, \ldots \ldots . s_{H}\right) x\left(i, H, s_{1} \ldots \ldots . s_{H-1}\right)\right]\right]
\end{aligned}
$$

In the above objective function, $F$ represents the financial value at the end of $H$ periods and is in dollar terms. Similarly, $S$ is the sustainability value at the end of $H$ periods and it is also 
in dollar terms as a result of normalization (equation 7.1) and scaling (equation 7.2) processes. In this formulation, the investment amount on each project (in dollars) is multiplied with the sustainability rate of returns (in percentage) for that project determined by stakeholders, and an expected value of sustainability improvement (in dollars) is calculated for each period by using the scenario probabilities (i.e., $\left.p\left(s_{t}\right)\right)$ and probabilities of experiencing the sustainability rate of return sets (i.e., $P_{j}$ ). Then, the expected sustainability improvement values of $\mathrm{H}$ periods are summed up to obtain the sustainability (S) value. The sustainability (S) value represents the expected amount of organizational improvement in the three dimensions of sustainability (i.e., economic, environmental and social) in dollar terms based on the perceptions of stakeholders. More specifically, it represents the improvement in dollar terms in the criteria that are considered under the economic, environmental and social clusters of the ANP model based on the perceptions of stakeholders.

\section{Constraints:}

The first constraint is simply to invest the initial wealth in $M$ projects:

$$
\begin{aligned}
& \sum_{i=1}^{M} x(i, 1)=b \\
& L(i, 1) \leq x(i, 1) \leq U(i, 1) \quad \text { for } 1 \leq i \leq M
\end{aligned}
$$

Constraint for periods $t=2, \ldots \ldots, H$ is, for $s_{1}, \ldots \ldots, s_{t-1}$ :

$-\sum_{i=1}^{M} \operatorname{IRR}\left(i, t-1, s_{1}, \ldots \ldots s_{t-1}\right) x\left(i, t-1, s_{1}, \ldots \ldots . s_{t-2}\right)+\sum_{i=1}^{M} x\left(i, t, s_{1}, \ldots \ldots . s_{t-1}\right)=0$

$L\left(i, t-1, s_{1}, \ldots \ldots s_{t-2}\right) \leq x\left(i, t-1, s_{1}, \ldots \ldots s_{t-2}\right) \leq U\left(i, t-1, s_{1}, \ldots \ldots s_{t-2}\right) \quad$ for $1 \leq i \leq M$

Shortage and surplus constraints are:

$$
\sum_{i=1}^{M} \operatorname{IRR}\left(i, H, s_{1}, \ldots \ldots, s_{H}\right) x\left(i, H, s_{1}, \ldots \ldots, s_{H-1}\right)-y\left(s_{1}, \ldots \ldots, s_{H}\right)+w\left(s_{1}, \ldots \ldots, s_{H}\right)=G
$$


$L\left(i, H, s_{1}, \ldots \ldots s_{H-1}\right) \leq x\left(i, H, s_{1}, \ldots \ldots s_{H-1}\right) \leq U\left(i, H, s_{1}, \ldots \ldots . s_{H-1}\right)$ for $1 \leq i \leq M$

Trivial constraints are:
$y\left(s_{1}, \ldots \ldots, s_{H}\right) \geq 0$
for all $s_{1}, \ldots \ldots, s_{H}$
$w\left(s_{1}, \ldots \ldots, s_{H}\right) \geq 0$
for all $s_{1}, \ldots \ldots, s_{H}$ 


\subsection{DEMONSTRATION OF THE PROPOSED MANAGEMENT TOOL}

Before applying the proposed tool to a real case, by utilizing a single person perspective in AHP and devised financial data, it is demonstrated and tested on a fictional case involving the U.S. electric utility industry. This industry is chosen because applying sustainability metrics and practices to energy utilities is a relatively innovative concept in the U.S. such that a 2002 PriceWaterhouseCoopers (PWC) survey found that only five out of nine energy companies surveyed in the U.S. have defined sustainability, even though the industry is closely tied to environmental and economic issues (Savitz et al., 2002).

Government concerns for the future of energy in the U.S. drive the need for future capacity and green power projects. Emissions control allowances are related to the considerations of global climate change. Financial measures and performance are always a concern for a commodity-based company that is part of the utility stock index, which historically are strong and stable performers. Finally, the aging workforce in the industry is a problem for all utilities; eleven to fifty percent of the workforce is eligible to retire in the next five to ten years (U.S. Dept. of Energy, 2006). In a Black and Veatch survey in 2006, energy companies and investor-owned utilities cite aging workforce as their number three overall concern, while municipalities cite it as their number one concern (Black and Veatch, 2006).

In that sense, five projects based on the above industry trends and issues are considered as alternatives in this demonstration. Table 2 in Chapter 7 provides an overview of those projects. Table 3 provides the assumed internal rate of returns (IRRs) for the projects under an economic boom and recession, respectively. For instance, the emissions control project (project 
3) has a $14 \%$ return rate if an economic boom occurs and a $12 \%$ return rate if an economic recession occurs. In a real case, these values can be estimated by using historical data, feasibility analyses, checking industry averages or benchmarking, and asking for expert opinion. And finally, in this demonstration for simplicity the probability of having a recession or boom in a period is assumed to be equal (i.e., $p\left(s_{t}=1\right)=p\left(s_{t}=2\right)=0.5$ ).

Table 3: Internal rate of returns (IRRs) of project alternatives during recession and boom times

\begin{tabular}{|c|c|c|c|c|c|c|}
\hline \multirow{2}{*}{\multicolumn{2}{|c|}{$\operatorname{IRR}\left(i, s_{t}\right)$}} & \multicolumn{5}{|c|}{ Alternative project $i$} \\
\hline & & 1 & 2 & 3 & 4 & 5 \\
\hline$s_{t}=1$ & $p\left(s_{t}=1\right)=0.5$ & 1.140 & 1.090 & 1.080 & 1.110 & 1.250 \\
\hline$s_{t}=2$ & $p\left(s_{t}=2\right)=0.5$ & 1.120 & 1.010 & 1.070 & 1.060 & 1.060 \\
\hline \multicolumn{2}{|c|}{$\begin{array}{c}\text { Expected } I R R \text { for project } i \\
\left.\quad \text { (i.e., } I R R_{i}\right)\end{array}$} & 1.130 & 1.050 & 1.075 & 1.085 & 1.155 \\
\hline
\end{tabular}

\subsubsection{Determination of Stakeholders}

Although a typical U.S. electric utility company has many stakeholder groups, for simplicity in this demonstration only the following three stakeholder groups are considered:

- Shareholders (SHA)

- $\quad$ GGOs (NGO)

- Employees (EMP) 


\subsubsection{Triple Bottom Line Sustainability Index System}

To integrate both financial and non-financial performance measures into the investment planning and capital budgeting process, the TBL sustainability index system which was developed by Wang and Lin (2007) is used as it is in this demonstration. None of the criteria is eliminated and neither industry specific criteria is added. However, it should be remembered that in a real case, it may be necessary to eliminate some of the criteria, add industry/organization specific criteria or make changes to the hierarchy and/or categories of some of the criteria based on the

characteristics of the company involved. For instance, in a real case, some of the financial, environmental and social sustainability indices in Wang and Lin's TBL sustainability index system may not be compatible with the business or industry in which the company resides. In such a case, eliminating some of the existing indices and sub-indices, adding new industry/organization specific ones or making changes in their hierarchy and category may be necessary.

\subsubsection{Analytic Hierarchy Process (AHP)}

The construction and development process of the AHP model, and the solution procedure are summarized in the following parts based on the first three steps of the AHP methodology described in Chapter 7:

\section{Problem Structuring}

SuperDecisions 1.6.0 (Beta), an AHP software package, is used to construct and analyze the model (Super Decisions Software for Decision-Making, 2008). As explained before, the TBL 
sustainability index system that was developed by Wang and Lin (2007) and five project alternatives based on the current industry trends and issues are used in the illustrative AHP model. The visual representation of the AHP model can be seen in Figure 8. Abbreviations used in the subcriteria and attribute clusters of the AHP model refer to the indices and sub-indices shown in Appendix A.

\section{Criteria and Alternative Prioritization}

By considering the behaviors and perspectives of typical representatives from each stakeholder group, i.e., shareholders (SHA), employees (EMP) and NGOs (NGO), the criteria, sub-criteria, attributes and alternatives in the model are prioritized with the help of SuperDecisions.

\section{Calculation of Ranks and Results}

After running the AHP model three times (one for each stakeholder perspective), overall weights of the alternative projects are obtained as shown in Table 4. For simplicity, in this demonstration it is assumed that the probability of experiencing the three $S R R$ sets are equal (i.e., $P_{1}=P_{2}=$ $\left.P_{3}=1 / 3\right)$.

\subsubsection{Three-Stage Stochastic Linear Program}

Table 5 presents the SRR values of each alternative project which are calculated by using the overall weights given in Table 4. In addition to the values of $I R R, S R R, M$ and $N$, the values of the remaining stochastic program model variables are assumed as the following:

$$
\begin{aligned}
& b=\$ 55 \text { million, } G=\$ 80 \text { million } \\
& p\left(s_{1}, s_{2}, s_{3}\right)=0.125 \text { for } s_{1}=1,2, s_{2}=1,2 \text { and } s_{3}=1,2\left(\text { as } p\left(s_{t}=1\right)=p\left(s_{t}=2\right)=0.5 \text { is assumed. }\right)
\end{aligned}
$$




$$
\begin{array}{ll}
r=4 & \text { for } s_{1}=1,2, s_{2}=1,2 \text { and } s_{3}=1,2 \\
q=1 & \text { for } s_{1}=1,2, s_{2}=1,2 \text { and } s_{3}=1,2
\end{array}
$$

The detailed numeric model which is constructed under the above assumptions can be seen in Appendix B. 


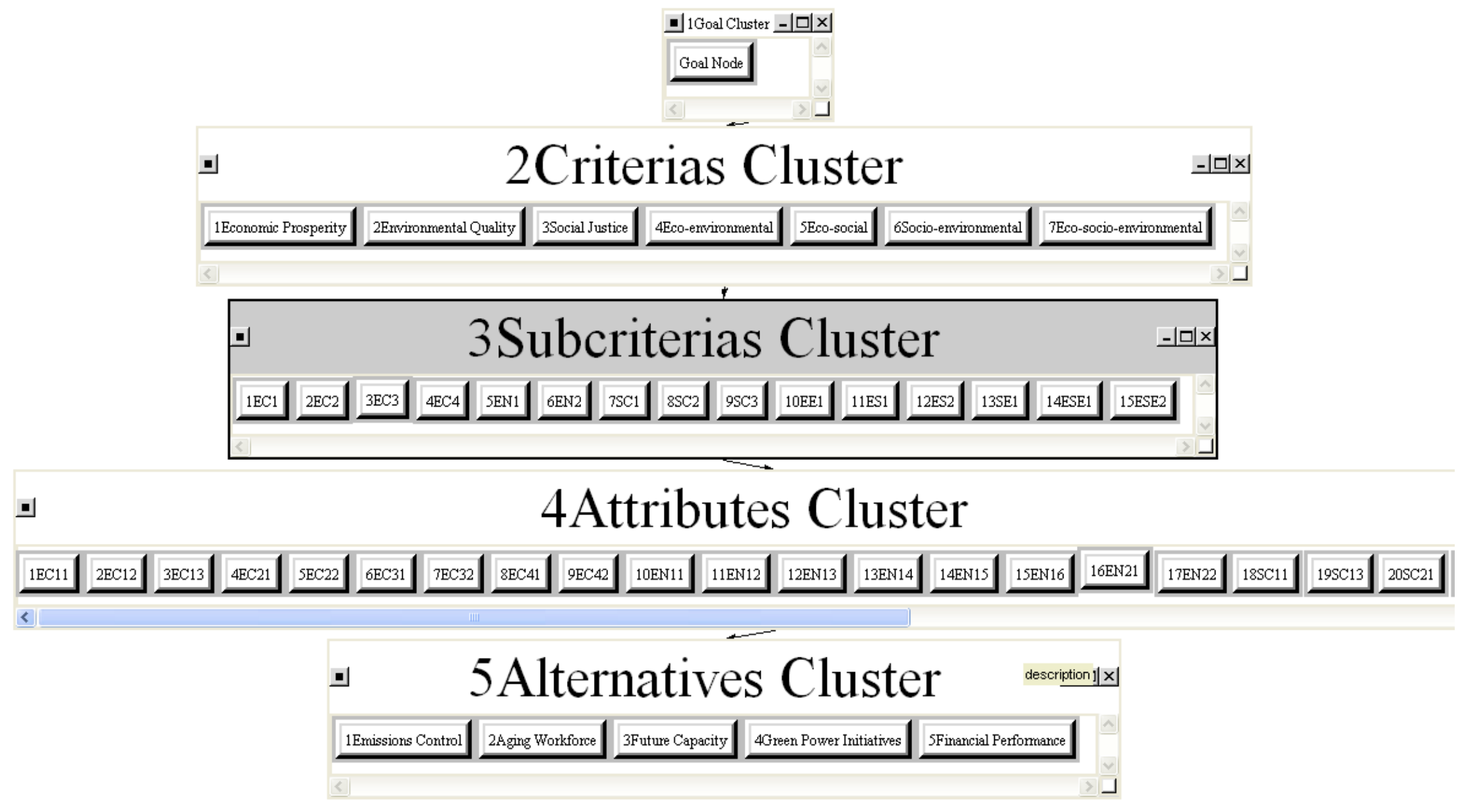

Figure 8: The AHP model and hierarchy of criteria, sub-criteria, attributes and alternatives 
Table 4: Overall weights of the project alternatives based on the perspectives of three stakeholder groups

\begin{tabular}{|c|c|c|c|c|c|c|}
\hline \multirow{2}{*}{\multicolumn{2}{|c|}{$O W_{i j}$}} & \multicolumn{5}{|c|}{ Alternative project $i$} \\
\hline & & 1 & 2 & 3 & 4 & 5 \\
\hline \multirow{3}{*}{ Stakeholder $j$} & 1 (SHA) & 0.200 & 0.150 & 0.150 & 0.100 & 0.400 \\
\hline & 2 (NGO) & 0.400 & 0.100 & 0.050 & 0.300 & 0.150 \\
\hline & 3 (EMP) & 0.150 & 0.400 & 0.100 & 0.200 & 0.150 \\
\hline \multicolumn{2}{|c|}{$\begin{array}{c}\text { Expected } O W_{i j} \text { for } \\
\text { alternative project } i \\
\quad\left(\text { i.e., } O W_{i}\right)\end{array}$} & 0.250 & 0.216 & 0.100 & 0.200 & 0.233 \\
\hline
\end{tabular}

Table 5: SRR values of the project alternatives (calculated by using the overall weights shown in Table 4)

\begin{tabular}{|c|c|c|c|c|c|c|}
\hline \multirow{2}{*}{\multicolumn{2}{|c|}{$\mathbf{S R} \mathbf{R}_{i j}$}} & \multicolumn{5}{|c|}{ Alternative project $\boldsymbol{i}$} \\
\hline & & 1 & 2 & 3 & 4 & 5 \\
\hline \multirow{3}{*}{ Stakeholder $j$} & 1 (SHA) & 1.200 & 1.150 & 1.150 & 1.100 & 1.400 \\
\hline & 2 (NGO) & 1.400 & 1.100 & 1.050 & 1.300 & 1.150 \\
\hline & 3 (EMP) & 1.150 & 1.400 & 1.100 & 1.200 & 1.150 \\
\hline \multicolumn{2}{|c|}{$\begin{array}{l}\text { Expected } S R R_{i j} \text { for } \\
\text { alternative project } i \\
\left(S R R_{i}\right)\end{array}$} & 1.250 & 1.216 & 1.100 & 1.200 & 1.233 \\
\hline
\end{tabular}




\subsubsection{Results}

To solve the three-stage stochastic linear program, ILOG Cplex 9.0 was used (ILOG, Cplex Documentation, 2008). The obtained results for several sustainability coefficient $(K)$ values are shown in Table 6.

As it is shown in Table 6 and Figure 9, five different investment portfolios are obtained after running the three-stage stochastic linear program for several sustainability coefficient $(K)$ values. Among these five, investment portfolio 3 is the optimal balanced portfolio since it provides the maximum marginal benefit in terms of improvement on sustainability. The details of the investment strategy proposed by investment portfolio 3 are shown in Appendix C. In this context, an investment portfolio represents an investment strategy which states how much should be invested on each of the five alternative projects at each of the 3 time periods. For example, as seen in Appendix C, investment portfolio 1 proposes to invest $\$ 13.520$ million and $\$ 41.479$ million on project alternatives 1 and 5 , respectively at time period 1 ; then for time period 2 , it suggests to invest $\$ 2.168$ million and $\$ 65.094$ million on alternative projects 1 and 5 , respectively if scenario 1 happens at the end of time period 1 and invest $\$ 22.368$ million and $\$ 36.743$ million on alternative projects 1 and 5 , respectively if scenario 2 happens at the end of time period 1; and so on. Investment portfolio 1 provides an investment strategy which considers only the economic concerns. For this reason, it provides the minimum sustainability value which is $\$ 236.418$ million. On the other hand, investment portfolio 5 provides an investment strategy which takes into account the environmental and social concerns at the maximum level in addition to the economic concerns. By investing $\$ 3.202$ million (i.e., $(-1.514)-(-4.716)=3.202)$ in the environment and society aspects, investment portfolios 1 and 5 improves the sustainability value 
of the organization from $\$ 236.418$ million to approximately $\$ 237.890$ million. The details of the investment strategy proposed by investment portfolio 5 are also shown in Appendix C.

Table 6: Model results for several K values

\begin{tabular}{|c|c|c|c|}
\hline \multicolumn{4}{|c|}{ MODEL RESULTS } \\
\hline $\begin{array}{c}\text { Sustainability } \\
\text { coefficient }(\boldsymbol{K})\end{array}$ & $\begin{array}{c}\text { Financial } \\
(\boldsymbol{F}) \text { value } \\
(\text { million } \mathbf{~})\end{array}$ & $\begin{array}{c}\text { Sustainability } \\
(\boldsymbol{S}) \text { value } \\
(\text { million } \mathbf{~})\end{array}$ & Investment strategy \\
\hline 0 & -1.514 & NA & Investment portfolio 1 \\
\hline 0.1 & -1.514 & 236.418 & Investment portfolio 1 \\
\hline 0.5 & -1.535 & 236.496 & Investment portfolio 2 \\
\hline 1 & -1.963 & 237.066 & Investment portfolio 3 \\
\hline 2 & -2.668 & 237.537 & Investment portfolio 4 \\
\hline 3 & -2.668 & 237.538 & Investment portfolio 4 \\
\hline 4 & -2.668 & 237.537 & Investment portfolio 4 \\
\hline 5 & -2.668 & 237.538 & Investment portfolio 4 \\
\hline 6 & -4.716 & 237.894 & Investment portfolio 5 \\
\hline 10 & -4.716 & 237.894 & Investment portfolio 5 \\
\hline 20 & -4.716 & 237.893 & Investment portfolio 5 \\
\hline 30 & -4.716 & 237.894 & Investment portfolio 5 \\
\hline 50 & -4.716 & 237.894 & Investment portfolio 5 \\
\hline
\end{tabular}




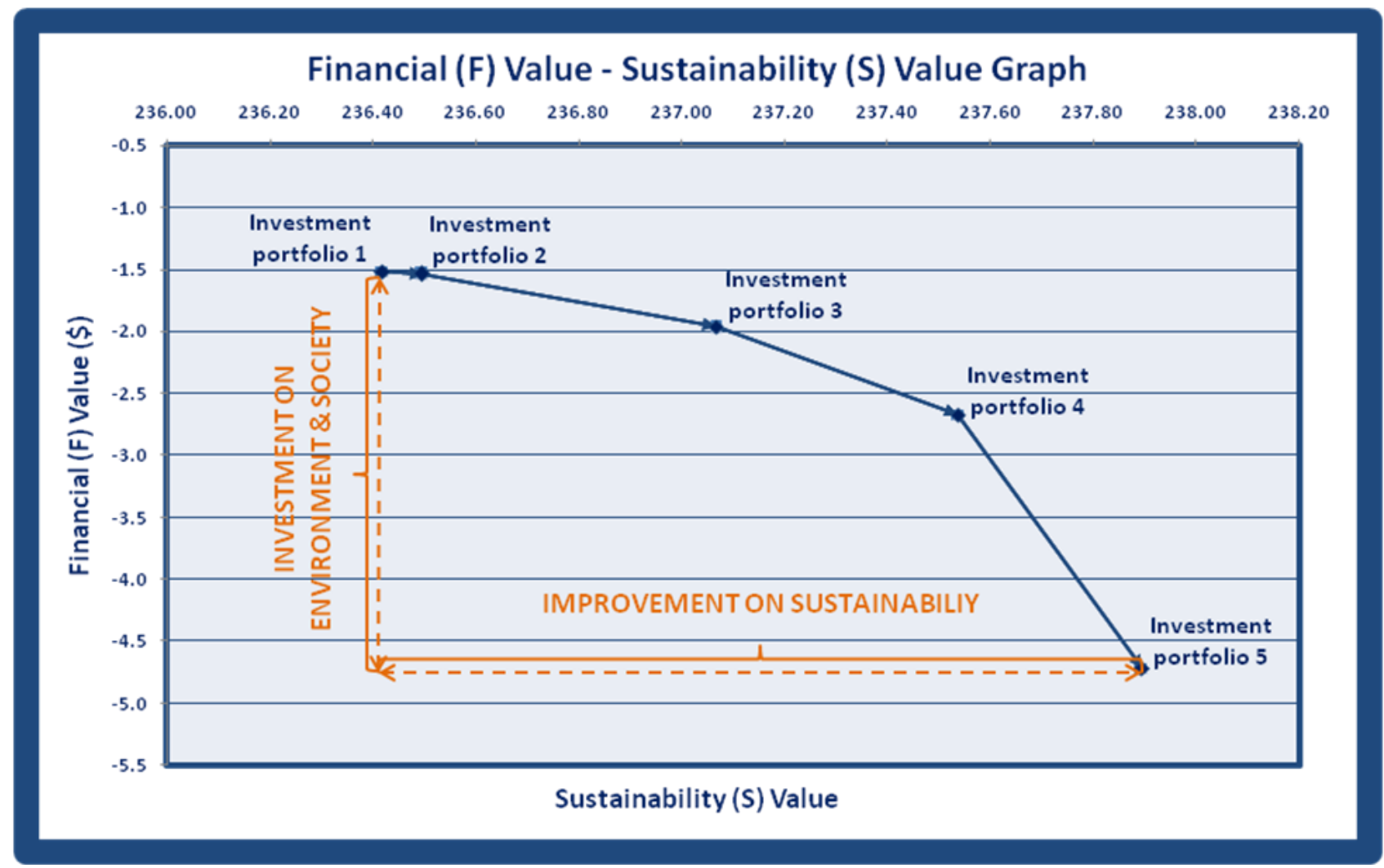

Figure 9: Investment portfolios on Financial (F) Value - Sustainability (S) Value graph

\subsubsection{Lessons Learned}

Demonstrating the developed tool on a numeric example allowed the methodology to be verified, and the necessary corrections to be made before extending it to the real life case. Two major deficiencies were observed in the tool based on the demonstration results.

First, it was realized that the actual prioritization results changed during the transition from Table 4 to Table 5. Since each stakeholder used different magnitudes while doing pairwise comparisons, without being normalized the values in Table 4 cannot be compared and used in the financial planning phase. 
Second, it was realized that there was a big difference in the relative magnitudes of the financial (F) values and sustainability (S) values shown in Table 6 and Figure 9 although they are both in dollar terms. It was thought that to compare the financial (F) values and sustainability (S) values in a more accurate way, it was necessary to scale the sustainability return rates (SRR) with respect to internal return rates (IRR) of the projects.

In the Cranberry Township case study discussed in the next chapter, the first deficiency was corrected by adding equation 7.1 (normalization) to the model. With this equation, the results obtained from AHP/ANP study are normalized.

Although the main interest is to observe how the sustainability (S) value changes with respect to the changes in the financial $(\mathrm{F})$ value, the second deficiency was also corrected by adding equation 7.2 (scaling) to the model. This equation enables one to make the relative magnitudes of the financial (F) values and sustainability (S) values closer by scaling the SRR values with respect to the IRR values of given projects. 


\subsection{CRANBERRY TOWNSHIP CASE STUDY}

Cranberry Township is a township in Butler County, Pennsylvania, United States. It is a suburb of the City of Pittsburgh with a population of 23,625 as of the 2000 census. Cranberry Township was selected as the case study organization for this research for several reasons. First, the township management already had several initiatives for sustainable development with the direction of experts at Sustainable Pittsburgh, a non-for-profit organization in Pittsburgh. More importantly, the management of the township is quite knowledgeable on sustainability issues and familiar with sustainable development principles. Second, it was thought that applying the developed tool on Cranberry Township would be important, since in addition to the financial sustainability, the environmental and social sustainability are also critical considerations for a local government.

Initial contact with the township management was performed through Sustainable Pittsburgh. Before starting the case study, the township management had worked on a project with the experts from Sustainable Pittsburgh to assess the current situation of the township in terms of sustainability features. With this assessment, Sustainable Pittsburgh experts recommended the implementation of several projects to the township management. With regard to this previous effort, the objective of this case study was to create an implementation and investment strategy for the projects that Sustainable Pittsburgh recommended by trying to answer 
the question of "Which project(s) (including the timing and financial level of investment) should the township management select in order to improve or even maximize the township's overall (financial, environmental and social) sustainability?" Appendix D.1 provides a copy of the document that was used for the initial contact with the township management to explain the details of the research and its potential benefits to them.

Before continuing with the technical details of the case study, a cartoon is presented in this section to provide intuition to the reader and introduce him/her to the case. The cartoon shown in Figure 10 visualizes a decision maker during a public speech having the City of Pittsburgh at the background. His audience consists of stakeholder groups existing in a network structure which creates an interaction and feedback mechanisms among them. 


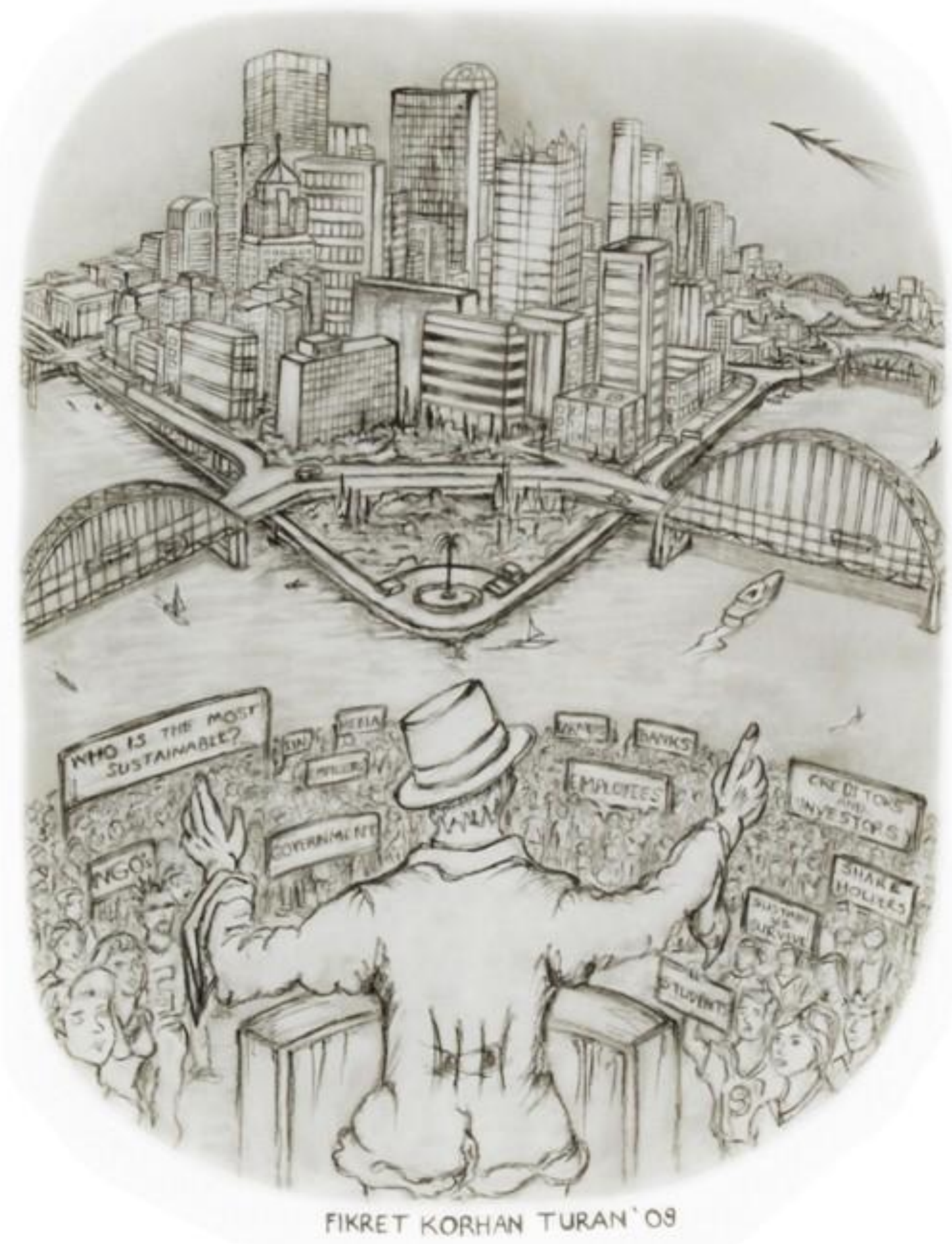

Figure 10: Towards Sustainable Organizations 
In the following sections of this chapter, first the projects recommended by the Sustainable Pittsburgh are briefly described, and their potential impact to sustainability performance criteria is discussed. Then, by considering the major stakeholder groups of the Cranberry Township management, the development of the ANP model that was used in the case study is presented. Additionally, how meetings with the stakeholder representatives were held and results of the ANP studies that were taken with them are discussed generally. In the next section, a comprehensive financial analysis for each project alternative is provided, and an optimal balanced investment portfolio is proposed based on the results of ANP studies taken with the stakeholder representatives and financial analyses of the project alternatives. Finally, implementation of the findings and validation of the tool are discussed providing the comments and feedback of Cranberry Township management and Sustainable Pittsburgh experts.

\subsection{PROJECT ALTERNATIVES}

Working together with Sustainable Pittsburgh, Cranberry Township management plans to implement a set of investment projects over time that will potentially improve the future sustainability of the township. More specifically, based on the recommendations of Sustainable Pittsburgh, the township management plans to implement the following five investment projects:

1. Building a Compost Facility (Compost): Cranberry Township currently accepts yard waste (leaves, lawn cuttings, weeds, non-woody, shrubs and tree pruning) as a part of its residential curbside pickup. While these bags of organic matter are not discarded, they are taken to an 
outside facility and lost for the township as a resource. Leaf and grass clippings from the various municipal facilities could also be composted to generate valuable leaf mulch. With this project, Cranberry Township plans to build a compost facility and use its output around municipal grounds, or offer it to the community for a fee or as a service.

2. Purchasing Alternative Fuel Vehicles for Township Fleet (Alternative Fuel): Alternative transportation fuels are the fuels other than gasoline or diesel. Examples of alternative transportation fuels include methanol, ethanol, propane or compressed natural gas, liquid natural gas, low-sulfur or "clean" diesel and electricity. With this project, Cranberry Township plans to reduce pollution, eliminate greenhouse gas emissions, minimize dependence on traditional fuels, and increase energy efficiency by purchasing alternative fuel vehicles for the township fleet.

3. Procurement of Renewable Energy Certificates (RECs): With this project, Cranberry Township plans to offset electricity consumption supplied from the traditional fossil-fuels and participate in the EPA Green Power Partnership Program by procuring RECs from local or national renewable energy resources. Procurement of RECs provides the most simple and cost effective means to demonstrate environmental responsibility within the township and become a carbon neutral community, although the procurement of RECs will be an incremental cost to the current electricity spend in the township.

4. Implementation of a Public Transportation System (Transit): Currently, Butler Transit Authority (BTA) does not provide bus service to the Cranberry area. With this project, 
Cranberry Township and BTA plan to work together to examine opportunities to implement bus service in and around Cranberry Township and find ways to fund capital and operating expenses. Although it is a capital intensive project, it will help to improve air quality, alleviate traffic congestion, and travel inexpensively and conveniently in and around Cranberry Township.

\section{Achieving a LEED Gold Status Certification for the Municipal Center (LEED): The} Leadership in Energy and Environmental Design (LEED) certification is a road map for delivering economically profitable, environmentally responsible, healthy, productive places to live and work. It is provided by the U.S. Green Building Council (USGBC) for the buildings which have sustainable green building and development practices. The context of this project includes subprojects that if implemented will provide credit for the Municipal Center to be certified. Some of these subprojects are upgrading lighting sources and improving waste management in the Municipal Center, implementing a modular green roof for the Municipal Center, and upgrading the Municipal Center HVAC system.

\subsection{SUSTAINABILITY PERFORMANCE CRITERIA SET}

In the prioritization process of these investment projects, the following decision criteria set was prepared for consideration by the township management by taking into account the impacts of the projects, as well as reviewing the sustainability index sets developed by Santa Monica, California (http://www.smgov.net/) management and Wang and Lin (2007). 


\section{- Economic Prosperity}

1. Debt-equity ratio: The debt-equity ratio is a measure of the long-term debt of the township relative to its equity. It is assumed that all five projects will have direct impact on the debt-equity ratio criterion.

\section{- Environmental Quality}

2. Energy consumption: Energy consumption is considered as a criterion to assess not only the energy efficiency, but also the quality of energy resource sustainable vs. unsustainable. It is considered that projects 2 (Alternative Fuel), 3 (RECs), 4 (Transit) and 5 (LEED) have direct impact on the energy consumption criterion.

3. Water and land use: Water and land use is added as a criterion to assess the amount and efficiency of water used, and land use quality. It is considered that project 5 (LEED) has a direct impact on the water and land use criterion.

4. Solid waste generation: Solid waste generation refers to the weight or volume of materials and products that enter the waste stream before recycling, composting, landfilling or combustion takes place. It is considered that projects 1 (Compost) and 5 (LEED) have direct impact on the solid waste generation criterion.

5. Greenhouse gases emissions: Greenhouse gas emissions refer to the amount of carbon dioxide $(\mathrm{CO} 2)$, methane $(\mathrm{CH} 4)$, nitrous oxide $(\mathrm{N} 2 \mathrm{O})$, hydrofluorocarbons (HFCs), perfluorocarbons (PFCs), sulpha hexafluoride (SF6), chlorofluorocarbons (CFCs) and hydrochlorofluorocarbons (HCFCs), together with the indirect greenhouse gas nitrogen oxides (NOx), carbon monoxide (CO) and nonmethane 
volatile organic compounds (NMVOCs) emitted to the atmosphere. It is considered that projects 2 (Alternative Fuel), 3 (RECs), 4 (Transit) and 5 (LEED) have direct impact on the greenhouse gas emissions criterion.

\section{- Social Justice}

6. Job creation: Job creation refers to the number of new jobs created. It is considered that projects 1 (Compost) and 4 (Transit) have direct impact on the job creation criterion.

7. Cost of living: Cost of living refers to the average cost of basic necessities of life such as food, shelter, clothing, transportation, etc. It is considered that projects 3 (RECs) and 4 (Transit) have direct impact on the cost of living criterion.

\section{Traffic congestion and sufficiency of transportation options: Traffic} congestion and sufficiency of transportation options is considered as a criterion to assess the general condition of traffic in terms of travel times, queues and speed of flow, and the availability of sustainable modes of transportation. It is considered that project 4 (Transit) has a direct impact on the traffic congestion and sufficiency of transportation options criterion.

This set of criteria was confirmed by the Sustainable Pittsburgh experts and Cranberry Township management for use in the case study. 


\subsection{MAJOR STAKEHOLDER GROUPS}

For the Cranberry Township case, seven entities were considered as the major stakeholders. These major stakeholders were determined by interviewing with the Cranberry Township management. Although all of these stakeholder groups were considered in the ANP model provided in the next section, only five representatives from these groups were able to participate in the ANP study and only two stakeholder groups were represented in the case study. In order to determine the potential impact of project alternatives to these stakeholder groups, the roles and responsibilities of these stakeholder groups were considered as well as the scope and context of the projects. Brief explanations about these seven major stakeholder groups are provided.

\section{- Regulators and Authorities}

\section{PA Department of Environmental Protection (DEP) (did not participate in} case study): The DEP is the state agency largely responsible for administering Pennsylvania's environmental laws and regulations. Its responsibilities include reducing air pollution, making sure drinking water is safe, protecting water quality in rivers and streams, making sure waste is handled properly, supporting community renewal and revitalization, promoting advanced energy technology, and helping citizens prevent pollution and comply with the commonwealth's environmental regulations. DEP is committed to general environmental education and encouraging effective public involvement in setting environmental policy. In this study, it is assumed that implementation of projects 2 (Alternative Fuel), 3 
(RECs) and 5 (LEED) will have direct impact on the PA Department of Environmental Protection.

2. PA Department of Transportation (DOT) (did not participate in case study): The DOT is the state agency responsible for ensuring a fast, safe, efficient, accessible and convenient transportation system that meets citizens' needs and enhances the quality of life. In this study, it is assumed that implementation of project 4 (Transit) will have a direct impact on the PA Department of Transportation.

\section{- Community and Major Employers}

3. Cranberry Township community (participated in the case study): In addition to John Trant - Chief Strategic Planning Officer of Cranberry Township, three other representatives from the Cranberry Area Chamber of Commerce, Cranberry Township Community Chest (CTCC), and Cranberry Homeowners Association participated in the ANP study. It is assumed that implementation of any of the five projects will have a direct impact on the Cranberry Township community.

4. Mine Safety Appliances (did not participate in case study): Mine Safety Appliances, headquartered in Pittsburgh, Pennsylvania, is a manufacturer of safety products which typically integrate any combination of electronics, mechanical systems and advanced materials to protect users against hazardous or life-threatening situations. With a division of nearly 500 employees in Cranberry Township, it is one of the major employers in the township. In this study, it is 
assumed that implementation of projects 3 (RECs) and 4 (Transit) will have direct impact on Mine Safety Appliances.

5. UPMC Health System (participated in the case study): UPMC is an integrated global health enterprise headquartered in Pittsburgh, Pennsylvania, and one of the leading nonprofit health systems in the United States. With a division of over 600 employees in Cranberry Township, it is one of the major employers in the township. In this study, one representative from UPMC Health System participated in the ANP study and it is assumed that implementation of projects 3 (RECs) and 4 (Transit) will have a direct impact on the UPMC Health System.

\section{Westinghouse Electric Company (did not participate in case study):} Westinghouse Electric Company whose headquarters is located in Cranberry Township operates in the worldwide commercial nuclear electric power industry. It provides fuel, services, technology, plant design, and equipment to utility and industrial customers. In this study, it is assumed that implementation of projects 3 (RECs) and 4 (Transit) will have a direct impact on Westinghouse Electric Company.

7. TRACO (did not participate in case study): TRACO operates in the building products industry by manufacturing windows, doors, storefront and entrances. Company headquarters and one of its manufacturing facilities are located in Cranberry Township. With well over 900 employees, it is one of the major employers in the township. In this study, it is assumed that implementation of projects 3 (RECs) and 4 (Transit) will have a direct impact on TRACO. 


\subsection{DEVELOPMENT OF ANP MODEL}

The ANP model built for the Cranberry Township case study is shown in Figure 11. In order to minimize the number of pairwise comparisons and hence the load on stakeholder representatives, the model is designed as a one layer simple network (i.e., there are no subnetworks, and all the clusters and nodes are in a single window).

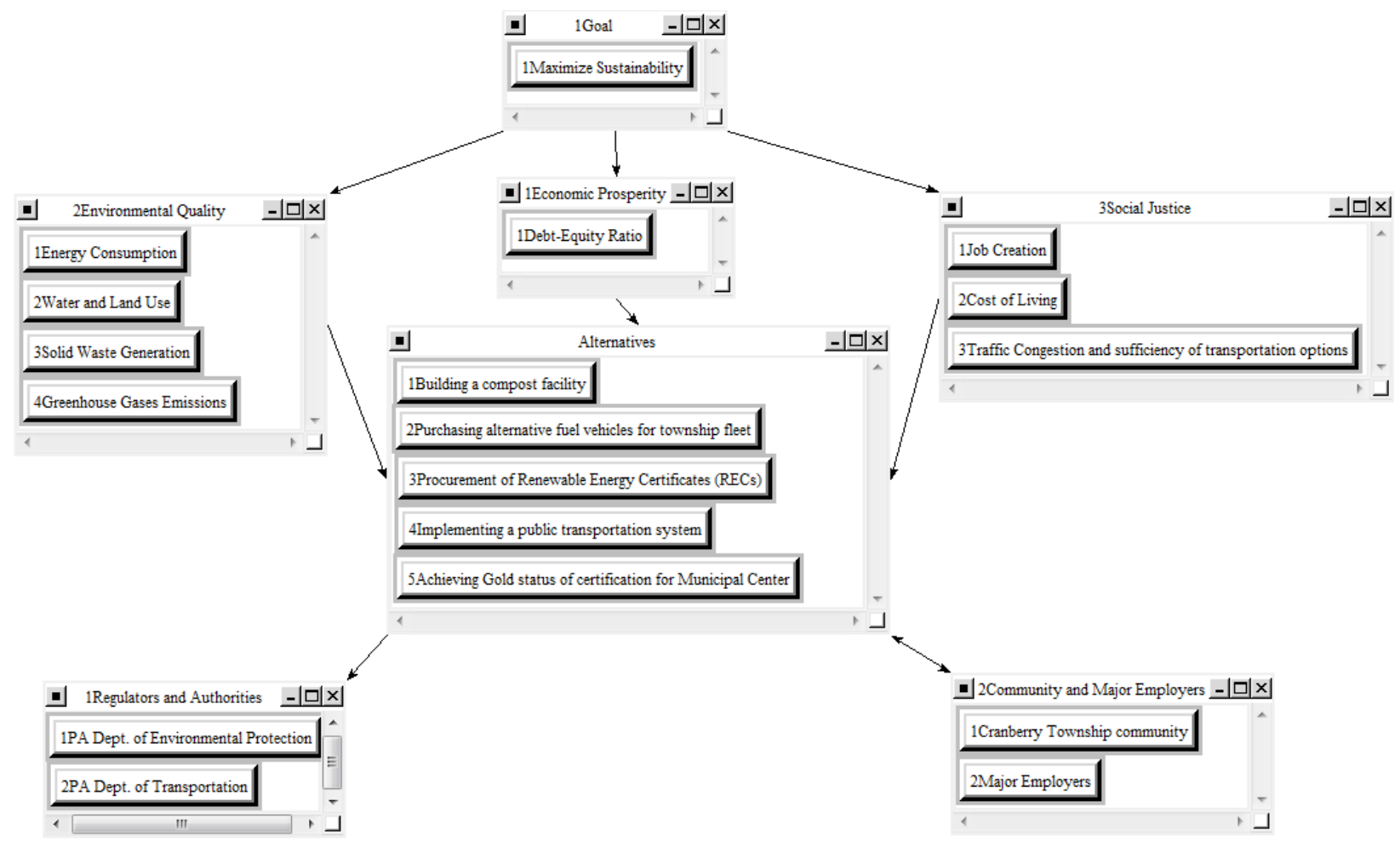

Figure 11: Final ANP model for Cranberry Township sustainability

The objective of the model is to maximize the sustainability of Cranberry Township. The model consists of three criteria clusters - economic prosperity, environmental quality and social justice. The nodes of criteria clusters are the specific performance criteria which were previously 
determined by taking into account the impacts of the projects, as well as reviewing the sustainability index sets developed by Santa Monica, California (http://www.smgov.net/) management and Wang and Lin (2007).

As depicted in Figure 11, the alternatives cluster appears at the center of the network and contains the five investment projects. All of the criteria clusters are connected to the alternatives cluster since the five investment projects will be prioritized based on these criteria. The model also contains two stakeholder clusters - regulators and authorities, and community and major employers. The alternatives cluster is connected to these stakeholder clusters since implementation of the projects will affect these stakeholders. Finally, in order to indicate the reaction of stakeholders, related stakeholder clusters are connected to the alternatives cluster.

One major drawback of the ANP methodology is the need for a large number of pairwise comparisons. Thus, if ANP is to be used for a real case, it is important to build the model in a way that the number of pairwise comparisons is kept to a minimum so as to reduce the data collection time and effort. Therefore, the ANP model shown in Figure 11 involves several evolutionary steps to simply the model. Figures provided in Appendix D.2 show the initial (full model) and interim (simplified) versions of the model.

The initial and interim ANP models require 318 and 188 pairwise comparisons respectively, which is not practical for this particular case due to time and resource constraints, as well as the cognitive burden this places on the stakeholders. For this reason, several pilot studies were conducted in order to gain insight in how best to reduce the number of pairwise comparisons. Based on these pilot studies, the following actions were taken: 


\section{Reducing the number of investment projects in consideration:}

- Advantage: Since the alternatives cluster is connected to all the other clusters (except the goal cluster), reducing the number of investment projects in consideration tremendously reduces the number of pairwise comparisons.

- Disadvantage: Reducing the number of investment projects in consideration narrows the scope of the case study and really does not truly reflect the considerations being undertaken by the Cranberry Township management.

— Incorporation into the model: Since the implementation of the projects "Upgrading lighting sources of township buildings" and "Implementing a modular green roof on Municipal Center" shown in the initial model provides credit for the Municipal Center to be LEED certified, these projects were considered as the subprojects under "Achieving Gold status of LEED certification for the Municipal Center."

\section{Eliminating the sustainability performance criteria which have less importance compared to the others:}

- Advantage: Eliminating the sustainability performance criteria which have less importance compared to the others helps in reducing the number of pairwise comparisons to some degree. For instance, a criterion which is not affected by any of the projects, or does not have a direct impact on the stakeholder groups might be considered less important than the others.

- Disadvantage: The prioritization of sustainability performance criteria is a prerequisite for the prioritization of investment projects such that investment projects will be 
prioritized with respect to the sustainability performance criteria which will also be prioritized by the stakeholder representatives. In that sense, without the stakeholders' views, it is difficult to decide for whom which criteria have less importance compared to the others.

— Incorporation into the model: First, "Water use" and "Land use" criteria shown in the initial and interim models are combined under one node called "Water and land use" in the model shown in Figure 8 since there is no project which has a direct impact on only water use criterion or land use criterion. Second, "Urban runoff reduction," "Environmentally preferable purchasing," "Health of Cranberry Township community" and "Image and reputation of Cranberry Township" criteria in the initial and interim models are eliminated since none of the projects has a direct impact on these criteria.

\section{Eliminating the stakeholders which have less importance compared to the others:}

- Advantage: Eliminating the stakeholders which have less importance compared to the others helps in reducing the number of pairwise comparisons to some degree.

- Disadvantage: Eliminating some of the stakeholders excludes the input from these stakeholders potentially resulting in sub-optimization.

- Incorporation into the model: Since not all the stakeholder groups participated in the study, the four stakeholder clusters were categorized under two clusters: 1) Regulators and Authorities 2) Community and Major Employers. The second category contains all the participative stakeholder groups. In this category, community refers to the township employees, Cranberry Area Chamber of Commerce, Cranberry Township Community Chest (CTCC), Seneca Valley School District and Cranberry Homeowners 
Association, whereas major employers refer to Mine Safety Appliance, UPMC Health Plan System, Westinghouse Electric Company and TRACO.

\section{Eliminating some of the feedback connections in the model:}

- Advantage: Eliminating some of the feedback connections in the model helps in reducing the number of pairwise comparisons to some degree.

- Disadvantage: Since implementing any of the investment projects will ultimately affect the stakeholders and stakeholders will react to this effect, valuable stakeholder reaction information will be lost if the feedback connections are eliminated.

- Incorporation into the model: In the model shown in Figure 11, only the "Community and Major Employers" cluster has a feedback mechanism because the "Regulators and Authorities" cluster does not contain any participative stakeholder group. Therefore, no further adjustments will be made to the model.

Overall, the final version of the model shown in Figure 11 is refined, but comprehensive. First, it has the main feedback mechanism from participative stakeholder groups. Second, it maintains the same scope as previous versions since it takes into account all the investment projects and important sustainability performance criteria. Finally, it requires only 50 pairwise comparisons substantially less than in the previous versions. All 50 of these pairwise comparisons can be seen in the Stakeholder Notification Document provided in Appendix D.3. 


\subsection{STAKEHOLDER MEETINGS}

In order to collect the stakeholder perception data, five separate stakeholder meetings were performed over a two-month period. These meetings were held with the following stakeholder representatives:

- John Trant - Chief Strategic Planning Officer of Cranberry Township, representing the Cranberry Township management

- Gary Mignogna - VP of Human Resources at UPMC - Passavant, representing a major employer in the township

- Duane McKee, representing the Cranberry Township Homeowners Association

- Jason Dailey, representing the Cranberry Township community

- Susan Balla, representing the Cranberry Township Chamber of Commerce

It was assumed that each stakeholder meeting would last 1 hour based on the estimations depicted in Table 7. 
Table 7: Detailed time allocation for a typical stakeholder meeting (See Appendix D.2 for comparison sets)

\begin{tabular}{|c|c|c|}
\hline Activity & Sub-Activity & $\begin{array}{c}\text { Duration } \\
\text { (minutes) }\end{array}$ \\
\hline Explanation of ANP methodology & N/A & 5 \\
\hline Demonstration of car purchase example & N/A & 5 \\
\hline $\begin{array}{c}\text { Explanation of the purpose of Cranberry } \\
\text { Township ANP study and related ANP model }\end{array}$ & N/A & 10 \\
\hline \multirow{5}{*}{ Performing pairwise comparisons } & Cluster comparison set 1 & 2.5 \\
\cline { 2 - 3 } & Cluster comparison set 2 & 1 \\
\cline { 2 - 3 } & Node comparison set 1 & 4 \\
\cline { 2 - 3 } & Node comparison set 2 & 2.5 \\
\cline { 2 - 3 } & Node comparison set 3 & 4 \\
\cline { 2 - 3 } & Node comparison set 4 & 1 \\
\cline { 2 - 3 } & Node comparison set 5 & 4 \\
\cline { 2 - 3 } & Node comparison set 6 & 6 \\
\cline { 2 - 3 } & Node comparison set 7 & 1 \\
\cline { 2 - 3 } & Node comparison set 8 & 1 \\
\cline { 2 - 3 } & Node comparison set 9 & 1 \\
\cline { 2 - 3 } & Node comparison set 10 & 1 \\
\cline { 2 - 3 } & Node comparison set 11 & 6 \\
\cline { 2 - 3 } & Inconsistency check & 5 \\
\hline
\end{tabular}

To help ensure an effective meeting, stakeholders were briefed in advance about the content of the project and ANP methodology via the Stakeholder Notification Document (see Appendix D.3) that was sent one week before the meeting. This document provides only a brief explanation about each project. It does not give any detailed financial information to the stakeholders about the projects. To ensure that the meetings were run consistently, a meeting checklist was also developed (see Checklist for Stakeholder Meetings Document in Appendix D.4).

After presenting the pairwise comparisons to the decision makers, instances of inconsistency needed to be resolved. As mentioned before an acceptable inconsistency ratio 
should be less than or equal to 0.1 . In cases where the stakeholder did not meet consistency, the stakeholder was asked to judge his/her preferences one more time via the SuperDecisions software. Table 8 summarizes all the statistics related to the stakeholder meetings.

Table 8: Information related to the stakeholder meetings

\begin{tabular}{|c|c|c|c|c|c|}
\hline $\begin{array}{c}\text { Stakeholder } \\
\text { Number }\end{array}$ & $\begin{array}{c}\text { Stakeholder } \\
\text { Group }\end{array}$ & Representative & $\begin{array}{c}\text { Meeting } \\
\text { Date }\end{array}$ & $\begin{array}{c}\text { Number of } \\
\text { inconsistency } \\
\text { cases }\end{array}$ & $\begin{array}{c}\text { Duration } \\
\text { (minutes) }\end{array}$ \\
\hline 1 & $\begin{array}{c}\text { Cranberry } \\
\text { Township } \\
\text { management }\end{array}$ & John Trant & $\begin{array}{c}\text { Feb. 25, } \\
2009\end{array}$ & 2 & 45 \\
\hline 2 & $\begin{array}{c}\text { UPMC - } \\
\text { Passavant }\end{array}$ & Gary Mignogna & $\begin{array}{c}\text { Apr. 02, } \\
2009\end{array}$ & 0 & 25 \\
\hline 3 & $\begin{array}{c}\text { Cranberry } \\
\text { Township } \\
\text { Homeowner's } \\
\text { Associations }\end{array}$ & Duane McKee & $\begin{array}{c}\text { Apr. 03, } \\
2009\end{array}$ & 2 & 35 \\
\hline 4 & $\begin{array}{c}\text { Cranberry } \\
\text { Township } \\
\text { employees }\end{array}$ & Jason Dailey & $\begin{array}{c}\text { Apr. 03, } \\
2009\end{array}$ & 2 & 37 \\
\hline 5 & $\begin{array}{c}\text { Cranberry } \\
\text { Chamber of } \\
\text { Commerce }\end{array}$ & Susan Balla & $\begin{array}{c}\text { Apr. 03, } \\
2009\end{array}$ & 7 & 40 \\
\hline
\end{tabular}

\subsection{ANP STUDY RESULTS}

Figures 12-16 show the final results of the ANP study taken with stakeholder representatives. As one can see, in 4 of the 5 final results, implementing a public transportation system has the highest priority. 
New synthesis for: Super Decisions Main Window: New_Model_Cranberry Sustain...
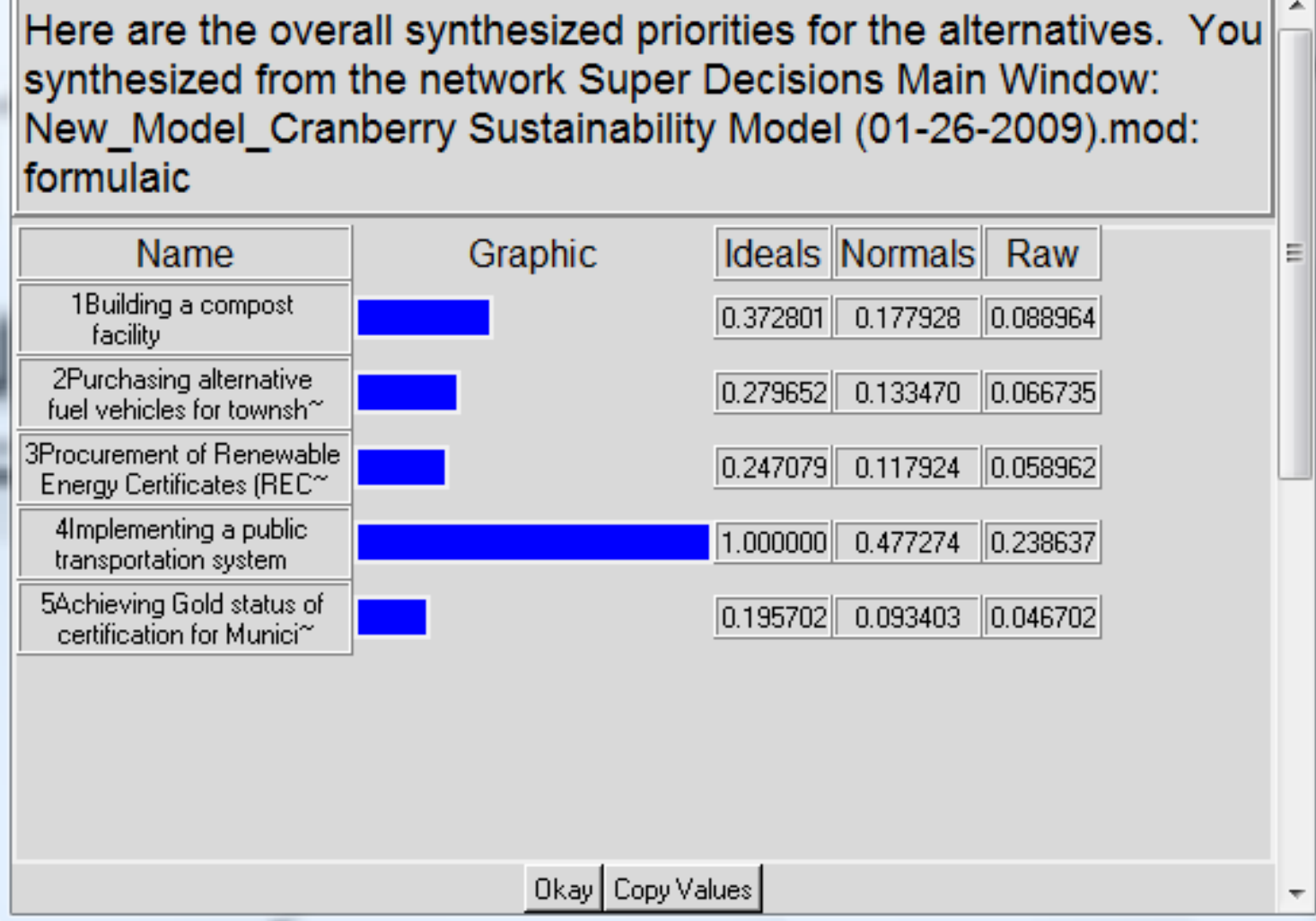

Figure 12: Final Results of ANP study taken with Cranberry Township management

For the Cranberry Township management, implementing a public transportation system has a high priority compared to the other projects. On the other hand, although achieving a Gold certification status for the Municipal Center has the lowest priority, the priorities of the three remaining projects are not well above its priority. The results can be interpreted in the following way. If implementing a public transportation system improves the sustainability of the township $100 \%$, then building a compost facility improves it by $37 \%$, purchasing alternative fuel vehicles improves it by $28 \%$, procurement of RECs improves it by $25 \%$, and achieving Gold status of certification improves it by $20 \%$. 


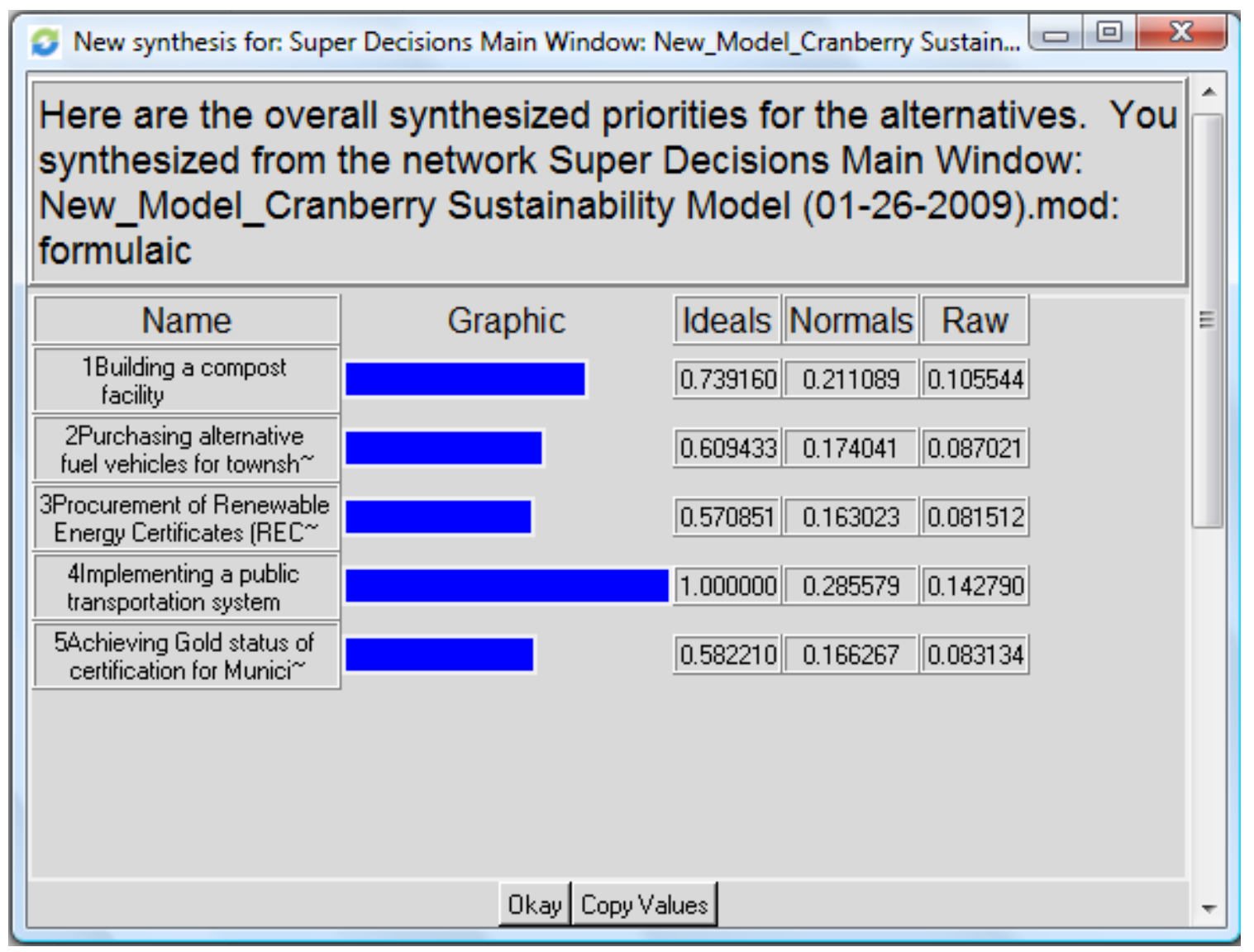

Figure 13: Final Results of ANP study taken with UPMC-Passavant

For the UPMC-Passavant, as one of the major employers in the township, although implementing a public transportation system has a higher priority than the other projects, the difference on the priorities of the five projects are not very high which reflects a fairly neutral perspective across the projects. The results can be interpreted in the following way. If implementing a public transportation system improves the sustainability of the township $100 \%$, then building a compost facility improves it by $74 \%$, purchasing alternative fuel vehicles improves it by $61 \%$, procurement of RECs improves it by $57 \%$, and achieving Gold status of certification improves it by $58 \%$. 


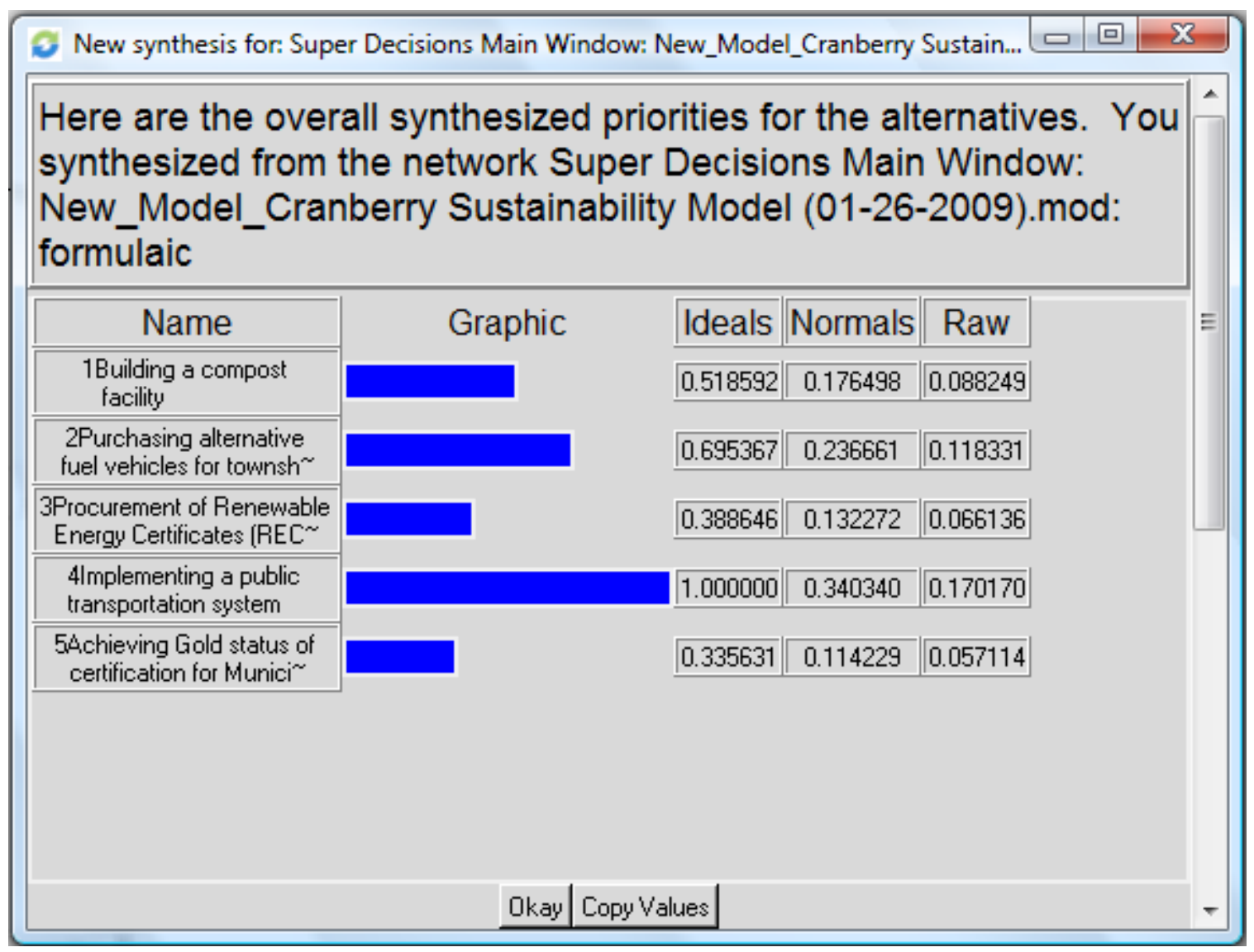

Figure 14: Final Results of ANP study taken with Cranberry Township Homeowner's Associations

For the Cranberry Township Homeowner's Associations, implementing a public transportation system has the highest priority whereas achieving a Gold certification status for the Municipal Center has the lowest priority which reflects a similar perspective with the township management. The results can be interpreted in the following way. If implementing a public transportation system improves the sustainability of the township 100\%, then building a compost facility improves it by $52 \%$, purchasing alternative fuel vehicles improves it by $70 \%$, 
procurement of RECs improves it by 39\%, and achieving Gold status of certification improves it by $34 \%$.

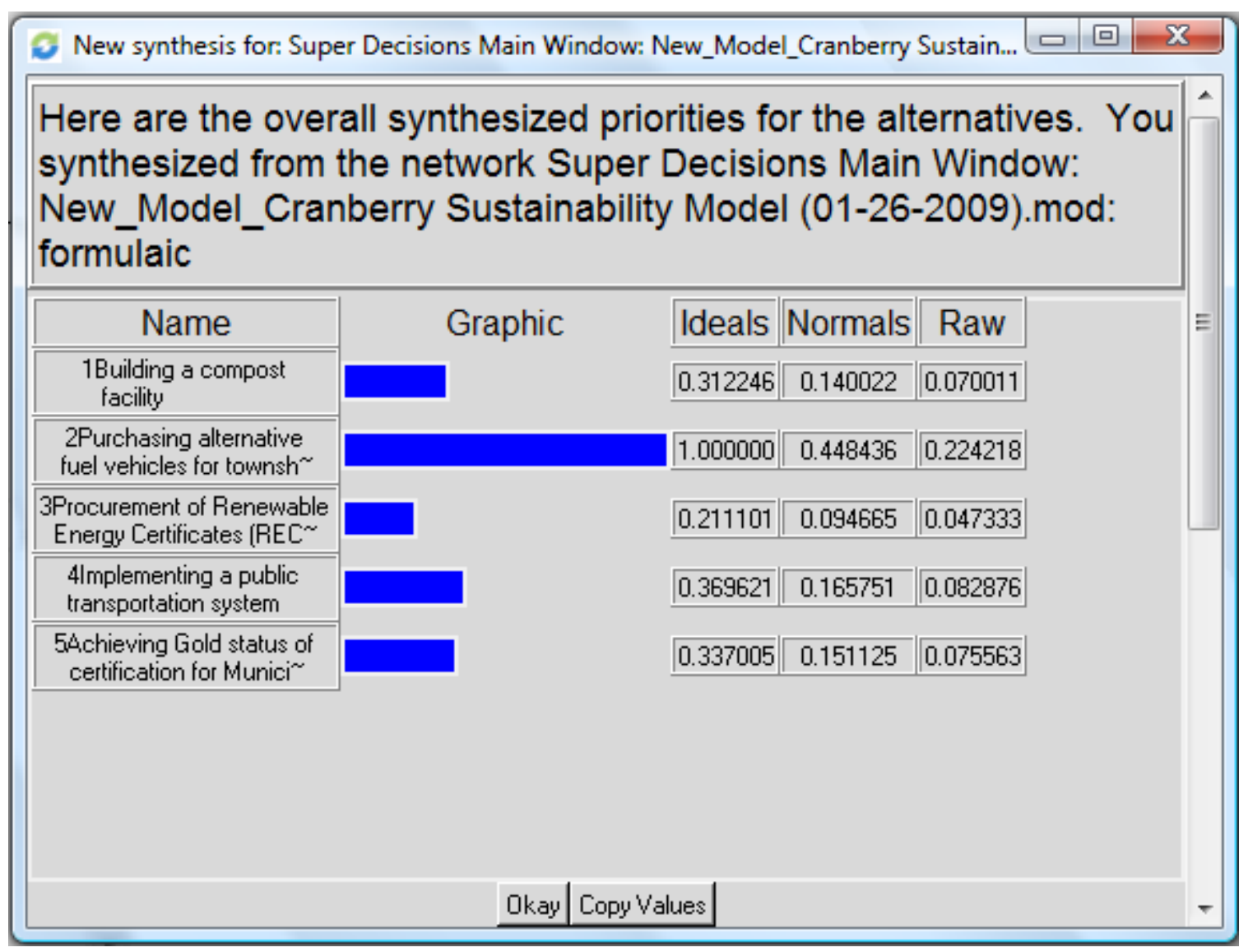

Figure 15: Final Results of ANP study taken with Cranberry Township employees

For the Cranberry Township employees, purchasing alternative fuel vehicles for the township fleet has a high priority compared to the other projects, and the priorities of the other four projects are low and close to each other. Since the township vehicles are in the usage of the township employees, it is reasonable to have a low priority for the implementing a public transportation system which is a different perspective than the other stakeholders reflect. The 
results can be interpreted in the following way. If purchasing alternative fuel vehicles improves the sustainability of the township $100 \%$, then building a compost facility improves it by $31 \%$, procurement of RECs improves it by $21 \%$, implementing a public transportation system improves it by $37 \%$, and achieving Gold status of certification improves it by $34 \%$.

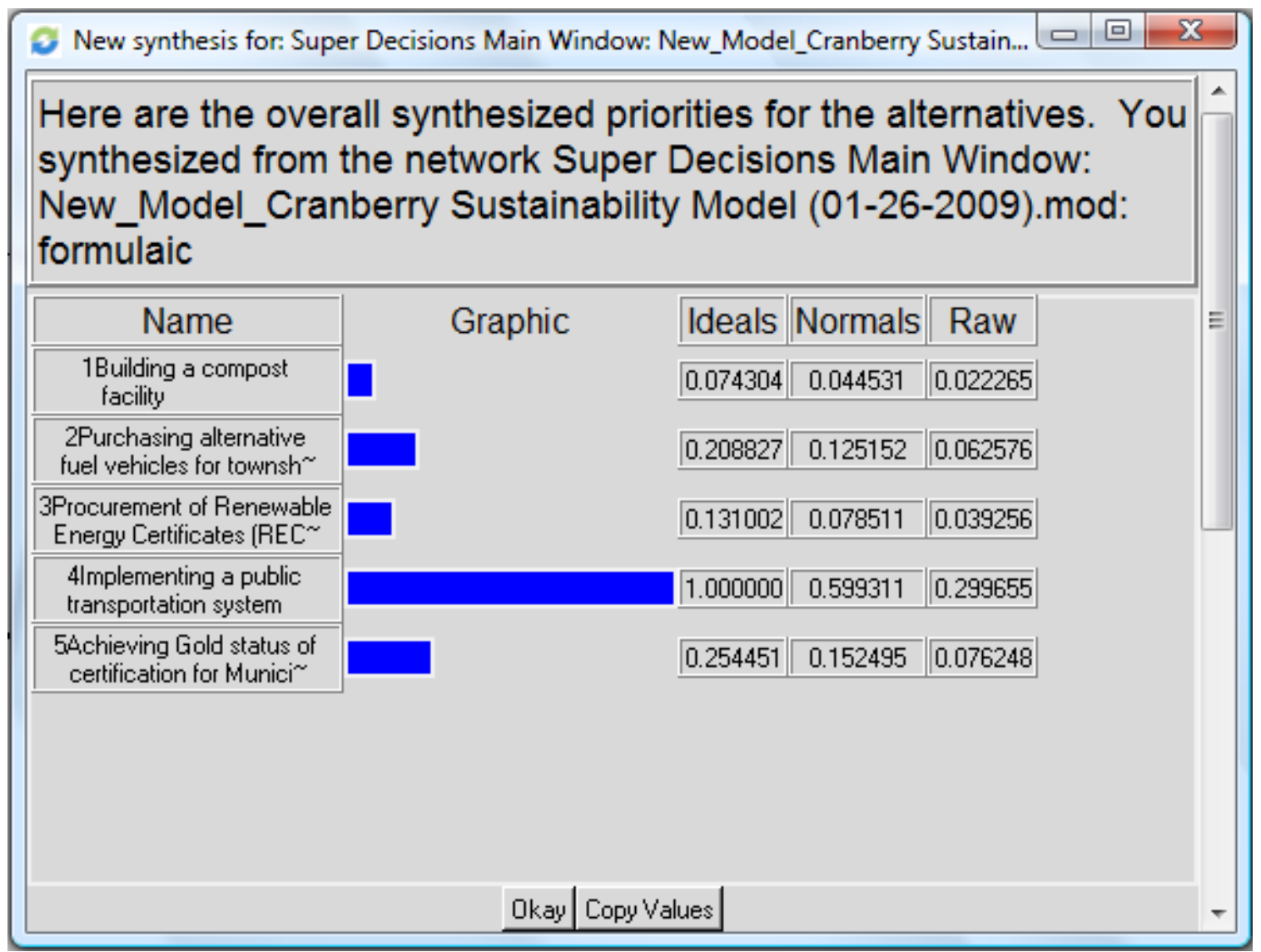

Figure 16: Final Results of ANP study taken with Cranberry Township Chamber of Commerce

Finally, for the Cranberry Township Chamber of Commerce, the priority of implementing a public transportation system is well above of the priorities of other projects, and building a compost facility has a quite low priority. This can interpreted that the Chamber of 
Commerce gives priority on the projects which will develop the economic activity and improve social life while protecting the environment. The results can be interpreted in the following way. If implementing a public transportation system improves the sustainability of the township $100 \%$, then building a compost facility improves it by $7 \%$, purchasing alternative fuel vehicles improves it by $21 \%$, procurement of RECs improves it by $13 \%$, and achieving Gold status of certification improves it by $25 \%$.

In sum, in 4 of the 5 final results, implementing a public transportation system has the highest priority. This implies that most of the stakeholders perceive that implementing a public transportation system in Cranberry Township will improve its overall sustainability much more than the other projects. Hence, in the financial planning model provided in the following sections, it has the highest sustainability return rate (SRR).

\subsection{FINANCIAL ANALYSIS OF PROJECT ALTERNATIVES}

The following sections provide the financial analyses of the projects that Cranberry Township management plans to implement. This includes the following: (1) building a compost facility (Compost), (2) purchasing alternative fuel vehicles for township fleet (Alternative Fuel), (3) procurement of renewable energy certificates (RECs), (4) implementation of a public transportation system (Transit), and (5) achieving Gold status of LEED certification for the Municipal Center (LEED). The financial analysis of the project alternatives are performed after the ANP study since the purpose of ANP study is to learn about the perceptions of stakeholders 
before taking any action or spending any effort related to the projects. These financial analyses are based on four assumptions:

1. Analyses do not involve taxation. Based on the U.S. Internal Revenue Services' (IRS) regulations, most state and local government entities are not required to pay federal income tax even though such governments all operate revenue producing enterprises. For this reason, financial analyses provided in the following sections do not involve taxation.

2. Analyses do not involve depreciation. Most property decreases in value with use and time; hence, it depreciates. Depreciation is used to determine taxable income since the law permits deduction of a reasonable allowance for wear and tear, natural decay or decline, exhaustion, or obsolescence of property used in a trade or business or of property held for the production of income (Bittker and Lokken, 1991). However, since the income is not taxed for state and local government entities, financial analyses of the projects do not involve depreciation.

3. Analyses do not involve inflation. Inflation is a frequently discussed subject in the area of economic analysis. Some argue that inflation effects can be ignored, since inflation will affect all investments in roughly the same way by considering that the relative differences in the alternatives will be approximately the same with or without inflation considered. Others argue that the inflation rate during the past few decades has been so dynamic, that an accurate prediction of the true inflation rate and its impact on future cash flows is not possible or very difficult (White et al., 1998). In that sense, since the projects that Cranberry Township management plans to implement are compared with each other in a relative manner, financial analyses of the projects do not consider inflation. 
4. No salvage value is assumed. Although capital assets such as equipment have a salvage value at the end of their useful life, in many cases this value is relatively small compared to the cost and revenue items related to that asset. For this reason, in the financial analyses of the projects, salvage value of the assets are not taken into account.

In addition to these four assumptions, financial analyses of the projects involve several other assumptions and estimations based on previous studies, technical reports, literature, and current market values. These accompanying assumptions and estimations are specific to the analyzed project; and are provided in the context of the related financial analysis. Further, IRR values calculated for each project are intended to measure the expected average rate of return of the related investment. And, although the provided financial analyses give valuable insight into the profitability of considered projects, it should not be forgotten that costs and revenues provided in these analyses are not intended to represent actual bids for the related projects and are subject to change.

\subsubsection{Project 1 - Building a Compost Facility (Compost)}

Cranberry Township currently accepts yard waste (leaves, lawn cuttings, weeds, non-woody, shrubs and tree pruning) as a part of its residential curbside pickup. While these bags of organic matter are not discarded, they are taken to an outside facility; and hence, are a loss for the township as a resource. Cranberry Township plans to build a compost facility and use its output around municipal grounds, or offer it to the community for a fee or as a service. 


\section{Facility Size}

A basic determinant for the size of the compost facility is the amount of the yard waste collected in the township. Cranberry Township management indicates that of the 6,700 tons of waste collected in 2007, 1,238 tons were yard waste (around 18.5\%) (Wills, 2008). Further, determination of the size of the facility should be based on the volume estimate of the yard waste collected because the Guidelines for Yard Waste Composting Facilities issued by the Pennsylvania Department of Environmental Protection (DEP) (2009) requires that no more than 3,000 cubic yards of waste shall be placed, stored, or processed on any acre of a facility where composting activity occurs or is planned to occur.

According to the Municipal Yard Waste Composting Reference Manual (1991) and Municipal Yard Waste Composting Facility - Operator's Reference Guide and Handbook (1999), the density of mixed yard waste, as collected, can range from 350 to 950 pounds per cubic yard. Since 1,238 tons (i.e., yard waste amount collected in 2007) is low compared to the amount of yard waste collected in similar sized townships, the lowest level of the range (i.e., 350 pounds per cubic yard) is used to calculate the size of the active composting area. Under this assumption, the compost facility that will be built in Cranberry Township should have an active composting area of 2.358 acres. In addition to that, by assuming a staging and buffer area of 3 acres and a storage area at approximately $50 \%$ of the active composting area, the total area needed for the compost facility is considered to be 6.537 acres.

\section{Capital Expenditures}

Capital expenditures involve site development, building construction and equipment costs. Site development costs are associated with preparing the site for composting. Examples include 
clearing and grubbing, cutting and filling, storm water management, soil erosion and sedimentation control, paving the access road to the facility, building parking lot, developing infrastructure for utility services and subdivision planning in the facility. On the other hand, equipment costs are related to the machinery and tools that are necessary to operate the facility.

For the site development and building construction costs, a feasibility report prepared for the townships of Dorrance, Fairview, Rice and Wright, and Nuangola Borough in Luzerne County (Development of a Multi-Municipal Yard Waste Composting Facility (2002)) provides valuable insight since these communities are also located in Pennsylvania. Note that Cranberry Township is located in the Southwestern corner of Butler County, Pennsylvania. For the proposed total area of 15 acres, the development of Luzerne County yard waste compost facility requires an allocation of $\$ 556,400$ and $\$ 138,000$ for the site development and building construction costs, respectively. Assuming a direct relationship between the size of the facility, and site development and building construction costs, Cranberry Township needs a compost facility with a total area of 6.537 acres, with estimated costs of $\$ 242,279$ for site development cost and $\$ 60,140$ for building construction cost. These cost items are shown in Table 9.

Regarding equipment, a compost facility typically requires a chipper/shredder, tub grinder, skid loader, screener, turner and support tools such as thermometers, $\mathrm{pH}$ and stability kits, etc. Although market values for these equipment may change depending on their brand, age, technical aspects, etc., Table 9 provides suitable estimated costs for these equipment based on the development of Luzerne County yard waste compost facility. 
Table 9: Capital expenditures

\begin{tabular}{|c|c|r|}
\hline \multicolumn{2}{|c|}{ Capital expenditures } & Amount (\$) \\
\hline \multicolumn{2}{|c|}{ Site development cost } & 242,279 \\
\hline \multicolumn{2}{|c|}{ Building construction cost } & 60,140 \\
\hline \multirow{4}{*}{ Equipment cost } & Chipper/Shredder & 19,675 \\
\cline { 2 - 3 } & Tub grinder & 52,850 \\
\cline { 2 - 3 } & Skid loader & 42,150 \\
\cline { 2 - 3 } & Screener & 54,000 \\
\cline { 2 - 3 } & Turner & 77,000 \\
\cline { 2 - 3 } & Support tools & 5,100 \\
\hline & & $\mathbf{5 5 3 , 1 9 4}$ \\
\hline
\end{tabular}

\section{Operating and Maintenance Costs}

Operating and maintenance costs for a compost facility involve labor, electricity, fuel and maintenance costs. Since Cranberry Township currently accepts yard waste (leaves, lawn cuttings, weeds, non-woody, shrubs and tree pruning) as a part of its residential curbside pickup, cost of collecting yard waste is not considered as an operating cost in this analysis. Estimations for the other costs are shown in Table 10. In the calculation of labor cost it is assumed that the labor needed to operate the compost facility is $0.18 /$ hours/ton and the labor rate is $\$ 60 /$ hour. These assumptions are based on a technical report prepared to plan and implement a yard waste composting site in the City of Pittsburgh - Yard Waste Facility in Pittsburgh (1999). In a similar way, electricity, fuel and maintenance cost values are adapted from a feasibility study prepared for building a compost facility for the usage of City of Lebanon and North Lebanon Township residents - Compost Site Feasibility and Design (2005), as the size of this facility is approximately the same as the one considered for Cranberry Township. 
Table 10: Operating and maintenance costs

\begin{tabular}{|c|r|}
\hline Operating and maintenance costs & Amount (\$/year) \\
\hline Labor cost & 13,370 \\
\hline Electricity cost & 500 \\
\hline Fuel cost & 1,800 \\
\hline Maintenance cost & 400 \\
\hline Total & $\mathbf{1 6 , 0 7 0}$ \\
\hline
\end{tabular}

\section{Revenues}

To generate revenue, it is reasonable for Cranberry Township management to request an average of $\$ 40 /$ ton process fee from the residents and companies that use the facility. (To determine the exact amounts of process fee for residents and companies, \$40/ton average process fee can be split depending on the amount of yard waste collected from residents and companies separately). In doing so, township management can generate a revenue of $\$ 49,520 /$ year. Further, if they could sell the final output of composting process (i.e., mulch) for $\$ 12$ per cubic yard, additional revenue can be created. This additional revenue computes to roughly $\$ 35,657 /$ year by assuming that the weight of yard waste is reduced by approximately $58 \%$ through the composting process as mentioned in Waste Reduction Fact Sheet - Yard Waste Management (1996). These revenue items are shown in Table 11.

Table 11: Revenues

\begin{tabular}{|r|r|}
\hline Revenues & $\begin{array}{c}\text { Amount } \\
\text { (\$/year) }\end{array}$ \\
\hline $\begin{array}{r}\text { Revenue by requesting } \\
\text { process fee }\end{array}$ & 49,520 \\
\hline Revenue by selling mulch & 35,657 \\
\hline Total & $\mathbf{8 5 , 1 7 7}$ \\
\hline
\end{tabular}




\section{Calculation of Internal Rate of Return (IRR)}

In calculating internal rate of return (IRR), the following assumptions are made.

- The compost facility is assumed to have an expected life of nine years since most of the equipment purchased have a life span of eight to ten years.

- Cranberry Township's population grew 34\%, to 14,816, between 1980 and 1990. The 2000 census placed its population at 23,625, up almost $60 \%$ from 1990. By considering these values, for the following nine years, it is assumed that Cranberry Township's population will increase by $47 \%$ (average of $34 \%$ and $60 \%$ ) and the amount of yard waste collected will increase to 1,819 tons from 1,238 tons by considering a direct relationship with the population increase. Additionally, while calculating the annual increase in operating and maintenance costs, and revenues, it is assumed that the increase from 1,238 to 1,819 tons in yard waste will be linear over nine years.

Table 12 shows three IRR values calculated for the compost facility. The IRR value for the most probable scenario is based on the estimated capital expenditures, operating and maintenance costs, and revenues provided in previous sections. The IRR values for the worst case and best case scenarios are obtained by making small changes to the assumed parameters such as process fees or the selling price of mulch. Specifically, for the worst case scenario, capital expenditures, operating and maintenance costs increase by $5 \%$, process fees decrease to $\$ 35 /$ ton from $\$ 40 /$ ton, and mulch prices decrease to $\$ 10$ per cubic yard from $\$ 12$ per cubic yard. In a similar way, for the best case scenario, capital expenditures, operating and maintenance costs decrease by $5 \%$, process fees increase to $\$ 45 /$ ton from $\$ 40 /$ ton, and mulch prices increase to $\$ 14$ per cubic yard from $\$ 12$ per cubic yard. 
The annual average rate of return of building a compost facility in Cranberry Township is expected to be $1.38 \%, 6.64 \%$ and $11.78 \%$ for the worst case, most probable and the best case, respectively.

Table 12: Internal rate of return (IRR) of building a compost facility in Cranberry Township (Project 1) for worst case, most probable and best case scenarios

\begin{tabular}{|c|c|c|c|}
\cline { 2 - 4 } \multicolumn{1}{c|}{} & $\begin{array}{c}\text { Worst case } \\
\text { scenario }\end{array}$ & $\begin{array}{c}\text { Most } \\
\text { probable scenario }\end{array}$ & $\begin{array}{c}\text { Best case } \\
\text { scenario }\end{array}$ \\
\hline Total capital expenditure (\$) & $\mathbf{- 5 8 0 , 8 5 3}$ & $\mathbf{- 5 5 3 , 1 9 4}$ & $\mathbf{- 5 2 5 , 5 3 4}$ \\
\hline Net cash flow in year 1 (\$) & 56,171 & 69,107 & 82,043 \\
\hline Net cash flow in year 2 (\$) & 59,471 & 73,167 & 86,863 \\
\hline Net cash flow in year 3 (\$) & 62,771 & 77,227 & 91,683 \\
\hline Net cash flow in year 4 (\$) & 66,071 & 81,287 & 96,503 \\
\hline Net cash flow in year 5 (\$) & 69,371 & 85,347 & 101,323 \\
\hline Net cash flow in year 6 (\$) & 72,671 & 89,407 & 106,143 \\
\hline Net cash flow in year 7 (\$) & 75,971 & 93,467 & 110,963 \\
\hline Net cash flow in year 8 (\$) & 79,271 & 97,527 & 115,783 \\
\hline Net cash flow in year 9 (\$) & 82,571 & 101,587 & 120,603 \\
\hline Internal rate of return $\mathbf{( I R R )}$ & $\mathbf{1 . 3 8 \%}$ & $\mathbf{6 . 6 4 \%}$ & $\mathbf{1 1 . 7 8 \%}$ \\
\hline
\end{tabular}

\subsubsection{Project 2 - Purchasing Alternative Fuel Vehicles for Cranberry Township Fleet}

\section{(Alternative Fuel)}

Alternative transportation fuels are the fuels other than gasoline or diesel. Examples of alternative transportation fuels include methanol, ethanol, propane or compressed natural gas, liquid natural gas, low-sulfur or "clean" diesel and electricity. For municipalities, vehicles that use alternative fuels are usually preferred for environmental and efficiency reasons even though they have higher purchase prices compared to gasoline or diesel vehicles. 
This analysis provides a review of the current status of the Cranberry Township fleet. Considering the future vehicle replacement needs of the township, the review determines the amount of extra investment required beyond the basic vehicle replacement plan to make the township's fleet green and related savings on fuel costs. Although alternative fuel vehicles are longer-lasting (since alternative fuel vehicles burn cleaner and do not dirty the motor oil as in a gasoline or diesel engine) and have lower maintenance cost, the major benefit of alternative fuel vehicles is their fuel efficiency. For this reason, this analysis focuses on the savings on fuel cost if the alternative fuel vehicles are preferred for the implementation of the Cranberry Township fleet replacement plan.

\section{Scope and Basic Assumptions}

Currently, the Cranberry Township fleet has 122 non-alternative fuel vehicles. Based on the Vehicle Replacement Program shown in Appendix E, the township management has a replacement plan until 2028. Although this plan is a target to renew the fleet and does not include alternative fuel vehicle purchases, the township management mentions that it is subject to change depending on several factors such as availability of budget, vehicle depreciation, and changes in future demand and technology. Because of uncertainty on these factors, this analysis focuses on the vehicle purchases that are planned for the first nine years of the replacement plan (i.e., from 2009 to 2017). Specifically, it investigates how much extra investment is required and how much related savings of fuel costs is obtained if the alternative fuel vehicles are the preferred purchases during these nine years.

The township's 122 vehicles have a total average annual usage of 798,580 miles/year. Since alternative fuel vehicles have a higher initial purchase price and lower operating costs 
compared to conventional vehicles, they are typically profitable and preferable when the vehicle usage and fuel prices are high (Sherman, 2007). For this reason, in order to maximize the profitability, this analysis considers only the sedans, SUVs, pick-ups and trucks whose annual usage is greater than or equal to 10,000 miles/year (making a total average annual usage of 468,363 miles/year). It is thought that replacing vehicles whose annual usage is less than 10,000 miles/year with alternative fuel vehicles will not provide a significant amount of savings on fuel cost compared to the extra investment spent to purchase the alternative fuel vehicles.

For simplification, the analysis assumes that sedans will be replaced (when it is appropriate) with the Chevrolet Malibu Hybrid, SUVs will be replaced with the Ford Escape Hybrid FWD, and pick-ups and trucks will be replaced with the Chevrolet Silverado 15 Hybrid 2WD. These models are selected since they are among the most efficient hybrid vehicles that are currently available in the market. Purchase prices for these alternative fuel vehicles are obtained from NADAguides.com - a comprehensive vehicle information website, and they include tax, license, title, registration and documentation fees which are assumed to be $9 \%$ of their manufacturer suggested retail prices (MSRPs).

Finally, per mile fuel cost for both gasoline or diesel and alternative fuel vehicles are obtained from the website of www.fueleconomy.gov by assuming a $45 \%$ highway, 55\% city driving, and a fuel price of $\$ 2.40$ per gallon of gasoline.

\section{Capital Expenditures and Savings on Fuel Costs}

Table 13 provides an estimate of how much extra investment is required to purchase alternative fuel vehicles and how much related savings on fuel costs is obtained if the alternative fuel vehicles are preferred in the vehicle purchases from 2009 to 2017. As mentioned, since 
alternative fuel vehicles are typically preferred when the vehicle usage and fuel prices are high (Sherman, 2007), it is assumed that there will not be significant differences in other operating costs such as maintenance.

For the extra investment in year 2011, a negative value is obtained because the purchase prices of the selected alternative fuel vehicles (i.e., the Chevrolet Malibu Hybrid, Ford Escape Hybrid FWD and Chevrolet Silverado 15 Hybrid 2WD) are less than the allocated budget for this year in the original replacement plan prepared by the township management. In the calculation of internal rate of return (IRR), this value is treated as a savings.

Additionally, throughout the nine-year planning horizon as the vehicles in the township fleet are replaced with alternative fuel vehicles, savings on fuel cost increases. This explains the savings on fuel cost column of Table 13 has an increasing trend.

Table 13: Extra investment required to purchase alternative fuel vehicles and related savings obtained on fuel cost if the alternative fuel vehicles are preferred

\begin{tabular}{|c|r|r|}
\hline Year & $\begin{array}{c}\text { Extra } \\
\text { investment } \\
\mathbf{( \$ )}\end{array}$ & $\begin{array}{c}\text { Savings on } \\
\text { fuel cost } \mathbf{( \$ )}\end{array}$ \\
\hline $\mathbf{2 0 0 9}$ & 17,289 & 8,309 \\
\hline $\mathbf{2 0 1 0}$ & 32,776 & 13,473 \\
\hline $\mathbf{2 0 1 1}$ & $-3,602$ & 14,372 \\
\hline $\mathbf{2 0 1 2}$ & 2,696 & 15,286 \\
\hline $\mathbf{2 0 1 3}$ & 4,359 & 17,178 \\
\hline $\mathbf{2 0 1 4}$ & 21,082 & 18,800 \\
\hline $\mathbf{2 0 1 5}$ & 6,584 & 18,800 \\
\hline $\mathbf{2 0 1 6}$ & 3,420 & 18,800 \\
\hline $\mathbf{2 0 1 7}$ & 34,833 & 18,800 \\
\hline
\end{tabular}




\section{Calculation of Internal Rate of Return (IRR)}

Tables 14,15 and 16 show three IRR values calculated for purchasing alternative fuel vehicles for Cranberry Township fleet. The IRR value for the most probable scenario is based on the estimated extra investment necessary to purchase alternative fuel vehicles and related savings on fuel costs provided in previous sections. Since the profitability of alternative fuel vehicles is very sensitive to fuel price, the IRR value for the most probable case is calculated by assuming a fuel price of $\$ 2.40$ per gallon of gasoline whereas the IRR values for the worst case and best case scenarios are calculated by assuming a fuel price of $\$ 2.80$ and $\$ 2.00$ per gallon of gasoline, respectively. Assumptions on the fuel prices are based on the historical fuel prices obtained from the website of Energy Information Administration (http://www.eia.doe.gov/). Although there are fluctuations in the fuel prices, there is an increasing trend in recent 10 years. For this reason, for the most probable case, average of the gasoline prices in last 5 years is assumed. And, for the worst case and best case scenarios, average of the gasoline prices in the last 2 years and 10 years are assumed.

Annual average rate of return of purchasing alternative fuel vehicles for Cranberry Township fleet is expected to be $1.04 \%, 28.69 \%$ and $49.04 \%$ at the worst case, most probably and at the best case, respectively. 
Table 14: Internal rate of return (IRR) of purchasing alternative fuel vehicles for Cranberry

Township fleet (Project 2) for worst case scenario

\begin{tabular}{|c|c|c|c|}
\hline \multicolumn{4}{|c|}{ Worst case scenario } \\
\hline Year & $\begin{array}{c}\text { Extra } \\
\text { investment } \\
(\$)\end{array}$ & $\begin{array}{l}\text { Savings on } \\
\text { fuel cost }(\$)\end{array}$ & $\begin{array}{l}\text { Net cash } \\
\text { flow (\$) }\end{array}$ \\
\hline 2009 & 17,289 & 6,924 & $-10,365$ \\
\hline 2010 & 32,776 & 11,228 & $-21,548$ \\
\hline 2011 & $-3,602$ & 11,977 & 15,579 \\
\hline 2012 & 2,696 & 12,738 & 10,042 \\
\hline 2013 & 4,359 & 14,315 & 9,956 \\
\hline 2014 & 21,082 & 15,667 & $-5,415$ \\
\hline 2015 & 6,584 & 15,667 & 9,083 \\
\hline 2016 & 3,420 & 15,667 & 12,247 \\
\hline 2017 & 34,833 & 15,667 & $-19,166$ \\
\hline \multicolumn{3}{|c|}{ Internal rate of return (IRR) } & $1.04 \%$ \\
\hline
\end{tabular}

Table 15: Internal rate of return (IRR) of purchasing alternative fuel vehicles for Cranberry Township fleet (Project 2) for most probable scenario

\begin{tabular}{|c|c|c|c|}
\hline \multicolumn{4}{|c|}{ Most probable scenario } \\
\hline Year & $\begin{array}{c}\text { Extra } \\
\text { investment (\$) }\end{array}$ & $\begin{array}{l}\text { Savings on } \\
\text { fuel cost (\$) }\end{array}$ & $\begin{array}{l}\text { Net cash } \\
\text { flow (\$) }\end{array}$ \\
\hline 2009 & 17,289 & 8,309 & $-8,980$ \\
\hline 2010 & 32,776 & 13,473 & $-19,303$ \\
\hline 2011 & $-3,602$ & 14,372 & 17,975 \\
\hline 2012 & 2,696 & 15,286 & 12,590 \\
\hline 2013 & 4,359 & 17,178 & 12,819 \\
\hline 2014 & 21,082 & 18,800 & $-2,282$ \\
\hline 2015 & 6,584 & 18,800 & 12,216 \\
\hline 2016 & 3,420 & 18,800 & 15,380 \\
\hline 2017 & 34,833 & 18,800 & $-16,033$ \\
\hline \multicolumn{3}{|c|}{ Internal rate of return (IRR) } & $28.69 \%$ \\
\hline
\end{tabular}


Table 16: Internal rate of return (IRR) of purchasing alternative fuel vehicles for Cranberry

Township fleet (Project 2) for best case scenario

\begin{tabular}{|c|c|c|c|}
\hline \multicolumn{4}{|c|}{ Best case scenario } \\
\hline Year & \begin{tabular}{|c|} 
Extra \\
investment $(\$)$
\end{tabular} & $\begin{array}{l}\text { Savings on } \\
\text { fuel cost }(\$)\end{array}$ & $\begin{array}{l}\text { Net cash } \\
\text { flow (\$) }\end{array}$ \\
\hline 2009 & 17,289 & 9,694 & $-7,595$ \\
\hline 2010 & 32,776 & 15,719 & $-17,057$ \\
\hline 2011 & $-3,602$ & 16,768 & 20,370 \\
\hline 2012 & 2,696 & 17,834 & 15,138 \\
\hline 2013 & 4,359 & 20,041 & 15,682 \\
\hline 2014 & 21,082 & 21,934 & 851 \\
\hline 2015 & 6,584 & 21,934 & 15,350 \\
\hline 2016 & 3,420 & 21,934 & 18,514 \\
\hline 2017 & 34,833 & 21,934 & $-12,899$ \\
\hline In & return & $\mathbf{R})$ & $49.04 \%$ \\
\hline
\end{tabular}

\subsubsection{Project 3 - Purchasing Renewable Energy Certificates (RECs)}

Although purchasing renewable energy certificates (RECs) provides several intangible benefits to Cranberry Township to include: favorable reputation, dedication to sustainability, certification by the Environmental Protection Agency (EPA), etc., it is not a direct cash generating investment option. For this reason, this analysis focuses only on the required amount of REC purchase and its cost to the township management.

\section{Scope and Cost of Purchasing Renewable Energy Certificates (RECs)}

Currently, Cranberry Township consumes approximately 8,552 MWh of electricity on an annual basis. The electricity used to power this consumption is produced through a combination of agreements with the local utility and a retail electricity supplier. Local renewable energy resources including wind, hydro, and solar account for less than one percent of all energy 
generation in the region. Further, due to the large dependence on coal-fired electricity generation, GHG emission rates in the region are well above the national average including carbon dioxide emissions, which are approximately $14 \%$ higher than the rest of the country (Mehalik et. al, 2008).

Cranberry Township can purchase RECs from local or national renewable energy resources to offset the electricity consumption from traditional fossil-fuels. By purchasing RECs, Cranberry Township can participate in the Green Power Partnership/Leadership Program of the U.S. Environmental Protection Agency (EPA). Based on EPA requirements, in order to participate to the Green Power Partnership Program, at least 6\% of Cranberry Township's power portfolio should come from renewable resources; and in order to participate to the Green Power Leadership Program, at least $60 \%$ of Cranberry Township's power portfolio should come from renewable resources. Tables 17 and 18 provide the costs of purchasing wind RECs (as of 2008) from local and national resources, respectively. Depending on available budget and preference, township management can perform the REC purchases either from local or national resources.

Table 17: Cost of purchasing PA wind RECs (Adapted from Mehalik et. al, 2008)

\begin{tabular}{|c|c|c|c|c|c|}
\hline & $\begin{array}{l}\text { Percentage of } \\
\text { purchased } \\
\text { REC }\end{array}$ & $\begin{array}{c}\text { Annual } \\
\text { electricity } \\
\text { usage } \\
\text { (MWh/year) }\end{array}$ & $\begin{array}{c}\text { Cost } \\
(\$ / M W h)\end{array}$ & $\begin{array}{l}\text { Total } \\
\text { cost } \\
\text { (\$/year) }\end{array}$ & $\begin{array}{c}\text { State of } \\
\text { origination }\end{array}$ \\
\hline $\begin{array}{c}\text { EPA Green Power } \\
\text { Leadership } \\
\text { Program }\end{array}$ & $\begin{array}{c}100 \% \text { PA } \\
\text { Wind }\end{array}$ & 8,552 & 8.5 & 72,692 & Pennsylvania \\
\hline $\begin{array}{c}\text { EPA Green Power } \\
\text { Leadership } \\
\text { Program }\end{array}$ & $60 \%$ PA Wind & 5,131 & 9.0 & 46,179 & Pennsylvania \\
\hline $\begin{array}{c}\text { EPA Green Power } \\
\text { Partnership } \\
\text { Program } \\
\end{array}$ & $6 \%$ PA Wind & 513 & 10.0 & 5,130 & Pennsylvania \\
\hline
\end{tabular}


Table 18: Cost of purchasing national wind RECs (Adapted from Mehalik et. al, 2008)

\begin{tabular}{|c|c|c|c|c|c|}
\hline & $\begin{array}{c}\text { Percentage of } \\
\text { purchased REC }\end{array}$ & $\begin{array}{c}\text { Annual } \\
\text { electricity } \\
\text { usage } \\
\text { (MWh/year) } \\
\end{array}$ & $\begin{array}{c}\text { Cost } \\
\text { (\$/MWh) }\end{array}$ & $\begin{array}{c}\text { Total } \\
\text { cost } \\
\text { (\$/year) }\end{array}$ & $\begin{array}{c}\text { State of } \\
\text { origination }\end{array}$ \\
\hline $\begin{array}{l}\text { EPA Green } \\
\text { Power } \\
\text { Leadership } \\
\text { Program }\end{array}$ & $\begin{array}{l}100 \% \text { national } \\
\text { Wind }\end{array}$ & 8,552 & 5.35 & 45,753 & Any \\
\hline $\begin{array}{l}\text { EPA Green } \\
\text { Power } \\
\text { Leadership } \\
\text { Program }\end{array}$ & $60 \%$ national Wind & 5,131 & 5.85 & 30,016 & Any \\
\hline $\begin{array}{l}\text { EPA Green } \\
\text { Power } \\
\text { Partnership } \\
\text { Program }\end{array}$ & $6 \%$ national Wind & 513 & 6.85 & 3,514 & Any \\
\hline
\end{tabular}

\section{Calculation of Internal Rate of Return (IRR)}

Since purchasing RECs does not generate revenue or provide direct savings, internal rate of return (IRR) calculations are not computed.

\subsubsection{Project 4 - Implementing Public Transportation System (Transit)}

Implementing a public transportation system around Cranberry Township requires a detailed, comprehensive financial analysis that involves demographic, geographic and infrastructural properties of the area. The township management conducted such a study - Cranberry Area Transit (CAT) Study prepared by Michael Baker Corporation (2005); and as a result this analysis will utilize the financial aspects recommended in the indicated study. 


\section{Scope}

The CAT Study includes municipalities in the Southwest corner of Butler County and in the Northwest portion of Allegheny County (Beaver County borders the study area to the West). Butler County municipalities included are the boroughs of Callery, Evans City, Harmony, Mars, Seven Fields, Valencia, and Zelienople, as well as the townships of Adams, Cranberry, Forward, Jackson, and Middlesex. Additionally, the study covers the townships of Marshall and Pine, located in Allegheny County.

Based on the current and future transit needs of the region, the CAT Study divides the transportation market into three segments:

- Local: Circular services that allow easier access to local jobs and retail centers

- Study Area: Connections to other activity centers and smaller municipalities such as Zelienople, Mars and current terminus of the Port Authority system in the US Route 19 corridor

- Regional: Commuting between the Cranberry area and the City of Pittsburgh

The study included several qualitative and quantitative criteria such as capital and operating cost, land use, community input, ridership estimation, quality of pedestrian environment, etc., for its analyses. After evaluating a set of alternative bus routes for each segment, the study recommends a bus service for the following routes:

- Local: L6 - Zelienople, L7 - East West and L8 - North South

- Study Area: S1 - Zelienople/Harmony and S3 - Mars/Evans City 
- Regional: R1 - Pittsburgh Express, R1A - Seven Fields Express, R3 - Zelienople Express, R4 - Butler Express, R5 - North Hills and R6 - Rochester

Detailed information for these routes can be obtained from the Cranberry Area Transit Study prepared by Michael Baker Corporation (2005).

\section{Capital Expenditures}

The CAT Study provides not only the appropriate routes for the bus service, but also recommends the capital assets required to run the system. These capital assets include a transit center (hub), a light-duty maintenance center, a park-and-ride/van pool lot and amenities (i.e., shelters, stations, bike paths, etc.). In addition, it is assumed that the system will operate using eight 30-foot mid-sized busses and 13 full-sized busses whose unit costs are $\$ 200,000$ and $\$ 350,000$, respectively. Costs related to these capital assets are shown in Table 19.

Table 19: Capital expenditures (Adapted from the CAT Study)

\begin{tabular}{|c|r|}
\hline Asset description & Cost $\mathbf{( \$ )}$ \\
\hline Transit center (Hub) & $4,000,000$ \\
\hline Light-duty maintenance center & $10,000,000$ \\
\hline Park-and-ride/Van pool lot & $6,000,000$ \\
\hline Amenities & 500,000 \\
\hline 8 30-foot mid-sized busses & $1,600,000$ \\
\hline 13 full-sized busses & $4,550,000$ \\
\hline Total & $\mathbf{2 6 , 6 5 0 , 0 0 0}$ \\
\hline
\end{tabular}




\section{Operating Costs and Revenues}

As in the estimation of capital expenditures, the Cranberry Area Transit Study provides valuable information for the operating costs. Table 20 summarizes the route operating costs provided in the CAT Study. To calculate the operating cost per service day, an average cost per service hour (\$65) is estimated based on other small transit properties in western Pennsylvania (CAT Study, 2005). This value is multiplied with the running time and number of trips per day. To obtain the annual operating cost, a default value of 300 days is used representing Monday through Saturday service with no service on Sundays or holidays.

Although the CAT Study does not provide any information, to estimate the revenues, it is assumed that for each trip on a random day, the average number of passengers in a mid-size bus is 20 whereas the average number of passengers in a full-size bus is 35 . The average passenger fares are assumed to be $\$ 2 /$ person/trip, \$2.5/person/trip, \$3/person/trip for local, study area and regional routes, respectively. Exact fares for adults, children, senior citizens, bus-pass users and transfer passengers can be determined by splitting the given average passenger fares based on the passenger demographics. Under these assumptions, route specific revenues are shown in Table 20. 
Table 20: Conceptual bus transportation system around Cranberry Township and related route specific capital cost, operating cost and revenue information

\begin{tabular}{|c|c|c|c|c|c|c|c|c|c|c|c|c|c|}
\hline \multirow[b]{3}{*}{ Route Name } & \multicolumn{3}{|c|}{ Local } & \multicolumn{2}{|c|}{ Study Area } & \multicolumn{8}{|c|}{ Regional } \\
\hline & L6 & L7 & L8 & S1 & S3 & \multicolumn{2}{|c|}{ R1 } & R1A & $\mathbf{R 3}$ & R4 & \multicolumn{2}{|c|}{ R5 } & R6 \\
\hline & $\begin{array}{c}\text { Zelienople } \\
\text { Loop }\end{array}$ & $\begin{array}{l}\text { East } \\
\text { West }\end{array}$ & $\begin{array}{l}\text { North } \\
\text { South }\end{array}$ & $\begin{array}{l}\text { Zelienople } \\
\text { /Harmony }\end{array}$ & \begin{tabular}{|c|} 
Mars/ \\
Evans City
\end{tabular} & \multicolumn{2}{|c|}{$\begin{array}{l}\text { Pittsburgh } \\
\text { Express }\end{array}$} & $\begin{array}{c}\text { Seven } \\
\text { Fields } \\
\text { Express } \\
\end{array}$ & \begin{tabular}{|c}
$\begin{array}{c}\text { Zelienopl } \\
\mathrm{e} \\
\text { Express }\end{array}$ \\
\end{tabular} & $\begin{array}{l}\text { Butler } \\
\text { Express }\end{array}$ & \multicolumn{2}{|c|}{$\begin{array}{l}\text { North } \\
\text { Hills }\end{array}$} & Rochester \\
\hline $\begin{array}{c}\text { Service } \\
\text { Characteristics }\end{array}$ & $\begin{array}{c}130 \text {-foot } \\
\text { mid-sized } \\
\text { bus }\end{array}$ & $\begin{array}{c}130 \text {-foot } \\
\text { mid-sized } \\
\text { bus }\end{array}$ & $\begin{array}{c}130 \text {-foot } \\
\text { mid-sized } \\
\text { bus }\end{array}$ & $\begin{array}{l}130 \text {-foot } \\
\text { mid-sized } \\
\text { bus }\end{array}$ & $\begin{array}{c}230-\text { foot } \\
\text { mid-sized } \\
\text { bus }\end{array}$ & \multicolumn{2}{|c|}{3 Full-sized busses } & $\begin{array}{l}3 \text { Full- } \\
\text { sized } \\
\text { busses }\end{array}$ & $\begin{array}{l}4 \text { Full- } \\
\text { sized } \\
\text { busses }\end{array}$ & $\begin{array}{l}3 \text { Full- } \\
\text { sized } \\
\text { busses }\end{array}$ & \multicolumn{2}{|c|}{$\begin{array}{l}130 \text {-foot } \\
\text { mid-sized } \\
\text { bus }\end{array}$} & $\begin{array}{c}130 \text {-foot } \\
\text { mid-sized } \\
\text { bus }\end{array}$ \\
\hline $\begin{array}{c}\text { Route Specific } \\
\text { Capital Cost (\$) }\end{array}$ & 200,000 & 200,000 & 200,000 & 200,000 & 400,000 & \multicolumn{2}{|c|}{$1,050,000$} & $1,050,000$ & $1,400,000$ & $1,050,000$ & \multicolumn{2}{|c|}{200,000} & 200,000 \\
\hline & & & & & & Peak & Off Peak & & & & Peak & Off Peak & \\
\hline $\begin{array}{l}\text { Round Trip Route } \\
\text { Length (Miles) }\end{array}$ & 8.2 & 14.4 & 13.6 & 19.9 & 27.6 & 42.8 & 42.8 & 44.0 & 60.2 & 85.5 & 19.0 & 19.0 & 24.6 \\
\hline $\begin{array}{l}\text { Average Speed } \\
\text { (Miles/Hour) }\end{array}$ & 20 & 20 & 20 & 20 & 20 & 35 & 35 & 35 & 35 & 35 & 25 & 25 & 25 \\
\hline $\begin{array}{c}\text { Round Trip Running } \\
\text { Time (Hours) }\end{array}$ & 0.41 & 0.72 & 0.68 & 1.00 & 1.38 & 1.22 & 1.22 & 1.26 & 1.72 & 2.44 & 0.76 & 0.76 & 0.98 \\
\hline Trips per Hour & 1 & 1 & 1 & 1 & 1 & 2 & 2 & 2 & 2 & 1 & 2 & 1 & 1 \\
\hline $\begin{array}{c}\text { Service Hours per } \\
\text { Day }\end{array}$ & 10 & 10 & 12 & 12 & 12 & 6 & 10 & 6 & 6 & 4 & 4 & 6 & 10 \\
\hline $\begin{array}{c}\text { Number of Round } \\
\text { Trips } \\
\text { per Day }\end{array}$ & 10 & 10 & 12 & 12 & 12 & 12 & 20 & 12 & 12 & 4 & 8 & 6 & 10 \\
\hline $\begin{array}{l}\text { Average Operating } \\
\text { Cost per Hour }\end{array}$ & $\$ 65$ & $\$ 65$ & $\$ 65$ & $\$ 65$ & $\$ 65$ & $\$ 65$ & $\$ 65$ & $\$ 65$ & $\$ 65$ & $\$ 65$ & $\$ 65$ & $\$ 65$ & $\$ 65$ \\
\hline $\begin{array}{c}\text { Average Operating } \\
\text { Cost per Day }\end{array}$ & $\$ 267$ & $\$ 468$ & $\$ 530$ & $\$ 776$ & $\$ 1,076$ & $\$ 954$ & $\$ 1,590$ & $\$ 981$ & $\$ 1,342$ & $\$ 635$ & $\$ 395$ & $\$ 296$ & $\$ 640$ \\
\hline $\begin{array}{c}\text { Operating } \\
\text { Cost (\$/year) }\end{array}$ & 79,950 & 140,400 & 159,120 & 232,830 & 322,920 & 286,149 & 476,914 & 294,171 & 402,480 & 190,543 & 118,560 & 88,920 & 191,880 \\
\hline $\begin{array}{l}\text { Revenue } \\
\text { (\$/year) }\end{array}$ & 240000 & 240000 & 288000 & 360000 & 360000 & 756000 & 1260000 & 756000 & 756000 & 252000 & 288000 & 216000 & 360000 \\
\hline
\end{tabular}




\section{Calculation of Internal Rate of Return (IRR)}

In calculating the internal rate of return (IRR), the following assumptions are made.

- It is assumed that the implemented bus transportation system will last nine years considering that a bus purchased has a useful life of approximately nine years.

- Cranberry Township's population grew 34\%, to 14,816, between 1980 and 1990 . The 2000 census placed its population at 23,625 , up almost $60 \%$ from 1990. By considering these values, for the following nine years, it is assumed that Cranberry Township's population will increase by $47 \%$ (average of $34 \%$ and $60 \%$ ) and for each trip on a random day, the average number of passengers in a mid-size bus will increase to 30 from 20 whereas average number of passengers in a full-size bus will increase to 52 from 35 by considering a direct relationship between the population increase and bus ridership. Additionally, it is assumed that the increase in the number of passengers will be approximately linear over nine years.

Table 21 shows three IRR values calculated for the bus transportation system. The IRR value for the most probable scenario is based on the estimated capital expenditures, operating costs and revenues provided in previous sections. The IRR values for the worst case and best case scenarios are obtained by making small changes to some of the assumed parameters such as the number of passengers or the passenger rates. More specifically, for the worst case scenario, capital expenditures are increased by $5 \%$ and passenger fares are decreased to $\$ 1.75 /$ person/trip, \$2.25/person/trip, \$2.75/person/trip from \$2/person/trip, \$2.5/person/trip, \$3/person/trip for local, study area and regional routes, respectively. In a similar way, for the best case scenario, capital expenditures are decreased by $5 \%$ and passenger fares are increased to $\$ 2.25 /$ person/trip, 
\$2.75/person/trip, \$3.25/person/trip from \$2/person/trip, \$2.5/person/trip, \$3/person/trip for local, study area and regional routes, respectively.

Annual average rate of return of implementing a bus transportation system in Cranberry Township is expected to be $0.55 \%, 5.43 \%$ and $10.21 \%$ for the worst case, most probable and best case, respectively.

Table 21: Internal rate of return (IRR) of implementing a bus transportation system around Cranberry Township (Project 4) for worst case, most probable and best case scenarios

\begin{tabular}{|c|c|c|c|}
\cline { 2 - 4 } \multicolumn{1}{c|}{} & $\begin{array}{c}\text { Worst case } \\
\text { scenario }\end{array}$ & $\begin{array}{c}\text { Most probable } \\
\text { scenario }\end{array}$ & $\begin{array}{c}\text { Best case } \\
\text { scenario }\end{array}$ \\
\hline Total capital expenditure (\$) & $\mathbf{- 2 7 , 9 8 2 , 5 0 0}$ & $\mathbf{- 2 6 , 6 5 0 , 0 0 0}$ & $\mathbf{- 2 5 , 3 1 7 , 5 0 0}$ \\
\hline Net cash flow in year 1 (\$) & $2,592,163$ & $3,147,163$ & $3,702,163$ \\
\hline Net cash flow in year 2 (\$) & $2,744,452$ & $3,332,058$ & $3,919,665$ \\
\hline Net cash flow in year 3 (\$) & $2,896,741$ & $3,516,953$ & $4,137,167$ \\
\hline Net cash flow in year 4 (\$) & $3,049,030$ & $3,701,848$ & $4,354,669$ \\
\hline Net cash flow in year 5 (\$) & $3,201,319$ & $3,886,743$ & $4,572,171$ \\
\hline Net cash flow in year 6 (\$) & $3,353,608$ & $4,071,638$ & $4,789,673$ \\
\hline Net cash flow in year 7 (\$) & $3,505,897$ & $4,256,533$ & $5,007,175$ \\
\hline Net cash flow in year 8 (\$) & $3,658,186$ & $4,441,428$ & $5,224,677$ \\
\hline Net cash flow in year 9 (\$) & $3,810,475$ & $4,626,323$ & $5,442,179$ \\
\hline Internal rate of return (IRR) & $\mathbf{0 . 5 5 \%}$ & $\mathbf{5 . 4 3 \%}$ & $\mathbf{1 0 . 2 1 \%}$ \\
\hline
\end{tabular}

\subsubsection{Project 5 - Achieving Gold status of LEED Certification for Municipal Center}

\section{(LEED)}

The context of this project includes subprojects whose implementation will provide credits for the Municipal Center to be certified by the USGBC. Some of these subprojects are implementing a modular green roof for the Municipal Center, upgrading lighting sources and improving waste management in the Municipal Center, and upgrading the Municipal Center HVAC system. Due 
to constraints of time and data availability, a separate financial analysis for each of these subprojects was not feasible. As a result, the overall investment is divided by two parts. The first part involves the analysis of implementing a modular green roof for the Municipal Center. The second part provides an approximate financial analysis for the remaining smaller scale subprojects considering the conceptual costs of implementation and LEED certification process for existing buildings.

\section{Financial Analysis of Implementing a Modular Green Roof for the Municipal Center}

The financial analysis for implementing a green roof on the Cranberry Township Municipal Center is based on several assumptions and estimations made to identify the required capital expenditures and subsequent savings. To make these assumptions and estimations, the analysis makes use of information specific to the Municipal Center, as well as other types of information provided from the literature, green roof companies and non-for-profit organizations. It should be noted that it is infeasible to perform an exact financial analysis since the resulting savings from a green roof are very sensitive to factors specific to green roofing and building.

\section{Scope and Basic Assumptions}

The roof of Municipal Center has many roof windows, HVAC units, drains, walking pads, hoods, exhaust fans, etc. which makes it too cluttered to consider installing a large-scale green roof project. However, it is possible to implement a modular green roof system. Modular systems are not built into the roof but rather placed on an existing roof. Typically, after plants are grown in boxes off site, they are placed adjacent to each other on the existing roof (Dinsdale et al., 2006). Figure 17 shows a diagram of a modular green roof system. 


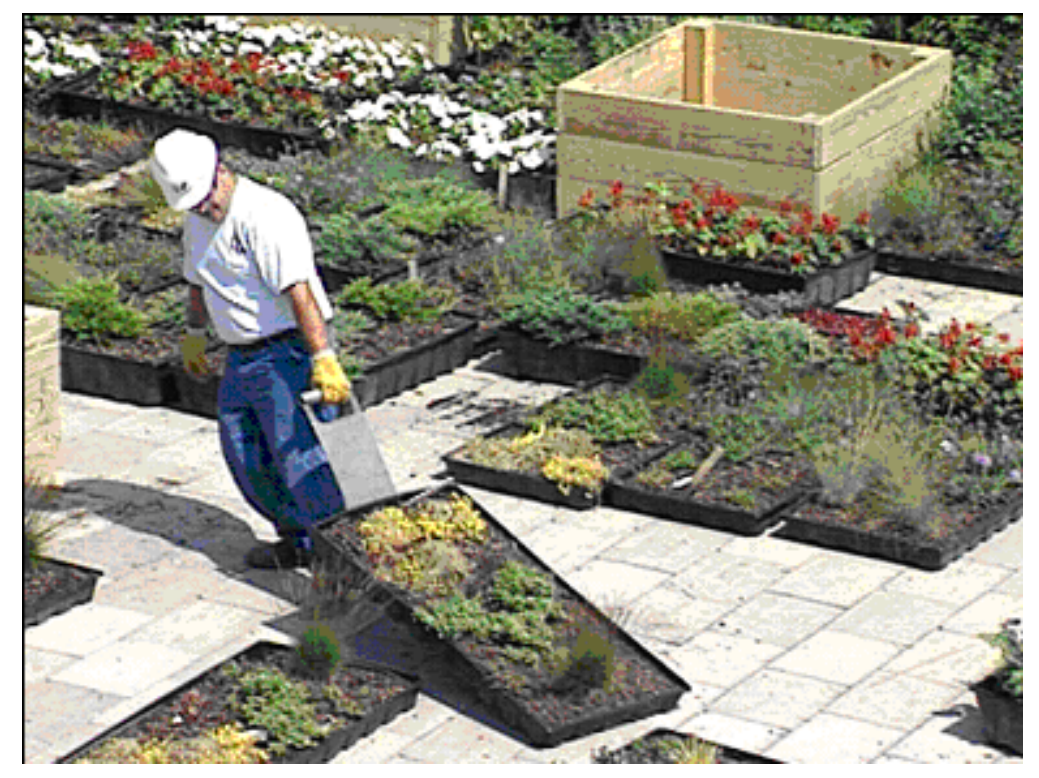

Figure 17: Modular green roof systems (Weston Solutions, Inc., 2009)

There are two types of green roofs: Intensive green roofs and extensive green roofs. Intensive green roofs are deeper than the extensive green roofs. This allows for the growth of larger plants such as trees and shrubs in intensive roofs. However, they have a higher installation cost and require more maintenance, irrigation and feeding. On the other hand, extensive green roofs contain smaller plants and are typically self sustaining except for bi-yearly maintenance. Compared to intensive green roofs, extensive green roofs have lower construction and maintenance costs (Dinsdale et al., 2006). Table 22 provides a comparison of the two green roof types by considering their advantages and disadvantages. 
Table 22: Advantages and disadvantages of intensive and extensive green roofs (Adapted from

Dinsdale et al., 2006)

\begin{tabular}{|c|c|c|c|}
\hline \multicolumn{2}{|c|}{ Advantages } & \multicolumn{2}{|c|}{ Disadvantages } \\
\hline Intensive & Extensive & Intensive & Extensive \\
\hline $\begin{array}{l}\text { Greater plant } \\
\text { diversity and } \\
\text { options } \\
\end{array}$ & Lightweight & $\begin{array}{l}\text { High weight } \\
\text { loading }\end{array}$ & Little plant choice \\
\hline Visually appealing & Low maintenance & $\begin{array}{c}\text { Need } \\
\text { irrigation/drainage } \\
\text { systems }\end{array}$ & $\begin{array}{l}\text { No recreational } \\
\text { access }\end{array}$ \\
\hline Good insulation & Low cost & High costs & Unattractive \\
\hline Used as open space & $\begin{array}{c}\text { Works on older } \\
\text { roofs }\end{array}$ & High maintenance & $\begin{array}{l}\text { Less storm water } \\
\text { retention }\end{array}$ \\
\hline $\begin{array}{l}\text { Potential for higher } \\
\text { energy savings }\end{array}$ & Easier to replace & $\begin{array}{l}\text { High replacement } \\
\text { cost }\end{array}$ & - \\
\hline $\begin{array}{l}\text { More storm water } \\
\text { retention }\end{array}$ & $\begin{array}{l}\text { Often no irrigation } \\
\text { or drainage } \\
\text { system }\end{array}$ & $\begin{array}{l}\text { More expertise } \\
\text { required }\end{array}$ & - \\
\hline
\end{tabular}

In this analysis, in order to keep the installation and maintenance costs at a minimum level, an extensive, inaccessible green roof is considered for the Municipal Center. And, it is assumed that $50 \%$ of the total roof area of the Municipal Center will be covered with the green roof since by covering at least $50 \%$ of the total roof area with a green/vegetated roof, the Municipal Center can directly obtain one LEED credit under the heat island effect category (USGBC, 2009). There is also potential for a green roof to earn credits in other categories with extra investment. For instance, Kula (2005) claims that green roofs can earn additional credits under the following categories:

- Reduced site disturbance,

- Protect or restore open space, 
- Storm water management,

- Water efficient landscaping,

- Innovative wastewater technologies, and

- Innovation in design.

Except for the innovation in design category, Sustainable Pittsburgh (2008) asserts that the Municipal Center can possibly achieve credits in the above categories through modest investments. These extra investments are considered under the analysis of smaller scale subprojects.

\section{Capital Expenditures}

Compared to conventional roofs, green roofs typically require greater initial investment. However, they do provide savings by extending the life of the roof membrane and reducing the heating and cooling costs of the building. Boston Metropolitan Area Planning Council (MAPC) cites that the cost of green roofs starts at $\$ 5$ per square foot. Paladino \& Company, Inc. (2004), a sustainability and green building consulting firm, states that green roofs have a higher initial construction cost almost twice that of a conventional roof installation or about $\$ 10$ to $\$ 15$ per square foot. Green Roofs for Healthy Cities, a non-for-profit industry association, (2009) reports that an installed extensive green roof with root repellant/waterproof membranes may be installed for $\$ 10-\$ 24$ per square foot. Since an extensive, inaccessible roof is under consideration for the Municipal Center, a relatively low value, $\$ 7$ per square foot is assumed for the installation cost in this analysis. And, by covering the 50\% of the total roof area of the Municipal Center $(75,511$ square feet), the capital expenditure is estimated to be $\$ 264,290$. 


\section{Maintenance Costs}

By choosing the plants that are common to the area and those that can withstand the harsh conditions, extensive roofs are built self-sustaining except for bi-yearly maintenance costs. Moreover, some reputable green roof companies offer lifetime warranties to repair any damage that occurs in the green roof. For instance, in the feasibility study for a green roof application on Queen's University Campus, Dinsdale et al. (2006) assert that the cost of maintaining an extensive green roof is negligible compared to its capital investment. In a similar study, Boodram et al. (2004) allocates a watering and fertilization cost of $\$ 0.25-\$ 4.10$ per square foot only for the first 2 years of the green roof to ensure its health. Hence, this analysis does not assume that a significant amount of maintenance cost will occur beyond the regular maintenance cost of a conventional roof.

\section{Energy Savings}

One of the major benefits of green roofs is increasing the energy efficiency of the buildings that they cover. Typically, they reduce the energy consumption of the buildings by adding insulation, providing shade and/or protecting roofs from wind-chill. Berkshire (2009) notes that a green roof can reduce heating and cooling requirements by as much as $20 \%$ to $30 \%$ percent for a one story structure. However, most of the green roof related research indicates that the savings in energy resulting from a green roof comes from cooling costs. For example, Liu and Baskaran (2003) assert that green roofs are more effective at preventing heat gain in the summer than heat loss in the winter. In their feasibility study for the green roof application on Queen's University Campus, Dinsdale et al. (2006) negated the heating energy savings and assumes a $15 \%$ reduction in cooling costs. 
In the Sustainability Assessment Report prepared for Cranberry Township, Sustainable Pittsburgh specifies that heating, cooling and ventilation costs for the Municipal Center are $\$ 32,439 /$ year, $\$ 18,320 /$ year and $\$ 10,486 /$ year, respectively. Using these costs and assuming a $20 \%$ reduction on them, the total energy savings for the Municipal Center resulting from a green roof is estimated as $\$ 12,249 /$ year.

\section{Financial Analysis of Smaller Scale Subprojects and LEED Certification Process}

The economics of the implementation of LEED for existing building standards and certification process varies significantly from building to building. For this analysis, statistical data for the costs and savings related to the smaller scale subprojects to make improvements in the building and LEED certification process has been used.

\section{Scope and Assumptions}

Although minor updates in the structure and requirements of LEED certification are expected for the 2009 version (version 3.0) of the manual for existing buildings, this analysis utilizes version 2.0 as most of the literature is based on this version.

In version 2.0 , credit requirements for certification are given as the following:

- Certified: 32-39 credits,

- Silver: $40-47$ credits,

- Gold: 48-63 credits, and

- Platinum: 64-85 credits. 
The Sustainability Assessment Report prepared by Sustainable Pittsburgh (2008) provides a preliminary study related to the LEED certification of the Municipal Center. Specifically, they assess the current status of the Municipal Center to explore the possibility of getting LEED certification (version 2.0). A checklist is provided that shows the actions the township management should take. And, Sustainable Pittsburgh classifies these action items by considering the degree of investment required. Results of this study can be summarized as the following.

- The Municipal Center in place practices what would qualify for 3 LEED credits without additional investment. However, before additional LEED credits can be granted towards certification, five prerequisite conditions (i.e., erosion and sedimentation control, minimum water efficiency, waste stream audit, storage and collection, and outside air introduction and exhaust systems) should be addressed.

- With modest investment, the Municipal Center has the potential to obtain credits in the areas of energy efficiency, waste management, green purchasing, operational procedures, and storm water management.

- Depending on the amount and degree of investment, the Municipal Center has the possibility of achieving Gold certification status. It is highly unlikely that the Municipal Center will be able to achieve platinum certification as it requires a higher amount of investment.

In summary, it is expected that at the best case the capital expenditures provided in this analysis will result in a Gold certification status. 


\section{Capital Expenditures}

By performing an empirical study based on 14 LEED certified existing buildings, Leonardo Academy, Inc., a nonprofit organization focusing on sustainability, (2008) provides an analysis of total costs, costs on square foot basis and costs for the level of LEED-EB (existing buildings) certification achieved (i.e., Certified, Gold, Silver, Platinum). They divide the capital expenditures needed for LEED implementation for existing building standards and certification process into two cost categories: soft and hard. Table 23 summarizes their findings as average values for soft and hard costs. Soft costs include labor costs, consulting costs, registration fees, and application fees while hard costs include the cost of actual building improvement projects. Hence, with a similar approach, in this analysis, the costs of the smaller scale subprojects to make improvements in the Municipal Center are categorized as hard costs and the others are considered under the soft costs category.

Table 23: Cost statistics of the implementation and certification processes for 14 LEED certified existing buildings (Adapted from Leonardo Academy, Inc., 2008)

\begin{tabular}{|c|c|c|c|c|c|}
\cline { 2 - 6 } \multicolumn{1}{c|}{} & \multicolumn{5}{c|}{ Mean cost (\$/square foot) } \\
\cline { 2 - 6 } & $\begin{array}{c}\text { Certified } \\
(\mathbf{n = 2})\end{array}$ & $\begin{array}{c}\text { Silver } \\
(\mathbf{n}=\mathbf{4})\end{array}$ & $\begin{array}{c}\text { Gold } \\
(\mathbf{n}=\mathbf{4})\end{array}$ & $\begin{array}{c}\text { Platinum } \\
(\mathbf{n = 4})\end{array}$ & $\begin{array}{c}\text { All } \\
\text { buildings } \\
(\mathbf{n = 1 4 )}\end{array}$ \\
\hline Labor costs & 0.82 & 0.66 & 0.51 & 0.73 & 0.66 \\
\hline $\begin{array}{c}\text { Consulting } \\
\text { costs }\end{array}$ & 0.12 & 0.60 & 0.22 & 0.79 & 0.39 \\
\hline $\begin{array}{c}\text { Registration } \\
\text { fee }\end{array}$ & 0.04 & 0.03 & 0.01 & 0.01 & 0.02 \\
\hline Application fee & 0.00 & 0.00 & 0.03 & 0.02 & 0.01 \\
\hline Total soft costs & 0.98 & 1.29 & 0.77 & 1.55 & 1.08 \\
\hline $\begin{array}{c}\text { Total hard } \\
\text { costs }\end{array}$ & 0.57 & 0.11 & 2.20 & 1.16 & 1.35 \\
\hline Total: All costs & $\mathbf{1 . 5 5}$ & $\mathbf{1 . 4 0}$ & $\mathbf{2 . 9 7}$ & $\mathbf{2 . 7 1}$ & $\mathbf{2 . 4 3}$ \\
\hline
\end{tabular}

112 
Although it is a rough estimation, for the purposes of this analysis, total capital expenditures needed to make improvements in the Municipal Center and certification process are estimated as $\$ 141,000$. This value is obtained by multiplying the total area of the Municipal Center (94,000 square foot) with $\$ 1.50 /$ square foot, assumed total cost per square foot. As seen from Table 23, the assumed total cost per square foot (i.e., $\$ 1.50 /$ square foot) places between the mean values of total costs of Silver and Gold certification for existing buildings (i.e., $\$ 1.40 /$ square foot and $\$ 2.97 /$ square foot) by considering that the township management targets the Gold certification for the Municipal Center. However, for a better estimation for this cost, further, building specific analysis is required.

\section{Savings on Operating Costs}

In addition to certification, implementation and process costs, Leonardo Academy, Inc. (2008) provides an analysis that compares the operating costs of 11 LEED certified existing buildings with the operating costs in the Building Owners and Managers Association (BOMA) International's 2007 Experience Exchange Report. In their analysis, they compare both the total operating costs of the buildings as well as the components of the building operating costs, including cleaning expenses, repair and maintenance expenses, roads/grounds expenses, security expenses, administrative and utility expenses. They find that the average operating cost of 11 LEED certified buildings is $\$ 0.17 /$ square foot/year less than the BOMA average. Given this, the savings on the operating costs for the Municipal Center after certification is estimated to be $\$ 15,980 /$ year. 


\section{Calculation of Internal Rate of Return (IRR)}

In the calculation of internal rate of return (IRR), the following assumptions are made:

- For most extensive green roofs, the expected life span of the roof system is expected to be 25 years, approximately double that for a conventional roof (Kosareo and Ries, 2007). For this reason, it is assumed that implemented green roof and renovations in the Municipal Center will last 25 years.

- Although there will be fluctuations in utility, repair, maintenance, security, administrative expenses, etc. during the 25 -year planning horizon, it is assumed that there won't be any dramatic change for the amounts of savings on energy and operating costs.

Table 24 provides three IRR values calculated for achieving Gold status of LEED certification for the Municipal Center. The IRR value for the most probable scenario is based on the estimated capital expenditures and savings on costs provided in previous sections. The IRR values for the worst case and best case scenarios are obtained by making small changes to some of the assumed parameters such as unit cost of green roofs or amount of savings on energy costs. More specifically, for the worst case scenario, unit cost of green roof is increased to $\$ 10 /$ square foot from $\$ 7 /$ square foot, unit cost of implementation and certification processes is increased to $\$ 1.7 /$ square foot from $1.5 /$ square foot, expected energy savings are decreased to $16 \%$ from $20 \%$ and expected savings on operating costs are decreased to 0.16 square foot/year from 0.17 /square foot/year. In a similar way, for the best case scenario, unit cost of green roof is decreased to $\$ 6 /$ square foot from $\$ 7 /$ square foot, unit cost of implementation and certification processes is decreased to $\$ 1.45 /$ square foot from $1.5 /$ square foot, expected energy savings are increased to 
$22 \%$ from $20 \%$ and expected savings on operating costs are increased to $0.18 /$ square foot/year from $0.17 /$ square foot/year.

Annual average rate of return of achieving Gold status of LEED certification for the Municipal Center is expected to be $1.54 \%, 4.82 \%$ and $6.73 \%$ at the worst case, most probable case and at the best case, respectively.

Table 24: Internal rate of return (IRR) of achieving Gold status of LEED certification for the Municipal Center (Project 5) for worst case, most probable and best case scenarios

\begin{tabular}{|c|c|c|c|}
\cline { 2 - 4 } \multicolumn{1}{c|}{} & $\begin{array}{c}\text { Worst case } \\
\text { scenario }\end{array}$ & $\begin{array}{c}\text { Most probable } \\
\text { scenario }\end{array}$ & $\begin{array}{c}\text { Best case } \\
\text { scenario }\end{array}$ \\
\hline Total capital expenditure (\$) & $\mathbf{- 5 3 7 , 3 5 7}$ & $\mathbf{- 4 0 5 , 2 9 0}$ & $\mathbf{- 3 6 2 , 8 3 4}$ \\
\hline Net cash flow in year 1 (\$) & 26,064 & 28,229 & 30,393 \\
\hline Net cash flow in year 2 (\$) & 26,064 & 28,229 & 30,393 \\
\hline Net cash flow in year 3 (\$) & 26,064 & 28,229 & 30,393 \\
\hline Net cash flow in year 4 (\$) & 26,064 & 28,229 & 30,393 \\
\hline Net cash flow in year 5 (\$) & 26,064 & 28,229 & 30,393 \\
\hline$:$ & $:$ & $:$ & $:$ \\
\hline$:$ & $:$ & $:$ & $:$ \\
\hline$:$ & $:$ & $:$ & $:$ \\
\hline Net cash flow in year 25 (\$) & 26,064 & 28,229 & 30,393 \\
\hline Internal rate of return (IRR) & $\mathbf{1 . 5 4 \%}$ & $\mathbf{4 . 8 2 \%}$ & $\mathbf{6 . 7 3 \%}$ \\
\hline
\end{tabular}

\subsection{CREATING AN OPTIMAL BALANCED INVESTMENT PORTFOLIO}

Table 25 summarizes the internal rate of returns of the five project alternatives at the worst case, most probable case and at the best case. Since purchasing RECs does not generate revenue or provide direct savings, internal rate of return (IRR) calculations are not computed. It can be seen 
that purchasing alternative fuel vehicles has the largest difference between its internal rate or return (IRR) values for the worst case and best case scenarios.

Table 25: Annual internal rate of returns (IRRs) of five project alternatives

\begin{tabular}{|c|c|c|c|}
\cline { 2 - 4 } \multicolumn{1}{c|}{} & \multicolumn{3}{c|}{ Annual internal rate of returns (IRRs) } \\
\cline { 2 - 4 } \multicolumn{1}{c|}{} & $\begin{array}{c}\text { Worst case } \\
\text { scenario }\end{array}$ & $\begin{array}{c}\text { Most probable } \\
\text { scenario }\end{array}$ & $\begin{array}{c}\text { Best case } \\
\text { scenario }\end{array}$ \\
\hline Project 1 (Compost) & $1.38 \%$ & $6.64 \%$ & $11.78 \%$ \\
\hline Project 2 (Alternative Fuel) & $1.04 \%$ & $28.69 \%$ & $49.04 \%$ \\
\hline Project 3 (RECs) & NA & NA & NA \\
\hline Project 4 (Transit) & $0.55 \%$ & $5.43 \%$ & $10.21 \%$ \\
\hline Project 5 (LEED) & $1.54 \%$ & $4.82 \%$ & $6.73 \%$ \\
\hline
\end{tabular}

By considering the rapid changes in technology, expected life times of the equipment purchased for the projects, and the computational burden of Stochastic Programming, nine years of planning horizon is assumed for the financial planning. And, it is divided into three periods assuming each of them is composed of three years. With this assumption, although project 5 (LEED) has a life time of 25 years, it is treated as if a project which has constant internal rate of returns throughout the nine years planning horizon. Under these assumptions, a three-stage stochastic linear program is developed which makes use of the three-year compounded internal rate of returns of the project alternatives as shown in Table 26. For instance, in a three-year period, Project 1 (Compost) will return $4 \%$ (i.e., $(101.38)^{3}-1=4 \%$ ) at the worst case, $40 \%$ (i.e., $(111.79)^{3}-1=40 \%$ ) at the best case, and $21 \%$ (i.e., $(106.64)^{3}-1=21 \%$ ) most probably. 
Table 26: Three-years compounded internal rate of returns (IRRs) of five project alternatives

\begin{tabular}{|c|c|c|c|}
\cline { 2 - 4 } \multicolumn{1}{c|}{} & \multicolumn{3}{c|}{ Three-year compounded internal rate of returns (IRRs) } \\
\cline { 2 - 4 } & $\begin{array}{c}\text { Worst case } \\
\text { scenario }\end{array}$ & $\begin{array}{c}\text { Most probable } \\
\text { scenario }\end{array}$ & $\begin{array}{c}\text { Best case } \\
\text { scenario }\end{array}$ \\
\hline Project 1 (Compost) & $4 \%$ & $21 \%$ & $40 \%$ \\
\hline Project 2 (Alternative Fuel) & $3 \%$ & $113 \%$ & $231 \%$ \\
\hline Project 3 (RECs) & NA & NA & NA \\
\hline Project 4 (Transit) & $2 \%$ & $17 \%$ & $22 \%$ \\
\hline Project 5 (LEED) & $5 \%$ & $15 \%$ & \\
\hline
\end{tabular}

To calculate the sustainability rate of returns of the project alternatives, first, the results of ANP study are normalized. Then, these values are scaled with respect to the internal rate of return values of the project alternatives shown in Table 26. The results of normalization and scaling steps are shown in Tables 27 and 28, respectively. For instance, the overall weight of Project 1 (Compost) for Stakeholder 1 is obtained by dividing the priority of Project 1 (Compost) determined by Stakeholder 1 (i.e., 0.177928 from Figure 12) with the priority of Project 4 (Transit), the highest ranked project by Stakeholder 1 (i.e., 0.477274 from Figure 12). And, the calculation of the sustainability rate of return (SRR) of Project 1 (Compost) determined by Stakeholder 1 is shown below. This calculation is based on Equation 7.2.

$$
0.87=\left[37.28 \times \frac{(231-2)}{(100-7.43)}\right] \times(2-7.43)
$$

As an example, the values shown in Table 28 can be interpreted in the following way. The compost facility improves Cranberry Township in the three dimensions of sustainability (i.e., economic, environmental and social) by $87 \%, 177 \%, 123 \%, 72 \%$ and $13 \%$ based on the perspectives of stakeholders 1, 2, 3, 4 and 5, respectively. Specific improvement on a specific 
criterion depends on the weight that the stakeholder gives to that criterion with respect to other criteria in the ANP study that he/she took.

Table 27: Normalized overall weights (OWs) of the five project alternatives

\begin{tabular}{|c|c|c|c|c|c|}
\cline { 2 - 6 } \multicolumn{1}{c|}{} & \multicolumn{5}{c|}{ Normalized OW } \\
\cline { 2 - 6 } & $\begin{array}{c}\text { Project 1 } \\
\text { (Compost) }\end{array}$ & $\begin{array}{c}\text { Project 2 } \\
\text { (Alternative } \\
\text { Fuel) }\end{array}$ & $\begin{array}{c}\text { Project 3 } \\
\text { (RECs) }\end{array}$ & $\begin{array}{c}\text { Project 4 } \\
\text { (Transit) }\end{array}$ & $\begin{array}{c}\text { Project 5 } \\
\text { (LEED) }\end{array}$ \\
\hline Stakeholder 1 & $37.28 \%$ & $27.97 \%$ & $24.71 \%$ & $100.00 \%$ & $19.57 \%$ \\
\hline Stakeholder 2 & $73.92 \%$ & $60.94 \%$ & $57.09 \%$ & $100.00 \%$ & $58.22 \%$ \\
\hline Stakeholder 3 & $51.86 \%$ & $69.54 \%$ & $38.86 \%$ & $100.00 \%$ & $33.56 \%$ \\
\hline Stakeholder 4 & $31.22 \%$ & $100.00 \%$ & $21.11 \%$ & $36.96 \%$ & $33.70 \%$ \\
\hline Stakeholder 5 & $7.43 \%$ & $20.88 \%$ & $13.10 \%$ & $100.00 \%$ & $25.45 \%$ \\
\hline
\end{tabular}

Table 28: Sustainability rate of returns (SRRs) of the five project alternatives

\begin{tabular}{|c|c|c|c|c|c|}
\cline { 2 - 6 } \multicolumn{1}{c|}{} & \multicolumn{5}{c|}{ Sustainability rate of returns (SRRs) } \\
\cline { 2 - 6 } & $\begin{array}{c}\text { Project 1 } \\
\text { (Compost) }\end{array}$ & $\begin{array}{c}\text { Project 2 } \\
\text { (Alternative } \\
\text { Fuel) }\end{array}$ & $\begin{array}{c}\text { Project 3 } \\
\text { (RECs) }\end{array}$ & $\begin{array}{c}\text { Project 4 } \\
\text { (Transit) }\end{array}$ & $\begin{array}{c}\text { Project 5 } \\
\text { (LEED) }\end{array}$ \\
\hline Stakeholder 1 & $87 \%$ & $64 \%$ & $55 \%$ & $242 \%$ & $43 \%$ \\
\hline Stakeholder 2 & $177 \%$ & $145 \%$ & $136 \%$ & $242 \%$ & $139 \%$ \\
\hline Stakeholder 3 & $123 \%$ & $167 \%$ & $91 \%$ & $242 \%$ & $77 \%$ \\
\hline Stakeholder 4 & $72 \%$ & $242 \%$ & $47 \%$ & $86 \%$ & $78 \%$ \\
\hline Stakeholder 5 & $13 \%$ & $46 \%$ & $27 \%$ & $242 \%$ & $57 \%$ \\
\hline
\end{tabular}

Since there are three periods, and there are three possibilities at each period (i.e., best case, most probable, and worst case scenarios), there are a total of 27 scenarios for the nine years planning horizon. While calculating probabilities of these 27 scenarios, it is assumed that at each period the probability of most probable scenario is 0.5 whereas the probabilities of best case and 
worst case scenarios are the same and 0.25 , since most of the time the economy is stable. Based on these assumptions, the scenario events and probabilities are shown in Figure 18 and Table 29. 


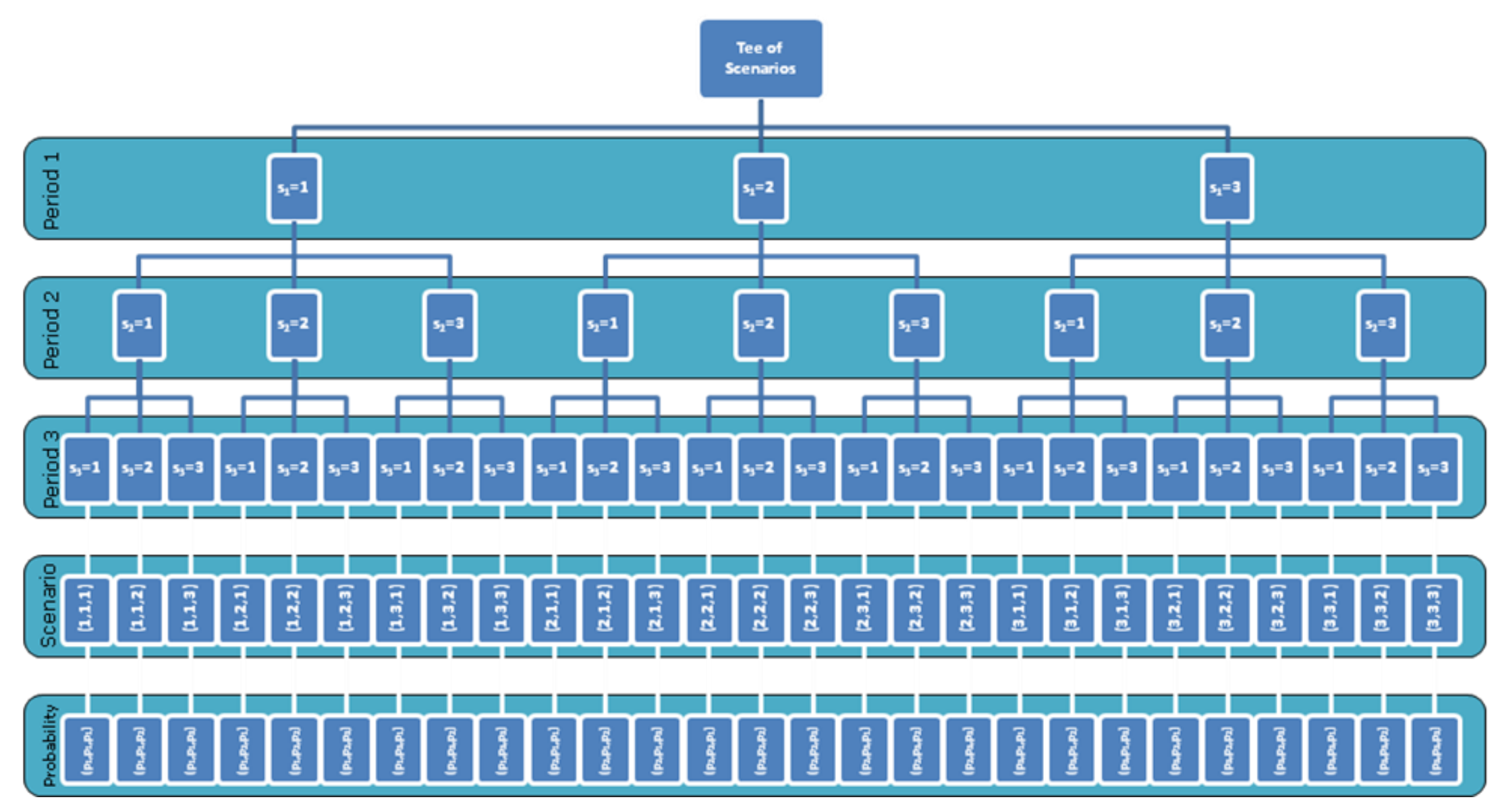

Figure 18: Tree of scenarios for the three periods

(1: Best case scenario, 2: Most probable scenario, 3: Worst case scenario) 
Table 29: Scenario probabilities

\begin{tabular}{|c|c|c|}
\hline $\begin{array}{c}\text { Scenario } \\
\text { number }\end{array}$ & $\begin{array}{c}\text { Scenario } \\
\text { events* }\end{array}$ & $\begin{array}{c}\text { Scenario } \\
\text { probability }\end{array}$ \\
\hline 1 & WWW & 0.015625 \\
\hline 2 & WWM & 0.031250 \\
\hline 3 & WWB & 0.015625 \\
\hline 4 & WMW & 0.031250 \\
\hline 5 & WMM & 0.062500 \\
\hline 6 & WMB & 0.031250 \\
\hline 7 & WBW & 0.015625 \\
\hline 8 & WBM & 0.031250 \\
\hline 9 & WBB & 0.015625 \\
\hline 10 & MWW & 0.031250 \\
\hline 11 & MWM & 0.062500 \\
\hline 12 & MWB & 0.031250 \\
\hline 13 & MMW & 0.062500 \\
\hline 14 & MMM & 0.125000 \\
\hline 15 & MMB & 0.062500 \\
\hline 16 & MBW & 0.031250 \\
\hline 17 & MBM & 0.062500 \\
\hline 18 & MBB & 0.031250 \\
\hline 19 & BWW & 0.015625 \\
\hline 20 & BWM & 0.031250 \\
\hline 21 & BWB & 0.015625 \\
\hline 22 & BMW & 0.031250 \\
\hline 23 & BMM & 0.062500 \\
\hline 24 & BMB & 0.031250 \\
\hline 25 & BBW & 0.015625 \\
\hline 26 & BBM & 0.031250 \\
\hline 27 & BBB & 0.015625 \\
\hline & & 1.000000 \\
\hline
\end{tabular}

*B: Best case scenario, M: Most probable scenario, W: Worst case scenario

Additionally, by interviewing the Cranberry Township management, probabilities of experiencing the SRR sets predicted by the stakeholders (i.e., $P_{j}$ values) are determined. This process can be thought of as assigning a weight to the perspective of each stakeholder for the 
contribution of project alternatives to the sustainability of the township. Table 30 shows the values obtained with this process. These values are totally based on the township management's preference and initiative. This enables the township management, as being the actual decision maker, to keep their preference, initiative or power in strategic decisions. For instance, the township management can ignore the perspective of any stakeholder group in the decisionmaking process by assigning a zero coefficient to the related SRR set.

Table 30: Probabilities assigned to each stakeholder perspective (i.e., $P_{j}$ values)

\begin{tabular}{|c|c|}
\cline { 2 - 2 } \multicolumn{1}{c|}{} & \multicolumn{1}{c|}{$\boldsymbol{P}_{\boldsymbol{j}}$ values } \\
\hline Stakeholder 1 & 0.250 \\
\hline Stakeholder 2 & 0.125 \\
\hline Stakeholder 3 & 0.250 \\
\hline Stakeholder 4 & 0.125 \\
\hline Stakeholder 5 & 0.250 \\
\hline
\end{tabular}

Finally, by interviewing the township management, initial wealth is assumed to be $\$ 7$ million and the target wealth is simply assumed to be zero. While the minimum and maximum investment amounts for the projects are determined by considering the investment amounts for worst case and best case scenarios. In addition to the trivial constraints, the constraints that the model uses related to the minimum and maximum investment amounts for the projects are provided below:

- The total investment amount for Project 1 (Compost) must be less than or equal to $\$ 580,853$ and greater than or equal to $\$ 525,534$. $\$ 580,853$ and $\$ 525,534$ are the total capital 
expenditures required for Project 1 (Compost) at the worst case and best case as seen from Table 12.

- The total investment amount for Project 2 (Alternative Fuel) must be less than or equal to $\$ 126,641$, and $\$ 126,641$ is the total investment amount required for Project 2 (Alternative Fuel) (See Table 14).

- The investment amount for Project 2 (Alternative Fuel) at period 1 must be less than or equal to $\$ 53,667$, and $\$ 53,667$ is the total investment amount required for Project 2 (Alternative Fuel) at period 1 (See Table 14).

- The investment amount for Project 2 (Alternative Fuel) at period 2 must be less than or equal to $\$ 28,137$, and $\$ 28,137$ is the total investment amount required for Project 2 (Alternative Fuel) at period 2 (See Table 14).

- The investment amount for Project 2 (Alternative Fuel) at period 3 must be less than or equal to $\$ 44,837$, and $\$ 44,837$ is the total investment amount required for Project 2 (Alternative Fuel) at period 3 (See Table 14).

- The total investment amount for Project 3 (RECs) at each period must be less than or equal to $\$ 218,076$ and greater than or equal to $\$ 10,542 . \$ 218,076$ is the total investment amount required for Project 3 (RECs) if PA wind RECs are purchased (See Table 17), and $\$ 10,542$ is the total investment amount required for Project 3 (RECs) if national wind RECs are purchased (See Table 18).

- The investment amount for Project 3 (RECs) at period 2 must be greater than or equal to the investment amount for Project 3 (RECs) at period 1. This constraint guarantees the continuity of EPA Partnership at period 2 if it is earned in period 1. 
- The investment amount for Project 3 (RECs) at period 3 must be greater than or equal to the investment amount for Project 3 (RECs) at period 2. This constraint guarantees the continuity of EPA Partnership at period 3 if it is earned in period 2.

- Since Project 4 (Transit) requires relatively huge amount of investment and very high sustainability rate of return compared to the other project alternatives, lower limit for the amount of investment on this project is simply assumed as zero, and no upper limit is considered.

- The total investment amount for Project 5 (LEED) must be less than or equal to $\$ 537,357$ and greater than or equal to $\$ 362,834$. $\$ 537,357$ and $\$ 362,834$ are the total capital expenditures required for Project 5 (LEED) at the worst case and best case as seen from Table 24.

The limits on the minimum and maximum investment amounts for the projects are summarized in Tables 31 and 32.

Table 31: Limits on total minimum and maximum investment amounts

\begin{tabular}{|c|c|c|c|c|}
\cline { 2 - 5 } \multicolumn{1}{c|}{} & Project 1 & Project 2 & Project 4 & Project 5 \\
\hline Min. investment amount & $\$ 525,534$ & 0 & 0 & $\$ 362,834$ \\
\hline Max. investment amount & $\$ 580,853$ & $\$ 126,641$ & No limit & $\$ 537,357$ \\
\hline
\end{tabular}


Table 32: Limits on minimum and maximum investment amounts at each period

\begin{tabular}{|c|c|c|}
\cline { 2 - 3 } \multicolumn{1}{c|}{} & Project 2 & Project 3 \\
\hline $\begin{array}{c}\text { Min. investment amount } \\
\text { at period 1 }\end{array}$ & $\$ 0$ & $\$ 10,542$ \\
\hline $\begin{array}{c}\text { Max. investment amount } \\
\text { at period 1 }\end{array}$ & $\$ 53,667$ & $\$ 218,076$ \\
\hline $\begin{array}{c}\text { Min. investment amount } \\
\text { at period 2 }\end{array}$ & $\$ 0$ & $\$ 10,542$ and investment amount at period 1 \\
\hline $\begin{array}{c}\text { Max. investment amount } \\
\text { at period 2 }\end{array}$ & $\$ 28,137$ & $\$ 218,076$ \\
\hline $\begin{array}{c}\text { Min. investment amount } \\
\text { at period 3 }\end{array}$ & $\$ 0$ & $\$ 10,542$ and investment amount at period 2 \\
\hline $\begin{array}{c}\text { Max. investment amount } \\
\text { at period 3 }\end{array}$ & $\$ 44,837$ & $\$ 218,076$ \\
\hline
\end{tabular}

A copy of the numeric model file where the sustainability coefficient $(\mathrm{K})$ is equal to 1 (i.e., Financial (F) Value and Sustainability (S) Value have equal importance) created in Notepad can be seen in Appendix F.

\subsubsection{Results}

To solve the three-stage stochastic linear program, ILOG Cplex 9.0 was used (ILOG, Cplex Documentation, 2008). The results obtained for several sustainability coefficient $(K)$ values are shown in Table 33.

As it is shown in Table 33 and Figure 19, three different investment portfolios are obtained after running the three-stage stochastic linear program for several sustainability coefficient $(K)$ values. By considering the marginal improvements shown in Table 34, the township management can select any one of the investment portfolios depending on the needs of 
the township and their preferences in pursuing sustainability practices (i.e., determining the value of sustainability coefficient (K)).

Table 33: Model results for several $\mathrm{K}$ values

\begin{tabular}{|c|c|c|c|}
\hline \multicolumn{4}{|c|}{ Model 1 Results for b=\$7,000,000 } \\
\hline $\begin{array}{c}\text { Sustainability } \\
\text { Coefficient K }\end{array}$ & $\begin{array}{c}\text { Financial } \\
(\mathbf{F}) \text { Value (\$) }\end{array}$ & $\begin{array}{c}\text { Sustainability } \\
\text { (S) Value (\$) }\end{array}$ & Investment Strategy \\
\hline 0 & $11,480,080$ & $79,241,200$ & Investment Portfolio 1 \\
\hline 0.025 & $11,480,080$ & $79,241,200$ & Investment Portfolio 1 \\
\hline 0.05 & $11,480,080$ & $79,241,200$ & Investment Portfolio 1 \\
\hline 0.075 & $11,477,020$ & $79,304,300$ & Investment Portfolio 2 \\
\hline 0.1 & $11,477,020$ & $79,304,300$ & Investment Portfolio 2 \\
\hline 0.5 & $11,477,020$ & $79,304,300$ & Investment Portfolio 2 \\
\hline 1 & $11,433,305$ & $79,348,015$ & Investment Portfolio 3 \\
\hline 2 & $11,433,305$ & $79,348,015$ & Investment Portfolio 3 \\
\hline 3 & $11,433,305$ & $79,348,015$ & Investment Portfolio 3 \\
\hline 5 & $11,433,305$ & $79,348,015$ & Investment Portfolio 3 \\
\hline 10 & $11,433,305$ & $79,348,015$ & Investment Portfolio 3 \\
\hline 100 & $11,433,305$ & $79,348,015$ & Investment Portfolio 3 \\
\hline 1000 & $11,433,305$ & $79,348,015$ & Investment Portfolio 3 \\
\hline
\end{tabular}




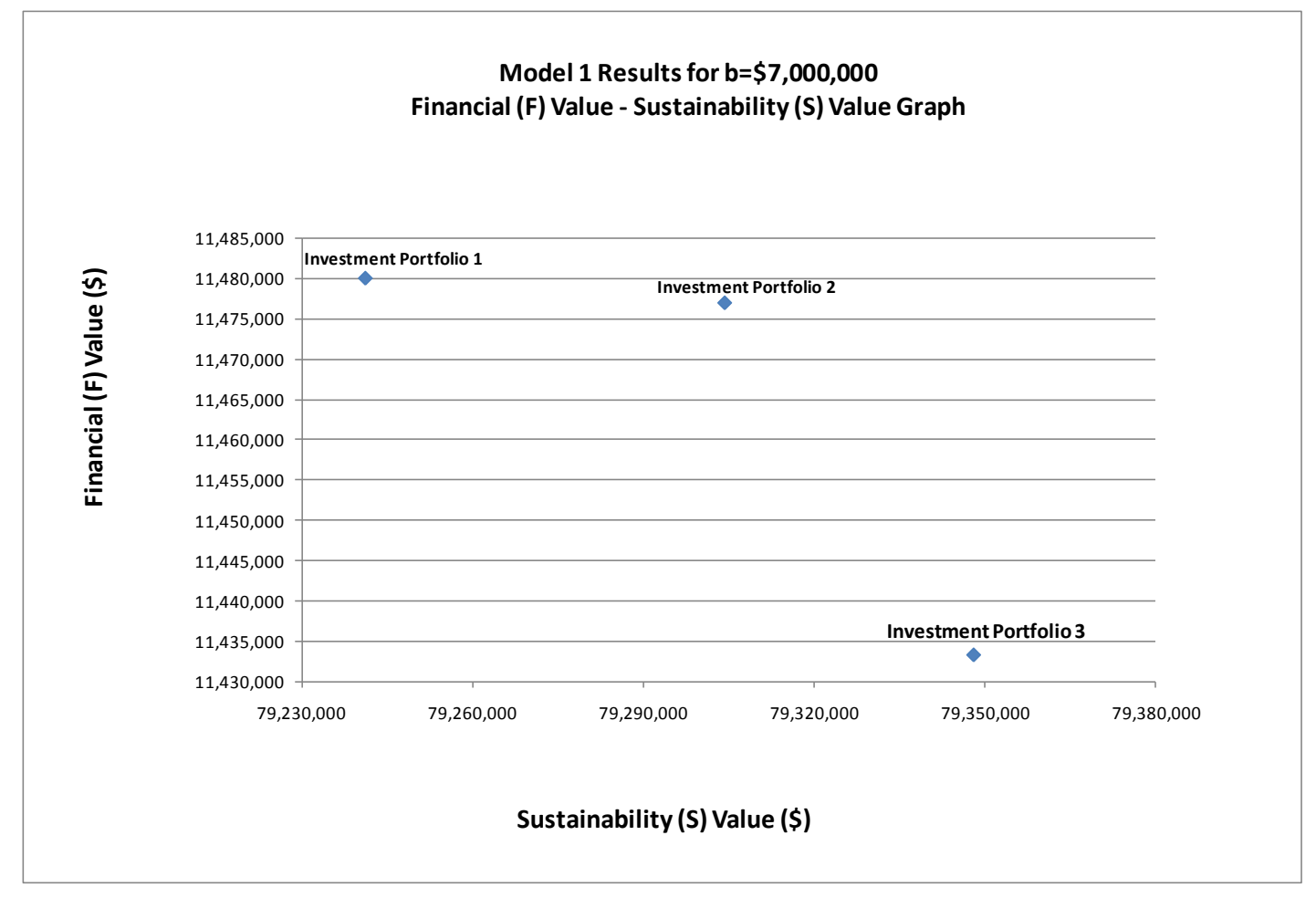

Figure 19: Investment portfolios on Financial (F) Value - Sustainability (S) Value graph

Table 34: Analysis of Model 1 results for $b=\$ 7,000,000$

\begin{tabular}{|c|c|c|c|}
\hline \multicolumn{4}{|c|}{ Analysis of Model 1 Results for b=\$7,000,000 } \\
\hline $\begin{array}{c}\text { Investment } \\
\text { Portfolios }\end{array}$ & $\begin{array}{c}\text { Difference in } \\
\text { Financial (F) } \\
\text { Values (\$) }\end{array}$ & $\begin{array}{c}\text { Difference in } \\
\text { Sustainability (S) } \\
\text { Values (\$) }\end{array}$ & $\begin{array}{c}\text { Marginal } \\
\text { Improvement } \\
\text { (S/F) }\end{array}$ \\
\hline 1 and 2 & $3,060.406$ & $63,100.406$ & 20.618 \\
\hline 2 and 3 & $43,714.641$ & $43,714.641$ & 1.000 \\
\hline
\end{tabular}

The details of the investment strategy proposed by investment portfolio 2 are provided in Table 35. In this context, an investment portfolio represents an investment strategy which states how much should be invested in each of the five projects at each of the 3 time periods. For example, as seen in Table 35, investment portfolio 2 proposes to invest $\$ 525,534, \$ 53,667$, 
$\$ 10,542$ and $\$ 6.410$ million on alternative projects 1 (Compost), 2 (Alternative Fuel), 3 (RECs) and 4 (Transit), respectively at time period 1; then for time period 2, it suggests to invest $\$ 28,137, \$ 10,542$ and $\$ 7.101$ million on alternative projects 2 (Alternative Fuel), 3 (RECs) and 4 (Transit), respectively if scenario 1 happens at the end of time period 1 ; invest $\$ 28,137, \$ 10,542$ and \$8.211 million on projects 2 (Alternative Fuel), 3 (RECs) and 4 (Transit), respectively if scenario 2 happens at the end of time period 1; and invest $\$ 28,137, \$ 10,542$ and $\$ 9.464$ million on projects 2 (Alternative Fuel), 3 (RECs) and 4 (Transit), respectively if scenario 3 happens at the end of time period 1 , so on.

Investment portfolio 1 provides an investment strategy which considers only the economic concerns. For this reason, it provides the minimum sustainability value which is $\$ 79.241$ million. On the other hand, investment portfolio 3 provides an investment strategy which takes into account the environmental and social concerns at the maximum level in addition to the economic concerns. By investing $\$ 46,775$ on environment and society, investment portfolio 3 improves the sustainability value of the organization from $\$ 79.241$ million to $\$ 79.348$ million. The details of the investment strategy proposed by investment portfolios 1 and 3 are also shown in Table 35. 
Table 35: Investment strategies proposed by investment portfolios 1, 2 and 3 $x(i, 1)=$ Amount invested on project $i$ in period 1 where $1 \leq i \leq 5$ $x\left(i, t, s_{1}, \ldots \ldots, s_{H}\right)=$ Amount invested on project $i$ in period $t$ of scenario $\left(s_{1}, \ldots \ldots, s_{H}\right)$ where $1 \leq i \leq 5$ and $2 \leq t \leq 3$

\begin{tabular}{|c|c|c|c|c|}
\hline \multicolumn{5}{|c|}{ Model 1 Investment Portfolios for $b=\$ 7,000,000$} \\
\hline $\begin{array}{l}\text { Planning } \\
\text { Horizon }\end{array}$ & $\begin{array}{l}\text { Investment } \\
\text { Amount (\$) }\end{array}$ & $\begin{array}{l}\text { Investment } \\
\text { Portfolio } 1\end{array}$ & $\begin{array}{l}\text { Investment } \\
\text { Portfolio } 2\end{array}$ & $\begin{array}{l}\text { Investment } \\
\text { Portfolio } 3\end{array}$ \\
\hline \multirow{5}{*}{ 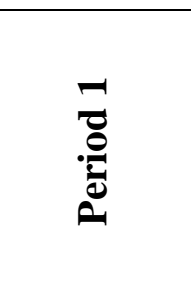 } & $x(1,1)$ & 580,853 & 525,534 & 525,534 \\
\hline & $x(2,1)$ & 53,667 & 53,667 & 53,667 \\
\hline & $x(3,1)$ & 10,542 & 10,542 & 10,542 \\
\hline & $x(4,1)$ & $6,354,938$ & $6,410,257$ & $6,410,257$ \\
\hline & $x(5,1)$ & 0 & 0 & 0 \\
\hline \multirow{15}{*}{ 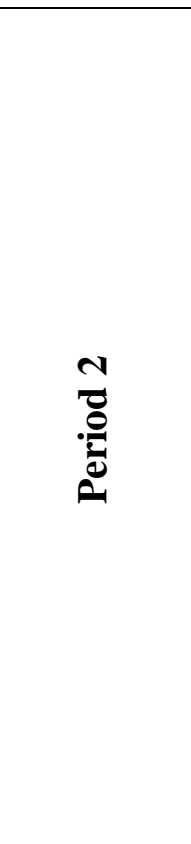 } & $x(1,2,1)$ & 0 & 0 & 0 \\
\hline & $x(2,2,1)$ & 28,137 & 28,137 & 28,137 \\
\hline & $x(3,2,1)$ & 10,542 & 10,542 & 10,542 \\
\hline & $x(4,2,1)$ & $7,102,722$ & $7,101,616$ & $7,101,616$ \\
\hline & $x(5,2,1)$ & 0 & 0 & 0 \\
\hline & $x(1,2,2)$ & 0 & 0 & 0 \\
\hline & $x(2,2,2)$ & 28,137 & 28,137 & 28,137 \\
\hline & $x(3,2,2)$ & 10,542 & 10,542 & 10,542 \\
\hline & $x(4,2,2)$ & $8,211,529$ & $8,211,529$ & $8,211,529$ \\
\hline & $x(5,2,2)$ & 0 & 0 & 0 \\
\hline & $x(1,2,3)$ & 0 & 0 & 0 \\
\hline & $x(2,2,3)$ & 28,137 & 28,137 & 28,137 \\
\hline & $x(3,2,3)$ & 10,542 & 10,542 & 10,542 \\
\hline & $x(4,2,3)$ & $9,464,451$ & $9,464,451$ & $9,464,451$ \\
\hline & $x(5,2,3)$ & 0 & 0 & 0 \\
\hline
\end{tabular}


Table 35 (continued)

\begin{tabular}{|c|c|c|c|c|}
\hline $\begin{array}{l}\text { Planning } \\
\text { Horizon }\end{array}$ & $\begin{array}{l}\text { Investment } \\
\text { Amount (\$) }\end{array}$ & $\begin{array}{l}\text { Investment } \\
\text { Portfolio } 1\end{array}$ & $\begin{array}{l}\text { Investment } \\
\text { Portfolio } 2\end{array}$ & $\begin{array}{l}\text { Investmen } \\
\text { Portfolio } 3\end{array}$ \\
\hline \multirow{20}{*}{ 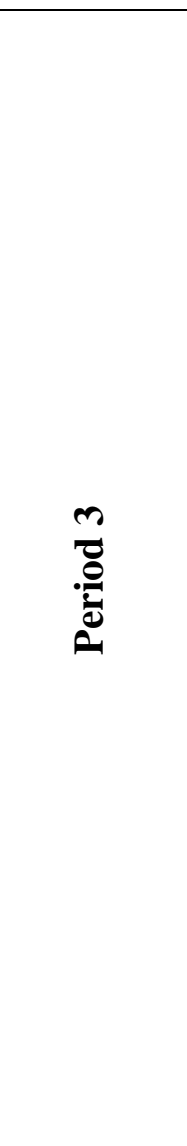 } & $x(1,3,1,1)$ & 0 & 0 & 0 \\
\hline & $x(2,3,1,1)$ & 44,837 & 44,837 & 0 \\
\hline & $x(3,3,1,1)$ & 10,542 & 10,542 & 10,542 \\
\hline & $x(4,3,1,1)$ & $6,854,416$ & $6,854,416$ & $6,899,253$ \\
\hline & $x(5,3,1,1)$ & 362,834 & 362,834 & 362,834 \\
\hline & $x(1,3,1,2)$ & 0 & 0 & 0 \\
\hline & $x(2,3,1,2)$ & 44,837 & 44,837 & 0 \\
\hline & $x(3,3,1,2)$ & 10,542 & 10,542 & 10,542 \\
\hline & $x(4,3,1,2)$ & $7,950,609$ & $7,950,609$ & $7,995,446$ \\
\hline & $x(5,3,1,2)$ & 362,834 & 362,834 & 362,834 \\
\hline & $x(1,3,1,3)$ & 0 & 0 & 0 \\
\hline & $x(2,3,1,3)$ & 44,837 & 44,837 & 0 \\
\hline & $x(3,3,1,3)$ & 10,542 & 10,542 & 10,542 \\
\hline & $x(4,3,1,3)$ & $9,191,085$ & $9,191,085$ & $9,235,922$ \\
\hline & $x(5,3,1,3)$ & 362,834 & 362,834 & 362,834 \\
\hline & $x(1,3,2,1)$ & 0 & 0 & 0 \\
\hline & $x(2,3,2,1)$ & 44,837 & 44,837 & 0 \\
\hline & $x(3,3,2,1)$ & 10,542 & 10,542 & 10,542 \\
\hline & $x(4,3,2,1)$ & $7,986,527$ & $7,986,527$ & $8,031,364$ \\
\hline & $x(5,3,2,1)$ & 362,834 & 362,834 & 362,834 \\
\hline
\end{tabular}


Table 35 (continued)

\begin{tabular}{|c|c|c|c|c|}
\hline $\begin{array}{c}\text { Planning } \\
\text { Horizon }\end{array}$ & $\begin{array}{l}\text { Investment } \\
\text { Amount (\$) }\end{array}$ & $\begin{array}{l}\text { Investment } \\
\text { Portfolio 1 } \\
\end{array}$ & $\begin{array}{l}\text { Investment } \\
\text { Portfolio 2 } \\
\end{array}$ & $\begin{array}{l}\text { Investment } \\
\text { Portfolio } 3 \\
\end{array}$ \\
\hline \multirow{25}{*}{ مُ } & $x(1,3,2,2)$ & 0 & 0 & 0 \\
\hline & $x(2,3,2,2)$ & 44,837 & 44,837 & 0 \\
\hline & $x(3,3,2,2)$ & 10,542 & 10,542 & 10,542 \\
\hline & $x(4,3,2,2)$ & $9,249,207$ & $9,249,207$ & $9,294,044$ \\
\hline & $x(5,3,2,2)$ & 362,834 & 362,834 & 362,834 \\
\hline & $x(1,3,2,3)$ & 0 & 0 & 0 \\
\hline & $x(2,3,2,3)$ & 44,837 & 44,837 & 0 \\
\hline & $x(3,3,2,3)$ & 10,542 & 10,542 & 10,542 \\
\hline & $x(4,3,2,3)$ & $10,678,370$ & $10,678,370$ & $10,723,210$ \\
\hline & $x(5,3,2,3)$ & 362,834 & 362,834 & 362,834 \\
\hline & $x(1,3,3,1)$ & 0 & 0 & 0 \\
\hline & $x(2,3,3,1)$ & 44,837 & 44,837 & 0 \\
\hline & $x(3,3,3,1)$ & 10,542 & 10,542 & 10,542 \\
\hline & $x(4,3,3,1)$ & $9,264,508$ & $9,264,508$ & $9,309,345$ \\
\hline & $x(5,3,3,1)$ & 362,834 & 362,834 & 362,834 \\
\hline & $x(1,3,3,2)$ & 0 & 0 & 0 \\
\hline & $x(2,3,3,2)$ & 44,837 & 44,837 & 0 \\
\hline & $x(3,3,3,2)$ & 10,542 & 10,542 & 10,542 \\
\hline & $x(4,3,3,2)$ & $10,715,130$ & $10,715,130$ & $10,759,960$ \\
\hline & $x(5,3,3,2)$ & 362,834 & 362,834 & 362,834 \\
\hline & $x(1,3,3,3)$ & 0 & 0 & 0 \\
\hline & $x(2,3,3,3)$ & 44,837 & 44,837 & 0 \\
\hline & $x(3,3,3,3)$ & 10,542 & 10,542 & 10,542 \\
\hline & $x(4,3,3,3)$ & $12,357,280$ & $12,357,280$ & $12,402,120$ \\
\hline & $x(5,3,3,3)$ & 362,834 & 362,834 & 362,834 \\
\hline
\end{tabular}

\subsubsection{Sensitivity Analysis}

In this section, a sensitivity analysis is performed and the related findings are discussed. This analysis is basically designed to deal with the following three concerns: 
1. The results of the initial model (Model 1) shown in Table 33 and Figure 19 are based on several assumptions made on the initial available budget (b), and lower and upper investment amounts for the projects ( $\mathrm{U}$ and $\mathrm{L}$ ). It is interesting to observe how the results change with the changes to these assumptions.

2. Project 4 (Transit) requires a relatively high amount of investment as compared to the other four projects. Hence, it tends to dominate the other projects thereby limiting the investment portfolio options for the decision maker.

3. The percentage change on the Sustainability (S) Value axis in Figure 19 is relatively low as the value of Sustainability Coefficient $(\mathrm{K})$ increases from 0 to 1 which may not be an interesting finding from the perspective of decision maker.

As a result, three additional models were created to investigate the sensitivity of the model. Each is subsequently described. For the first two concerns, the following two models are developed and they are solved for several different values for the initial investment amount.

Model 2 is similar to Model 1 . However, in this model, the lower limit for the investment amount of Project 3 (RECs) is set to zero, and a \$27,982,500 upper limit constraint is added for the investment amount of Project 4 (Transit).

Model 3 is also similar to Model 1. However, in this model, the lower limit for the investment amount of Project 3 (RECs) is set to zero, and a $\$ 1,000,000$ upper limit constraint is added for the investment amount of Project 4 (Transit).

Model 4 is created to deal with the third concern. Since all of the five projects are actually sustainability initiative projects, it was thought that it would be possible to increase the 
percentage change on the Sustainability (S) Value axis by considering a primarily financial investment project (i.e., a project with a relatively high IRR, but a relatively low SRR compared to the other projects) with the same size of Project 4 (Transit) as an alternative investment project. As a result, Model 4 is similar to Model 3; however, in this model, Project 3 (RECs) is replaced with a primarily financial investment project, namely Project 3 (Financial), whose characteristics are presented in Tables 36, 37 and 38.

Table 36: Three-year internal rate of return (IRR) values of Project 3 (Financial) assumed for the worst case, most probable case and best case scenarios

\begin{tabular}{|c|c|c|c|}
\cline { 2 - 4 } \multicolumn{1}{c|}{} & \multicolumn{3}{|c|}{ Three-Year Compounded Internal Rate of Returns (IRRs) } \\
\cline { 2 - 4 } \multicolumn{1}{c|}{} & $\begin{array}{c}\text { Worst Case } \\
\text { Scenario }\end{array}$ & $\begin{array}{c}\text { Most Probable } \\
\text { Scenario }\end{array}$ & $\begin{array}{c}\text { Best Case } \\
\text { Scenario }\end{array}$ \\
\hline Project 3 (Financial) & $5 \%$ & $20 \%$ & $100 \%$ \\
\hline
\end{tabular}

Table 37: Assumed sustainability rate of return (SRR) values for Project 3 (Financial)

\begin{tabular}{|c|c|}
\cline { 2 - 2 } \multicolumn{1}{c|}{} & Sustainability Rate of Returns (SRRs) \\
\cline { 2 - 2 } \multicolumn{1}{c|}{} & Project 3 (Financial) \\
\hline Stakeholder 1 & $13 \%$ \\
\hline Stakeholder 2 & $13 \%$ \\
\hline Stakeholder 3 & $13 \%$ \\
\hline Stakeholder 4 & $13 \%$ \\
\hline Stakeholder 5 & $13 \%$ \\
\hline
\end{tabular}

Table 38: Limits on minimum and maximum investment amounts on Project 3 (Financial)

\begin{tabular}{|c|c|}
\cline { 2 - 2 } \multicolumn{1}{c|}{} & Project 3 (Financial) \\
\hline Min. investment amount & $\$ 0$ \\
\hline Max. investment amount & $\$ 1,000,000$ \\
\hline
\end{tabular}


Table 36 shows the IRR values assumed for Project 3 (Financial) at the worst case, most probable case and best case. These IRR values are selected relatively high compared to the IRR values of the other four projects. Similarly, Table 37 shows the assumed SRR values for Project 3 (Financial). For all of the stakeholder perspectives, the SRR value of Project 3 (Financial) is simply set to $13 \%$ which is the lowest SRR value among the SRR values of the other four projects. Finally, Table 38 presents the lower and upper investment amounts for Project 3 (Financial). As mentioned before, Project 3 (Financial) is assumed to be the same size as Project 4 (Transit), and hence similar to Project 4 (Transit), its minimum and maximum investment amounts are set to zero and $\$ 1,000,000$, respectively.

\section{Results of Model 2:}

Table 39 and Figure 20 show the results obtained with Model 2 when the initial wealth is set to $\$ 283,000$. Since the model has lower limit constraints for the investment amounts of Project 1 (Compost) and Project 5 (LEED), values less than $\$ 283,000$ for the initial wealth end up being infeasible. Here, $\$ 283,000$ represents the minimum investment amount that is necessary to obtain a feasible solution under the given constraints. Model 2 generates only two investment portfolios limiting the options for the decision maker since the initial investment amount is very low. To compare the two investment portfolios, Table 40 provides the ratio of the change in Financial $(\mathrm{F})$ Value (\$) to change in Sustainability (S) Value (\$) when one shifts from investment portfolio 1 to investment portfolio 2. The details of the investment portfolios can be seen in Appendix G.1. 
Table 39: Model 2 results when initial wealth is $\$ 283,000$

\begin{tabular}{|c|c|c|c|}
\hline \multicolumn{4}{|c|}{ Model 2 Results for b=\$283,000 } \\
\hline $\begin{array}{c}\text { Sustainability } \\
\text { Coefficient K }\end{array}$ & $\begin{array}{c}\text { Financial } \\
(\text { F) Value } \mathbf{( \$ )}\end{array}$ & $\begin{array}{c}\text { Sustainability } \\
(\mathbf{S}) \text { Value } \mathbf{( \$ )}\end{array}$ & Investment Strategy \\
\hline 0 & 523,981 & $2,026,842$ & Investment Portfolio 1 \\
\hline 0.5 & 523,981 & $2,026,842$ & Investment Portfolio 1 \\
\hline 1 & 484,344 & $2,069,476$ & Investment Portfolio 2 \\
\hline 10 & 484,344 & $2,069,476$ & Investment Portfolio 2 \\
\hline
\end{tabular}

Model 2 Results for $b=\$ 283,000$

Financial (F) Value - Sustainability (S) Value Graph

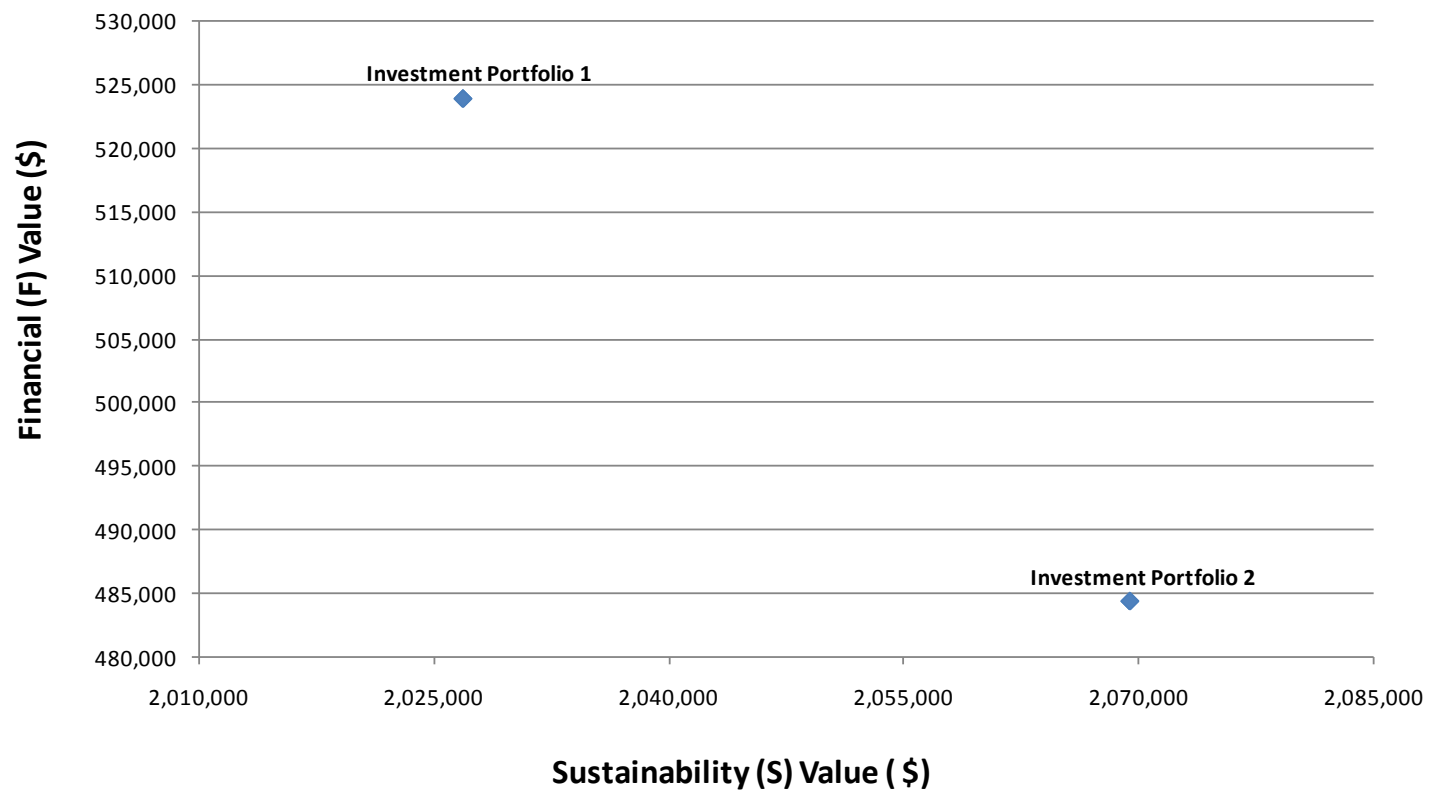

Figure 20: Model 2 results on Financial (F) Value - Sustainability (S) Value graph when initial wealth is $\$ 283,000$ 
Table 40: Analysis of Model 2 results when initial wealth is $\$ 283,000$

\begin{tabular}{|c|c|c|c|}
\hline \multicolumn{5}{|c|}{ Analysis of Model 2 Results for b=\$283,000 } \\
\hline $\begin{array}{c}\text { Investment } \\
\text { Portfolios }\end{array}$ & $\begin{array}{c}\text { Difference in } \\
\text { Financial (F) Values (\$) }\end{array}$ & $\begin{array}{c}\text { Difference in } \\
\text { Sustainability (S) } \\
\text { Values (\$) }\end{array}$ & $\begin{array}{c}\text { Marginal } \\
\text { Improvement } \\
\text { (S/F) }\end{array}$ \\
\hline 1 and 2 & 39,637 & 42,634 & 1.076 \\
\hline
\end{tabular}

Table 41 and Figure 21 show the results obtained with Model 2 when the initial wealth is set to $\$ 5,000,000$. Although the initial wealth is relatively high, Model 2 still generates a limited number of options (three investment portfolios) for the decision maker since Project 4 (Transit) dominates the other projects. To compare the three investment portfolios, Table 42 provides the ratio of the change in Financial (F) Value (\$) to change in Sustainability (S) Value (\$) when one shifts from investment portfolio 1 to investment portfolio 2 and then to investment portfolio 3 . The details of the investment portfolios can be seen in Appendix G.1.

Table 41: Model 2 results when initial wealth is $\$ 5,000,000$

\begin{tabular}{|c|c|c|c|}
\hline \multicolumn{4}{|c|}{ Model 2 Results for b=\$5,000,000 } \\
\hline $\begin{array}{c}\text { Sustainability } \\
\text { Coefficient K }\end{array}$ & $\begin{array}{c}\text { Financial } \\
(\text { F) Value (\$) }\end{array}$ & $\begin{array}{c}\text { Sustainability } \\
\text { (S) Value (\$) }\end{array}$ & Investment Strategy \\
\hline 0 & $8,279,649$ & $56,484,012$ & Investment Portfolio 1 \\
\hline 0.05 & $8,279,649$ & $56,484,012$ & Investment Portfolio 1 \\
\hline 0.1 & $8,276,594$ & $56,543,511$ & Investment Portfolio 2 \\
\hline 0.25 & $8,276,594$ & $56,543,511$ & Investment Portfolio 2 \\
\hline 0.5 & $8,276,594$ & $56,543,511$ & Investment Portfolio 2 \\
\hline 0.75 & $8,276,594$ & $56,543,511$ & Investment Portfolio 2 \\
\hline 0.8 & $8,276,594$ & $56,543,511$ & Investment Portfolio 2 \\
\hline 0.9 & $8,276,594$ & $56,543,511$ & Investment Portfolio 2 \\
\hline 1 & $8,232,879$ & $56,590,531$ & Investment Portfolio 3 \\
\hline 10 & $8,232,879$ & $56,590,531$ & Investment Portfolio 3 \\
\hline
\end{tabular}




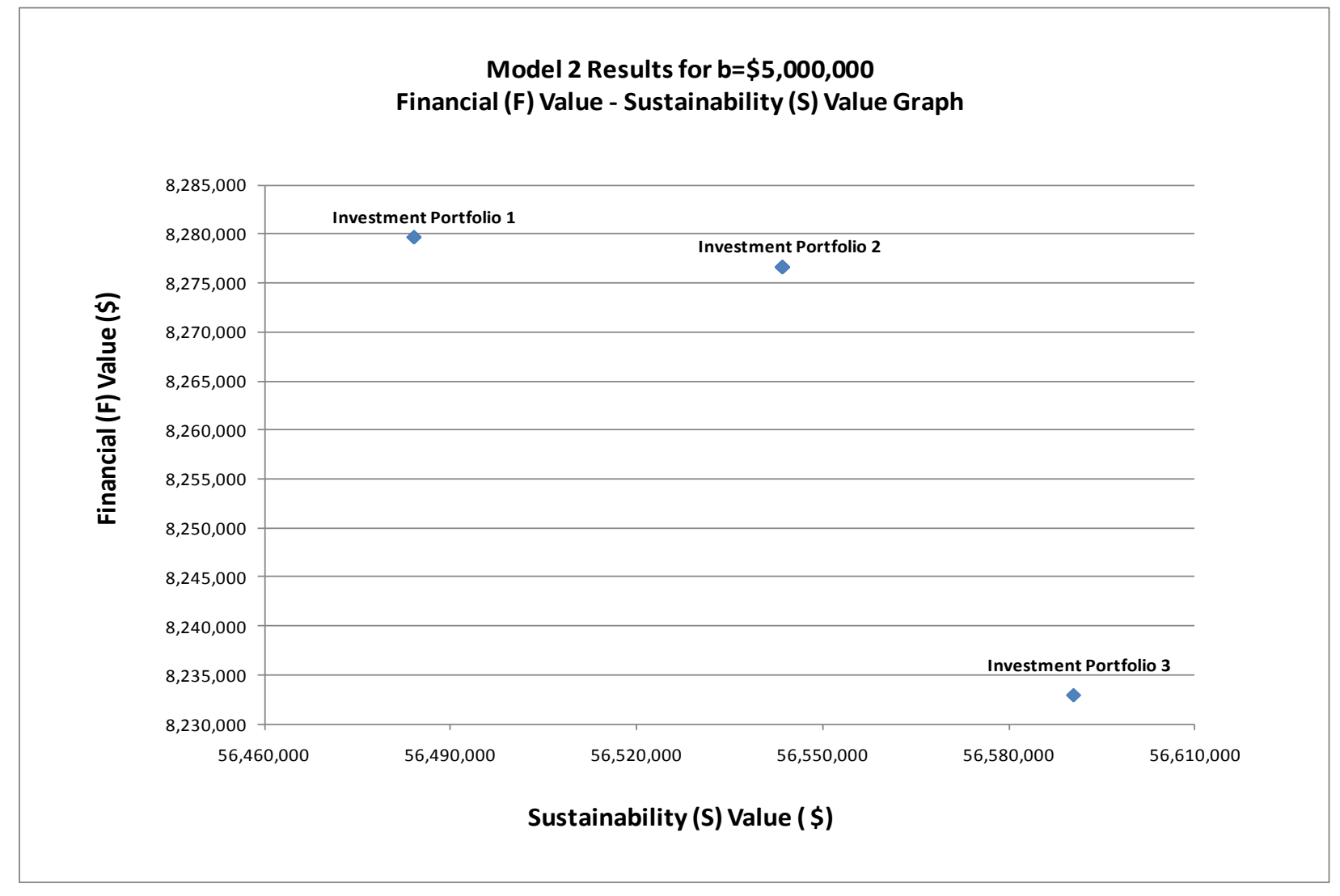

Figure 21: Model 2 results on Financial (F) Value - Sustainability (S) Value graph when initial wealth is $\$ 5,000,000$

Table 42: Analysis of Model 2 results when initial wealth is $\$ 5,000,000$

\begin{tabular}{|c|c|c|c|}
\hline \multicolumn{4}{|c|}{ Analysis of Model 2 Results for b=\$5,000,000 } \\
\hline $\begin{array}{c}\text { Investment } \\
\text { Portfolios }\end{array}$ & $\begin{array}{c}\text { Difference in } \\
\text { Financial (F) } \\
\text { Values (\$) }\end{array}$ & $\begin{array}{c}\text { Difference in } \\
\text { Sustainability (S) } \\
\text { Values (\$) }\end{array}$ & $\begin{array}{c}\text { Marginal } \\
\text { Improvement } \\
\text { (S/F) }\end{array}$ \\
\hline 1 and 2 & 3,055 & 59,499 & 19.476 \\
\hline 2 and 3 & 43,716 & 47,020 & 1.076 \\
\hline
\end{tabular}

Table 43 and Figure 22 show the results obtained with Model 2 when the initial wealth is set to $\$ 6,000,000$. Similar to the case when the initial wealth is set to $5,000,000$, although initial wealth 
is relatively high, Model 2 generates a limited number of options (three investment portfolios) for the decision maker since Project 4 (Transit) dominates the other projects. To compare the three investment portfolios, Table 44 provides the ratio of the change in Financial (F) Value (\$) to change in Sustainability (S) Value (\$) when one shifts from investment portfolio 1 to investment portfolio 2 and then to investment portfolio 3. The details of the investment portfolios can be seen in Appendix G.1.

Table 43: Model 2 results when initial wealth is $\$ 6,000,000$

\begin{tabular}{|c|c|c|c|}
\hline & \multicolumn{3}{c|}{ Model 2 Results for b=\$6,000,000 } \\
\hline $\begin{array}{c}\text { Sustainability } \\
\text { Coefficient K }\end{array}$ & $\begin{array}{c}\text { Financial } \\
(\mathbf{F}) \text { Value (\$) }\end{array}$ & $\begin{array}{c}\text { Sustainability } \\
(\mathbf{S}) \text { Value } \mathbf{( \$ )}\end{array}$ & Investment Strategy \\
\hline 0 & $9,901,885$ & $67,950,908$ & Investment Portfolio 1 \\
\hline 0.05 & $9,901,885$ & $67,950,908$ & Investment Portfolio 1 \\
\hline 0.1 & $9,898,829$ & $68,010,401$ & Investment Portfolio 2 \\
\hline 0.25 & $9,898,829$ & $68,010,401$ & Investment Portfolio 2 \\
\hline 0.5 & $9,898,829$ & $68,010,401$ & Investment Portfolio 2 \\
\hline 0.75 & $9,898,829$ & $68,010,401$ & Investment Portfolio 2 \\
\hline 1 & $9,855,112$ & $68,057,418$ & Investment Portfolio 3 \\
\hline 10 & $9,855,112$ & $68,057,418$ & Investment Portfolio 3 \\
\hline
\end{tabular}




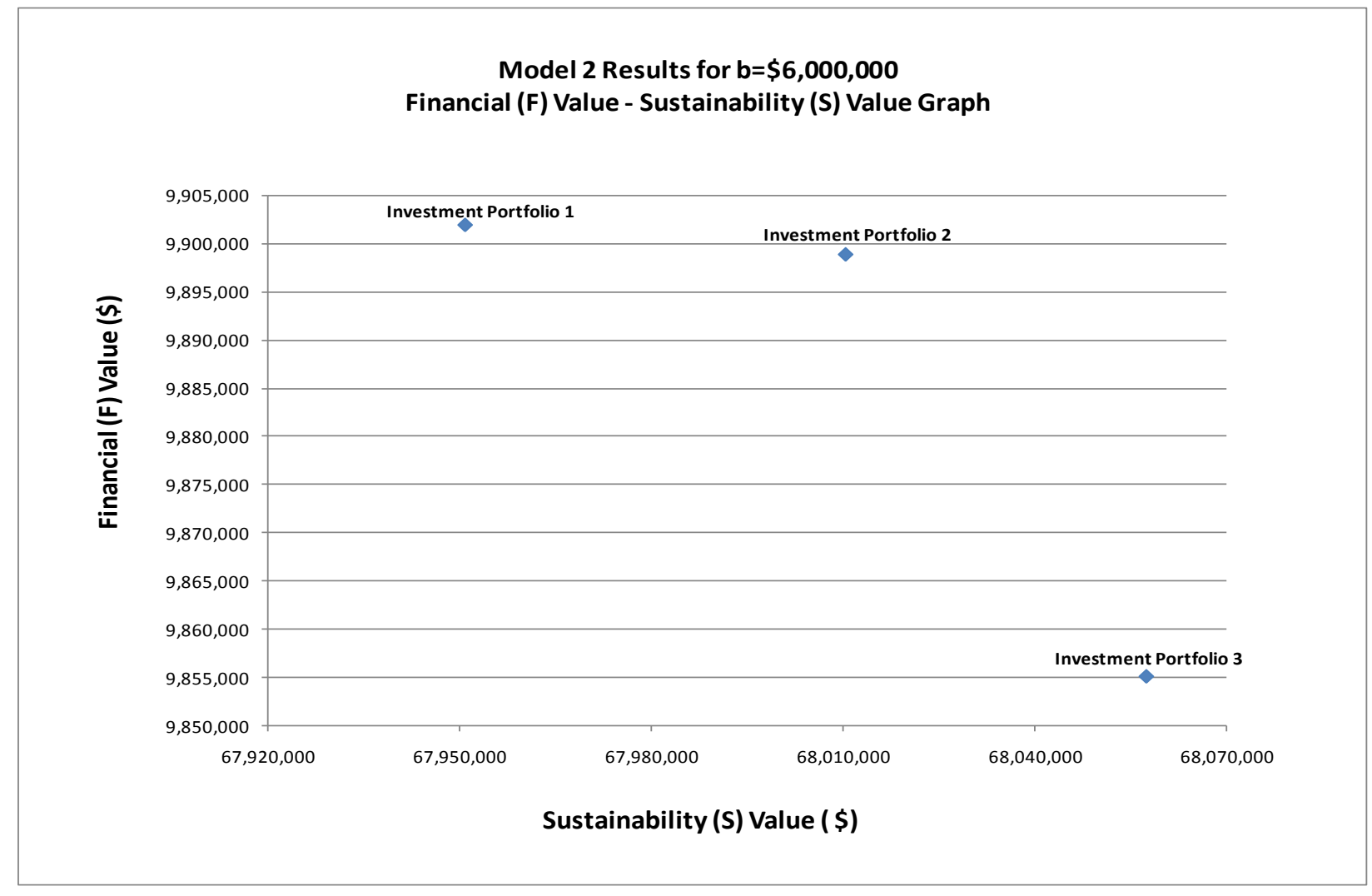

Figure 22: Model 2 results on Financial (F) Value - Sustainability (S) Value graph when initial wealth is $\$ 6,000,000$

Table 44: Analysis of Model 2 results when initial wealth is $\$ 6,000,000$

\begin{tabular}{|c|c|c|c|}
\hline \multicolumn{4}{|c|}{ Analysis of Model 2 Results for b=\$6,000,000 } \\
\hline $\begin{array}{c}\text { Investment } \\
\text { Portfolios }\end{array}$ & $\begin{array}{c}\text { Difference in } \\
\text { Financial (F) } \\
\text { Values (\$) }\end{array}$ & $\begin{array}{c}\text { Difference in } \\
\text { Sustainability (S) } \\
\text { Values (\$) }\end{array}$ & $\begin{array}{c}\text { Marginal } \\
\text { Improvement (S/F) }\end{array}$ \\
\hline 1 and 2 & 3,055 & 59,493 & 19.473 \\
\hline 2 and 3 & 43,717 & 47,016 & 1.075 \\
\hline
\end{tabular}

Table 45 and Figure 23 show the results obtained with Model 2 when the initial wealth is set to $\$ 7,000,000$. In this case, Model 2 generates four investment portfolios providing more options for the decision maker compared to the previous cases due to the increase in the initial 139 
investment amount. To compare the four investment portfolios, Table 46 provides the ratio of the change in Financial (F) Value (\$) to change in Sustainability (S) Value (\$) when one shifts through the four investment portfolios. The details of the investment portfolios can be seen in Appendix G.1.

Table 45: Model 2 results when initial wealth is $\$ 7,000,000$

\begin{tabular}{|c|c|c|c|}
\hline \multicolumn{4}{|c|}{ Model 2 Results for b=\$7,000,000 } \\
\hline $\begin{array}{c}\text { Sustainability } \\
\text { Coefficient K }\end{array}$ & $\begin{array}{c}\text { Financial } \\
(\mathbf{F}) \text { Value } \mathbf{( \$ )}\end{array}$ & $\begin{array}{c}\text { Sustainability } \\
\text { (S) Value } \mathbf{\$} \text { ) }\end{array}$ & Investment Strategy \\
\hline 0 & $11,519,095$ & $79,286,188$ & Investment Portfolio 1 \\
\hline 0.0025 & $11,519,095$ & $79,286,188$ & Investment Portfolio 1 \\
\hline 0.05 & $11,515,987$ & $79,441,247$ & Investment Portfolio 2 \\
\hline 0.1 & $11,515,987$ & $79,441,247$ & Investment Portfolio 2 \\
\hline 0.25 & $11,515,987$ & $79,441,247$ & Investment Portfolio 2 \\
\hline 0.5 & $11,515,987$ & $79,441,247$ & Investment Portfolio 2 \\
\hline 0.75 & $11,513,305$ & $79,446,487$ & Investment Portfolio 3 \\
\hline 0.8 & $11,513,305$ & $79,446,487$ & Investment Portfolio 3 \\
\hline 0.9 & $11,513,305$ & $79,446,487$ & Investment Portfolio 3 \\
\hline 1 & $11,472,322$ & $79,490,578$ & Investment Portfolio 4 \\
\hline 10 & $11,472,322$ & $79,490,578$ & Investment Portfolio 4 \\
\hline
\end{tabular}


Model 2 Results for $b=\$ 7,000,000$

Financial (F) Value - Sustainability (S) Value Graph

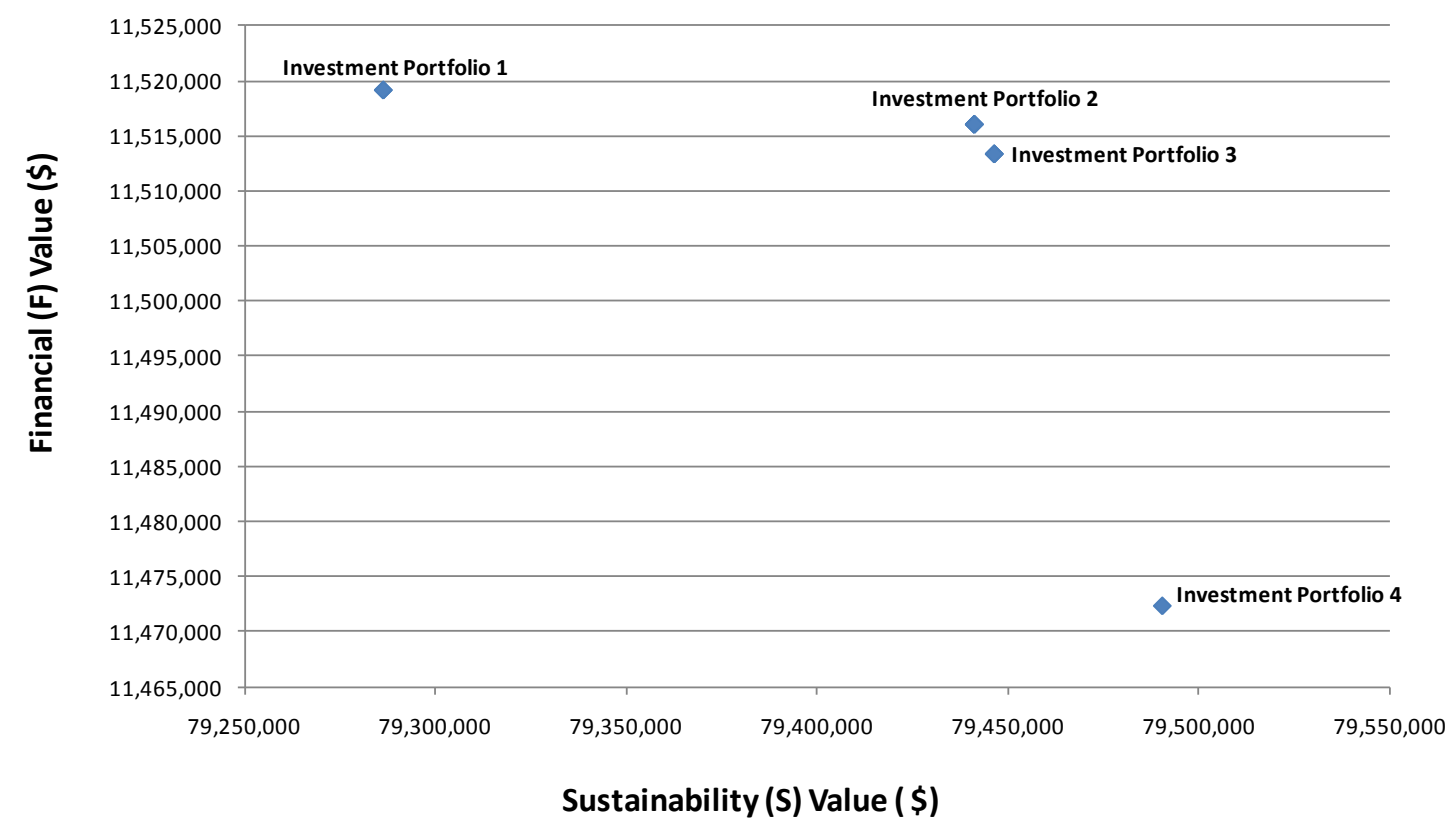

Figure 23: Model 2 results on Financial (F) Value - Sustainability (S) Value graph when initial wealth is $\$ 7,000,000$

Table 46: Analysis of Model 2 results when initial wealth is $\$ 7,000,000$

\begin{tabular}{|c|c|c|c|}
\hline \multicolumn{4}{|c|}{ Analysis of Model 2 Results for $\mathbf{b = \$ 7 , 0 0 0 , 0 0 0}$} \\
\hline $\begin{array}{c}\text { Investment } \\
\text { Portfolios }\end{array}$ & $\begin{array}{c}\text { Difference in } \\
\text { Financial (F) } \\
\text { Values (\$) }\end{array}$ & $\begin{array}{c}\text { Difference in } \\
\text { Sustainability (S) } \\
\text { Values (\$) }\end{array}$ & $\begin{array}{c}\text { Marginal } \\
\text { Improvement (S/F) }\end{array}$ \\
\hline 1 and 2 & 3,108 & 155,059 & 49.890 \\
\hline 2 and 3 & 2,682 & 5,240 & 1.954 \\
\hline 3 and 4 & 40,982 & 44,091 & 1.076 \\
\hline
\end{tabular}

Table 47 and Figure 24 show the results obtained with Model 2 when the initial wealth is set to $\$ 7,350,000$ (Since $\$ 8,000,000$ initial wealth ended up being infeasible, a $\$ 350,000$ jump up was 
selected.) Similar to the case when the initial wealth is set to $\$ 7,000,000$, it generates four investment portfolios. To compare the four investment portfolios, Table 48 provides the ratio of the change in Financial (F) Value (\$) to change in Sustainability (S) Value (\$) when one shifts through the four investment portfolios. The details of the investment portfolios can be seen in Appendix G.1.

Table 47: Model 2 results when initial wealth is $\$ 7,350,000$

\begin{tabular}{|c|c|c|c|}
\hline \multicolumn{5}{|c|}{ Model 2 Results for b=\$7,350,000 } \\
\hline $\begin{array}{c}\text { Sustainability } \\
\text { Coefficient K }\end{array}$ & $\begin{array}{c}\text { Financial } \\
\text { (F) Value (\$) }\end{array}$ & $\begin{array}{c}\text { Sustainability } \\
\text { (S) Value (\$) }\end{array}$ & Investment Strategy \\
\hline 0 & $11,551,637$ & $80,941,225$ & Investment Portfolio 1 \\
\hline 0.0025 & $11,551,637$ & $80,941,225$ & Investment Portfolio 1 \\
\hline 0.05 & $11,549,689$ & $80,990,015$ & Investment Portfolio 2 \\
\hline 0.1 & $11,549,689$ & $80,990,015$ & Investment Portfolio 2 \\
\hline 0.2 & $11,530,345$ & $81,119,330$ & Investment Portfolio 3 \\
\hline 0.25 & $11,530,345$ & $81,119,330$ & Investment Portfolio 3 \\
\hline 0.5 & $11,530,345$ & $81,119,330$ & Investment Portfolio 3 \\
\hline 1 & $11,489,360$ & $81,163,410$ & Investment Portfolio 4 \\
\hline 10 & $11,489,360$ & $81,163,410$ & Investment Portfolio 4 \\
\hline
\end{tabular}




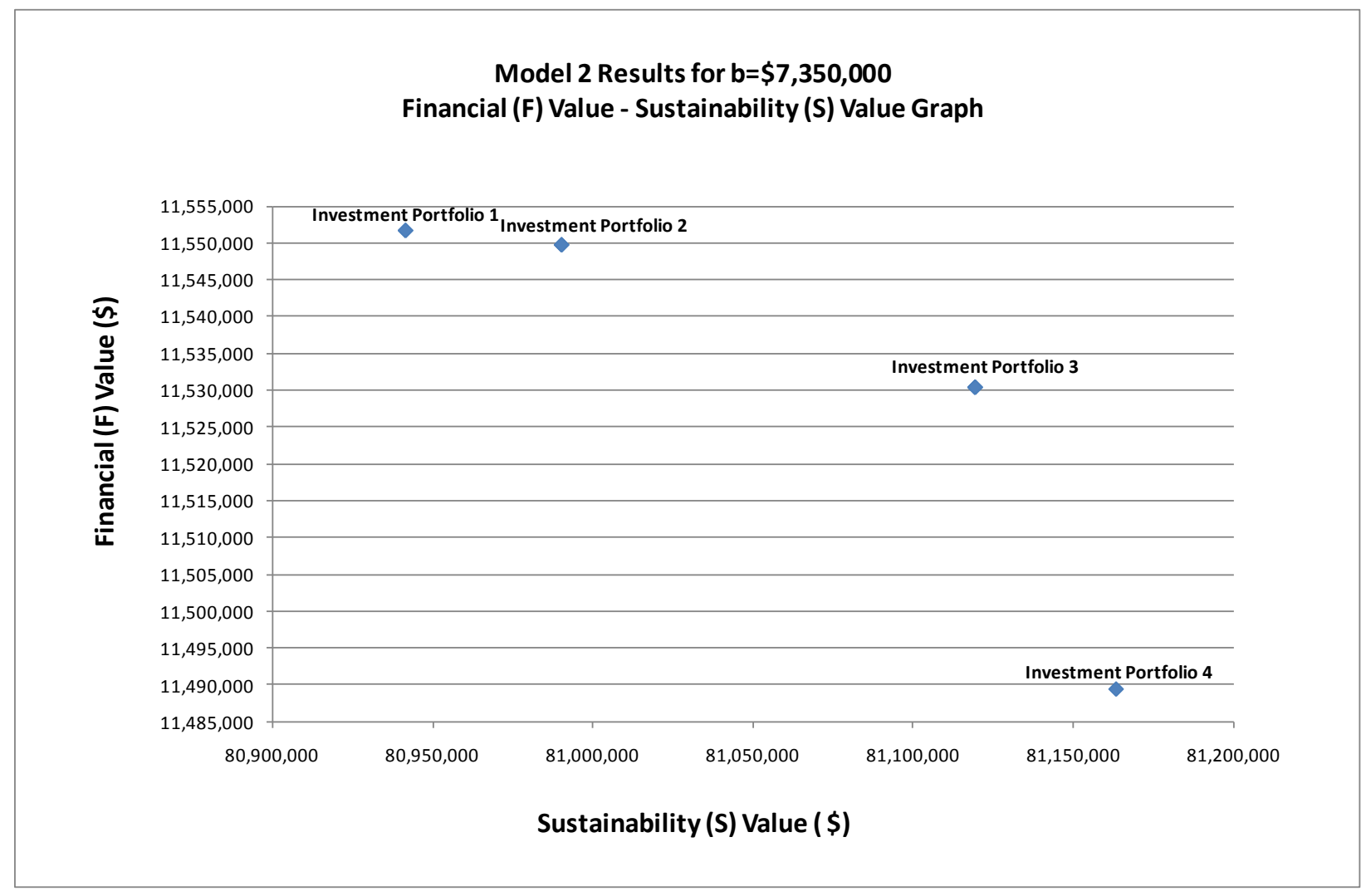

Figure 24: Model 2 results on Financial (F) Value - Sustainability (S) Value graph when initial wealth is $\$ 7,350,000$

Table 48: Analysis of Model 2 results when initial wealth is $\$ 7,350,000$

\begin{tabular}{|c|c|c|c|}
\hline \multicolumn{5}{|c|}{ Analysis of Model 2 Results for b=\$7,350,000 } \\
\hline $\begin{array}{c}\text { Investment } \\
\text { Portfolios }\end{array}$ & $\begin{array}{c}\text { Difference in } \\
\text { Financial (F) } \\
\text { Values (\$) }\end{array}$ & $\begin{array}{c}\text { Difference in } \\
\text { Sustainability (S) } \\
\text { Values (\$) }\end{array}$ & $\begin{array}{c}\text { Marginal } \\
\text { Improvement (S/F) }\end{array}$ \\
\hline 1 and 2 & 1,948 & 48,790 & 25.041 \\
\hline 2 and 3 & 19,344 & 129,316 & 6.685 \\
\hline 3 and 4 & 40,985 & 44,079 & 1.076 \\
\hline
\end{tabular}

Table 49 and Figure 25 show the results obtained with Model 2 when the initial wealth is set to $\$ 7,478,000$. Through the sensitivity analysis, this value represents the upper limit. Since the 
model has upper limit constraints for the investment amounts of all projects, values greater than $\$ 7,478,000$ for the initial wealth end up with infeasibility. Here, $\$ 7,478,000$ represents the maximum investment amount that can initially be invested to obtain a feasible solution under the given constraints. Similar to the cases when the initial wealth is set to $\$ 7,000,000$ and $\$ 7,350,000$, it generates four investment portfolios. To compare the four investment portfolios, Table 50 provides the ratio of the change in Financial (F) Value (\$) to change in Sustainability (S) Value (\$) when one shifts through the four investment portfolios. The details of the investment portfolios can be seen in Appendix G.1.

Table 49: Model 2 results when initial wealth is $\$ 7,478,000$

\begin{tabular}{|c|c|c|c|}
\hline \multicolumn{5}{|c|}{ Model 2 Results for b=\$7,478,000 } \\
\hline $\begin{array}{c}\text { Sustainability } \\
\text { Coefficient K }\end{array}$ & $\begin{array}{c}\text { Financial } \\
\text { (F) Value (\$) }\end{array}$ & $\begin{array}{c}\text { Sustainability } \\
\text { (S) Value (\$) }\end{array}$ & Investment Strategy \\
\hline 0 & $11,278,098$ & $80,448,706$ & Investment Portfolio 1 \\
\hline 0.0025 & $11,278,098$ & $80,448,706$ & Investment Portfolio 1 \\
\hline 0.05 & $11,276,150$ & $80,501,099$ & Investment Portfolio 2 \\
\hline 0.1 & $11,276,150$ & $80,501,099$ & Investment Portfolio 2 \\
\hline 0.2 & $11,275,688$ & $80,504,203$ & Investment Portfolio 3 \\
\hline 0.25 & $11,275,688$ & $80,504,203$ & Investment Portfolio 3 \\
\hline 0.5 & $11,275,688$ & $80,504,203$ & Investment Portfolio 3 \\
\hline 0.75 & $11,275,688$ & $80,504,203$ & Investment Portfolio 4 \\
\hline 0.8 & $11,275,688$ & $80,504,203$ & Investment Portfolio 4 \\
\hline 0.9 & $11,275,688$ & $80,504,203$ & Investment Portfolio 4 \\
\hline 1 & $11,234,705$ & $80,548,285$ & Investment Portfolio 4 \\
\hline 10 & $11,234,705$ & $80,548,285$ & Investment Portfolio 4 \\
\hline
\end{tabular}


Model 2 Results for $b=\$ 7,478,000$

Financial (F) Value - Sustainability (S) Value Graph

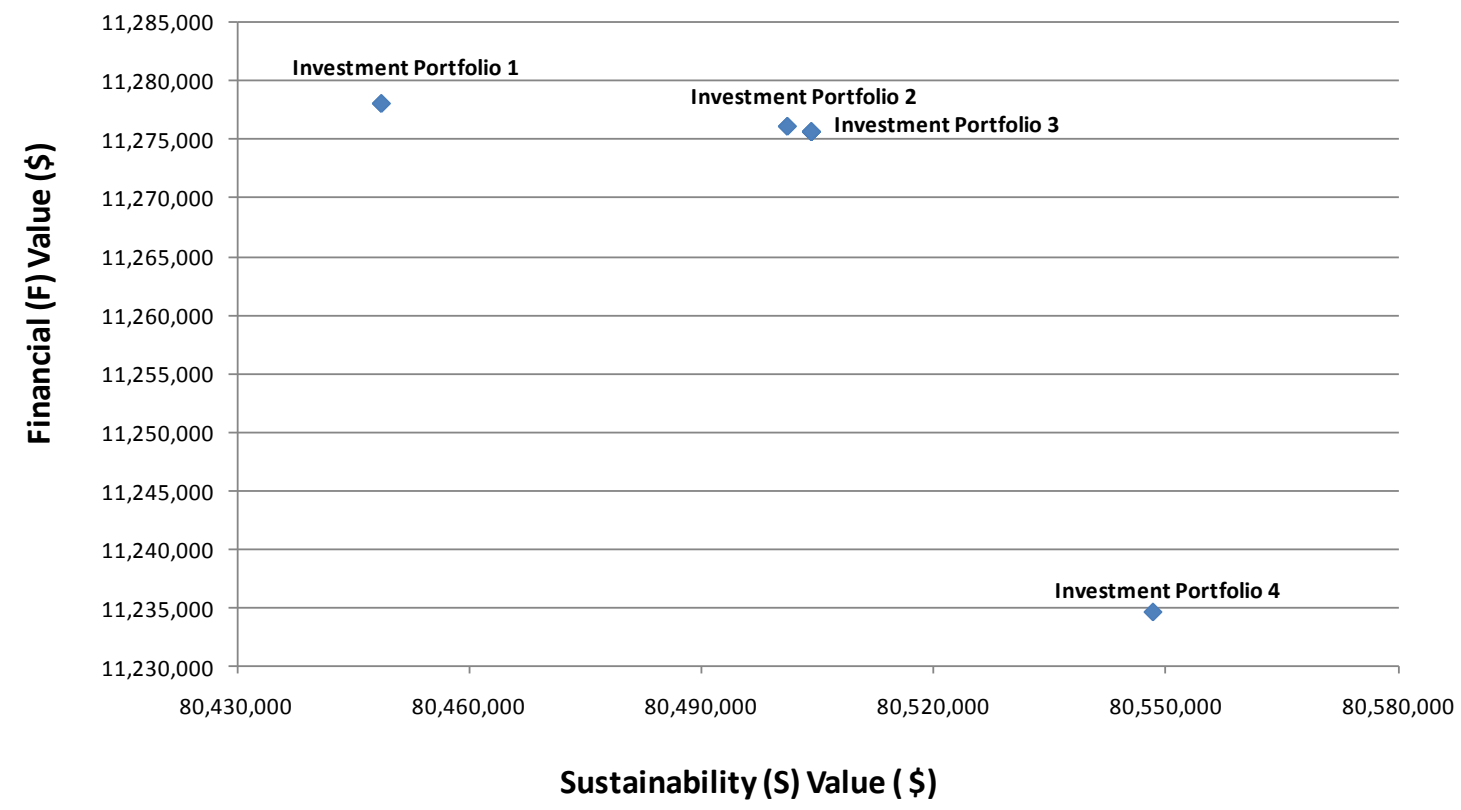

Figure 25: Model 2 results on Financial (F) Value - Sustainability (S) Value graph when initial wealth is $\$ 7,478,000$

Table 50: Analysis of Model 2 results when initial wealth is $\$ 7,478,000$

\begin{tabular}{|c|c|c|c|}
\hline \multicolumn{4}{|c|}{ Analysis of Model 2 Results for $\mathbf{b = \$ 7 , 4 7 8 , 0 0 0}$} \\
\hline $\begin{array}{c}\text { Investment } \\
\text { Portfolios }\end{array}$ & $\begin{array}{c}\text { Difference in } \\
\text { Financial (F) } \\
\text { Values (\$) }\end{array}$ & $\begin{array}{c}\text { Difference in } \\
\text { Sustainability (S) } \\
\text { Values (\$) }\end{array}$ & $\begin{array}{c}\text { Marginal } \\
\text { Improvement (S/F) }\end{array}$ \\
\hline 1 and 2 & 1,948 & 52,393 & 26.894 \\
\hline 2 and 3 & 462 & 3,105 & 6.723 \\
\hline 3 and 4 & 40,983 & 44,081 & 1.076 \\
\hline
\end{tabular}




\section{Results of Model 3:}

Table 51 and Figure 26 show the results obtained with Model 3 when the initial wealth is set to $\$ 283,000$. Since the model has lower limit constraints for the investment amounts of Project 1 (Compost) and Project 5 (LEED), values less than $\$ 283,000$ for the initial wealth end up being infeasible. Here, $\$ 283,000$ represents the minimum investment amount that is necessary to obtain a feasible solution under the given constraints. Model 2 generates only two investment portfolios limiting the options for the decision maker since the initial investment amount is very low. To compare the two investment portfolios, Table 52 provides the ratio of the change in Financial (F) Value (\$) to change in Sustainability (S) Value (\$) when one shifts from investment portfolio 1 to investment portfolio 2. The details of the investment portfolios can be seen in Appendix G.2.

Table 51: Model 3 results when initial wealth is $\$ 283,000$

\begin{tabular}{|c|c|c|c|}
\hline \multicolumn{4}{|c|}{ Model 3 Results for b=\$283,000 } \\
\hline $\begin{array}{c}\text { Sustainability } \\
\text { Coefficient K }\end{array}$ & $\begin{array}{c}\text { Financial } \\
\text { (F) Value (\$) }\end{array}$ & $\begin{array}{c}\text { Sustainability } \\
\text { (S) Value (\$) }\end{array}$ & Investment Strategy \\
\hline 0 & 523,981 & $2,026,842$ & Investment Portfolio 1 \\
\hline 0.5 & 523,981 & $2,026,842$ & Investment Portfolio 1 \\
\hline 0.75 & 523,981 & $2,026,842$ & Investment Portfolio 1 \\
\hline 0.8 & 523,981 & $2,026,842$ & Investment Portfolio 1 \\
\hline 0.9 & 523,981 & $2,026,842$ & Investment Portfolio 1 \\
\hline 1 & 484,344 & $2,069,476$ & Investment Portfolio 2 \\
\hline 2 & 484,344 & $2,069,476$ & Investment Portfolio 2 \\
\hline 10 & 484,344 & $2,069,476$ & Investment Portfolio 2 \\
\hline 100 & 484,344 & $2,069,476$ & Investment Portfolio 2 \\
\hline
\end{tabular}




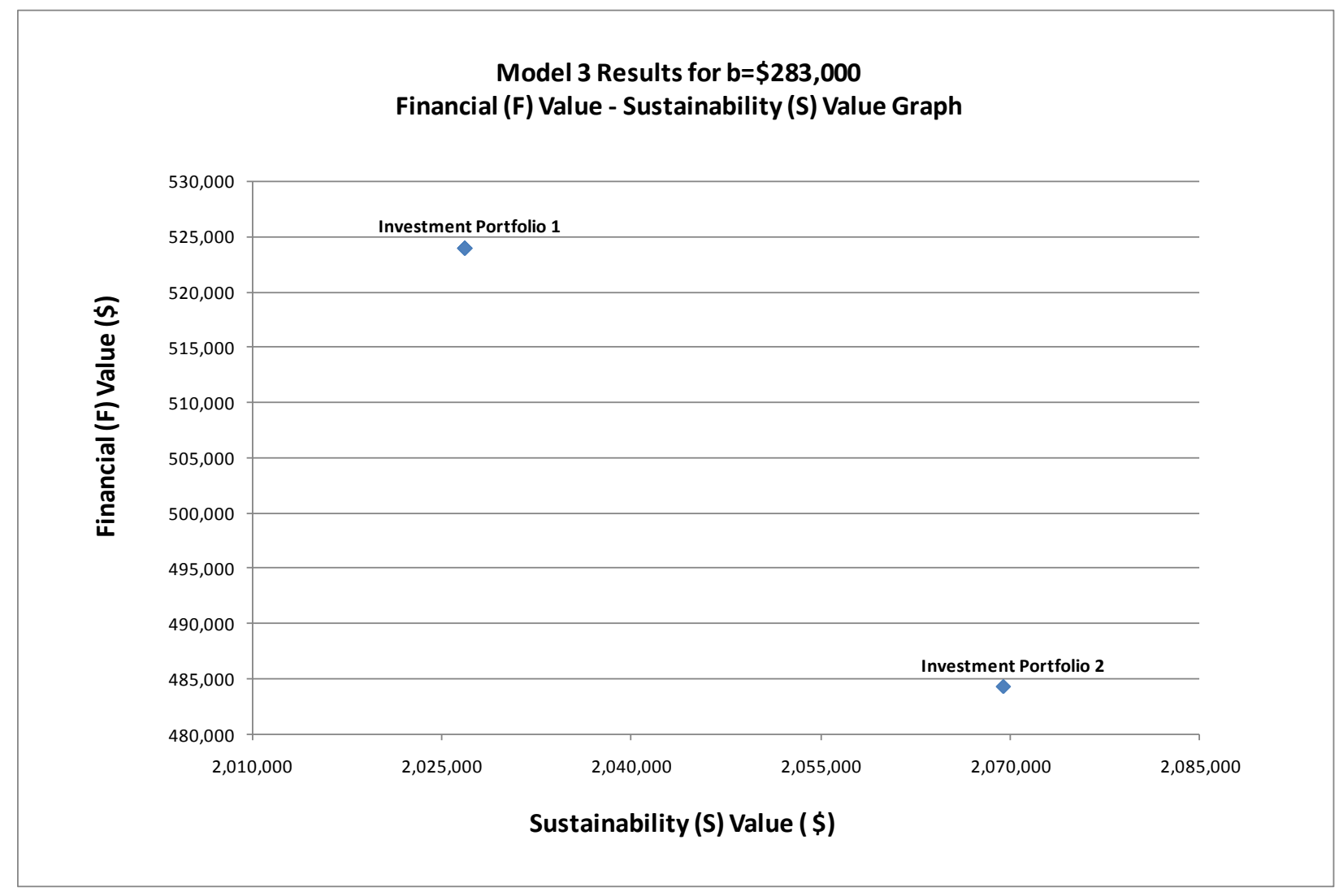

Figure 26: Model 3 results on Financial (F) Value - Sustainability (S) Value graph when initial wealth is $\$ 283,000$

Table 52: Analysis of Model 3 results when initial wealth is $\$ 283,000$

\begin{tabular}{|c|c|c|c|}
\hline \multicolumn{4}{|c|}{ Analysis of Model 3 Results for $\mathbf{b = \$ 2 8 3 , 0 0 0}$} \\
\hline $\begin{array}{c}\text { Investment } \\
\text { Portfolios }\end{array}$ & $\begin{array}{c}\text { Difference in } \\
\text { Financial (F) } \\
\text { Values (\$) }\end{array}$ & $\begin{array}{c}\text { Difference in } \\
\text { Sustainability (S) } \\
\text { Values (\$) }\end{array}$ & $\begin{array}{c}\text { Marginal } \\
\text { Improvement (S/F) }\end{array}$ \\
\hline 1 and 2 & 39,637 & 42,634 & 1.076 \\
\hline
\end{tabular}

Table 53 and Figure 27 show the results obtained with Model 3 when the initial wealth is set to $\$ 500,000$. It generates eight investment portfolios providing many options for the decision maker compared to the previous cases. There are two reasons for this. First, by limiting the investment 
amount on Project 4 (Transit) by $\$ 1,000,000$, dominance of this project over the others is alleviated. Second, the $\$ 500,000$ initial investment is relatively high compared to the minimum investment amount needed for feasibility (i.e., \$283,000). To compare the eight investment portfolios, Table 54 provides the ratio of the change in Financial (F) Value (\$) to change in Sustainability (S) Value (\$) when one shifts through the eight investment portfolios. The details of the investment portfolios can be seen in Appendix G.2.

Table 53: Model 3 results when initial wealth is $\$ 500,000$

\begin{tabular}{|c|c|c|c|}
\hline \multicolumn{4}{|c|}{ Model 3 Results for b=\$500,000 } \\
\hline $\begin{array}{c}\text { Sustainability } \\
\text { Coefficient K }\end{array}$ & $\begin{array}{c}\text { Financial } \\
\text { (F) Value (\$) }\end{array}$ & $\begin{array}{c}\text { Sustainability } \\
\text { (S) Value (\$) }\end{array}$ & Investment Strategy \\
\hline 0 & 966,449 & $4,747,718$ & Investment Portfolio 1 \\
\hline 0.025 & 966,449 & $4,747,718$ & Investment Portfolio 1 \\
\hline 0.05 & 965,799 & $4,764,699$ & Investment Portfolio 2 \\
\hline 0.0625 & 965,081 & $4,776,590$ & Investment Portfolio 3 \\
\hline 0.075 & 963,570 & $4,800,710$ & Investment Portfolio 4 \\
\hline 0.1 & 963,570 & $4,800,710$ & Investment Portfolio 4 \\
\hline 0.2 & 961,884 & $4,810,536$ & Investment Portfolio 5 \\
\hline 0.3 & 960,657 & $4,815,009$ & Investment Portfolio 6 \\
\hline 0.5 & 960,657 & $4,815,009$ & Investment Portfolio 6 \\
\hline 0.75 & 960,657 & $4,815,009$ & Investment Portfolio 6 \\
\hline 0.8 & 956,248 & $4,820,763$ & Investment Portfolio 7 \\
\hline 0.9 & 956,248 & $4,820,763$ & Investment Portfolio 7 \\
\hline 1 & 928,925 & $4,850,152$ & Investment Portfolio 8 \\
\hline 2 & 928,925 & $4,850,152$ & Investment Portfolio 8 \\
\hline 10 & 928,925 & $4,850,152$ & Investment Portfolio 8 \\
\hline 100 & 928,925 & $4,850,152$ & Investment Portfolio 8 \\
\hline
\end{tabular}




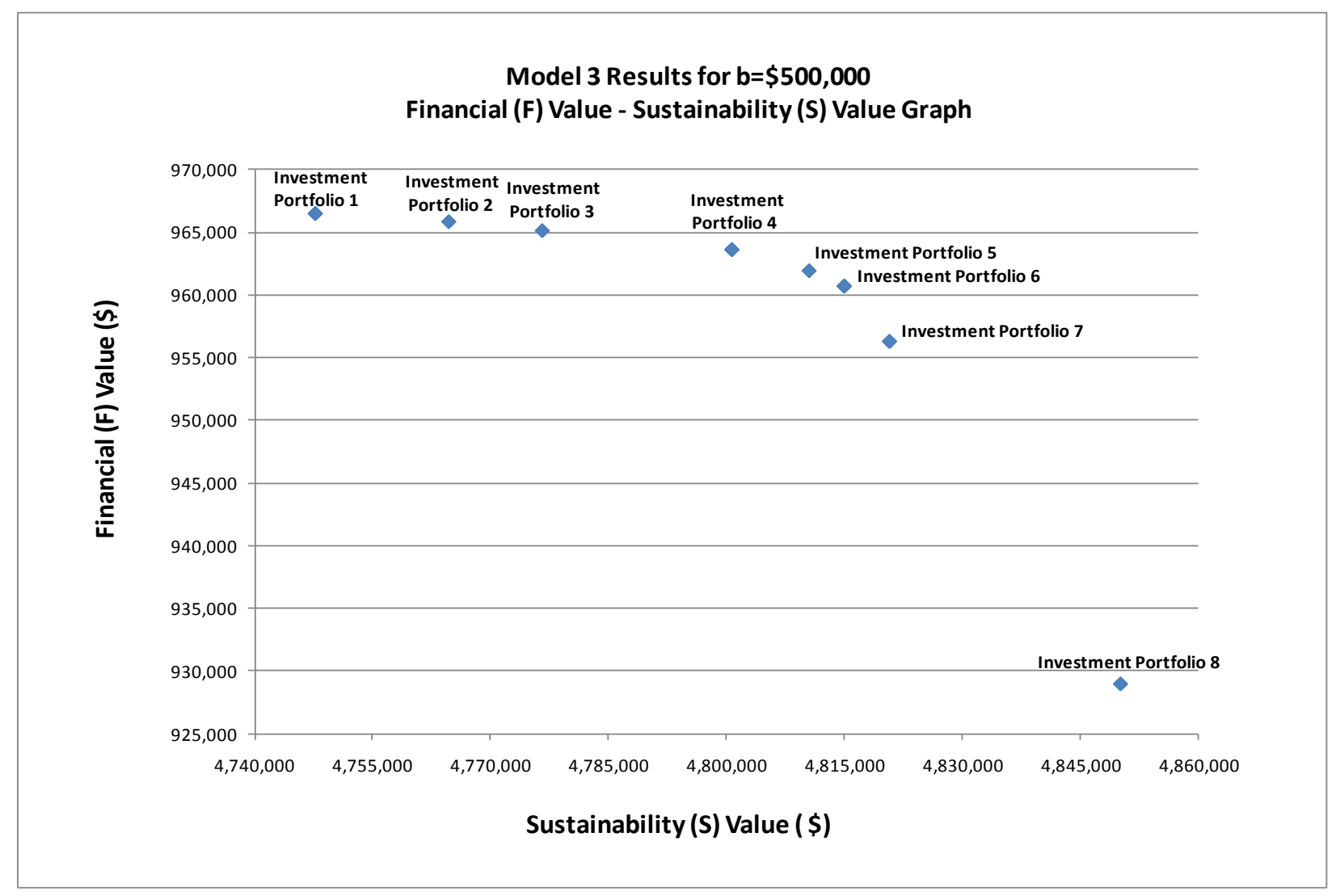

Figure 27: Model 3 results on Financial (F) Value - Sustainability (S) Value graph when initial wealth is $\$ 500,000$

Table 54: Analysis of Model 3 results when initial wealth is $\$ 500,000$

\begin{tabular}{|c|c|c|c|}
\hline \multicolumn{4}{|c|}{ Analysis of Model 3 Results for b=\$500,000 } \\
\hline $\begin{array}{c}\text { Investment } \\
\text { Portfolios }\end{array}$ & $\begin{array}{c}\text { Difference in } \\
\text { Financial (F) } \\
\text { Values (\$) }\end{array}$ & $\begin{array}{c}\text { Difference in } \\
\text { Sustainability (S) } \\
\text { Values (\$) }\end{array}$ & $\begin{array}{c}\text { Marginal } \\
\text { Improvement (S/F) }\end{array}$ \\
\hline 1 and 2 & 650 & 16,981 & 26.127 \\
\hline 2 and 3 & 718 & 11,891 & 16.563 \\
\hline 3 and 4 & 1,511 & 24,121 & 15.961 \\
\hline 4 and 5 & 1,686 & 9,826 & 5.827 \\
\hline 5 and 6 & 1,227 & 4,473 & 3.645 \\
\hline 6 and 7 & 4,409 & 5,754 & 1.305 \\
\hline 7 and 8 & 27,322 & 29,389 & 1.076 \\
\hline
\end{tabular}


Table 55 and Figure 28 show the results obtained with Model 3 when the initial wealth is set to $\$ 750,000$. Similar to the case when the initial wealth is set to $\$ 500,000$, the model provides many options (ten investment portfolios) for the decision maker. In fact, the number of investment portfolios increases from eight to ten since there is an increase from $\$ 500,000$ to $\$ 750,000$ in initial wealth. To compare the ten investment portfolios, Table 56 provides the ratio of the change in Financial (F) Value (\$) to change in Sustainability (S) Value (\$) when one shifts through the ten among investment portfolios. The details of the investment portfolios can be seen in Appendix G.2.

Table 55: Model 3 results when initial wealth is $\$ 750,000$

\begin{tabular}{|c|c|c|c|}
\hline \multicolumn{4}{|c|}{ Model 3 Results for b=\$750,000 } \\
\hline $\begin{array}{c}\text { Sustainability } \\
\text { Coefficient K }\end{array}$ & $\begin{array}{c}\text { Financial } \\
\text { (F) Value (\$) }\end{array}$ & $\begin{array}{c}\text { Sustainability } \\
\text { (S) Value (\$) }\end{array}$ & Investment Strategy \\
\hline 0 & 942,624 & $5,753,878$ & Investment Portfolio 1 \\
\hline 0.0025 & 942,624 & $5,753,878$ & Investment Portfolio 1 \\
\hline 0.025 & 942,390 & $5,767,661$ & Investment Portfolio 2 \\
\hline 0.05 & 942,390 & $5,767,661$ & Investment Portfolio 2 \\
\hline 0.1 & 941,634 & $5,779,717$ & Investment Portfolio 3 \\
\hline 0.2 & 941,574 & $5,780,256$ & Investment Portfolio 4 \\
\hline 0.25 & 940,131 & $5,786,189$ & Investment Portfolio 5 \\
\hline 0.3 & 939,904 & $5,786,992$ & Investment Portfolio 6 \\
\hline 0.5 & 917,066 & $5,840,763$ & Investment Portfolio 7 \\
\hline 0.75 & 917,066 & $5,840,763$ & Investment Portfolio 7 \\
\hline 0.8 & 917,066 & $5,840,763$ & Investment Portfolio 7 \\
\hline 0.9 & 917,066 & $5,840,763$ & Investment Portfolio 7 \\
\hline 1 & 912,234 & $5,845,962$ & Investment Portfolio 8 \\
\hline 2 & 909,631 & $5,847,770$ & Investment Portfolio 9 \\
\hline 10 & 906,362 & $5,848,615$ & Investment Portfolio 10 \\
\hline 100 & 906,362 & $5,848,615$ & Investment Portfolio 10 \\
\hline
\end{tabular}




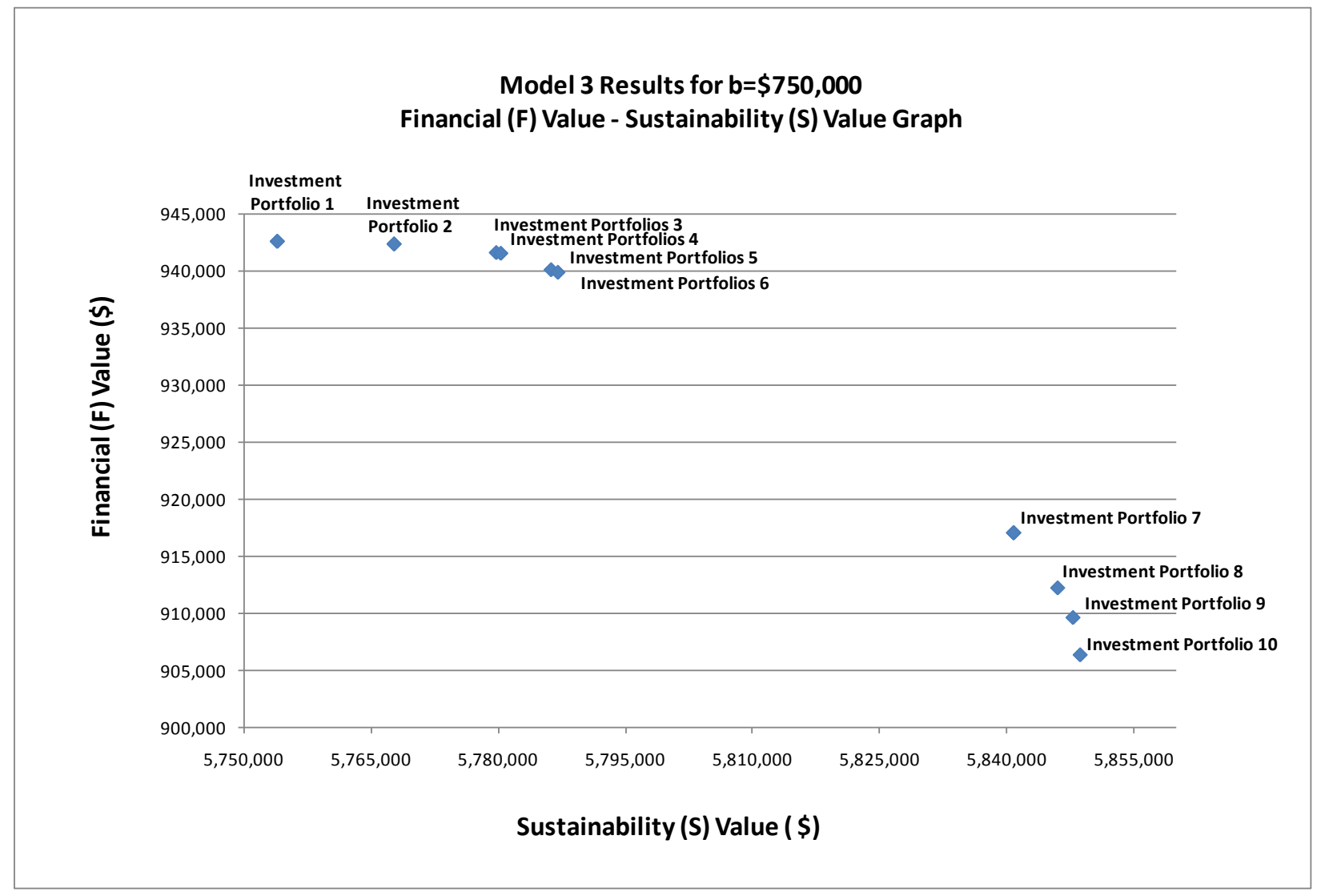

Figure 28: Model 3 results on Financial (F) Value - Sustainability (S) Value graph when initial wealth is $\$ 750,000$ 
Table 56: Analysis of Model 3 results when initial wealth is $\$ 750,000$

\begin{tabular}{|c|c|c|c|}
\hline \multicolumn{4}{|c|}{ Analysis of Model 3 Results for $\mathbf{b = \$ 7 5 0 , 0 0 0}$} \\
\hline $\begin{array}{c}\text { Investment } \\
\text { Portfolios }\end{array}$ & $\begin{array}{c}\text { Difference in } \\
\text { Financial (F) } \\
\text { Values (\$) }\end{array}$ & $\begin{array}{c}\text { Difference in } \\
\text { Sustainability (S) } \\
\text { Values (\$) }\end{array}$ & $\begin{array}{c}\text { Marginal } \\
\text { Improvement (S/F) }\end{array}$ \\
\hline 1 and 2 & 234 & 13,784 & 58.839 \\
\hline 2 and 3 & 756 & 12,056 & 15.954 \\
\hline 3 and 4 & 60 & 539 & 8.909 \\
\hline 4 and 5 & 1,443 & 5,933 & 4.111 \\
\hline 5 and 6 & 226 & 803 & 3.548 \\
\hline 6 and 7 & 22,838 & 53,772 & 2.354 \\
\hline 7 and 8 & 4,832 & 5,199 & 1.076 \\
\hline 8 and 9 & 2,603 & 1,808 & 0.694 \\
\hline 9 and 10 & 3,269 & 845 & 0.259 \\
\hline
\end{tabular}

Table 57 and Figure 29 show the results obtained with Model 3 when the initial wealth is set to $\$ 953,000$. Since the model has upper limit constraints for the investment amounts of all projects, values greater than $\$ 953,000$ for the initial wealth end up being infeasible. Here, $\$ 953,000$ represents the maximum investment amount that can initially be invested to obtain a feasible solution under the given constraints. In this case, the model generates four investment portfolios. The number of investment portfolio options decreases compared to the cases when the initial wealth is set to $\$ 500,000$ and $\$ 750,000$ because with a high initial investment, the investment amounts on the projects easily reach their upper limits. To compare the four investment portfolios, Table 58 provides the ratio of the change in Financial (F) Value (\$) to change in Sustainability (S) Value (\$) when one shifts through the four investment portfolios. The details of the investment portfolios can be seen in Appendix G.2. 
Table 57: Model 3 results when initial wealth is $\$ 953,000$

\begin{tabular}{|c|c|c|c|}
\hline \multicolumn{4}{|c|}{ Model 3 Results for b=\$953,000 } \\
\hline $\begin{array}{c}\text { Sustainability } \\
\text { Coefficient K }\end{array}$ & $\begin{array}{c}\text { Financial } \\
\text { (F) Value (\$) }\end{array}$ & $\begin{array}{c}\text { Sustainability } \\
\text { (S) Value (\$) }\end{array}$ & Investment Strategy \\
\hline 0 & 691,480 & $5,646,073$ & Investment Portfolio 1 \\
\hline 0.025 & 691,480 & $5,646,073$ & Investment Portfolio 1 \\
\hline 0.05 & 690,180 & $5,680,017$ & Investment Portfolio 2 \\
\hline 0.1 & 690,180 & $5,680,017$ & Investment Portfolio 2 \\
\hline 0.2 & 688,510 & $5,692,631$ & Investment Portfolio 3 \\
\hline 0.25 & 688,510 & $5,692,631$ & Investment Portfolio 3 \\
\hline 0.5 & 688,510 & $5,692,631$ & Investment Portfolio 3 \\
\hline 0.75 & 688,510 & $5,692,631$ & Investment Portfolio 3 \\
\hline 0.8 & 688,510 & $5,692,631$ & Investment Portfolio 3 \\
\hline 0.9 & 688,510 & $5,692,631$ & Investment Portfolio 3 \\
\hline 1 & 650,258 & $5,733,777$ & Investment Portfolio 4 \\
\hline 2 & 650,258 & $5,733,777$ & Investment Portfolio 4 \\
\hline 10 & 650,258 & $5,733,777$ & Investment Portfolio 4 \\
\hline
\end{tabular}


Model 3 Results for $b=\$ 953,000$

Financial (F) Value - Sustainability (S) Value Graph

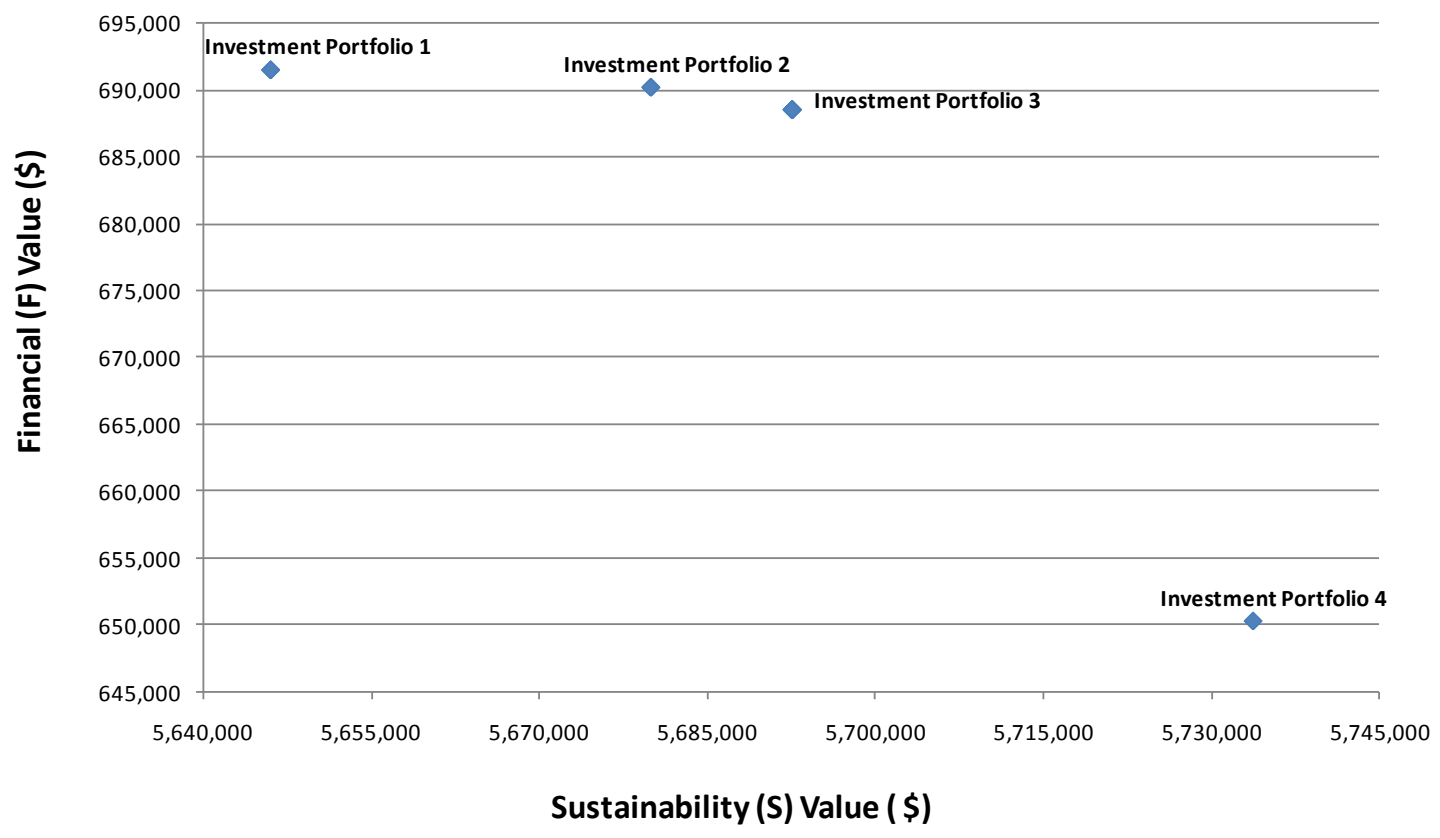

Figure 29: Model 3 results on Financial (F) Value - Sustainability (S) Value graph when initial wealth is $\$ 953,000$

Table 58: Analysis of Model 3 results when initial wealth is $\$ 953,000$

\begin{tabular}{|c|c|c|c|}
\hline \multicolumn{4}{|c|}{ Analysis of Model 3 Results for b=\$953,000 } \\
\hline $\begin{array}{c}\text { Investment } \\
\text { Portfolios }\end{array}$ & $\begin{array}{c}\text { Difference in } \\
\text { Financial (F) } \\
\text { Values (\$) }\end{array}$ & $\begin{array}{c}\text { Difference in } \\
\text { Sustainability (S) } \\
\text { Values (\$) }\end{array}$ & $\begin{array}{c}\text { Marginal } \\
\text { Improvement (S/F) }\end{array}$ \\
\hline 1 and 2 & 1,300 & 33,944 & 26.111 \\
\hline 2 and 3 & 1,671 & 12,614 & 7.550 \\
\hline 3 and 4 & 38,252 & 41,146 & 1.076 \\
\hline
\end{tabular}




\section{Results of Model 4:}

Table 59 and Figure 30 show the results obtained with Model 4 when the initial wealth is set to $\$ 500,000$. The model generates ten investment portfolios. As mentioned before, Model 4 is similar to Model 3 except that Project 3 (RECs) is replaced with Project 3 (Financial). By doing so, the percentage change on the Sustainability (S) Value axis is highly increased such that while in Figure 27 the Sustainability (S) Value increases from $\$ 4,747,718$ to $\$ 4,850,152$ (a $2.2 \%$ change), in Figure 30 it increases from $\$ 3,633,601$ to $\$ 4,842,230$ (a $33.3 \%$ change). Since Project 3 (RECs) is replaced with a primarily financial project, a notable increase is also observed on the percentage change of the Financial (F) Value axis. To compare the four investment portfolios, Table 60 provides the ratio of the change in Financial (F) Value (\$) to the change in Sustainability (S) Value (\$) when one shifts through the ten investment portfolios. The details of the investment portfolios can be seen in Appendix G.3. 
Table 59: Model 4 results when initial wealth is $\$ 500,000$

\begin{tabular}{|c|c|c|c|}
\hline \multicolumn{5}{|c|}{ Model 4 Results for b=\$500,000 } \\
\hline $\begin{array}{c}\text { Sustainability } \\
\text { Coefficient K }\end{array}$ & $\begin{array}{c}\text { Financial } \\
\text { (F) Value (\$) }\end{array}$ & $\begin{array}{c}\text { Sustainability } \\
\text { (S) Value } \mathbf{\$})\end{array}$ & Investment Strategy \\
\hline 0 & $1,172,279$ & $3,633,601$ & Investment Portfolio 1 \\
\hline 0.025 & $1,172,279$ & $3,633,601$ & Investment Portfolio 1 \\
\hline 0.05 & $1,172,279$ & $3,633,601$ & Investment Portfolio 1 \\
\hline 0.075 & $1,171,500$ & $3,646,689$ & Investment Portfolio 2 \\
\hline 0.1 & $1,117,984$ & $4,244,148$ & Investment Portfolio 3 \\
\hline 0.125 & $1,117,984$ & $4,244,150$ & Investment Portfolio 3 \\
\hline 0.15 & $1,107,383$ & $4,315,861$ & Investment Portfolio 4 \\
\hline 0.2 & $1,102,059$ & $4,344,388$ & Investment Portfolio 5 \\
\hline 0.25 & $1,016,101$ & $4,700,458$ & Investment Portfolio 6 \\
\hline 0.3 & 996,153 & $4,768,307$ & Investment Portfolio 7 \\
\hline 0.5 & 980,276 & $4,811,483$ & Investment Portfolio 8 \\
\hline 0.75 & 980,276 & $4,811,483$ & Investment Portfolio 8 \\
\hline 0.8 & 980,276 & $4,811,483$ & Investment Portfolio 8 \\
\hline 0.9 & 980,276 & $4,811,483$ & Investment Portfolio 8 \\
\hline 1 & 952,953 & $4,840,872$ & Investment Portfolio 9 \\
\hline 2 & 951,500 & $4,842,230$ & Investment Portfolio 10 \\
\hline 10 & 951,500 & $4,842,230$ & Investment Portfolio 10 \\
\hline 100 & 951,500 & $4,842,230$ & Investment Portfolio 10 \\
\hline
\end{tabular}


Model 4 Results for $b=\$ 500,000$

Financial (F) Value - Sustainability (S) Value Graph

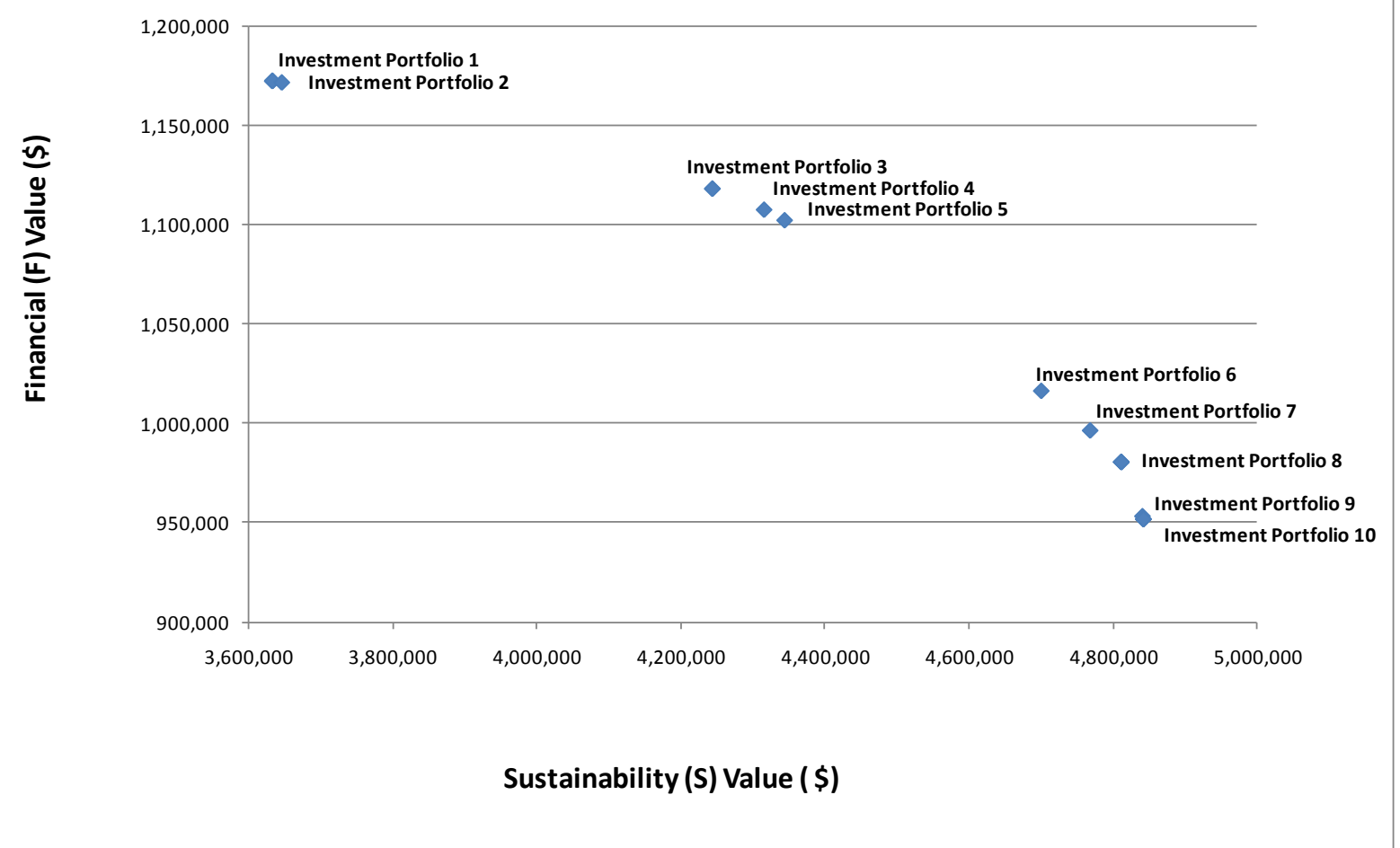

Figure 30: Model 4 results on Financial (F) Value - Sustainability (S) Value graph when initial wealth is $\$ 500,000$ 
Table 60: Analysis of Model 4 results when initial wealth is $\$ 500,000$

\begin{tabular}{|c|c|c|c|}
\hline \multicolumn{4}{|c|}{ Analysis of Model 4 Results for $\mathbf{b = \$ 5 0 0 , 0 0 0}$} \\
\hline $\begin{array}{c}\text { Investment } \\
\text { Portfolios }\end{array}$ & $\begin{array}{c}\text { Difference in } \\
\text { Financial (F) } \\
\text { Values (\$) }\end{array}$ & $\begin{array}{c}\text { Difference in } \\
\text { Sustainability (S) } \\
\text { Values (\$) }\end{array}$ & $\begin{array}{c}\text { Marginal } \\
\text { Improvement (S/F) }\end{array}$ \\
\hline 1 and 2 & 779 & 13,088 & 16.809 \\
\hline 2 and 3 & 53,516 & 597,459 & 11.164 \\
\hline 3 and 4 & 10,601 & 71,711 & 6.764 \\
\hline 4 and 5 & 5,323 & 28,526 & 5.359 \\
\hline 5 and 6 & 85,959 & 356,070 & 4.142 \\
\hline 6 and 7 & 19,948 & 67,849 & 3.401 \\
\hline 7 and 8 & 15,878 & 43,176 & 2.719 \\
\hline 8 and 9 & 27,322 & 29,389 & 1.076 \\
\hline 9 and 10 & 1,453 & 1,358 & 0.935 \\
\hline
\end{tabular}

\subsection{IMPLEMENTATION AND VALIDATION}

Since the developed managerial decision-making tool involves both qualitative and quantitative aspects, it is difficult to fully validate the tool given one case study. However, experience gained with the demonstration and the Cranberry Township case study provides valuable insight on whether the developed tool is helpful in making "good/reasonable" decisions. In that sense, the objective of this section is to provide the comments and feedback from the experts whom we collaborated with for the Cranberry Township case study on the applicability, usefulness, helpfulness, and face validity of the developed tool in making "reasonable" decisions.

- Feedback from Cranberry Township management: Since the planning horizon considered in this study is nine years, and the organization specific information is confidential, the actual 
implementation process and outcomes of the Cranberry Township case study has not been observed. However, John Trant - the Chief Strategic Planning Officer of the township commented that the developed tool added significant value to the management of sustainable development practices as a useful decision support tool. He especially mentioned that the tool was useful in quantifying the sustainability impacts of organizational initiatives and activities. Regarding the applicability and validity of the tool, his major concern was about whether it was possible to add other projects in the future to the assessment and investment planning process. However, this will not be an issue since the tool is very flexible, and the applied process can be repeated at any point in the planning horizon depending on the changes in available projects, involved stakeholder groups, and their perceptions/expectations. In addition, it is always reasonable to receive the feedback of the stakeholder groups periodically throughout the planning horizon even if there is no significant change to the conditions since the main objective of the tool is not to put a strict plan but to provide valuable insight to make "reasonable" decisions. However, for these updates, the township management will need technical assistance since the developed tool has not had a user interface yet.

- Feedback from Sustainable Pittsburgh: As mentioned before, the projects considered in the Cranberry Township case study were the recommendations made to the township management by Sustainable Pittsburgh experts. For this reason, by providing an implementation and investment strategy for the recommended projects, the developed tool contributes to the initiatives taken by Sustainable Pittsburgh in the local region. Dr. Matthew Mehalik - Program Manager of Sustainable Pittsburgh commented that the developed tool was useful and could be applied easily to other similar organizations. For instance, a potential 
future case study that is of interest to the research team is to apply the developed tool on Vandergrift, a town located at approximately 40 miles east of the City of Pittsburgh. He also stated that in addition to the governmental organizations, the tool could be applied to private companies. Since the primary objective of an enterprise is to make profit, final results obtained from a private company will be different than those obtained from a municipality. And, finally, he indicated that at the macro level, the developed tool could be used by governments while making planning decisions related to their sustainability initiatives.

Although "face validation" provides a noteworthy reference for a methodological decision making tool, observation of the implementation process and the actual implementation outcomes will strengthen the validity of this tool. Further case studies coupled with implementation will ultimately provide proper validation. Additionally, using a good literature base for the tool is one form of validation, as well as validation of the developed stochastic linear program. 


\subsection{LIMITATIONS AND CRITIQUES}

The major limitations and critiques regarding to the developed tool can be summarized as the following:

- Difficulty in integrating all of the stakeholder groups into the process: Due to limitations in resources such as time, it is difficult to perform the ANP study with all of the stakeholder groups. For instance, in the Cranberry Township case study, although all of the major stakeholder groups were considered in the ANP model, only five representatives from these groups were able to participate in the ANP study and only two stakeholder groups were represented in the case study. For this reason, the results of the case study might have been somewhat skewed. However, this limitation can easily be avoided in the future by training the stakeholders in the process and making use of technology. For instance, it is possible to construct a website in which stakeholders can be trained about the process and have the ANP study through the Internet. This may improve the quality of final results and provide a more "democratic" decision-making environment by integrating many different perspectives into the decision-making process and creating a "mind of society" as whole.

- The burden of a large amount of pairwise comparisons in the AHP/ANP methodology:

In the literature, there are several criticisms of the AHP and ANP methodologies. For 
instance, when a new alternative is added to the decision problem, the rankings of the existing alternatives can change (Gass, 2005; Goodwin, 2004). In addition, because AHP and ANP models often require a large number of pairwise comparisons, the judgments made by decision makers can be taxing. In 1995, Olson et al. showed that the requirement to answer a large number of questions reduced the attractiveness of AHP in the eyes of decision makers although the questions themselves were considered to be easy. However, in this research the AHP/ANP model is an appropriate project portfolio management approach for organizational sustainability due to several reasons. First, organizational sustainability requires a long-term perspective; hence the evaluation and prioritization of potential projects is a strategic decision not a periodic tactical or routine operational decision. Further, because of the complexity of the organizational sustainability concept AHP/ANP actually allows for a more practical approach than other methods. Finally, although there are some literature based applications of AHP/ANP on project selection (Lee and Kim, 2000; Meade and Presley, 2002; Cheng and Li, 2005; Mohanty et al., 2005; Dikmen et al., 2007), an AHP/ANP approach to organizational sustainability is relatively new.

- The effort that is spent to collect quantitative data such as IRR values for the alternative projects: To make reasonable decisions, quantitative data is essential, and IRR is a popular method that is used in capital budgeting and investment decisions. For the cases where there are too many investment projects, it is possible for decision makers to collaborate with outside agents such as consulting companies. They can easily ask a consulting company to perform feasibility studies for the potential project that they plan to invest and determine their IRR values. 
- The computational burden of solving large scale stochastic linear programs: For the cases where the planning horizon consists of too many periods, it may be problematic to solve the large scale stochastic linear program. However, the literature provides some heuristic methods to solve such problems. Although these methods may not always yield the optimal solution, it is relatively easy to obtain near optimal solutions with these heuristic methods.

The balance among these limitations shifts from one to the other depending on the number of decision makers, criteria that are used in the AHP/ANP methodology, alternative investment projects, etc. 


\subsection{SUMMARY OF MAJOR RESEARCH FINDINGS}

\subsection{SUMMARY}

In this research, a comprehensive, new managerial decision-making tool for organizational sustainability was developed by examining the research questions and related considerations stated in Chapter 4. This section summarizes how and to what extent these research questions are answered and the related considerations are handled throughout the research. Basically, for the research questions, a multi-stage stochastic linear program was developed to be used to create an optimal balanced investment plan for a set of alternative projects. This program uses not only the financial measures that are traditionally used in investment planning and capital budgeting decisions, but also the non-financial ones related to sustainability issues by considering the perspectives of stakeholder groups. Perspectives of stakeholder groups on sustainability issues are integrated into the multi-stage stochastic linear program by utilizing the previous related management tools, group decision making and decision analysis techniques found in the literature or used in practice. The following discussion provides detailed explanation about how these tools and techniques are utilized and the research questions are answered.

First, Chapter 5 provides an extensive literature review and discussion on the formation and development of management tools for organizational sustainability from an evolutionary perspective. It first focuses on non-financial performance measures that of the Balanced 164 
Scorecard (BSC) and the Triple Bottom Line (TBL) accounting system as the tools and methods developed for performance management and cost management. Then, it discusses the Sustainability Balanced Scorecard (SBSC) and Wang and Lin's (2007) sustainability optimization model as the tools developed to manage organizational sustainability.

As mentioned, most traditional management practices focus on shareholder-centered performance. Although they seem to provide successful results in the short-term, they potentially end up with failures in the long-run as they do not take into account the impacts of their organization's activities to their stakeholders (beyond just the shareholders). The tool developed in this research focuses on stakeholder-centered performance, and targets success not only in the short-term, but also in the long-term by enabling decision makers to understand the perceptions, views and expectations of their stakeholders with respect to their organization's activities, and the related economic, environmental and social issues. The developed tool provides a platform to integrate not only the shareholders, but also the suppliers, employees, customers, NGOs, financial partners (banks, insurance companies, etc.), regulators and public authorities, and local, national and international communities into the decision making process. By targeting success in the long-term in addition to success in the short-term, and considering the economic, environmental and social issues, it implicitly considers new generations as a stakeholder group.

The ANP methodology is used to quantify the perspectives, views and expectations of stakeholder groups with respect to organizational activities, and related economic, environmental and social issues. By using the results of the ANP study while making investment and capital budgeting decisions, the developed tool enables an organization to be perceived as sustainable from those different perspectives. Further, by assigning a specific weight to the perspective of each stakeholder group, decision makers can keep their preference, initiative, or power in 
strategic decisions, and determine the degree of sustainability perceived by each stakeholder group at the end of the planning horizon since they formally take into account each stakeholder's opinion in their sustainability related decisions. The higher the weight given to the perspective of a specific stakeholder group, the closer the final investment plan to that specific stakeholder group's perspective. As a result, this indirectly enables decision makers to determine the degree of satisfaction of each stakeholder group at the end of the planning horizon.

Although the primary objective of this research is not to develop sustainability performance criteria, it extensively makes use of the related literature. For instance, for the generic ANP sustainability model provided in Section 7.1.1, it makes use of the sustainability criteria set developed by Wang and Lin (2007). For the Cranberry Township case study, in addition to the Wang and Lin (2007) criteria set, it makes use of the Santa Monica sustainability criteria set. While categorizing these sustainability criteria, it accepts the TBL framework as a basis (i.e., economic, environmental, and social sustainability criteria). The ANP methodology also helps to quantify these criteria and to determine their importance with respect to stakeholder perceptions which enables the decision makers to improve their organization's stakeholdercentered performance.

The main model of the generic ANP model provided in Section 7.1.1 is a benefits, opportunities, costs, risks (BOCR) model. While evaluating and prioritizing the project alternatives, it makes use of the TBL sustainability criteria set and perceptions of stakeholder groups. Hence, the developed tool naturally deals with the trade-offs and risks among the financial, environmental and social impacts of organizational activities and projects on different stakeholder groups. 
With an optimization model that considers the uncertainty of the future, the developed tool assists decision makers in improving or even maximizing the sustainability of their organization by answering the question "Which projects should be selected, at what point should these projects be selected, and to what level should an organization invest in these projects to improve or even maximize its sustainability?"

The objective function of the developed multi-stage stochastic linear program is a multiobjective function whose dimensions are financial $(\mathrm{F})$ value and sustainability $(\mathrm{S})$ value. By determining the magnitude of the sustainability coefficient $(\mathrm{K})$, decision makers have the ability to deal with the trade-off between the financial $(\mathrm{F})$ value and sustainability $(\mathrm{S})$ value.

Lastly, the final output of the research enables decision makers to assess different investment portfolios with respect to multiple characteristics of the organization (i.e., economic, environmental and social). For instance, as the final output, alternative investment portfolios are mapped on the financial value-sustainability value $(\mathrm{F}-\mathrm{S})$ graph so that decision makers can select the investment portfolio that matches with their strategy on each of these characteristics.

\subsection{CONTRIBUTION FROM AN ACADEMIC PERSPECTIVE}

This research has several important contributions from an academic perspective. First, sustainability is a relatively new and emerging research field. Due to global economic, environmental and social problems, scientists' focus on it has tremendously increased in recent years. However, the literature still provides very limited information about it. Moreover, there are just a few quantitative approaches to managing sustainability practices and related issues. In 
that sense, by providing one of the first sustainability optimization models in the literature, this research has a unique contribution from an academic perspective. The developed multi-stage stochastic linear program integrates the qualitative information (i.e., contribution of alternative projects to organizational sustainability) into the decision-making process in addition to quantitative information (i.e., internal rate of returns of alternative projects). More importantly, it

explicitly considers uncertainty in the model which is not an aspect of the optimization model developed by Wang and Lin (2007).

Second, by involving many different fields such as engineering management and economics, finance, environmental and social sciences, and making use of a variety of tools including stakeholder theory, AHP/ANP methodology and stochastic linear programming, it is a demonstration of interdisciplinary research.

Third, it minimizes the gap between the theory and practice by providing a systematic methodology to solve a complex decision making problem which involves both qualitative and quantitative aspects, and a high amount of uncertainty. It is thought that the developed tool can assist decision makers with developing and making proactive decisions which support the strategy of their organization with respect to economic, environmental and social issues, ensuring the sustainability of their organization in the future.

\subsection{CONTRIBUTION FROM DECISION MAKER'S PERSPECTIVE}

In addition to the contributions from an academic perspective, this research also provides important contributions from a decision maker's perspective. For instance, it supplies the need 
for a single, overarching management tool that will combine the three dimensions of sustainability - economic, environmental and social - with the organization's overall strategy. Moreover, it enables policy makers, and corporate and engineering managers to deal with the trade-offs and risks among the financial, environmental and social impacts of their investment and capital budgeting decisions.

Finally, as a whole, it contributes to the creation of a sustainability culture both in academic world and business environment, and encourages other communities for sustainable development through the Cranberry Township case study. 


\subsection{FUTURE RESEARCH DIRECTIONS}

This research provides several future research directions. Depending on the future needs and conditions, one can focus on one or more of the following possible future research directions:

- Applying the developed tool on other real life cases: Based on the needs and requirements of the participating organization and decision makers, it can be extended in several ways. First, although for a governmental organization such as Cranberry Township management, environmental and social sustainability are as important as financial sustainability, for a private profit seeking company, financial sustainability has the priority. For this reason, applying the tool to a private profit-seeking company may result in quite different results. Besides that, the attitude of the decision makers toward risk plays an important role on the results. For instance, if the decision maker is risk-seeking, the priorities associated with the benefits and opportunities subnetworks of the ANP model provided in Section 7.1 can be of primary interest. On the other hand, if the decision maker is risk-averse, attention may be given to the priorities obtained from the costs and risks subnetworks.

- Applying the Delphi method in cases where conflict occurs: The decision making process for a single decision maker is relatively simple as compared to the process for a complicated problem containing multiple criteria and requiring the collaborative work of a group of 
experts. Without a systematic group decision making process, it may be difficult to arrive at a final decision (or even it is possible to commit an error) due to certain barriers such as nonconformity on the principle of anonymity and domination of the whole group by dominant individuals. In order to overcome these typical problems, in 1959, Olaf Helmer, Nicholas Rescher and Morman Dalkey developed the Delphi method as a group decision making tool (Helmer and Rescher, 1959). Then, Linstone and Turoff (1975) provided a comprehensive study about the Delphi method including its philosophy, applications, limitations and future in their book The Delphi Method: Techniques and Applications. The method has two basic elements: anonymity which means that no one knows anything about the others who are participating in the study and feedback which is feeding back the reasons of extreme opinions to the group for further analysis (Gordon, 1994). It is an iterative process, and consists of a series of questionnaires that are sent to the pre-determined group of experts and after each questionnaire round, the experts are asked to reassess their responses based on the feedback of the previous round which is summarized and given by the researcher. In general, this feedback consists of the range of opinions and reasons for extreme views. In that sense, the Delphi method can be considered as a controlled debate (Gordon, 1994) and can be used while determining the several coefficients used in the tool such as sustainability coefficient $(\mathrm{K})$ if any conflict occurs. However, before applying the Delphi method, its drawbacks should be considered. For instance, its major drawback is the time that it takes such that a single round can easily require three weeks and a three-round Delphi can take at least three or four months, including the preparation and analysis time (Gordon, 1994). 
- Updating and/or making changes on the TBL sustainability index system: As the world and business environment change, sustainability performance criteria change. For this reason, they need to be reviewed periodically and updated as required. Possible changes include eliminating some of the criteria, adding industry/organization specific criteria or changing the hierarchy and category of some criteria.

- Performing sensitivity analysis: To arrive at a good decision, it is necessary to perform sensitivity analysis. In this research, the stochastic linear program already takes into account the uncertainty; and some sensitivity analysis is already provided. However, it is possible to perform further sensitivity analysis on the AHP/ANP study results, coefficients used in the tool, and financial analyses of the alternative projects.

- Using other multicriteria decision making (MCDM) tools instead of AHP/ANP methodology: Instead of AHP/ANP methodology, several other MCDM tools such as utility theory and non-traditional capital investment criteria (NCIC) methodology can be used. However, before using them one should carefully judge their advantages and disadvantages by considering the requirements and nature of the specific application case.

- Varying certain assumptions: The demonstration and Cranberry Township case study provided in Chapters 8 and 9, respectively have several assumptions related to the number of alternative projects, number of possible economic scenarios, number of periods for the planning horizon, etc. By eliminating some of these assumptions, a large scale multi-stage stochastic linear program can be developed and solution methodologies such as heuristic methods can be investigated. 
- Developing software with a user-friendly interface: It is desirable for decision makers to be able to use the tool independently, without outside assistance as needed. For this reason, a possible future extension would be to develop a user-friendly software interface. 
APPENDIX A

TRIPLE BOTTOM LINE SUSTAINABILITY INDEX SYSTEM 
Triple bottom line sustainability index system (Wang and Lin, 2007)

\begin{tabular}{|c|c|c|c|c|}
\hline Category & & Index & & Sub-index \\
\hline \multirow[t]{4}{*}{$\begin{array}{l}\text { Economic } \\
\text { prosperity }\end{array}$} & $\mathrm{EC}_{1}$ & Shareholder's value & $\begin{array}{l}\mathrm{EC}_{11} \\
\mathrm{EC}_{12} \\
\mathrm{EC}_{13}\end{array}$ & $\begin{array}{l}\text { Sales } \\
\text { Profit } \\
\text { Debt-equity ratio }\end{array}$ \\
\hline & $\mathrm{EC}_{2}$ & Customer loyalty & $\begin{array}{l}\mathrm{EC}_{21} \\
\mathrm{EC}_{22}\end{array}$ & $\begin{array}{l}\text { Customer retention rate } \\
\text { Market share }\end{array}$ \\
\hline & $\mathrm{EC}_{3}$ & Employee loyalty & $\begin{array}{l}\mathrm{EC}_{31} \\
\mathrm{EC}_{32}\end{array}$ & $\begin{array}{l}\text { Employee retention rate } \\
\text { Hiring yield rate }\end{array}$ \\
\hline & $\mathrm{EC}_{4}$ & Industry specific & $\begin{array}{l}\mathrm{EC}_{41} \\
\mathrm{EC}_{42}\end{array}$ & $\begin{array}{l}\text { Board strength } \\
\text { R\&D investment }\end{array}$ \\
\hline \multirow[t]{2}{*}{$\begin{array}{l}\text { Environmental } \\
\text { quality }\end{array}$} & $\mathrm{EN}_{1}$ & $\begin{array}{l}\text { Environmental } \\
\text { performance }\end{array}$ & $\begin{array}{l}\mathrm{EN}_{11} \\
\mathrm{EN}_{12} \\
\mathrm{EN}_{13} \\
\mathrm{EN}_{14} \\
\mathrm{EN}_{15} \\
\mathrm{EN}_{16}\end{array}$ & $\begin{array}{l}\text { Energy consumption } \\
\text { Resource consumption } \\
\text { Water use } \\
\text { Land use } \\
\text { Non-hazardous waste generation } \\
\text { Emissions of greenhouse gases }\end{array}$ \\
\hline & $\mathrm{EN}_{2}$ & Industry specific & $\begin{array}{l}\mathrm{EN}_{21} \\
\mathrm{EN}_{22}\end{array}$ & $\begin{array}{l}\text { Environmental policy } \\
\text { Green product stewardship }\end{array}$ \\
\hline \multirow[t]{3}{*}{ Social justice } & $\mathrm{SC}_{1}$ & $\begin{array}{l}\text { Health and safety } \\
\text { performance }\end{array}$ & $\begin{array}{l}\mathrm{SC}_{11} \\
\mathrm{SC}_{13}\end{array}$ & $\begin{array}{l}\text { Lost-time accidents } \\
\text { Cost of claim }\end{array}$ \\
\hline & $\mathrm{SC}_{2}$ & $\begin{array}{l}\text { Human and minority } \\
\text { rights }\end{array}$ & $\begin{array}{l}\mathrm{SC}_{21} \\
\mathrm{SC}_{22}\end{array}$ & $\begin{array}{l}\text { Minority professionals } \\
\text { Women professionals }\end{array}$ \\
\hline & $\mathrm{SC}_{3}$ & Social responsibility & $\begin{array}{l}\mathrm{SC}_{31} \\
\mathrm{SC}_{32}\end{array}$ & $\begin{array}{l}\text { Donations in community } \\
\text { development } \\
\text { Supplier's sustainability } \\
\text { performance }\end{array}$ \\
\hline $\begin{array}{l}\text { Eco- } \\
\quad \text { environmental }\end{array}$ & $\mathrm{EE}_{1}$ & Eco-efficiency & $\begin{array}{l}\mathrm{EE}_{11} \\
\mathrm{EE}_{12}\end{array}$ & $\begin{array}{l}\text { Reuse rate } \\
\text { Recycling rate }\end{array}$ \\
\hline \multirow[t]{2}{*}{ Eco-social } & $\mathrm{ES}_{1}$ & Community development & $\mathrm{ES}_{11}$ & Job creation \\
\hline & $\mathrm{ES}_{2}$ & Employee trust & $\begin{array}{l}\mathrm{ES}_{21} \\
\mathrm{ES}_{22}\end{array}$ & $\begin{array}{l}\text { Investment in employee training } \\
\text { Employee benefits }\end{array}$ \\
\hline $\begin{array}{l}\text { Socio- } \\
\quad \text { environmental }\end{array}$ & $\mathrm{SE}_{1}$ & Toxicity & $\begin{array}{l}\mathrm{SE}_{11} \\
\mathrm{SE}_{12}\end{array}$ & $\begin{array}{l}\text { Hazardous waste disposed } \\
\text { Air emission }\end{array}$ \\
\hline \multirow[t]{2}{*}{$\begin{array}{l}\text { Eco-socio- } \\
\text { environmental }\end{array}$} & $\mathrm{ESE}_{1}$ & $\begin{array}{l}\text { Culture development } \\
\text { in sustainability }\end{array}$ & $\begin{array}{l}\mathrm{ESE}_{11} \\
\mathrm{ESE}_{12}\end{array}$ & $\begin{array}{l}\text { Sustainability management system } \\
\text { Sustainability audit and } \\
\text { communication }\end{array}$ \\
\hline & $\mathrm{ESE}_{2}$ & $\begin{array}{l}\text { Corporate license to } \\
\text { operate }\end{array}$ & $\begin{array}{l}\mathrm{ESE}_{21} \\
\mathrm{ESE}_{22}\end{array}$ & $\begin{array}{l}\text { Non-compliance to regulations } \\
\text { Corporate image and reputation }\end{array}$ \\
\hline
\end{tabular}




\section{APPENDIX B}

\section{THREE-STAGE STOCHASTIC LINEAR PROGRAM - NUMERIC MODEL}

\section{Objective function:}

$$
\begin{aligned}
& \operatorname{Max} Z= \\
& 0.125 y_{111}+0.125 y_{112}+0.125 y_{121}+0.125 y_{122}+0.125 y_{211}+0.125 y_{212}+0.125 y_{221}+0.125 y_{222} \\
& -0.5 w_{111}-0.5 w_{112}-0.5 w_{121}-0.5 w_{122}-0.5 w_{211}-0.5 w_{212}-0.5 w_{221}-0.5 w_{222} \\
& +K(0.333334)\left(1.2 x_{11}+1.15 x_{21}+1.15 x_{31}+1.1 x_{41}+1.4 x_{51}+0.6 x_{121}+0.575 x_{221}+0.575\right. \\
& x_{321}+0.55 x_{421}+0.7 x_{521}+0.6 x_{122}+0.575 x_{222}+0.575 x_{322}+0.55 x_{422}+0.7 x_{522}+0.3 x_{1311}+ \\
& 0.2875 x_{2311}+0.2875 x_{3311}+0.275 x_{4311}+0.35 x_{5311}+0.3 x_{1312}+0.2875 x_{2312}+0.2875 x_{3312}+ \\
& 0.275 x_{4312}+0.35 x_{5312}+0.3 x_{1321}+0.2875 x_{2321}+0.2875 x_{3321}+0.275 x_{4321}+0.35 x_{5321}+0.3 \\
& x_{1322}+0.2875 x_{2322}+0.2875 x_{3322}+0.275 x_{4322}+0.35 x_{5322} \\
& +K(0.333334)\left(1.4 x_{11}+1.1 x_{21}+1.05 x_{31}+1.3 x_{41}+1.15 x_{51}+0.7 x_{121}+0.55 x_{221}+0.525 x_{321}\right. \\
& +0.65 x_{421}+0.575 x_{521}+0.7 x_{122}+0.55 x_{222}+0.525 x_{322}+0.65 x_{422}+0.575 x_{522}+0.35 x_{1311}+ \\
& 0.275 x_{2311}+0.2625 x_{3311}+0.325 x_{4311}+0.2875 x_{5311}+0.35 x_{1312}+0.275 x_{2312}+0.2625 x_{3312}+
\end{aligned}
$$




$$
\begin{aligned}
& 0.325 x_{4312}+0.2875 x_{5312}+0.35 x_{1321}+0.275 x_{2321}+0.2625 x_{3321}+0.325 x_{4321}+0.2875 x_{5321}+ \\
& 0.35 x_{1322}+0.275 x_{2322}+0.2625 x_{3322}+0.325 x_{4322}+0.2875 x_{5322} \\
& +K(0.333334)\left(1.15 x_{11}+1.4 x_{21}+1.1 x_{31}+1.2 x_{41}+1.15 x_{51}+0.575 x_{121}+0.7 x_{221}+0.55 x_{321}\right. \\
& +0.6 x_{421}+0.575 x_{521}+0.575 x_{122}+0.7 x_{222}+0.55 x_{322}+0.6 x_{422}+0.575 x_{522}+0.2875 x_{1311}+ \\
& 0.35 x_{2311}+0.275 x_{3311}+0.3 x_{4311}+0.2875 x_{5311}+0.2875 x_{1312}+0.35 x_{2312}+0.275 x_{3312}+0.3 \\
& x_{4312}+0.2875 x_{5312}+0.2875 x_{1321}+0.35 x_{2321}+0.275 x_{3321}+0.3 x_{4321}+0.2875 x_{5321}+0.2875 \\
& x_{1322}+0.35 x_{2322}+0.275 x_{3322}+0.3 x_{4322}+0.2875 x_{5322}
\end{aligned}
$$

S. t.

\section{First constraint is to invest the initial wealth on $M$ projects:}

$x_{11}+x_{21}+x_{31}+x_{41}+x_{51}=55$

\section{Constraints for period 2:}

$-1.14 x_{11}-1.09 x_{21}-1.08 x_{31}-1.11 x_{41}-1.25 x_{51}+x_{121}+x_{221}+x_{321}+x_{421}+x_{521}=0$

$-1.12 x_{11}-1.01 x_{21}-1.07 x_{31}-1.06 x_{41}-1.06 x_{51}+x_{122}+x_{222}+x_{322}+x_{422}+x_{522}=0$

\section{Constraints for period 3:}

$-1.14 x_{121}-1.09 x_{221}-1.08 x_{321}-1.11 x_{421}-1.25 x_{521}+x_{1311}+x_{2311}+x_{3311}+x_{4311}+x_{5311}=0$

$-1.12 x_{121}-1.01 x_{221}-1.07 x_{321}-1.06 x_{421}-1.06 x_{521}+x_{1312}+x_{2312}+x_{3312}+x_{4312}+x_{5312}=0$

$-1.14 x_{122}-1.09 x_{222}-1.08 x_{322}-1.11 x_{422}-1.25 x_{522}+x_{1321}+x_{2321}+x_{3321}+x_{4321}+x_{5321}=0$

$-1.12 x_{122}-1.01 x_{222}-1.07 x_{322}-1.06 x_{422}-1.06 x_{522}+x_{1322}+x_{2322}+x_{3322}+x_{4322}+x_{5322}=0$

\section{Shortage and surplus constraints:}

$$
\begin{aligned}
& 1.14 x_{1311}+1.09 x_{2311}+1.08 x_{3311}+1.11 x_{4311}+1.25 x_{5311}-y_{111}+w_{111}=80 \\
& 1.12 x_{1311}+1.01 x_{2311}+1.07 x_{3311}+1.06 x_{4311}+1.06 x_{5311}-y_{112}+w_{112}=80 \\
& 1.14 x_{1312}+1.09 x_{2312}+1.08 x_{3312}+1.11 x_{4312}+1.25 x_{5312}-y_{121}+w_{121}=80
\end{aligned}
$$


$1.12 x_{1312}+1.01 x_{2312}+1.07 x_{3312}+1.06 x_{4312}+1.06 x_{5312}-y_{122}+w_{122}=80$

$1.14 x_{1321}+1.09 x_{2321}+1.08 x_{3321}+1.11 x_{4321}+1.25 x_{5321}-y_{211}+w_{211}=80$

$1.12 x_{1321}+1.01 x_{2321}+1.07 x_{3321}+1.06 x_{4321}+1.06 x_{5321}-y_{212}+w_{212}=80$

$1.14 x_{1322}+1.09 x_{2322}+1.08 x_{3322}+1.11 x_{4322}+1.25 x_{5322}-y_{221}+w_{221}=80$

$1.12 x_{1322}+1.01 x_{2322}+1.07 x_{3322}+1.06 x_{4322}+1.06 x_{5322}-y_{222}+w_{222}=80$

Trivial constraints:

$\begin{array}{llll}x_{11}>=0 & x_{422}>=0 & x_{3321}>=0 & y_{212}>=0 \\ x_{21}>=0 & x_{522}>=0 & x_{4321}>=0 & y_{221}>=0 \\ x_{31}>=0 & x_{1311}>=0 & x_{5321}>=0 & y_{222}>=0 \\ x_{41}>=0 & x_{2311}>=0 & x_{1322}>=0 & w_{111}>=0 \\ x_{51}>=0 & x_{3311}>=0 & x_{2322}>=0 & w_{112}>=0 \\ x_{121}>=0 & x_{4311}>=0 & x_{3322}>=0 & w_{121}>=0 \\ x_{221}>=0 & x_{5311}>=0 & x_{4322}>=0 & w_{221}>=0 \\ x_{321}>=0 & x_{1312}>=0 & x_{5322}>=0 & w_{222}>=0 \\ x_{421}>=0 & x_{2312}>=0 & y_{111}>=0 & w_{122}>=0 \\ x_{521}>=0 & x_{3312}>=0 & y_{211}>=0 & w_{211}>=0 \\ x_{122}>=0 & x_{4312}>=0 & y_{122}>=0 & w_{212}>=0 \\ x_{222}>=0 & x_{1321}>=0 & y_{121}>=0 & \\ x_{322}>=0 & x_{2321}>=0 & y_{112}>=0 & \end{array}$


APPENDIX C

INVESTMENT STRATEGIES PROPOSED BY PORTFOLIOS 1, 3 AND 5

Investment strategies proposed by investment portfolios 1,3 and 5

\begin{tabular}{|c|c|c|c|c|}
\hline $\begin{array}{c}\text { Planning } \\
\text { horizon }\end{array}$ & $\begin{array}{l}\text { Investment } \\
\text { amount (\$) }\end{array}$ & $\begin{array}{l}\text { Investment } \\
\text { portfolio } 1\end{array}$ & $\begin{array}{l}\text { Investment } \\
\text { portfolio } 3\end{array}$ & $\begin{array}{l}\text { Investment } \\
\text { portfolio } 5\end{array}$ \\
\hline \multirow{5}{*}{ 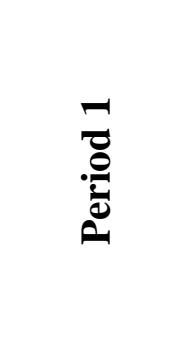 } & $x(1,1)$ & 13.520 & 0.000 & 0.000 \\
\hline & $x(2,1)$ & 0.000 & 0.000 & 0.000 \\
\hline & $x(3,2)$ & 0.000 & 0.000 & 0.000 \\
\hline & $x(4,1)$ & 0.000 & 0.000 & 0.000 \\
\hline & $x(5,1)$ & 41.479 & 55.000 & 55.000 \\
\hline \multirow{10}{*}{ 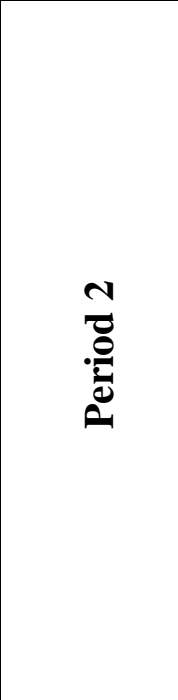 } & $x(1,2,1)$ & 2.168 & 0.000 & 0.000 \\
\hline & $x(2,2,1)$ & 0.000 & 0.000 & 0.000 \\
\hline & $x(3,2,1)$ & 0.000 & 0.000 & 0.000 \\
\hline & $x(4,2,1)$ & 0.000 & 0.000 & 0.000 \\
\hline & $x(5,2,1)$ & 65.094 & 68.750 & 68.750 \\
\hline & $x(1,2,2)$ & 22.368 & 13.149 & 0.000 \\
\hline & $x(2,2,2)$ & 0.000 & 0.000 & 0.000 \\
\hline & $x(3,2,2)$ & 0.000 & 0.000 & 0.000 \\
\hline & $x(4,2,2)$ & 0.000 & 0.000 & 0.000 \\
\hline & $x(5,2,2)$ & 36.743 & 45.150 & 58.300 \\
\hline
\end{tabular}




\begin{tabular}{|c|c|c|c|c|}
\hline $\begin{array}{l}\text { Planning } \\
\text { horizon }\end{array}$ & $\begin{array}{l}\text { Investment } \\
\text { amount (\$) }\end{array}$ & $\begin{array}{c}\text { Investment } \\
\text { portfolio } 1\end{array}$ & $\begin{array}{c}\text { Investment } \\
\text { portfolio } 3\end{array}$ & $\begin{array}{l}\text { Investment } \\
\text { portfolio } 5\end{array}$ \\
\hline \multirow{20}{*}{ ? } & $x(1,3,1,1)$ & 0.000 & 85.937 & 85.937 \\
\hline & $x(2,3,1,1)$ & 0.000 & 0.000 & 0.000 \\
\hline & $x(3,3,1,1)$ & 0.000 & 0.000 & 0.000 \\
\hline & $x(4,3,1,1)$ & 0.000 & 0.000 & 0.000 \\
\hline & $x(5,3,1,1)$ & 83.839 & 0.000 & 0.000 \\
\hline & $x(1,3,1,2)$ & 71.428 & 72.875 & 72.875 \\
\hline & $x(2,3,1,2)$ & 0.000 & 0.000 & 0.000 \\
\hline & $x(3,3,1,2)$ & 0.000 & 0.000 & 0.000 \\
\hline & $x(4,3,1,2)$ & 0.000 & 0.000 & 0.000 \\
\hline & $x(5,3,1,2)$ & 0.000 & 0.000 & 0.000 \\
\hline & $x(1,3,2,1)$ & 71.428 & 71.428 & 72.875 \\
\hline & $x(2,3,2,1)$ & 0.000 & 0.000 & 0.000 \\
\hline & $x(3,3,2,1)$ & 0.000 & 0.000 & 0.000 \\
\hline & $x(4,3,2,1)$ & 0.000 & 0.000 & 0.000 \\
\hline & $x(5,3,2,1)$ & 0.000 & 0.000 & 0.000 \\
\hline & $x(1,3,2,2)$ & 0.000 & 0.000 & 61.798 \\
\hline & $x(2,3,2,2)$ & 0.000 & 0.000 & 0.000 \\
\hline & $x(3,3,2,2)$ & 0.000 & 0.000 & 0.000 \\
\hline & $x(4,3,2,2)$ & 0.000 & 0.000 & 0.000 \\
\hline & $x(5,3,2,2)$ & 64.000 & 71.428 & 0.000 \\
\hline
\end{tabular}




\section{APPENDIX D}

\section{DOCUMENTS USED FOR THE CASE STUDY}

Appendix D provides the copies of the documents that were used for the Cranberry Township case study. These documents include Case Study Request Document, Stakeholder Notification Document, and Checklist for Stakeholder Meetings Document.

\section{D.1 CASE STUDY REQUEST DOCUMENT}

Case Study Request Document was used for the initial contact with the potential case study organizations to ask whether they are interested in the research and developed tool.

\section{Copy of Case Study Request Document}

Project/Research title: Integration of Financial and Non-financial Performance Measures into the Process of Project Portfolio Management, Investment Planning and Budgeting Decisions under Uncertainty - A Multi-Stage Stochastic Linear Program that can be used to Improve Organizational Sustainability 
Project/Research description: In today's rapidly changing global world, the sustainability of an organization depends not only upon its financial performance, but also upon its environmental and social performance. It is suggested that policy makers, and corporate and engineering managers integrate economic, environmental and social objectives (i.e., the triple bottom line (TBL)) into their overall strategic plan and consider these objectives in their decision making. Investment planning and capital budgeting decisions play a critical role in aligning an organization with its economic, environmental and social strategic objectives. This research introduces a new decision making tool that integrates both financial and non-financial performance measures into the process of investment planning and capital budgeting via the TBL. It makes use of stakeholder theory for group decision making, analytic hierarchy process (AHP) and/or analytic network process (ANP) as a decision support tool, and stochastic linear programming to create an optimal investment portfolio. This new tool evaluates and prioritizes a set of projects and creates a long-term balanced investment portfolio based upon the perspectives and priorities of the stakeholder groups and decision makers. It can assist decision makers with developing and making proactive decisions which support the strategy of their organization with respect to economic, environmental and social issues, ensuring the sustainability of their organization in the future.

Aim of the effort: It is thought that applying and validating the developed tool on a real life case will be not only an interesting case study, but also quite beneficial for both the researchers and related organization's management. In that sense, the aim of this effort is to discuss the details of the case study request among the researchers and organization's management. This includes how 
the organization and researchers will benefit from the collaboration, how the process would proceed and what the expected time frame for the study.

\section{Contact information:}

\section{Kim L. Needy, Ph.D., P.E., CFPIM}

Professor and Department Head

Department of Industrial Engineering

University of Arkansas

4207 Bell Engineering Center

Fayetteville, AR 72701

Tel: (479) 575-6029 (office)

Fax: (479) 575-8431

kneedy@uark.edu

\section{Fikret K. Turan, M.S.}

Ph.D. Student

Department of Industrial Engineering

University of Pittsburgh

1048 Benedum Hall

Pittsburgh, PA 15261

Tel: (412) 715-5105 (mobile)

Fax: (412) 624-9831

fkt1@pitt.edu 


\section{What are the potential benefits to the case study organization?}

- The study will closely match the organization's strategic objectives and sustainability culture.

- It will enable the organization's management to create an investment planning strategy for a predetermined planning horizon through the evaluation of a set of potential investment projects by considering their impacts on the organization's major stakeholders such as shareholders, NGO's, employees, customers, suppliers, etc.

- It will assist the organization's management in answering "In which projects, when and how much should they invest to improve or even maximize the sustainability of their organization?"

\section{What are the benefits to the researchers?}

- The study will be an interesting real life application since it will allow the researchers to test and validate the management tool that is developed as a doctoral dissertation thesis and can be used to improve organizational sustainability.

- The study can be published in the future as a conference/journal paper while maintaining strict confidentiality on all sensitive organizational data.

- It is an opportunity to minimize the gap between the theory and practice in sustainability related research and create a sustainability culture.

\section{How will the study unfold?}

- Review of the organization's performance measurement system: The similarity of the organization's performance measurement system and Wang and Lin's TBL sustainability index system will be checked and the preplanning values of the performance measures that 
are currently used in the organization will be saved. If necessary, new performance measures including the organization and/or industry specific ones will be added.

- Data collection:

i. Quantitative data

1. A reasonable planning horizon and an investment budget will be determined.

2. A set of potential investment projects that are planned to be invested during the planning horizon are identified including their internal rate of return (IRR), and minimum and maximum investment requirements.

ii. Qualitative data

1. An AHP/ANP study will be performed by meeting with the organization's management and representatives of the major stakeholder groups.

- Validation: By face validity and/or comparing the preplanning values of the performance measures with their values at the end of the planning horizon, the developed management tool will be validated.

\section{What is the expected time frame for the whole process?}

- Review of the organization's performance measurement system: 1 month

- Data collection: 2 months

- Model run: 2 months

- Reporting: 2 months

- Validation: 1 month 


\section{What will be the final result or output of the study?}

By evaluating each potential investment project based on its contribution to not only the financial performance but also the environmental and social performance of the organization, the study aims to assist the organization's management in creating the optimal investment portfolio which will improve or even maximize the sustainability of their organization. For example, the graph shown below contains numeric output from an illustrative case:

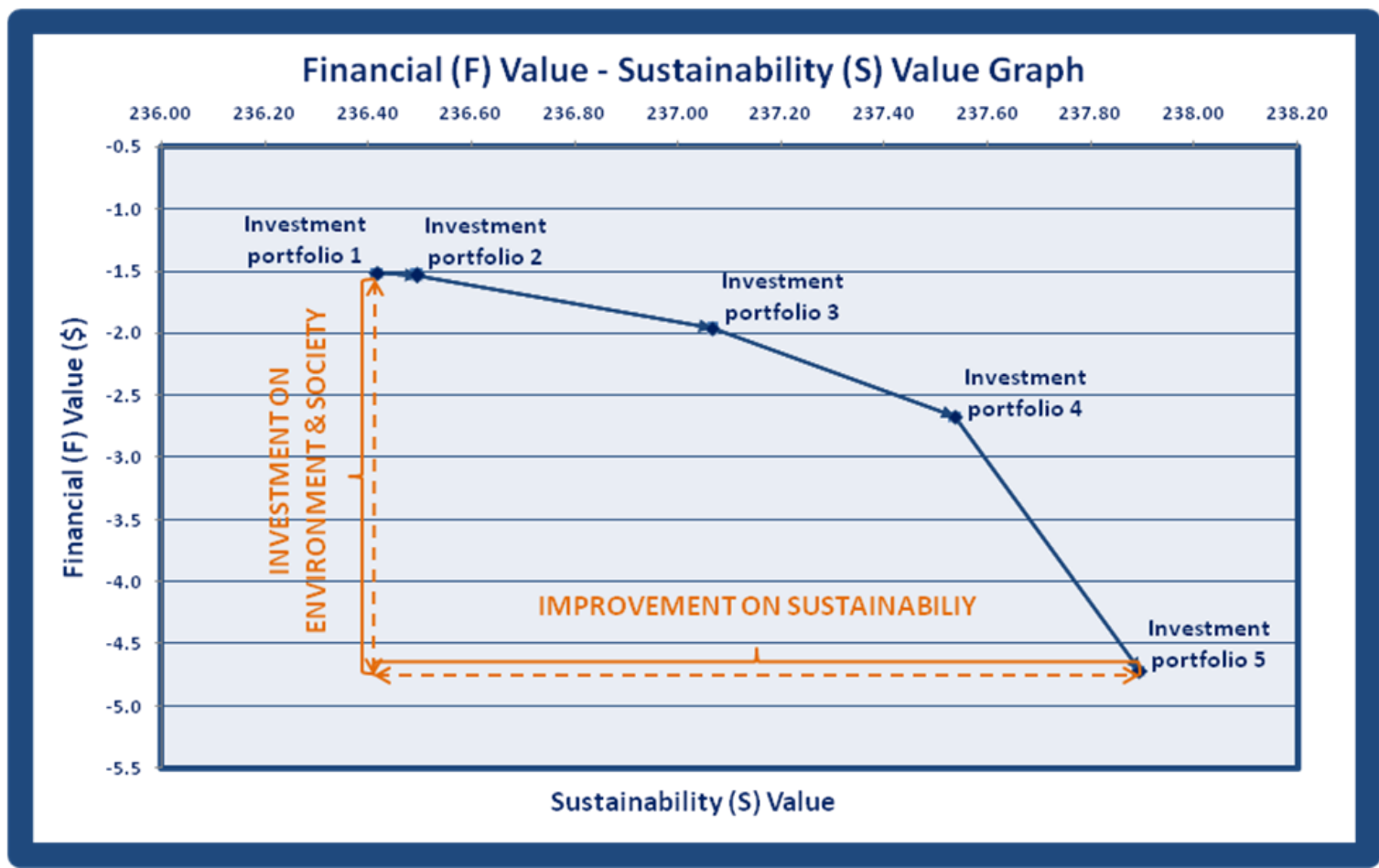

The graph shows five different investment portfolios obtained after running the model on this test case. Among these five, investment portfolio 3 is the optimal one since it provides the maximum $(F+S)$ value which is around $\$ 235.1037$ million, or alternatively since it provides the maximum marginal benefit in terms of environmental and social sustainability. 
On the other hand, investment portfolio 1 provides an investment strategy which considers only the economic concerns. For this reason, it provides the minimum sustainability value which is $\$ 236.4187$ million. And, investment portfolio 5 provides an investment strategy which takes into account the environmental and social concerns at the maximum level in addition to the economic concerns. By investing $\$ 3.2025$ million (i.e., $(-1.5140)-(-4.7165)=3.2025)$ on the environment and society, investment portfolio 5 improves the sustainability value of the organization from $\$ 236.4187$ million to $\approx \$ 237.89$ million. Sensitivity analysis can also be performed in this type of analysis to account for the uncertainty associated with the estimation of project costs and benefits. 


\section{D.2 INITIAL AND INTERIM VERSIONS OF THE ANP MODEL FOR CRANBERRY TOWNSHIP CASE STUDY}

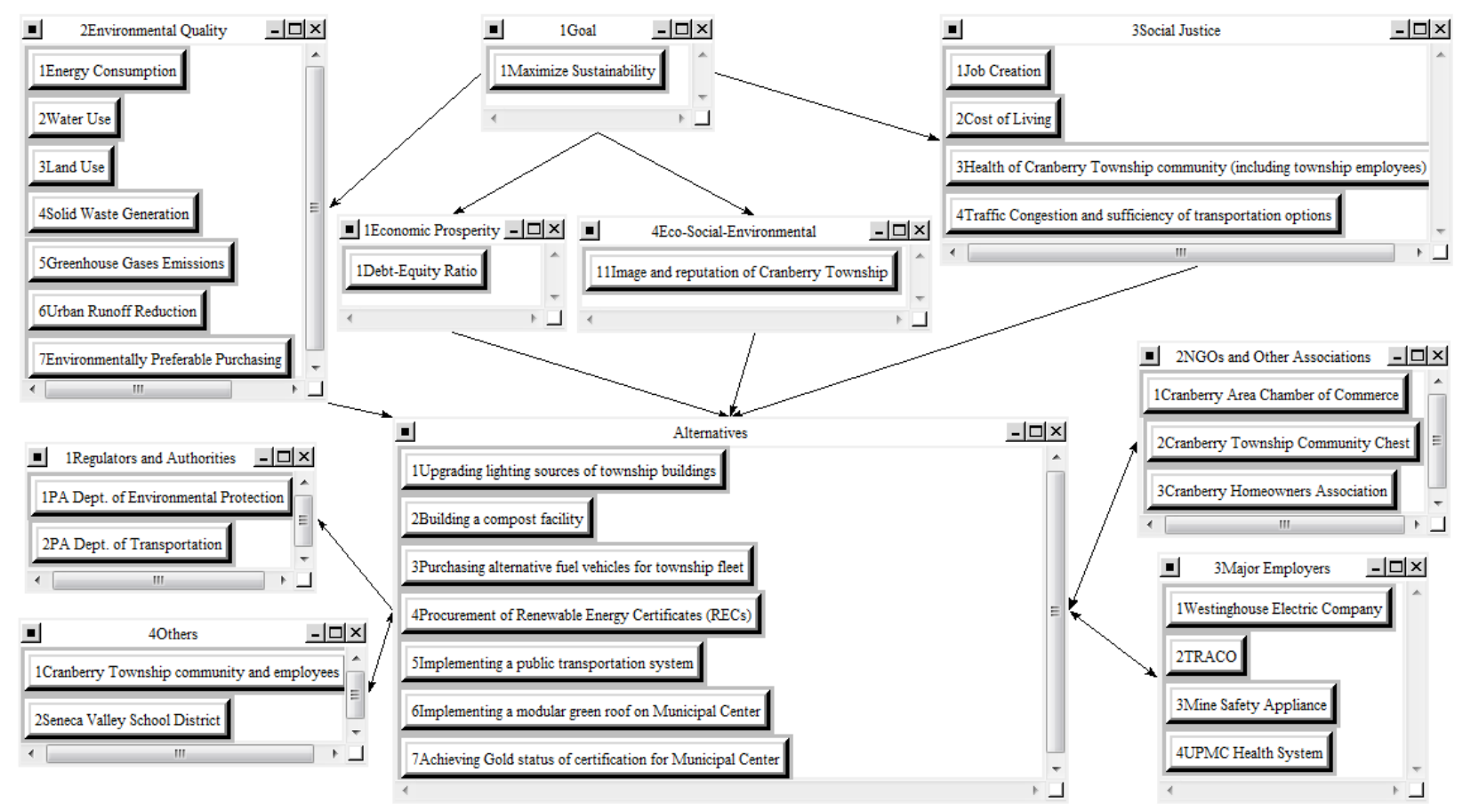

Initial version of the ANP model for Cranberry Township sustainability 


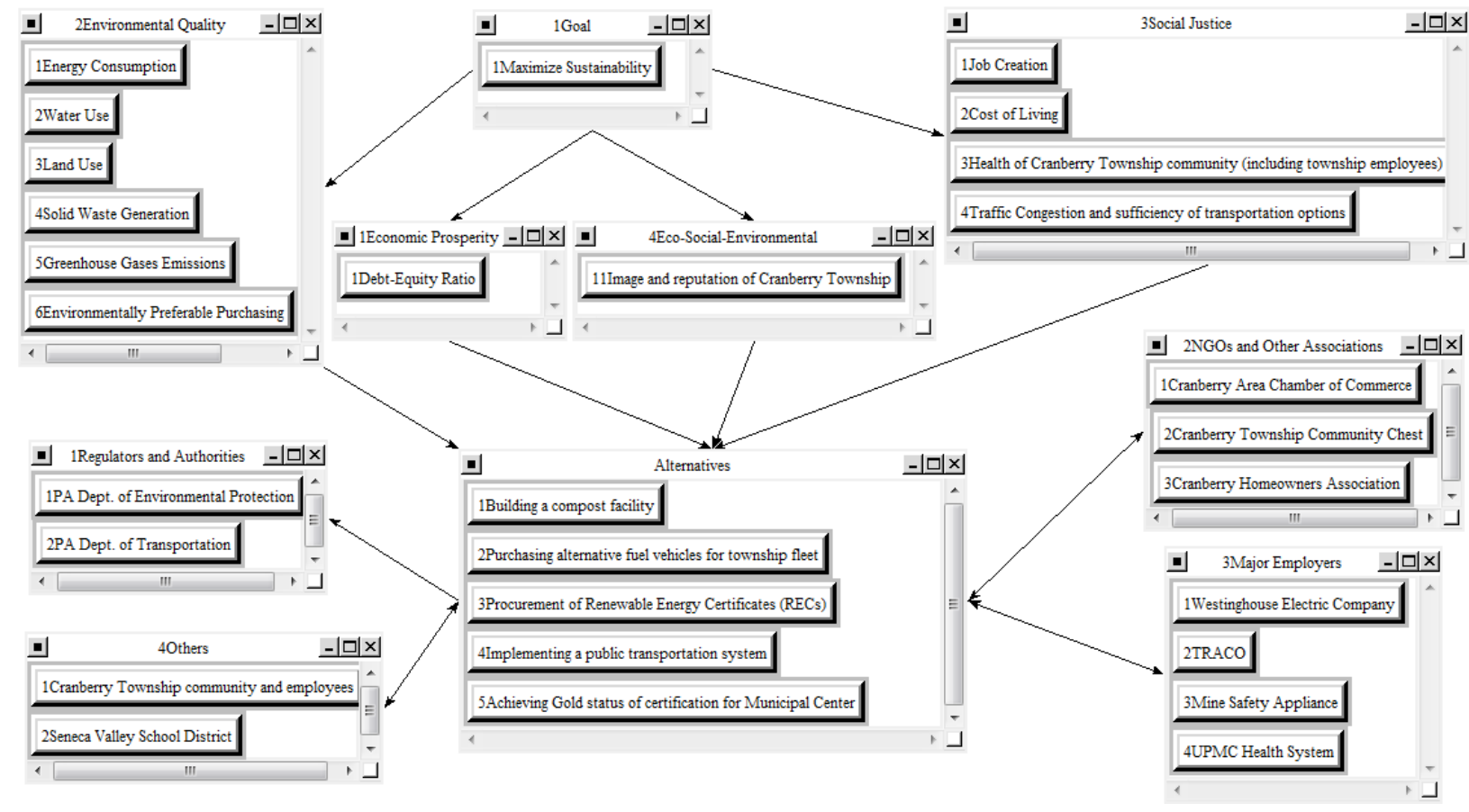

Interim version of the ANP model for Cranberry Township sustainability 


\section{D.3 STAKEHOLDER NOTIFICATION DOCUMENT}

Stakeholder Notification Document was provided to the stakeholder representatives of the Cranberry Township who participated to the ANP study to inform them in advance about the project objectives and the ANP study meetings.

\section{Copy of Stakeholder Notification Document}

\section{Objective of case study}

Working together with Sustainable Pittsburgh and University of Pittsburgh, Cranberry Township management plans to implement a set of investment projects that will potentially improve the sustainability of township. The objective of case study is to prioritize these investment projects based on their contribution to the sustainability of township by considering the perspectives of major stakeholder groups. In the study, the following 5 investment projects will be considered:

\section{-Waste and Recycling}

1. Building a compost facility: Cranberry Township currently accepts yard waste (leaves, lawn cuttings, weeds, non-woody, shrubs and tree prunings) as a part of its residential curbside pickup. While these bags of organic matter are not discarded, they are taken to an outside facility and lost for the township as a resource. Leaf and grass clippings from the various municipal facilities could also be composted to generate valuable leaf mulch. With this project, Cranberry Township plans to build a compost facility and use its output around municipal grounds, or offer it to the community for a fee or as a service. 


\section{- Environmentally Preferable Purchasing (EPP)}

2. Purchasing alternative fuel vehicles for township fleet: Alternative transportation fuels are the fuels other than gasoline or diesel. Examples of alternative transportation fuels include methanol, ethanol, propane or compressed natural gas, liquid natural gas, low-sulfur or "clean" diesel and electricity. With this project, Cranberry Township plans to reduce pollution, eliminate greenhouse gas emissions, minimize dependence on traditional fuels, and increase energy efficiency by purchasing alternative fuel vehicles for the township fleet.

\section{- Renewable Energy and Carbon Dioxide Mitigation Strategies}

3. Procurement of Renewable Energy Certificates (RECs): With this project, Cranberry Township plans to offset electricity consumption supplied from the traditional fossil-fuels and participate in the EPA Green Power Partnership Program by procuring RECs from local or national renewable energy resources. Procurement of RECs provides the most simple and cost effective means to demonstrate environmental responsibility within the township and become a carbon neutral community, although the procurement of RECs will be an incremental cost to the current electricity spend in the township.

\section{- Municipal Center Parking}

4. Implementation of a public transportation system: Currently, Butler Transit Authority (BTA) does not provide bus service to Cranberry area. With this project, Cranberry Township and BTA plans to work together to examine opportunities to 
implement bus service in and around Cranberry Township and find ways to fund capital and operating expenses. Although it is a capital intensive project, it will enable to improve air quality, alleviate traffic congestion, and travel inexpensively and conveniently in and around Cranberry Township.

\section{- LEED Certification}

5. Achieving Gold status of LEED certification for the Municipal Center: The Leadership in Energy and Environmental Design (LEED) certification is a road map for delivering economically profitable, environmentally responsible, healthy, productive places to live and work. It is provided by the U.S. Green Building Council (USGBC) for the buildings which have sustainable green building and development practices. The context of this project includes subprojects whose implementation will provide credit for the Municipal Center to be certified. Some of these subprojects are upgrading lighting sources and improving waste management in the Municipal Center, implementing a modular green roof for the Municipal Center, and upgrading the Municipal Center HVAC system.

\section{How will the study unfold?}

It is planned that representatives from major stakeholder groups of Cranberry Township will participate to the study. With each of the stakeholder representatives, a separate meeting which will approximately take $1 \mathrm{hr}$. will be held. During a stakeholder meeting, an Analytic Network Process (ANP) study will be performed to prioritize the 5 investment projects. 


\section{What is Analytic Network Process (ANP)?}

Analytic Network Process (ANP) is a multicriteria decision making (MCDM) technique that enables to prioritize a set of alternatives depending on the preferences of decision maker. It is based on relative comparisons of the alternatives with respect to a certain goal and criteria set which are in a network (or hierarchical in special cases) structure. The final product of an ANP study is the prioritization of the alternatives according to their contributions to the goal. Figure 1 shows a simple ANP model that can be used when selecting a car for purchase. The goal of the model is to select the car that maximizes benefits and minimizes costs; decision criteria set includes price, fuel consumption, prestige and comfort; and alternative cars are Toyota Corolla, Mazda 3, Ford Focus and Dodge Neon. Figure 2 provides an example pairwise comparison performed by decision maker by using the fundamental scale shown in Table 1 . For instance, as seen in Figure 2, with respect to the price criterion, Mazda 3 is equally to moderately more important (or cheaper, or preferable) than Toyota Corolla. Final priorities of the alternative cars obtained at the end of the study are shown on the normals column of Figure 3. 


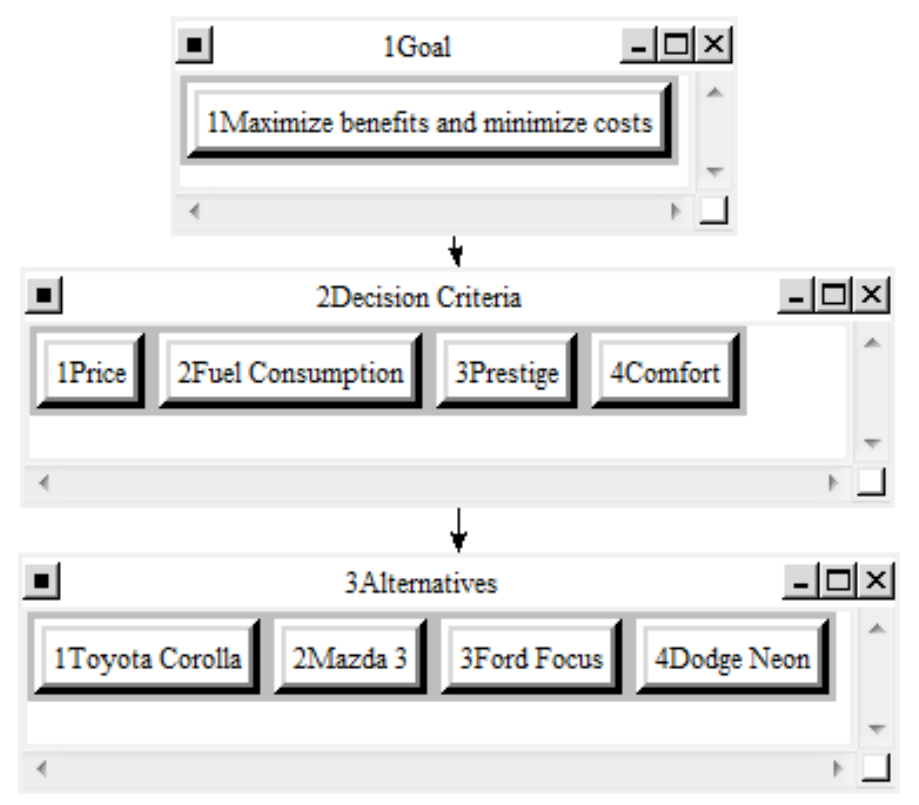

Figure 1: ANP model for selecting a car

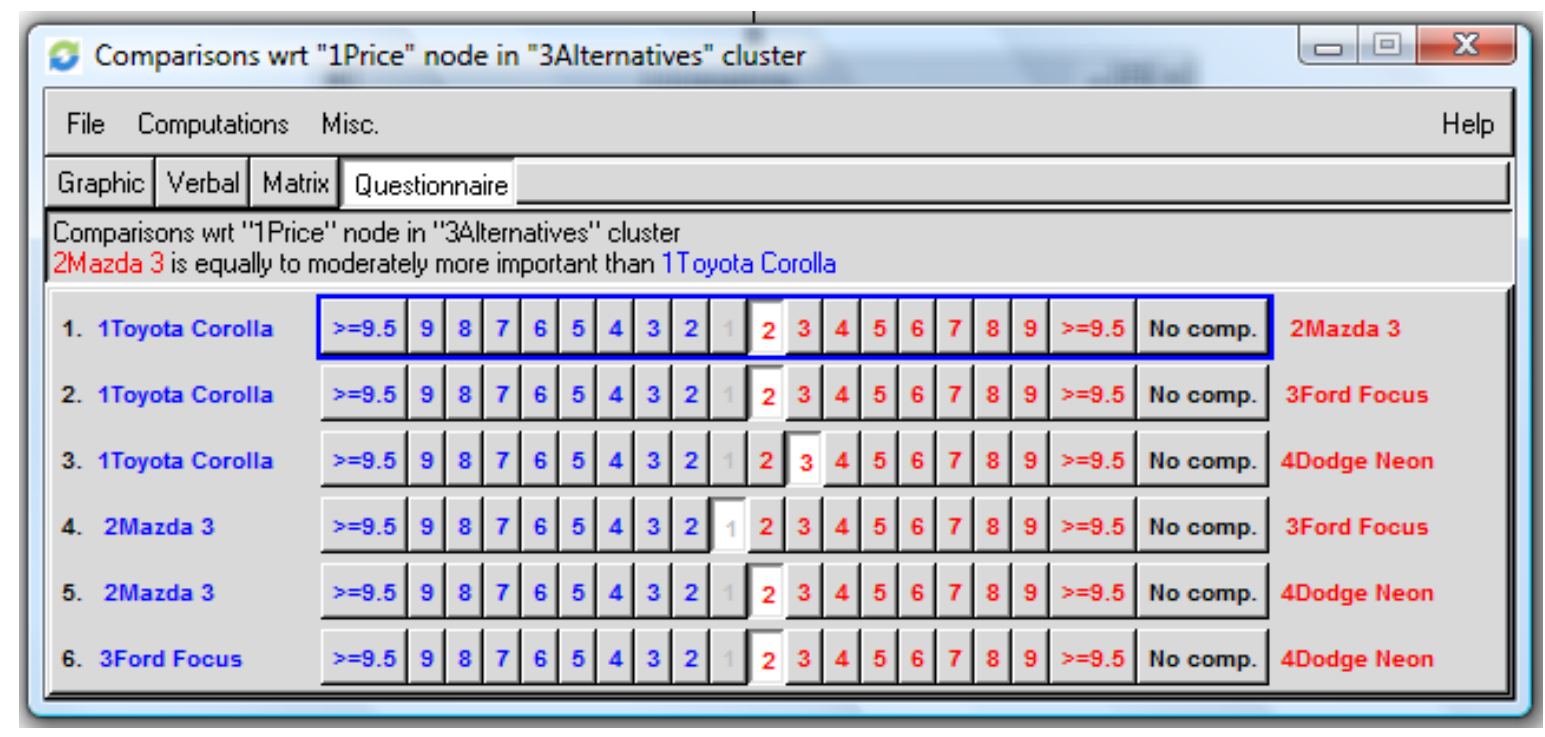

Figure 2: An example pairwise comparison screen 
Table 1: Fundamental scale used in pairwise comparisons

\begin{tabular}{|c|c|}
\hline 1 & Equal \\
\hline 2 & Between Equal and Moderate \\
\hline 3 & Moderate \\
\hline 4 & Between Moderate and Strong \\
\hline 5 & Strong \\
\hline 6 & Between Strong and Very Strong \\
\hline 7 & Very Strong \\
\hline 8 & Between Very Strong and Extreme \\
\hline 9 & Extreme \\
\hline
\end{tabular}

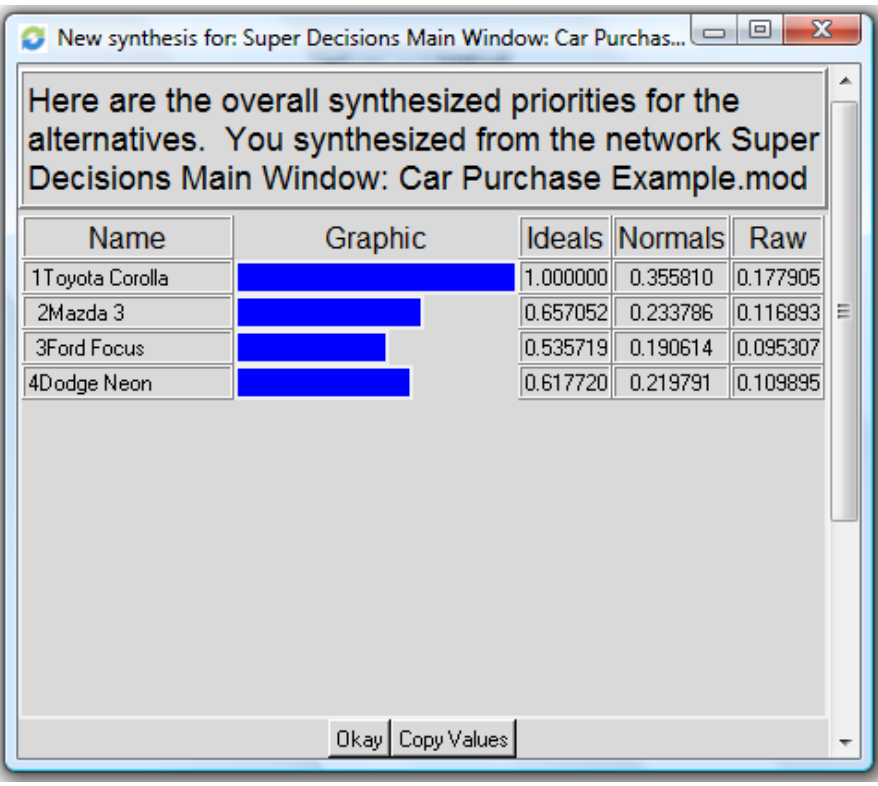

Figure 3: Final priorities screen

\section{ANP model for Cranberry Township sustainability}

The ANP model that will be used in Cranberry Township case is shown in Figure 4. 


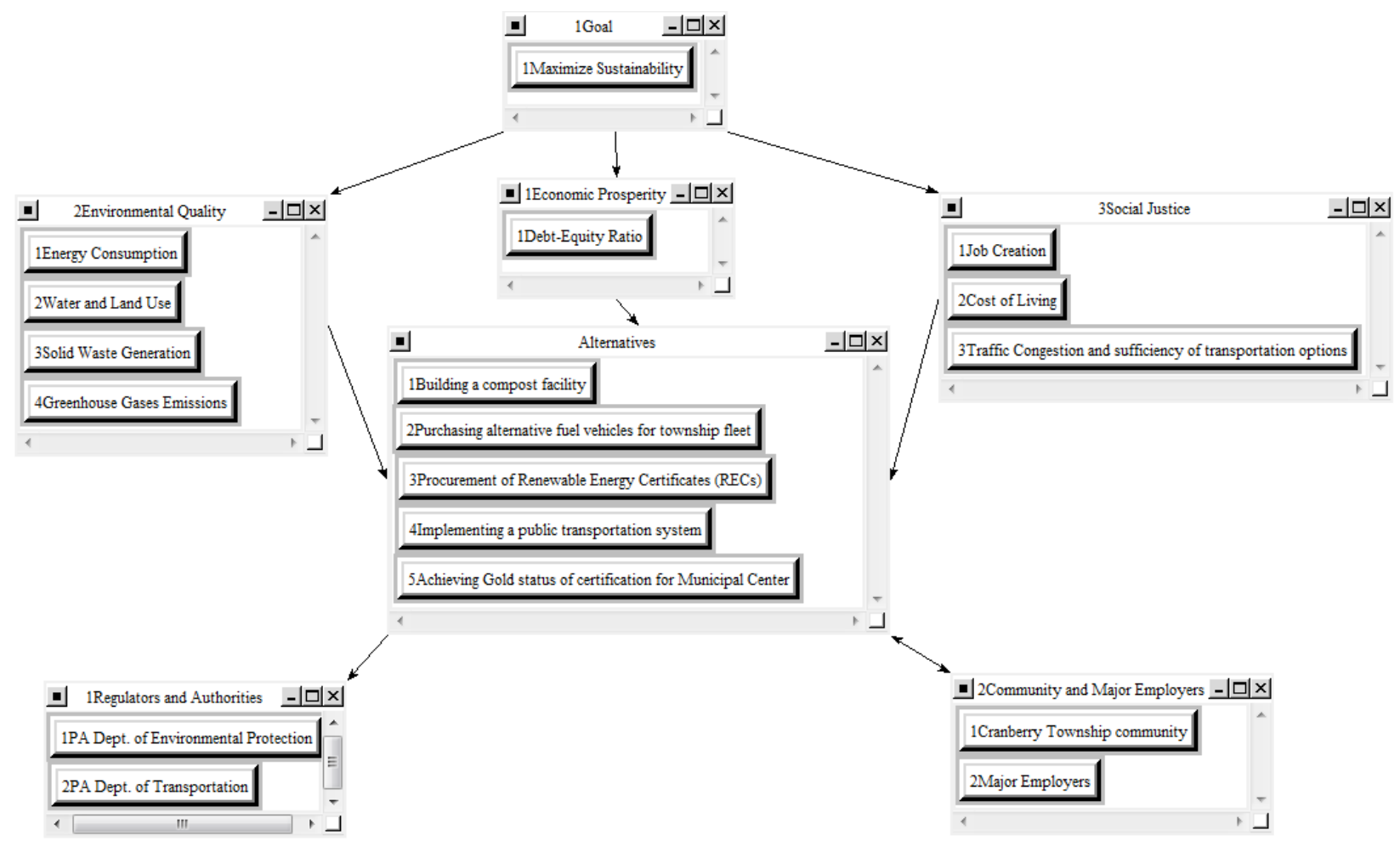

Figure 4: ANP model for Cranberry Township sustainability

The objective of the model is to maximize the sustainability of Cranberry Township. It makes use of the following decision criteria set to prioritize the investment projects with respect to their contribution to the sustainability of township:

\section{- Economic Prosperity}

1. Debt-equity ratio: Debt-equity ratio is a measure of the long-term debt of the township relative to its equity. It is considered that all of the 5 projects have direct impact on debt-equity ratio criterion. 


\section{- Environmental Quality}

2. Energy consumption: Energy consumption is considered as a criterion to assess not only the energy efficiency but also the quality of energy resource - sustainable vs. unsustainable. It is considered that projects 2, 3, 4 and 5 have direct impact on energy consumption criterion.

3. Water and land use: Water and land use is added as a criterion to assess amount and efficiency of water used, and land use quality. It is considered that project 5 has a direct impact on water and land use criterion.

4. Solid waste generation: Solid waste generation refers to the weight or volume of materials and products that enter the waste stream before recycling, composting, landfilling or combustion takes place. It is considered that projects 1 and 5 have direct impact on solid waste generation criterion.

5. Greenhouse gases emissions: Greenhouse gases emissions refer to the amount of carbon dioxide $(\mathrm{CO} 2)$, methane $(\mathrm{CH} 4)$, nitrous oxide $(\mathrm{N} 2 \mathrm{O})$, hydrofluorocarbons (HFCs), perfluorocarbons (PFCs), sulpha hexafluoride (SF6), chlorofluorocarbons (CFCs) and hydrochlorofluorocarbons (HCFCs), together with the indirect greenhouse gases nitrogen oxides $(\mathrm{NOx})$, carbon monoxide $(\mathrm{CO})$ and nonmethane volatile organic compounds (NMVOCs) emitted to the atmosphere. It is considered that projects 2, 3, 4 and 5 have direct impact on greenhouse gases emissions criterion.

\section{- Social Justice}

6. Job creation: Job creation refers to the number of new jobs created. It is considered that projects 1 and 4 have direct impact on job creation criterion. 
7. Cost of living: Cost of living refers to average cost of basic necessities of life such as food, shelter, clothing, transportation, etc. It is considered that projects 3 and 4 have direct impact on cost of living criterion.

8. Traffic congestion and sufficiency of transportation options: Traffic congestion and sufficiency of transportation options is considered as a criterion to assess the general condition of traffic in terms of travel times, queues and speed of flow, and the availability of sustainable modes of transportation. It is considered that project 4 has a direct impact on traffic congestion and sufficiency of transportation options criterion.

Additionally, the model involves the following 7 major stakeholder groups. It is planned that 5 to 8 representatives from these stakeholder groups will participate to the ANP study.

\section{- Regulators and Authorities}

1. PA Department of Environmental Protection (DEP): DEP is the state agency largely responsible for administering Pennsylvania's environmental laws and regulations. Its responsibilities include reducing air pollution, making sure drinking water is safe, protecting water quality in rivers and streams, making sure waste is handled properly, supporting community renewal and revitalization, promoting advanced energy technology, and helping citizens prevent pollution and comply with the commonwealth's environmental regulations. DEP is committed to general environmental education and encouraging effective public involvement in setting environmental policy. In this study, it is considered that 
implementation of projects 2, 3 and 5 will have direct impact on PA Department of Environmental Protection.

2. PA Department of Transportation (DOT): DOT is the state agency responsible for ensuring a fast, safe, efficient, accessible and convenient transportation system that meets citizens' vital national interests and enhances the quality of life. In this study, it is considered that implementation of project 4 will have a direct impact on PA Department of Transportation.

\section{- Community and Major Employers}

3. Cranberry Township community: In addition to John Trant - Chief Strategic Planning Officer of Cranberry Township, it is expected that 2 to 5 representatives from Cranberry Area Chamber of Commerce, Cranberry Township Community Chest (CTCC), Seneca Valley School District and Cranberry Homeowners Association will participate to the ANP study. It is considered that implementation of any of the 5 projects will have a direct impact on Cranberry Township community.

\section{- Community and Major Employers}

4. Mine Safety Appliance: Mine Safety Appliance, headquartered in Pittsburgh, Pennsylvania, is a manufacturer of sophisticated safety products which typically integrate any combination of electronics, mechanical systems and advanced materials to protect users against hazardous or life-threatening situations. Having a division of 469 employees in Cranberry Township, it is one of the major 
employers in the township. In this study, it is expected that one representative from Mine Safety Appliance will participate to the ANP study and it is considered that implementation of projects 3 and 4 will have direct impact on Mine Safety Appliance.

5. UPMC Health System: UPMC is an integrated global health enterprise headquartered in Pittsburgh, Pennsylvania, and one of the leading nonprofit health systems in the United States. Having a division of 642 employees in Cranberry Township, it is one of the major employers in the township. In this study, it is expected that one representative from UPMC Health System will participate to the ANP study and it is considered that implementation of projects 3 and 4 will have a direct impact on UPMC Health System.

6. Westinghouse Electric Company: Westinghouse Electric Company whose headquarters is located in Cranberry Township operates in the worldwide commercial nuclear electric power industry. It provides fuel, services, technology, plant design, and equipment to utility and industrial customers. In this study, it is considered that implementation of projects 3 and 4 will have a direct impact on Westinghouse Electric Company.

7. TRACO: TRACO operates in building products industry by manufacturing windows, doors, storefront and entrances. Headquarters of the company and one of its manufacturing facilities are located in Cranberry Township. With 958 employees, it is one of the major employers in the township. In this study, it is considered that implementation of projects 3 and 4 will have a direct impact on TRACO. 


\section{How will the stakeholder meetings be held?}

Pairwise comparisons related to the model shown in Figure 4 are given in Appendix section on page 8 . There are totally 50 pairwise comparisons composed of 11 sets. In a stakeholder meeting, stakeholder representative will be asked to perform these pairwise comparison based on his/her perspective. It is expected that the allocated $1 \mathrm{hr}$. duration will be spent as shown in Table 2 .

Table 2: Detailed time allocation for a typical stakeholder meeting (See Appendix for comparison sets)

\begin{tabular}{|c|c|c|}
\hline Activity & Sub-Activity & $\begin{array}{c}\text { Duration } \\
\text { (minute) }\end{array}$ \\
\hline Explanation of ANP methodology & N/A & 5 \\
\hline Demonstration of car purchase example & N/A & 5 \\
\hline Explanation of the purpose of Cranberry Township & N/A & 10 \\
\hline ANP study and related ANP model & Cluster comparison set 1 & 2.5 \\
\cline { 2 - 3 } & Cluster comparison set 2 & 1 \\
\cline { 2 - 3 } & Node comparison set 1 & 4 \\
\cline { 2 - 3 } & Node comparison set 2 & 2.5 \\
\cline { 2 - 3 } & Node comparison set 3 & 4 \\
\cline { 2 - 3 } & Node comparison set 4 & 1 \\
\cline { 2 - 3 } & Node comparison set 5 & 4 \\
\cline { 2 - 3 } & Node comparison set 6 & 6 \\
\cline { 2 - 3 } & Node comparison set 7 & 1 \\
\cline { 2 - 3 } & Node comparison set 8 & 1 \\
\cline { 2 - 3 } & Node comparison set 9 & 1 \\
\cline { 2 - 3 } & Node comparison set 10 & 1 \\
\cline { 2 - 3 } & Node comparison set 11 & 6 \\
\cline { 2 - 3 } & Inconsistency check & 5 \\
\hline \multicolumn{3}{|c|}{ TOTAL DURATION (minute) } \\
\hline
\end{tabular}




\section{Project team}

\section{Kim L. Needy, Ph.D., P.E., CFPIM}

Professor and Department Head

Department of Industrial Engineering

University of Arkansas

4207 Bell Engineering Center

Fayetteville, AR 72701

Tel: (479) 575-6029 (office)

Fax: (479) 575-8431

E-mail: kneedy@uark.edu

Mary E. Besterfield-Sacre, Ph.D.

Associate Professor

Dept. of Industrial Engineering

University of Pittsburgh

1048 Benedum Hall

Pittsburgh, PA, 15261

Tel: (412) 624-9836 (office)

Fax: (412) 624-9831

E-mail: mbsacre@ pitt.edu

Matt Mehalik, Ph.D.

Program Manager 
Sustainable Pittsburgh

425 Sixth Avenue, Suite 1335

Pittsburgh, PA 15219

Tel: (412) 258-6642 (office)

Fax: (412) 258-6645

E-mail: mmehalik@pitt.edu

Fikret K. Turan, M.S.

Ph.D. Candidate

Dept. of Industrial Engineering

University of Pittsburgh

1048 Benedum Hall

Pittsburgh, PA 15261

Tel: (412) 715-5105 (mobile)

Fax: (412) 624-9831

E-mail: fkt1@ @itt.edu

John K. Trant Jr.

Chief Strategic Planning Officer

Cranberry Township

2525 Rochester Road, Suite 400

Cranberry Township, PA 16066

Tel: (724) 776-4806 Extension: 1114 (office) 
Fax: (724) 776-5488

E-mail: John.TrantJr@cranberrytownship.org

\section{Pairwise Comparisons Used in Stakeholder Meetings}

\section{Cluster comparison Set 1 (Allocated time $=2.5$ minutes):}

1. For the sustainability of Cranberry Township, how much more important are economic prosperity criteria than environmental quality criteria? (Or, vice versa)

2. For the sustainability of Cranberry Township, how much more important are economic prosperity criteria than social justice criteria? (Or, vice versa)

3. For the sustainability of Cranberry Township, how much more important are environmental quality criteria than social justice criteria? (Or, vice versa)

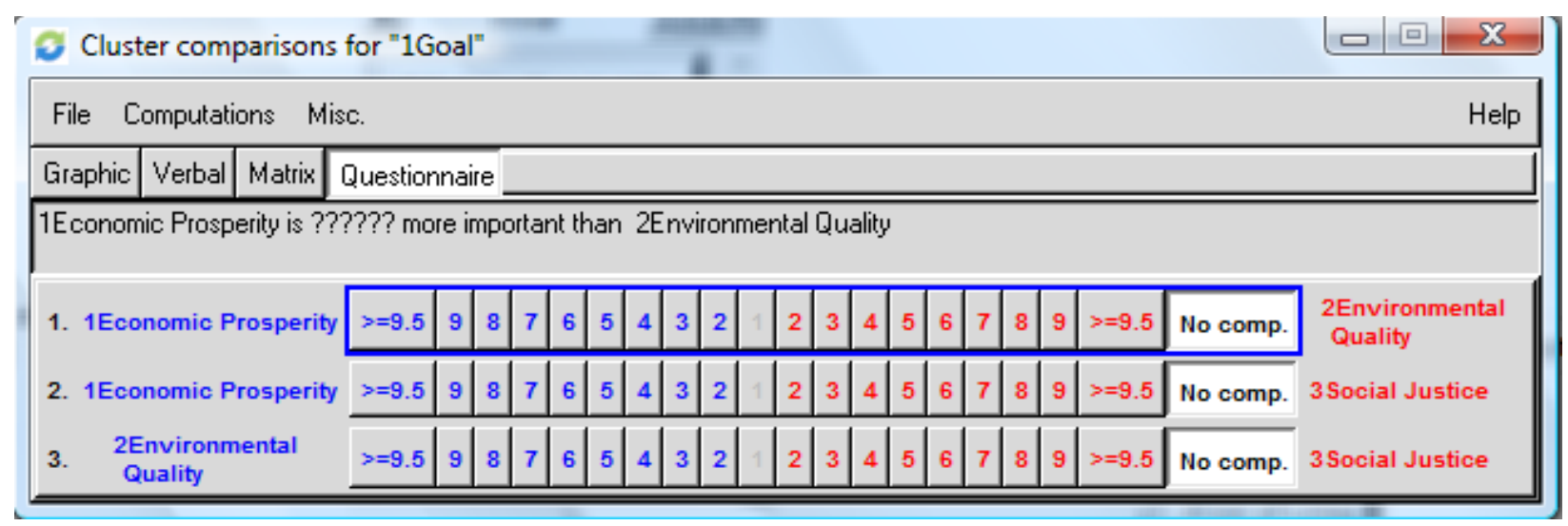

\section{Cluster comparison set $2($ Allocated time $=1$ minute):}

1. For the sustainability of Cranberry Township, how much more important are regulators and authorities than community and major employers? (Or, vice versa) 


\section{Node comparison set 1 (Allocated time $=4$ minutes):}

1. For the sustainability of Cranberry Township, how much more important is energy consumption criterion than water and land use criterion? (Or, vice versa)

2. For the sustainability of Cranberry Township, how much more important is energy consumption criterion than solid waste generation criterion? (Or, vice versa)

3. For the sustainability of Cranberry Township, how much more important is energy consumption criterion than greenhouse gases emissions criterion? (Or, vice versa)

4. For the sustainability of Cranberry Township, how much more important is water and land use criterion than solid waste generation criterion? (Or, vice versa)

5. For the sustainability of Cranberry Township, how much more important is water and land use criterion than greenhouse gases emissions criterion? (Or, vice versa)

6. For the sustainability of Cranberry Township, how much more important is solid waste generation criterion than greenhouse gases emissions criterion? (Or, vice versa) 


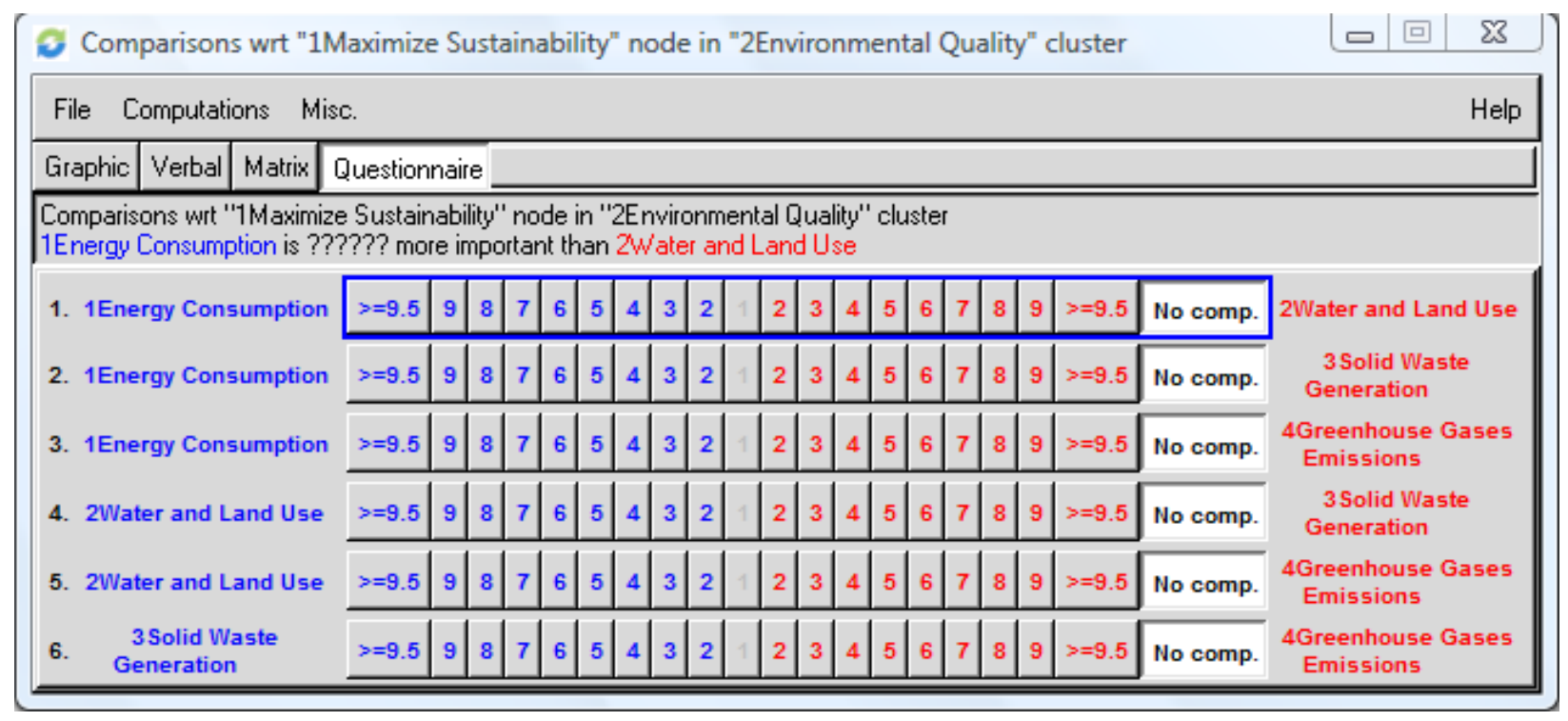

\section{Node comparison set 2 (Allocated time $=2.5$ minutes):}

1. For the sustainability of Cranberry Township, how much more important is job creation criterion than cost of living criterion? (Or, vice versa)

2. For the sustainability of Cranberry Township, how much more important is job creation criterion than traffic congestion and sufficiency of transportation options criterion? (Or, vice versa)

3. For the sustainability of Cranberry Township, how much more important is cost of living criterion than traffic congestion and sufficiency of transportation options criterion? (Or, vice versa) 


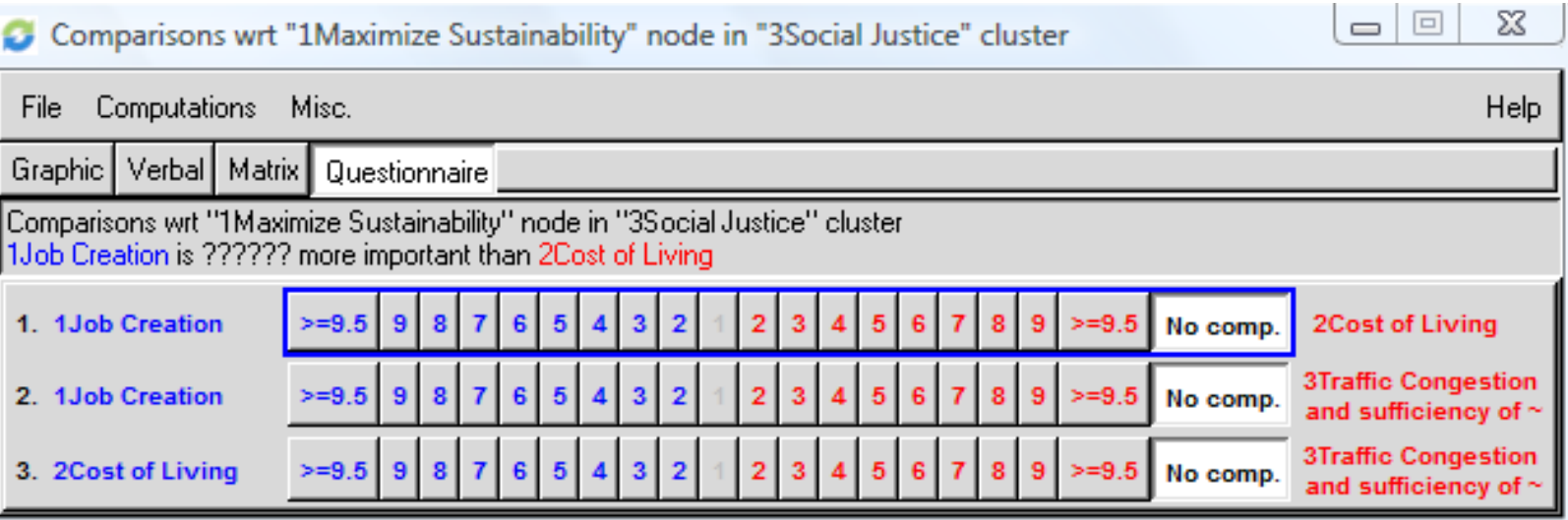

\section{Node comparison set 3 (Allocated time $=4$ minutes):}

1. How much more contribution does purchasing alternative fuel vehicles for township fleet make to improving the energy consumption criterion than procurement of renewable energy certificates (RECs)? (Or, vice versa)

2. How much more contribution does purchasing alternative fuel vehicles for township fleet make to improving the energy consumption criterion than implementing a public transportation system? (Or, vice versa)

3. How much more contribution does purchasing alternative fuel vehicles for township fleet make to improving the energy consumption criterion than achieving gold status of certification for Municipal Center? (Or, vice versa)

4. How much more contribution does procurement of renewable energy certificates (RECs) make to improving the energy consumption criterion than implementing a public transportation system? (Or, vice versa)

5. How much more contribution does procurement of renewable energy certificates (RECs) make to improving the energy consumption criterion than achieving gold status of certification for Municipal Center? (Or, vice versa) 
6. How much more contribution does implementing a public transportation system make to improving the energy consumption criterion than achieving gold status of certification for Municipal Center? (Or, vice versa)

\section{Comparisons wrt "1Energy Consumption" node in "Alternatives" cluster}

\begin{tabular}{l|l|l|l} 
Graphic & Verbal & Matrix & Questionnaire \\
\hline
\end{tabular}

Comparisons wrt "1Energy Consumption" node in "Alternatives" cluster

2Purchasing alternative fuel vehicles for township fleet is ?????? more important than 3Procurement of Renewable Energy Certificates (RECs

\begin{tabular}{|c|c|c|c|c|c|c|c|c|c|c|c|c|c|c|c|c|c|c|c|c|}
\hline $\begin{array}{l}\text { 2Purchasing } \\
\text { 1. alternative fuel ve }\end{array}$ & $>=9.5$ & 9 & 8 & 7 & 6 & 5 & 4 & 3 & 2 & 2 & 3 & 4 & 5 & 6 & 7 & 8 & 9 & $>=9.5$ & No comp. & $\begin{array}{l}\text { 3Procurement of } \\
\text { Renewable Energy Ce }\end{array}$ \\
\hline $\begin{array}{l}\text { 2Purchasing } \\
\text { 2. alternative fuel ve }\end{array}$ & $>=9.5$ & 9 & 8 & 7 & 6 & 5 & 4 & 3 & 2 & 2 & 3 & 4 & 5 & 6 & 7 & 8 & 9 & $>=9.5$ & No comp. & $\begin{array}{l}\text { 4lmplementing a } \\
\text { public transportati }\end{array}$ \\
\hline $\begin{array}{l}\text { 2Purchasing } \\
\text { 3. alternative fuel ve }\end{array}$ & $>=9.5$ & 9 & 8 & 7 & 6 & 5 & 4 & 3 & 2 & 2 & 3 & 4 & 5 & 6 & 7 & 8 & 9 & $=9.5$ & No comp. & $\begin{array}{l}\text { 5Achieving Gold } \\
\text { status of certifica }\end{array}$ \\
\hline $\begin{array}{l}\text { 3Procurement of } \\
\text { Renewable Energy Ce }\end{array}$ & $>=9.5$ & 9 & 8 & 7 & 6 & 5 & 4 & 3 & 2 & 2 & 3 & 4 & 5 & 6 & 7 & 8 & 9 & $>=9.5$ & No comp. & $\begin{array}{l}\text { 4lmplementing a } \\
\text { public transportati }\end{array}$ \\
\hline $\begin{array}{l}\text { 3Procurement of } \\
\text { Renewable Energy } \mathrm{Ce} \sim\end{array}$ & $>=9.5$ & 9 & 8 & 7 & 6 & 5 & 4 & 3 & 2 & 2 & 3 & 4 & 5 & 6 & 7 & 8 & 9 & $>=9.5$ & No comp. & $\begin{array}{l}\text { 5Achieving Gold } \\
\text { status of certifica }\end{array}$ \\
\hline $\begin{array}{l}\text { 4Implementing a } \\
\text { public transportati }\end{array}$ & $>=9.5$ & 9 & 8 & 7 & 6 & 5 & 4 & 3 & 2 & 2 & 3 & 4 & 5 & 6 & 7 & 8 & 9 & $>=9.5$ & No comp. & $\begin{array}{l}\text { 5Achieving Gold } \\
\text { status of certifica }\end{array}$ \\
\hline
\end{tabular}

\section{Node comparison set 4 (Allocated time $=1$ minute):}

1. How much more contribution does building a compost facility make to improving the solid waste generation criterion than achieving gold status of certification for Municipal Center? (Or, vice versa)

\begin{tabular}{l|l|l|l|l}
\hline Graphic & Verbal & Matrix & Questionnaire \\
\hline
\end{tabular}

Comparisons wrt "3Solid Waste Generation" node in "Alternatives" cluster

1Building a compost facility is ?????? more important than 54 chieving Gold status of certification for Municipal Center
1. 1Building a compost
\begin{tabular}{|l|l|l|l|l|l|l|l|l|}
\hline$>=9.5$ & 9 & 8 & 7 & 6 & 5 & 4 & 3 & 2 \\
\hline
\end{tabular}
\begin{tabular}{|l|l|l|l|l|l|l|l|l|l|l}
2 & 3 & 4 & 5 & 6 & 7 & 8 & 9 & $>=9.5$ & No comp. \\
\hline
\end{tabular} 


\section{Node comparison set 5 (Allocated time $=4$ minutes):}

1. How much more contribution does purchasing alternative fuel vehicles for township fleet make to improving the greenhouse gases emissions criterion than procurement of renewable energy certificates (RECs)? (Or, vice versa)

2. How much more contribution does purchasing alternative fuel vehicles for township fleet make to improving the greenhouse gases emissions criterion than implementing a public transportation? (Or, vice versa)

3. How much more contribution does purchasing alternative fuel vehicles for township fleet make to improving the greenhouse gases emissions criterion than achieving gold status of certification for Municipal Center? (Or, vice versa)

4. How much more contribution does procurement of renewable energy certificates (RECs) make to improving the greenhouse gases emissions criterion than implementing a public transportation system? (Or, vice versa)

5. How much more contribution does procurement of renewable energy certificates (RECs) make to improving the greenhouse gases emissions criterion than achieving gold status of certification for Municipal Center? (Or, vice versa)

6. How much more contribution does implementing a public transportation system make to improving the greenhouse gases emissions criterion than achieving gold status of certification for Municipal Center? (Or, vice versa) 


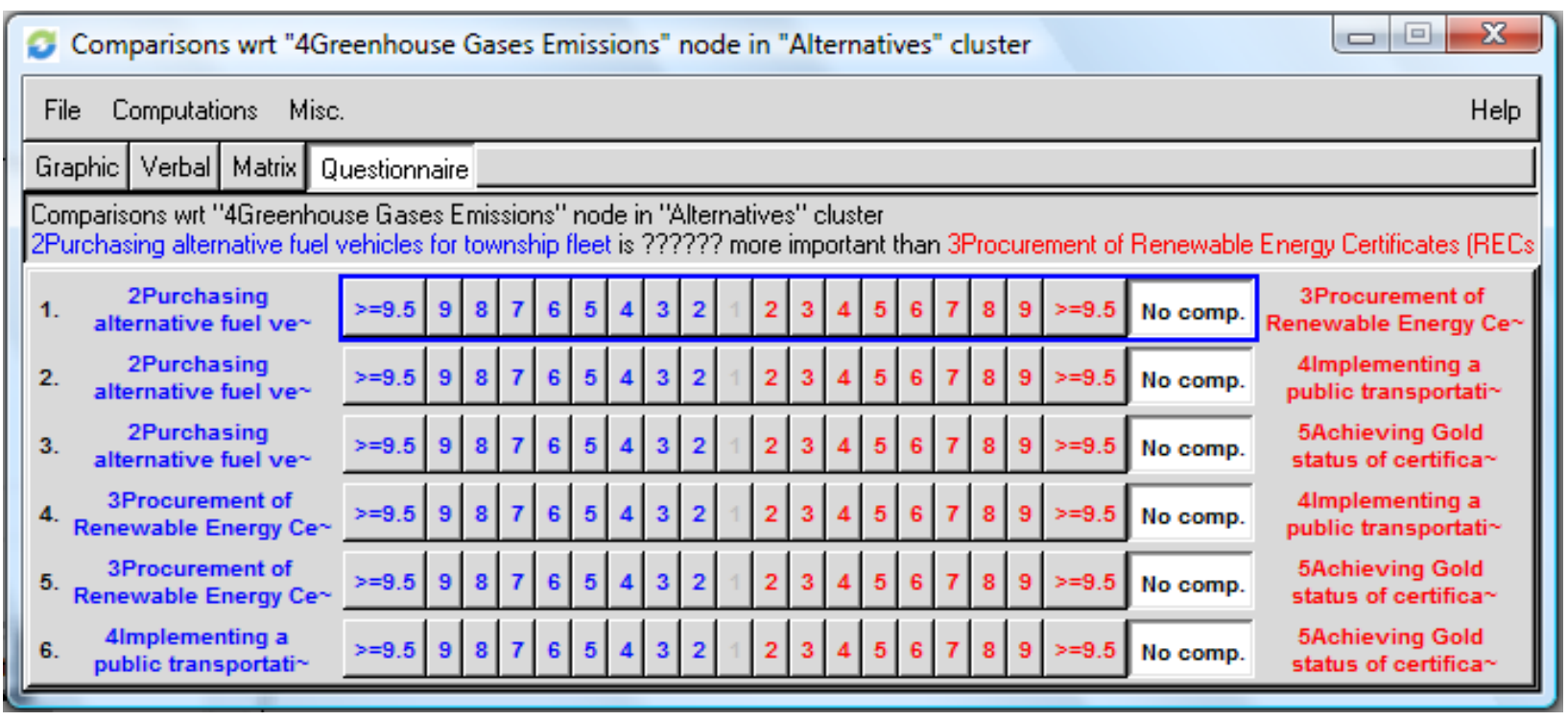

\section{Node comparison set 6 (Allocated time $=6$ minutes $)$ :}

1. How much more contribution does building a compost facility make to improving the debtequity ratio criterion than purchasing alternative fuel vehicles for township fleet? (Or, vice versa)

2. How much more contribution does building a compost facility make to improving the debtequity ratio criterion than procurement of renewable energy certificates (RECs)? (Or, vice versa)

3. How much more contribution does building a compost facility make to improving the debtequity ratio criterion than implementing a public transportation system? (Or, vice versa)

4. How much more contribution does building a compost facility make to improving the debtequity ratio criterion than achieving gold status of certification for Municipal Center? (Or, vice versa) 
5. How much more contribution does purchasing alternative fuel vehicles for township fleet make to improving the debt-equity ratio criterion than procurement of renewable energy certificates (RECs)? (Or, vice versa)

6. How much more contribution does purchasing alternative fuel vehicles for township fleet make to improving the debt-equity ratio criterion than implementing a public transportation system? (Or, vice versa)

7. How much more contribution does purchasing alternative fuel vehicles for township fleet make to improving the debt-equity ratio criterion than achieving gold status of certification for Municipal Center? (Or, vice versa)

8. How much more contribution does procurement of renewable energy certificates (RECs) make to improving the debt-equity ratio criterion than implementing a public transportation system? (Or, vice versa)

9. How much more contribution does procurement of renewable energy certificates (RECs) make to improving the debt-equity ratio criterion than achieving gold status of certification for Municipal Center? (Or, vice versa)

10. How much more contribution does implementing a public transportation system make to improving the debt-equity ratio criterion than achieving gold status of certification for Municipal Center? (Or, vice versa) 
\begin{tabular}{|l|l|l|l|}
\hline Graphic & Verbal & Matrix & Questionnaire \\
\hline
\end{tabular}

Comparisons wrt "1Debt-Equity Ratio" node in "Alternatives" cluster

1Building a compost facility is ?????? more important than 2Purchasing alternative fuel vehicles for township fleet

1. 1Building a compost facility

1Building a compost facility

3. 1Building a compost facility

4. 1Building a compost facility

5. 2Purchasing alternative fuel ver

2Purchasing

6. alternative fuel ver

2Purchasing
alternative fuel ve

3Procurement of
Renewable Energy Ce

3Procurement of

9. Renewable Energy Cer

10. 4 Implementing a public transportati

\begin{tabular}{|c|c|c|c|c|c|c|c|c|c|c|c|c|c|c|c|c|c|c|c|c|}
\hline$>=9.5$ & 9 & 8 & 7 & 6 & 5 & 4 & 3 & 2 & & 2 & 3 & 4 & 5 & 6 & 7 & 8 & 9 & $>=9.5$ & No comp. & $\begin{array}{l}\text { 2Purchasing } \\
\text { alternative fuel ve }\end{array}$ \\
\hline$>=9.5$ & 9 & 8 & 7 & 6 & 5 & 4 & 3 & 2 & & 2 & 3 & 4 & 5 & 6 & 7 & 8 & 9 & $>=9.5$ & No comp. & $\begin{array}{c}\text { 3Procurement of } \\
\text { Renewable Energy Ce }\end{array}$ \\
\hline$>=9.5$ & 9 & 8 & 7 & 6 & 5 & 4 & 3 & 2 & | & 2 & 3 & 4 & 5 & 6 & 7 & 8 & 9 & $>=9.5$ & No comp. & $\begin{array}{l}\text { 4lmplementing a } \\
\text { public transportati }\end{array}$ \\
\hline$>=9.5$ & 9 & 8 & 7 & 6 & 5 & 4 & 3 & 2 & 1 & 2 & 3 & 4 & 5 & 6 & 7 & 8 & 9 & $>=9.5$ & No comp. & $\begin{array}{l}\text { 5Achieving Gold } \\
\text { status of certifica }\end{array}$ \\
\hline$>=9.5$ & 9 & 8 & 7 & 6 & 5 & 4 & 3 & 2 & 1 & 2 & 3 & 4 & 5 & 6 & 7 & 8 & 9 & $>=9.5$ & No comp. & $\begin{array}{l}\text { 3Procurement of } \\
\text { Renewable Energy Ce }\end{array}$ \\
\hline$>=9.5$ & 9 & 8 & 7 & 6 & 5 & 4 & 3 & 2 & 1 & 2 & 3 & 4 & 5 & 6 & 7 & 8 & 9 & $>=9.5$ & No comp. & $\begin{array}{l}\text { 4Implementing a } \\
\text { public transportati }\end{array}$ \\
\hline$>=9.5$ & 9 & 8 & 7 & 6 & 5 & 4 & 3 & 2 & 1 & 2 & 3 & 4 & 5 & 6 & 7 & 8 & 9 & $>=9.5$ & No comp. & $\begin{array}{l}\text { 5Achieving Gold } \\
\text { status of certifica }\end{array}$ \\
\hline$>=9.5$ & 9 & 8 & 7 & 6 & 5 & 4 & 3 & 2 & 1 & 2 & 3 & 4 & 5 & 6 & 7 & 8 & 9 & $>=9.5$ & No comp. & $\begin{array}{l}\text { 4lmplementing a } \\
\text { public transportati }\end{array}$ \\
\hline$>=9.5$ & 9 & 8 & 7 & 6 & 5 & 4 & 3 & 2 & 1 & 2 & 3 & 4 & 5 & 6 & 7 & 8 & 9 & $>=9.5$ & No comp. & $\begin{array}{l}\text { 5Achieving Gold } \\
\text { status of certifica }\end{array}$ \\
\hline$>=9.5$ & 9 & 8 & 7 & 6 & 5 & 4 & 3 & 2 & t & 2 & 3 & 4 & 5 & 6 & 7 & 8 & 9 & $>=9.5$ & No comp. & $\begin{array}{l}\text { 5Achieving Gold } \\
\text { status of certifica }\end{array}$ \\
\hline
\end{tabular}

\section{Node comparison set 7 (Allocated time $=1$ minute):}

1. How much more contribution does building a compost facility make to improving the job creation criterion than implementing a public transportation system? (Or, vice versa)

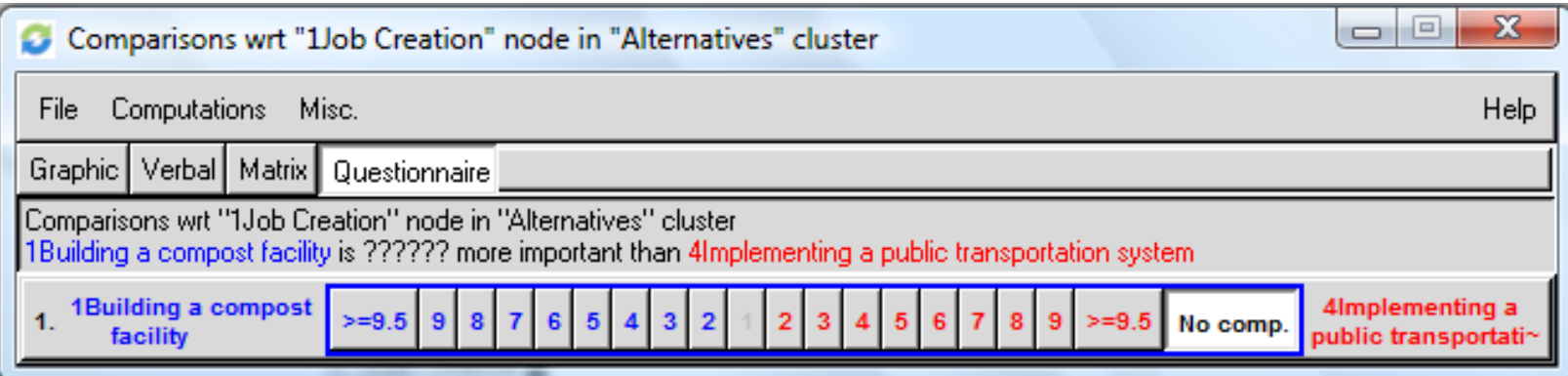




\section{Node comparison set 8 (Allocated time $=1$ minute):}

1. How much more contribution does procurement of renewable energy certificates (RECs) make to improving the cost of living criterion than implementing a public transportation system? (Or, vice versa)

\section{Comparisons wrt "2Cost of Living" node in "Alternatives" cluster}

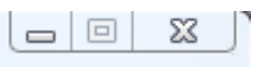

File

\begin{tabular}{|l|l|l|l|l}
\hline Graphic & Verbal & Matrix & Questionnaire \\
\hline
\end{tabular}

Comparisons wrt "2Cost of Living" node in "Alternatives" cluster

3Procurement of Renewable Energy Certificates (RECs) is ?????? more important than 4 mplementing a public transportation system

\begin{tabular}{|c|c|c|c|c|c|c|c|c|c|c|c|c|c|c|c|c|c|c|c|c|c|}
\hline $\begin{array}{l}\text { 3Procurement of } \\
\text { 1. Renewable Energy } \mathrm{Ce} \sim\end{array}$ & $>=9.5$ & 9 & 8 & 7 & 6 & 5 & 4 & 3 & 2 & 1 & 2 & 3 & 4 & 5 & 6 & 7 & 8 & 9 & $>=9.5$ & No comp. & $\begin{array}{l}\text { 4Implementing a } \\
\text { public transportati } ~\end{array}$ \\
\hline
\end{tabular}

\section{Node comparison set 9 (Allocated time $=1$ minute):}

1. How much more impact does procurement of renewable energy certificates (RECs) have on Cranberry Township community than major employers? (Or, vice versa)

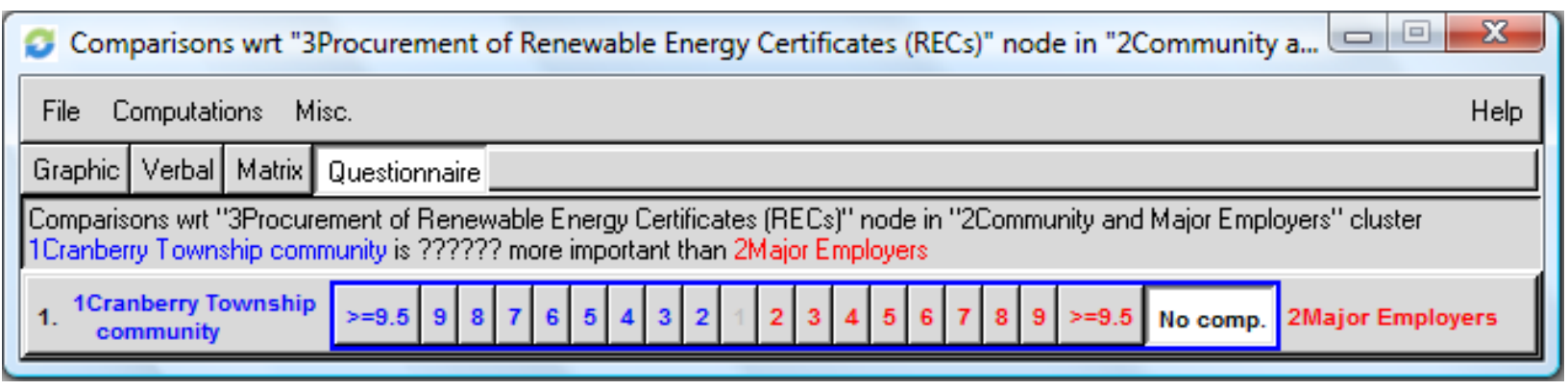

\section{Node comparison set $10($ Allocated time $=1$ minute $)$ :}

1. How much more impact does implementing a public transportation system have on Cranberry Township community than major employers? (Or, vice versa) 
Graphic Verbal Matrix Questionnaire

Comparisons wrt "4Implementing a public transportation system" node in "2Community and Major Employers" cluster 1Cranberry Township community is ?????? more important than 2Major Employers

1. 1Cranberry Township community

\section{Node comparison set 11 (For Cranberry Township community representatives, allocated}

time $=6$ minutes):

1. For Cranberry Township community, how much more important is building a compost facility than purchasing alternative fuel vehicles for township fleet? (Or, vice versa)

2. For Cranberry Township community, how much more important is building a compost facility than procurement of renewable energy certificates (RECs)? (Or, vice versa)

3. For Cranberry Township community, how much more important is building a compost facility than implementing a public transportation system? (Or, vice versa)

4. For Cranberry Township community, how much more important is building a compost facility than achieving gold status of certification for Municipal Center? (Or, vice versa)

5. For Cranberry Township community, how much more important purchasing alternative fuel vehicles for township fleet than procurement of renewable energy certificates (RECs)? (Or, vice versa)

6. For Cranberry Township community, how much more important purchasing alternative fuel vehicles for township fleet than implementing a public transportation system? (Or, vice versa) 
7. For Cranberry Township community, how much more important purchasing alternative fuel vehicles for township fleet than achieving gold status of certification for Municipal Center? (Or, vice versa)

8. For Cranberry Township community, how much more important procurement of renewable energy certificates (RECs) than implementing a public transportation system? (Or, vice versa)

9. For Cranberry Township community, how much more important procurement of renewable energy certificates (RECs) than achieving gold status of certification for Municipal Center? (Or, vice versa)

10. For Cranberry Township community, how much more important implementing a public transportation system than achieving gold status of certification for Municipal Center? (Or, vice versa)

\begin{tabular}{|c|c|c|c|c|c|c|c|c|c|c|c|c|c|c|c|c|c|c|c|c|c|}
\hline \multicolumn{20}{|c|}{3 Comparisons wrt "1Cranberry Township community" node in "Alternatives" cluster } & \multirow{2}{*}{\multicolumn{2}{|c|}{ 口回 }} \\
\hline \multicolumn{20}{|c|}{ File Computations Misc. } & & \\
\hline Graphic & Verbal & Matrix Qu & estionna & & & & & & & & & & & & & & & & & & \\
\hline \multicolumn{22}{|c|}{$\begin{array}{l}\text { Comparisons wrt "1Cranberry Township community" node in "Alternatives" cluster } \\
1 \text { Building a compost facility is ?????? more important than 2Purchasing alternative fuel vehicles for township fleet }\end{array}$} \\
\hline 1. 1 & \multicolumn{2}{|c|}{$\begin{array}{l}\text { 1Building a compost } \\
\text { facility }\end{array}$} & $>=9.5$ & & 8 & 7 & 6 & 5 & 4 & 3 & 2 & 2 & 3 & \begin{tabular}{|l|l}
4 & 5 \\
\end{tabular} & \begin{tabular}{|l|l|}
5 & 6 \\
\end{tabular} & \begin{tabular}{|l|l|}
7 & 8 \\
\end{tabular} & 9 & $>=9.5$ & No comp. & $\begin{array}{l}\text { 2Purchas } \\
\text { alternative } \mathrm{ft}\end{array}$ & ve \\
\hline \multicolumn{3}{|c|}{ 1Building a com } & $>=9.5$ & 9 & 8 & 7 & 6 & 5 & 4 & 3 & 2 & 2 & 3 & \begin{tabular}{l|l}
4 & 5 \\
\end{tabular} & \begin{tabular}{l|l|l|l|l}
5 & 6 & -1 \\
\end{tabular} & \begin{tabular}{|l|l|l|l|l}
7 & 8 \\
\end{tabular} & 9 & $>=9.5$ & No comp. & \multicolumn{2}{|c|}{$\begin{array}{c}\text { 3Procurement of } \\
\text { Renewable Energy Ce }\end{array}$} \\
\hline \multicolumn{3}{|c|}{ 3. $1 \mathrm{Bu}$} & $>=9.5$ & 9 & 8 & 7 & 6 & 5 & 4 & 3 & 2 & 2 & 3 & \begin{tabular}{l|l}
4 & 5 \\
\end{tabular} & \begin{tabular}{l|l|}
5 & 6 \\
\end{tabular} & \begin{tabular}{|l|l|}
7 & 8 \\
\end{tabular} & 9 & $>=9.5$ & No comp. & \multicolumn{2}{|c|}{$\begin{array}{l}\text { 4Implementing a } \\
\text { public transportati } ~\end{array}$} \\
\hline \multicolumn{3}{|l|}{4.} & $>=9.5$ & 9 & 8 & 7 & 6 & 5 & 4 & 3 & 2 & 2 & 3 & \begin{tabular}{l|l}
4 & 5 \\
\end{tabular} & \begin{tabular}{l|l|}
5 & 6 \\
\end{tabular} & \begin{tabular}{|l|l|}
7 & 8 \\
\end{tabular} & 9 & $>=9.5$ & No comp. & \multicolumn{2}{|c|}{$\begin{array}{l}\text { 5Achieving Gold } \\
\text { status of certifica }\end{array}$} \\
\hline 5. & $\begin{array}{l}\text { 2Purch } \\
\text { ternative }\end{array}$ & $\begin{array}{l}\text { lasing } \\
\text { e fuel ve }\end{array}$ & $>=9.5$ & 9 & 8 & 7 & 6 & 5 & 4 & 3 & 2 & 2 & 3 & \begin{tabular}{l|l}
4 & 5 \\
\end{tabular} & \begin{tabular}{l|l|}
5 & 6 \\
\end{tabular} & \begin{tabular}{|l|l|}
7 & 8 \\
\end{tabular} & 9 & $>=9.5$ & No comp. & \multicolumn{2}{|c|}{$\begin{array}{l}\text { 3Procurement of } \\
\text { Renewable Energy Cer }\end{array}$} \\
\hline \multicolumn{3}{|l|}{6.} & $>=9.5$ & 9 & 8 & 7 & 6 & 5 & 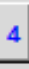 & 3 & 2 & 2 & 3 & \begin{tabular}{l|l}
4 & 5 \\
\end{tabular} & \begin{tabular}{l|l|}
5 & 6 \\
\end{tabular} & \begin{tabular}{|l|l|}
7 & 8 \\
\end{tabular} & 9 & $>=9.5$ & No comp. & \multicolumn{2}{|c|}{$\begin{array}{c}\text { 4implementing a } \\
\text { public transportati } \sim\end{array}$} \\
\hline \multicolumn{3}{|l|}{7} & $>=9.5$ & 9 & 8 & 7 & 6 & 5 & 4 & 3 & 2 & 2 & 3 & \begin{tabular}{l|l}
4 & 5 \\
\end{tabular} & \begin{tabular}{l|l}
5 & 6 \\
\end{tabular} & \begin{tabular}{|l|l|}
7 & 8 \\
\end{tabular} & 9 & $>=9.5$ & No comp. & \multicolumn{2}{|c|}{$\begin{array}{l}\text { 5Achieving Gold } \\
\text { status of certifica }\end{array}$} \\
\hline \multicolumn{3}{|c|}{$\begin{array}{l}\text { 3Procurement of } \\
\text { Renewable Energy Ce }\end{array}$} & $>=9.5$ & 9 & 8 & 7 & 6 & 5 & 4 & 3 & 2 & 2 & 3 & \begin{tabular}{l|l}
4 & 5 \\
\end{tabular} & $\begin{array}{l}5 \\
5\end{array}$ & \begin{tabular}{|l|l|}
7 & 8 \\
\end{tabular} & 9 & $>=9.5$ & No comp. & \multicolumn{2}{|c|}{$\begin{array}{l}\text { 4Implementing a } \\
\text { public transportati }\end{array}$} \\
\hline \multirow{2}{*}{\multicolumn{3}{|c|}{$\begin{array}{l}\text { 3Procurement of } \\
\text { 9. Renewable Energy Ce } \\
\text { 10. } \begin{array}{c}\text { 4Implementing a } \\
\text { public transportati }\end{array}\end{array}$}} & $>=9.5$ & 9 & 8 & 7 & 6 & 5 & 4 & 3 & 2 & 2 & 3 & \begin{tabular}{l|l}
4 & 5 \\
\end{tabular} & \begin{tabular}{l|l}
5 & 6 \\
\end{tabular} & \begin{tabular}{|l|l|}
7 & 8 \\
\end{tabular} & 9 & $>=9.5$ & No comp. & \multirow{2}{*}{\multicolumn{2}{|c|}{$\begin{array}{l}\text { 5Achieving Gold } \\
\text { status of certifica } \\
\text { 5Achieving Gold } \\
\text { status of certifica }\end{array}$}} \\
\hline & & & $>=9.5$ & 9 & 8 & 7 & 6 & 5 & 4 & 3 & 2 & 2 & 3 & \begin{tabular}{l|l}
4 & 5 \\
\end{tabular} & \begin{tabular}{|l|l|}
5 & 6 \\
\end{tabular} & \begin{tabular}{|l|l|}
7 & 8 \\
\end{tabular} & 9 & $>=9.5$ & No comp. & & \\
\hline
\end{tabular}


Node comparison set 11 (For major employers' representatives, allocated time $=6$ minutes):

1. For major employers in Cranberry Township, how much more important is building a compost facility than purchasing alternative fuel vehicles for township fleet? (Or, vice versa)

2. For major employers in Cranberry Township, how much more important is building a compost facility than procurement of renewable energy certificates (RECs)? (Or, vice versa)

3. For major employers in Cranberry Township, how much more important is building a compost facility than implementing a public transportation system? (Or, vice versa)

4. For major employers in Cranberry Township, how much more important is building a compost facility than achieving gold status of certification for Municipal Center? (Or, vice versa)

5. For major employers in Cranberry Township, how much more important purchasing alternative fuel vehicles for township fleet than procurement of renewable energy certificates (RECs)? (Or, vice versa)

6. For major employers in Cranberry Township, how much more important purchasing alternative fuel vehicles for township fleet than implementing a public transportation system? (Or, vice versa)

7. For major employers in Cranberry Township, how much more important purchasing alternative fuel vehicles for township fleet than achieving gold status of certification for Municipal Center? (Or, vice versa)

8. For major employers in Cranberry Township, how much more important procurement of renewable energy certificates (RECs) than implementing a public transportation system? (Or, vice versa) 
9. For major employers in Cranberry Township, how much more important procurement of renewable energy certificates (RECs) than achieving gold status of certification for Municipal Center? (Or, vice versa)

10. For major employers in Cranberry Township, how much more important implementing a public transportation system than achieving gold status of certification for Municipal Center?

(Or, vice versa)

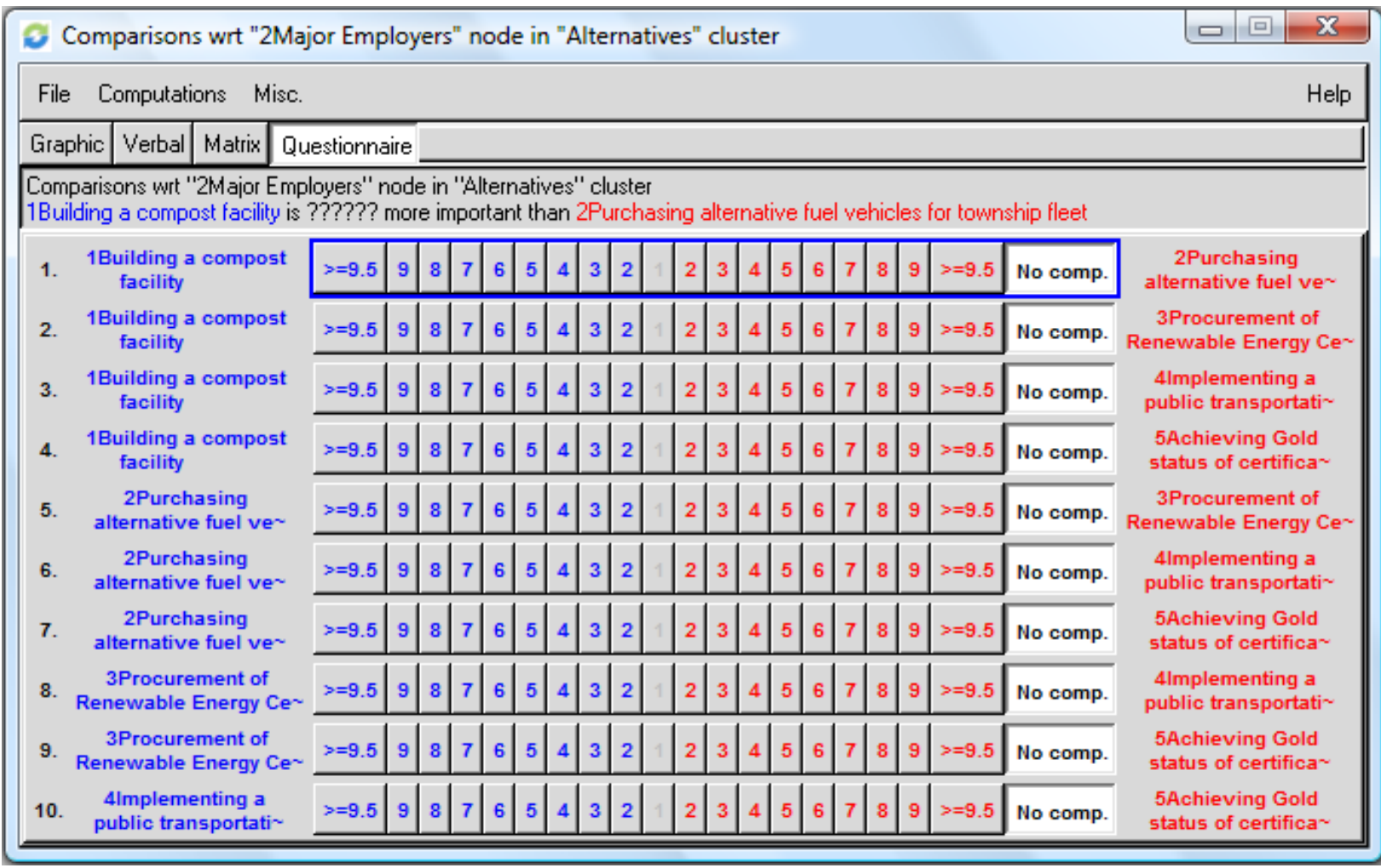

\section{D.4 CHECKLIST FOR STAKEHOLDER MEETINGS DOCUMENT}

In order to spend the allocated time efficiently and get rid of possible mistakes/problems during the stakeholder meetings, a checklist document was prepared and used. 


\section{Copy of Checklist for Stakeholder Meetings Document}

1. Give a piece of paper, pen/pencil and rubber to the stakeholder representative

2. Make sure that all the pairwise comparisons have an inconsistency less than 0.1

3. Make sure to save the prioritized ANP file in a secure place

4. Make sure to give a business card to the stakeholder representative

5. Make sure to receive a business card from the stakeholder representative

6. After meeting, send a thank you e-mail to the stakeholder representative 


\section{APPENDIX E}

\section{VEHICLE REPLACEMENT PROGRAM}

Vehicle Replacement Program provides the guidelines that are currently used by the Cranberry Township management while making decisions related to the replacement of the vehicles in the township fleet. 


\section{Vehicle Replacement Program}

The guidelines set below are established to prescribe a replacement schedule for all fleet vehicles and equipment operated by Township. Vehicle and equipment replacement programs evolve around several different sound business reasons, maintenance cost, reliability, employee safety, and employee moral. Maintaining mission critical vehicles is extremely important although maintaining equipment to project a professional image and maintain employee satisfaction and productivity are also considered. Keeping in mind there are uncontrollable factors such as major failures, accidents or natural disaster to be considered as well.

Incorporating a Best Practice management theory to determine the ideal time to replace a vehicle or piece of equipment before the maintenance and repair costs are higher than the value of the item.

The criteria listed below was collected by the American Public Works Association (APWA). The data was is a compliation of the US Government, Canadian and a private leasing company.

Replacement cost criteria

\begin{tabular}{|l|l|l|c|}
\hline Vehicle Type & Age criteria & Usage criteria & $\begin{array}{l}\text { Point } \\
\text { Replacement }\end{array}$ \\
\hline Admin vehicle & $5-10$ years & $75,000-100 \mathrm{~K}$ miles & 23 \\
\hline Police vehicle & $1-3$ years & $85,000-100 \mathrm{~K}$ miles & 23 \\
\hline Medium Duty, gas & $7-10$ years & $100,000-120 \mathrm{~K}$ miles & 25 \\
\hline Medium Duty, diesel $(350,450,550)$ & $10-12$ years & $150,000-250 \mathrm{~K}$ miles & 38 \\
\hline Heavy Duty, diesel $(1$ axle, 2 axle) & $12-15$ years & $150,000-250 \mathrm{~K}$ miles & 40 \\
\hline Heavy Equip( loader, backhoe) & $7-10$ years & $6,000-10 \mathrm{~K}$ hours & 32 \\
\hline Lawn Tractors, diesel $(>50 \mathrm{hp})$ & $7-10$ years & $8,000-10 \mathrm{~K}$ hours & 34 \\
\hline Lawn Mowers ( $<50 \mathrm{hp})$ & $7-10$ years & $8,000-10 \mathrm{~K}$ hours & 34 \\
\hline Trailer(>5 ton) & $15-20$ years & N/A & 28 \\
\hline Street Sweeper & $10-12$ years & 75,000 -100K miles & 30 \\
\hline
\end{tabular}




\begin{tabular}{|l|l|l|l|}
\hline mini/ midi excavator & $5-7$ years & $6,000-7,000$ hours & \\
\hline Skid Steer & $5-7$ years & $6,000-7,000$ hours & \\
\hline & & & \\
\hline
\end{tabular}

Replacement Analysis: Yearly evaluation of vehicles and equipment using a point system. The system uses a number system of $1-5$. One being the highest score and 5 being the lowest score. Since our record keeping is revolves around preventive maintenance or a use basis our emphasis is on use, not age.

Example

reference APWA Vehicle Replacement Guide

\begin{tabular}{|c|c|c|c|c|c|c|c|c|c|c|c|}
\hline $\begin{array}{l}\text { Vabiclo } \\
\text { (IDik) } \\
\text { milago }\end{array}$ & Year & $\begin{array}{l}\text { Purchase } \\
\text { price (\$) }\end{array}$ & $\begin{array}{l}\text { Replacement } \\
\text { (\$) }\end{array}$ & $\begin{array}{l}\text { MskR } \\
\text { (5) }\end{array}$ & $\begin{array}{l}\text { Agre } \\
\text { (pt) }\end{array}$ & $\begin{array}{l}\text { milzgo } \\
\text { (pt) }\end{array}$ & $\begin{array}{l}\text { Rolisbility } \\
\text { (pt) }\end{array}$ & $\begin{array}{l}\text { Use } \\
(\mathrm{pt})\end{array}$ & $\begin{array}{l}\text { M\&R } \\
\text { (pt) }\end{array}$ & $\begin{array}{l}\text { Coudition } \\
\text { (pt) }\end{array}$ & Total \\
\hline $\begin{array}{l}\text { sad } z= \\
(10042) \\
85000\end{array}$ & 1996 & $\$ 14,000$ & $\$ 16,000$ & $\$ 2,000$ & 8 & 8.5 & 3 & 1 & 2 & 4 & 26.5 \\
\hline & & & & & & & & & & & \\
\hline
\end{tabular}

Purchase price: $\quad$ Actual purchase price of item

Age: $\quad$ The number of years old, one point per year

Milage: $\quad 1$ point for every 10,000 miles or 2000 hours

Reliability: $\quad 1,3$ or 5 points assigned based on the frequence the vehicle is in the shop for repair. Reactive work orders. A 5 for over 2 times a month, 3 for 2 times a half year, a 1 for 2 times a year

Use: $\quad$ Emergence or mission critical vehicles or back up replacement readily available. 1,3 or 5,5 for emergence and critical, 3 for operations other than service, 1 for administration.

Maintain \& repair: Cost associated with work performed to the vehicle, in house and out of house. $1-5,5$ for expenses over $50 \%$ of the purchase price , 1 for expenses less than $30 \%$ of the purchase price.

Condition: $\quad$ The overall condition interior and exterior. $1-5,5$ being the poorest.

See the replacement criteria table for minimum replacement points. 


\section{APPENDIX F}

\section{THREE-STAGE STOCHASTIC LINEAR PROGRAM FOR K=1}

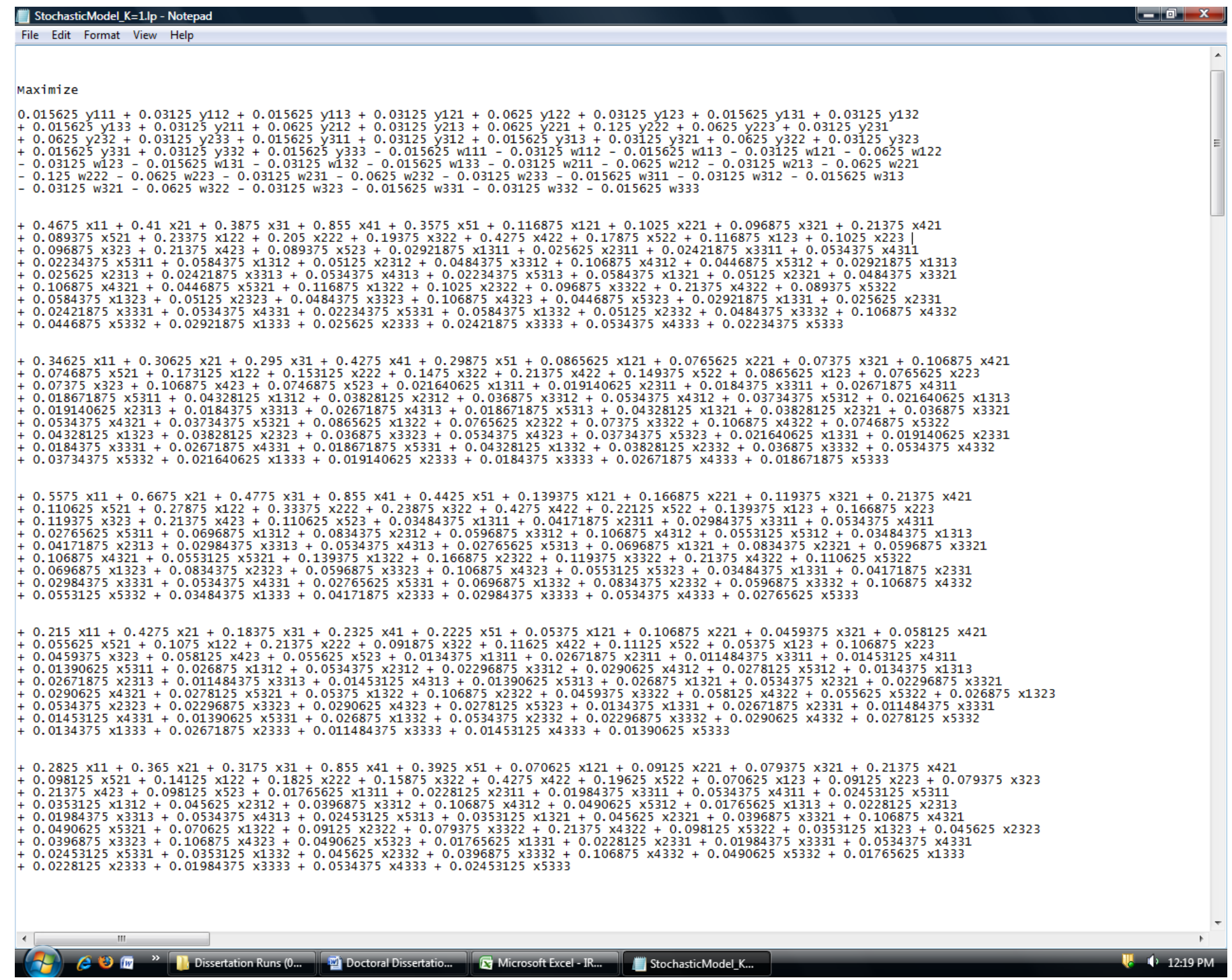


subject To $x 11+x 21+x 31+x 41+x 51=7$

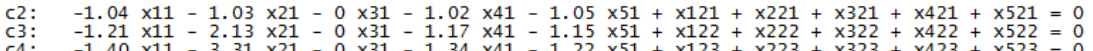

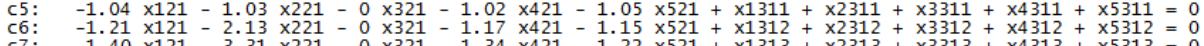

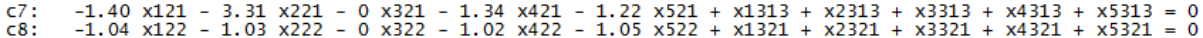

C9: $\quad-1.21 \times 122-2.13 \times 222-0 \times 322-1.17 \times 422-1.15 \times 522+\times 1322+\times 2322+\times 3322+\times 4322+\times 5322=0$

x122-3.31 $\times 222-0 \times 322-1.34 \times 422-1.22 \times 522+\times 1323+\times 2323+\times 3323+\times 4323+\times 5323=0$

$\mathrm{c} 12:-1.21 \times 123-2.13 \times 223-0 \times 323-1.17 \times 423-1.15 \times 523+\times 1332+\times 2332+\times 3332+\times 4332+\times 5332=0$
$\mathrm{c}^{3}:-1.40 \times 123-3.31 \times 223-0 \times 323-1.34 \times 423-1.22 \times 523+\times 1333+\times 2333+\times 3333+\times 4333+\times 5333=0$

$\begin{array}{lll}\mathrm{c} 14: & 1.04 \times 1311+1.03 \times 2311+0 \times 3311+1.02 \times 4311+1.05 \times 5311-\mathrm{y} 1111+\mathrm{w} 1111=0 \\ \mathrm{c} 15: & 1.21 \times 1311+2.13 \times 2311+0 \times 3311+1.17 \times 4311+1.15 \times 5311-\mathrm{y} 112+\mathrm{w} 112=0\end{array}$

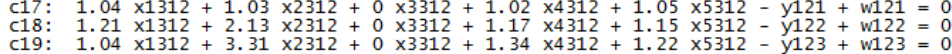

$c 20: 1.04 \times 1313+1.03 \times 2313+0 \times 3313+1.02 \times 4313+1.05 \times 5313-y 131+w 131=0$

$\begin{array}{lll}\mathrm{c} 21: & 1.21 \times 1313+2.13 \times 2313+0 \times 3313+1.17 \times 4313+1.15 \times 5313-\mathrm{y} 132+\mathrm{w} 132=0 \\ \mathrm{c} 22: & 1.04 \times 1313+3.31 \times 2313+0 \times 3313+1.34 \times 4313+1.22 \times 5313-\mathrm{y} 133+\mathrm{w} 133=0\end{array}$

$c 23: 1.04 \times 1321+1.03 \times 2321+0 \times 3321+1.02 \times 4321+1.05 \times 5321-y 211+w 211=0$

$\begin{array}{lll}\mathrm{C} 24: & 1.21 \times 1321+2.13 \times 2321+0 \times 3321+1.17 \times 4321+1.15 \times 5321-\mathrm{y} 212+\mathrm{w} 212=0 \\ \mathrm{C} 25: & 1.04 \times 1321+3.31 \times 2321+0 \times 3321+1.34 \times 4321+1.22 \times 5321-\mathrm{y} 213+\mathrm{w} 213=0\end{array}$

c26: $1.04 \times 1322+1.03 \times 2322+0 \times 3322+1.02 \times 4322+1.05 \times 5322-\mathrm{y} 221+\mathrm{w} 221=0$

$\begin{array}{ll}\mathrm{C} 27: & 1.21 \times 1322+2.13 \times 2322+0 \times 3322+1.17 \times 4322+1.15 \times 5322-\mathrm{y} 222+\mathrm{w} 222=0 \\ \mathrm{c} 28: & 1.04 \times 1322+3.31 \times 2322+0 \times 3322+1.34 \times 4322+1.22 \times 5322-\mathrm{y} 223+\mathrm{w} 223=0\end{array}$

$c 29: 1.04 \times 1323+1.03 \times 2323+0 \times 3323+1.02 \times 4323+1.05 \times 5323-y 231+w 231=0$

$\begin{array}{lll}\text { c30: } & 1.21 \times 1323+2.13 \times 2323+0 \times 3323+1.17 \times 4323+1.15 \times 5323-\mathrm{y} 232+\mathrm{w} 232=0 \\ \text { c31: } & 1.04 \times 1323+3.31 \times 2323+0 \times 3323+1.34 \times 4323+1.22 \times 5323-\mathrm{y} 233+\mathrm{w} 233=0\end{array}$

C32: $1.04 \times 1331+1.03 \times 2331+0 \times 3331+1.02 \times 4331+1.05 \times 5331-\mathrm{y} 311+\mathrm{w} 311=0$
c33: $1.21 \times 1331+2.13 \times 2331+0 \times 3331+1.17 \times 4331+1.15 \times 5331-\mathrm{y} 312+\mathrm{w} 312=0$

c34: $1.04 \times 1331+3.31 \times 2331+0 \times 3331+1.34 \times 4331+1.22 \times 5331-\mathrm{y} 313+\mathrm{w} 313=0$

c35: $1.04 \times 1332+1.03 \times 2332+0 \times 3332+1.02 \times 4332+1.05 \times 5332-\mathrm{y} 321+\mathrm{w} 321=0$
c36: $1.21 \times 1332+2.13 \times 2332+0 \times 3332+1.17 \times 432+1.15 \times 5332-\mathrm{y} 222+\mathrm{w} 222=0$
c37: $1.04 \times 1332+3.31 \times 2332+0 \times 3332+1.34 \times 4332+1.22 \times 5332-\mathrm{y} 323+\mathrm{w} 323=0$

c38: $1.04 \times 1333+1.03 \times 2333+0 \times 3333+1.02 \times 4333+1.05 \times 5333-y 331+w 331=0$

$\begin{array}{ll}\mathrm{c} 39: & 1.21 \times 1333+2.13 \times 2333+0 \times 3333+1.17 \times 4333+1.15 \times 5333-\mathrm{y} 332+\mathrm{w} 332=0 \\ \mathrm{C} 40: & 1.04 \times 1333+3.31 \times 2333+0 \times 3333+1.34 \times 4333+1.22 \times 5333-\mathrm{y} 333+\mathrm{w} 333=0\end{array}$

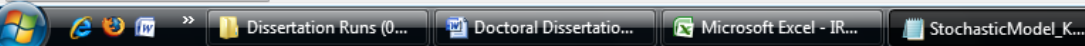




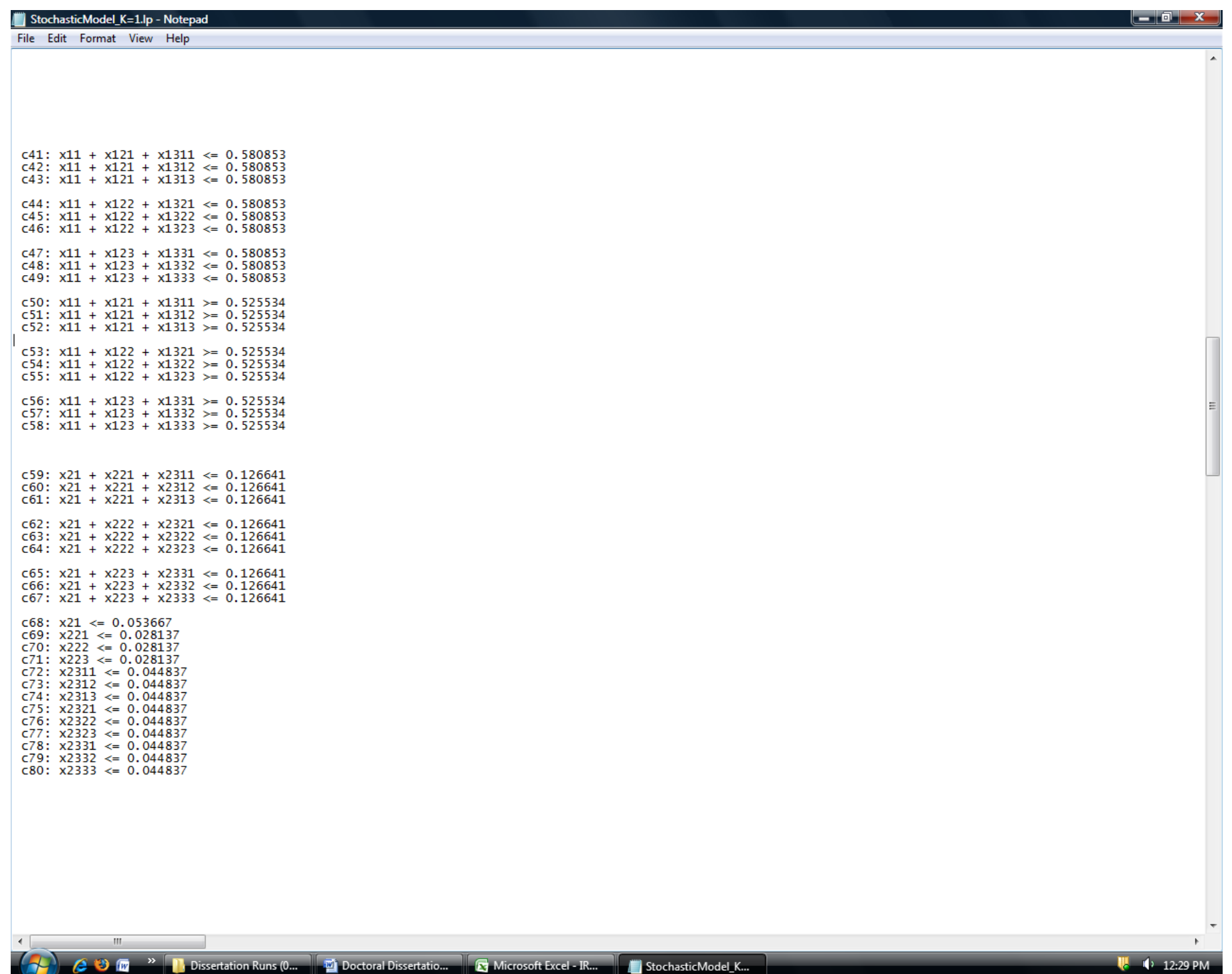

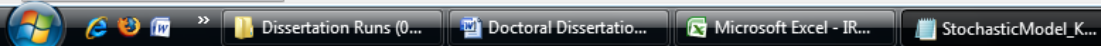




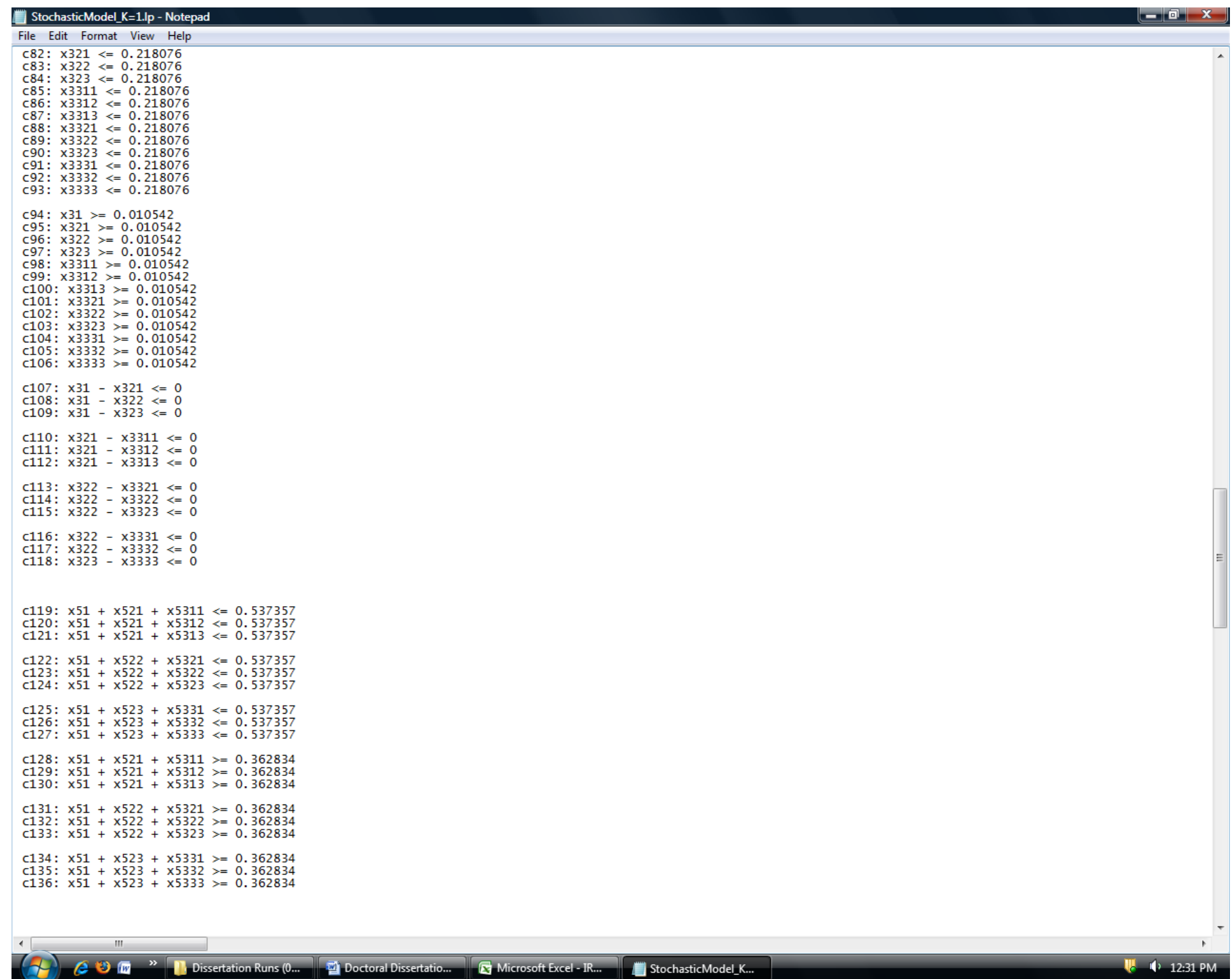




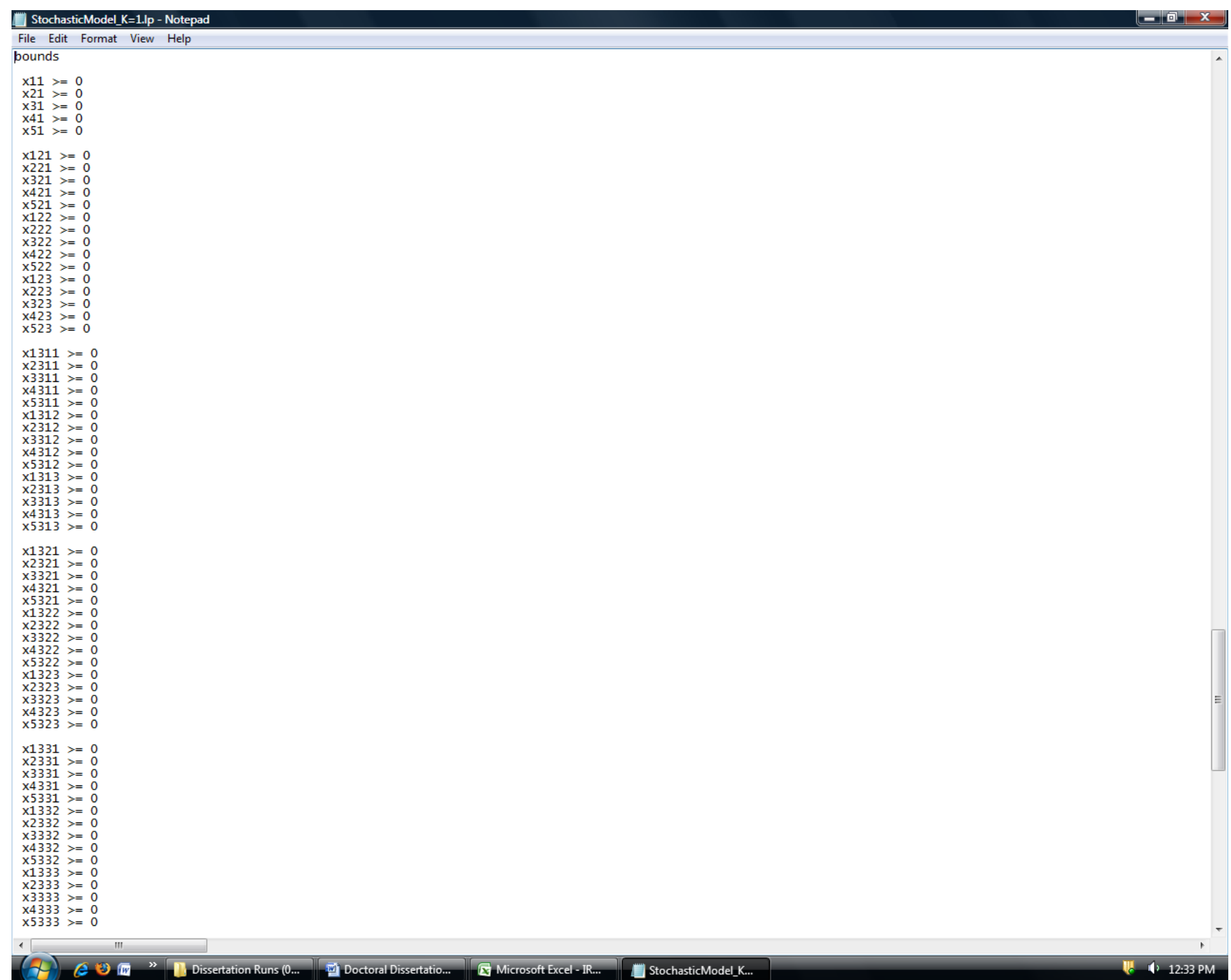




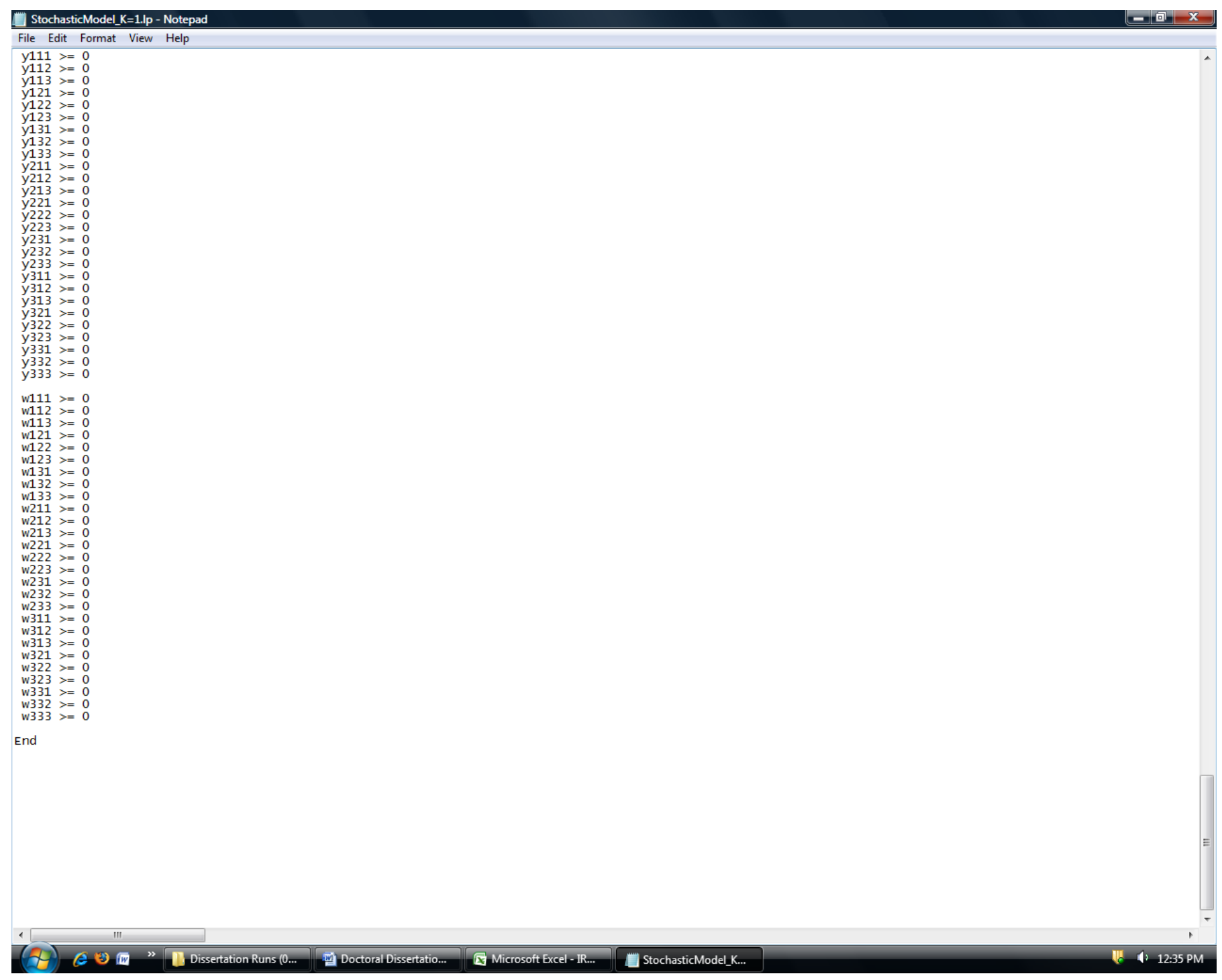




\section{APPENDIX G}

\section{G.1 DETAILS OF MODEL 2 RESULTS}

\begin{tabular}{|c|c|c|}
\hline \multicolumn{3}{|c|}{ Model 2 Investment Portfolios for $b=\$ 283,000$} \\
\hline $\begin{array}{l}\text { Investment } \\
\text { Amount (\$) }\end{array}$ & $\begin{array}{l}\text { Investment } \\
\text { Portfolio } 1\end{array}$ & $\begin{array}{l}\text { Investment } \\
\text { Portfolio } 2\end{array}$ \\
\hline$x(1,1)$ & 155,417 & 155,417 \\
\hline$x(2,1)$ & 0 & 0 \\
\hline$x(3,1)$ & 0 & 0 \\
\hline$x(4,1)$ & 0 & 0 \\
\hline$x(5,1)$ & 127,583 & 127,583 \\
\hline$x(1,2,1)$ & 60,345 & 60,345 \\
\hline$x(2,2,1)$ & 0 & 0 \\
\hline$x(3,2,1)$ & 0 & 0 \\
\hline$x(4,2,1)$ & 0 & 0 \\
\hline$x(5,2,1)$ & 235,251 & 235,251 \\
\hline$x(1,2,2)$ & 306,638 & 306,638 \\
\hline$x(2,2,2)$ & 28,137 & 28,137 \\
\hline$x(3,2,2)$ & 0 & 0 \\
\hline$x(4,2,2)$ & 0 & 0 \\
\hline$x(5,2,2)$ & 0 & 0 \\
\hline$x(1,2,3)$ & 345,098 & 345,098 \\
\hline$x(2,2,3)$ & 28,137 & 28,137 \\
\hline$x(3,2,3)$ & 0 & 0 \\
\hline$x(4,2,3)$ & 0 & 0 \\
\hline$x(5,2,3)$ & 0 & 0 \\
\hline
\end{tabular}




\begin{tabular}{|c|c|c|}
\hline $\begin{array}{c}\text { Investment } \\
\text { Amount } \mathbf{( \$ )}\end{array}$ & $\begin{array}{c}\text { Investment } \\
\text { Portfolio 1 }\end{array}$ & $\begin{array}{c}\text { Investment } \\
\text { Portfolio 2 }\end{array}$ \\
\hline$x(1,3,1,1)$ & 309,772 & 309,772 \\
\hline$x(2,3,1,1)$ & 0 & 0 \\
\hline$x(3,3,1,1)$ & 0 & 0 \\
\hline$x(4,3,1,1)$ & 0 & 0 \\
\hline$x(5,3,1,1)$ & 0 & 0 \\
\hline$x(1,3,1,2)$ & 309,772 & 309,772 \\
\hline$x(2,3,1,2)$ & 33,784 & 0 \\
\hline$x(3,3,1,2)$ & 0 & 0 \\
\hline$x(4,3,1,2)$ & 0 & 33,784 \\
\hline$x(5,3,1,2)$ & 0 & 0 \\
\hline$x(1,3,1,3)$ & 309,772 & 309,772 \\
\hline$x(2,3,1,3)$ & 44,837 & 0 \\
\hline$x(3,3,1,3)$ & 0 & 0 \\
\hline$x(4,3,1,3)$ & 16,880 & 61,717 \\
\hline$x(5,3,1,3)$ & 0 & 0 \\
\hline$x(1,3,2,1)$ & 63,479 & 63,479 \\
\hline$x(2,3,2,1)$ & 44,837 & 0 \\
\hline$x(3,3,2,1)$ & 0 & 0 \\
\hline$x(4,3,2,1)$ & 4,318 & 49,155 \\
\hline$x(5,3,2,1)$ & 235,251 & 235,251 \\
\hline
\end{tabular}




\begin{tabular}{|c|c|c|}
\hline $\begin{array}{c}\text { Investment } \\
\text { Amount (\$) }\end{array}$ & $\begin{array}{c}\text { Investment } \\
\text { Portfolio 1 }\end{array}$ & $\begin{array}{c}\text { Investment } \\
\text { Portfolio 2 }\end{array}$ \\
\hline$x(1,3,2,2)$ & 63,479 & 63,479 \\
\hline$x(2,3,2,2)$ & 44,837 & 0 \\
\hline$x(3,3,2,2)$ & 0 & 0 \\
\hline$x(4,3,2,2)$ & 87,397 & 132,234 \\
\hline$x(5,3,2,2)$ & 235,251 & 235,251 \\
\hline$x(1,3,2,3)$ & 63,479 & 63,479 \\
\hline$x(2,3,2,3)$ & 44,837 & 0 \\
\hline$x(3,3,2,3)$ & 0 & 0 \\
\hline$x(4,3,2,3)$ & 178,860 & 223,697 \\
\hline$x(5,3,2,3)$ & 235,251 & 235,251 \\
\hline$x(1,3,3,1)$ & 25,019 & 25,019 \\
\hline$x(2,3,3,1)$ & 44,837 & 0 \\
\hline$x(3,3,3,1)$ & 0 & 0 \\
\hline$x(4,3,3,1)$ & 82,776 & 127,613 \\
\hline$x(5,3,3,1)$ & 235,251 & 235,251 \\
\hline$x(1,3,3,2)$ & 25,019 & 25,019 \\
\hline$x(2,3,3,2)$ & 44,837 & 0 \\
\hline$x(3,3,3,2)$ & 0 & 0 \\
\hline$x(4,3,3,2)$ & 172,394 & 217,231 \\
\hline$x(5,3,3,2)$ & 235,251 & 235,251 \\
\hline$x(1,3,3,3)$ & 25,019 & 25,019 \\
\hline$x(2,3,3,3)$ & 44,837 & 0 \\
\hline$x(3,3,3,3)$ & 0 & 0 \\
\hline$x(4,3,3,3)$ & 271,164 & 316,001 \\
\hline$x(5,3,3,3)$ & 235,251 & 235,251 \\
\hline
\end{tabular}




\begin{tabular}{|c|c|c|c|c|}
\hline \multicolumn{5}{|c|}{ Model 2 Investment Portfolios for b=\$5,000,000 } \\
\hline $\begin{array}{c}\text { Planning } \\
\text { Horizon }\end{array}$ & $\begin{array}{c}\text { Investment } \\
\text { Amount (\$) }\end{array}$ & $\begin{array}{c}\text { Investment } \\
\text { Portfolio 1 }\end{array}$ & $\begin{array}{c}\text { Investment } \\
\text { Portfolio 2 }\end{array}$ & $\begin{array}{c}\text { Investment } \\
\text { Portfolio 3 }\end{array}$ \\
\hline \multirow{4}{*}{} & $x(1,1)$ & 580,853 & 525,534 & 525,534 \\
\cline { 2 - 5 } & $x(2,1)$ & 53,667 & 53,667 & 53,667 \\
\cline { 2 - 5 } & $x(3,1)$ & 0 & 0 & 0 \\
\cline { 2 - 5 } & $x(4,1)$ & $4,365,480$ & $4,420,799$ & $4,420,799$ \\
\cline { 2 - 5 } & $x(5,1)$ & 0 & 0 & 0 \\
\hline \multirow{4}{*}{} & $x(1,2,1)$ & 0 & 0 & 0 \\
\cline { 2 - 5 } & $x(2,2,1)$ & 28,137 & 28,137 & 28,137 \\
\cline { 2 - 5 } & $x(3,2,1)$ & 0 & 0 & 0 \\
\cline { 2 - 5 } & $x(4,2,1)$ & $5,084,017$ & $5,082,910$ & $5,082,910$ \\
\cline { 2 - 5 } & $x(5,2,1)$ & 0 & 0 & 0 \\
\cline { 2 - 5 } & $x(1,2,2)$ & 0 & 0 & 0 \\
\cline { 2 - 5 } & $x(2,2,2)$ & 28,137 & 28,137 & 28,137 \\
\cline { 2 - 5 } & $x(3,2,2)$ & 0 & 0 & 0 \\
\cline { 2 - 5 } & $x(4,2,2)$ & $5,896,617$ & $5,894,405$ & $5,894,405$ \\
\cline { 2 - 5 } & $x(5,2,2)$ & 0 & 0 & 0 \\
\cline { 2 - 5 } & $x(1,2,3)$ & 0 & 0 & 0 \\
\cline { 2 - 5 } & $x(2,2,3)$ & 28,137 & 28,137 & 28,137 \\
\cline { 2 - 5 } & $x(3,2,3)$ & 0 & 0 & 0 \\
\cline { 2 - 5 } & $x(4,2,3)$ & $6,812,438$ & $6,809,119$ & $6,809,119$ \\
\cline { 2 - 5 } & $x(5,2,3)$ & 0 & 0 & 0 \\
\hline
\end{tabular}




\begin{tabular}{|c|c|c|c|c|}
\hline $\begin{array}{c}\text { Planning } \\
\text { Horizon }\end{array}$ & $\begin{array}{l}\text { Investment } \\
\text { Amount (\$) }\end{array}$ & $\begin{array}{l}\text { Investment } \\
\text { Portfolio } 1\end{array}$ & $\begin{array}{l}\text { Investment } \\
\text { Portfolio } 2 \\
\end{array}$ & $\begin{array}{l}\text { Investment } \\
\text { Portfolio } 2 \\
\end{array}$ \\
\hline \multirow{20}{*}{ 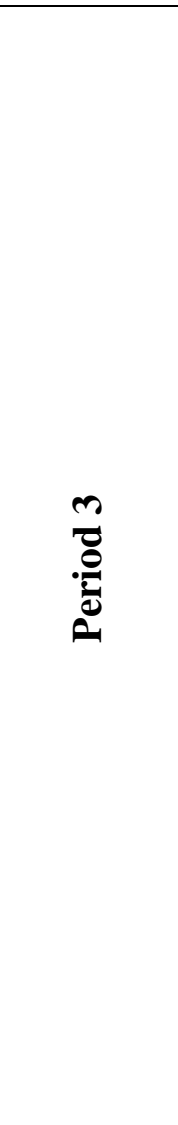 } & $x(1,3,1,1)$ & 0 & 0 & 0 \\
\hline & $x(2,3,1,1)$ & 44,837 & 44,837 & 0 \\
\hline & $x(3,3,1,1)$ & 0 & 0 & 0 \\
\hline & $x(4,3,1,1)$ & $4,807,007$ & $4,805,879$ & $4,850,716$ \\
\hline & $x(5,3,1,1)$ & 362,834 & 362,834 & 362,834 \\
\hline & $x(1,3,1,2)$ & 0 & 0 & 0 \\
\hline & $x(2,3,1,2)$ & 44,837 & 44,837 & 0 \\
\hline & $x(3,3,1,2)$ & 0 & 0 & 0 \\
\hline & $x(4,3,1,2)$ & $5,600,560$ & $5,599,266$ & $5,644,103$ \\
\hline & $x(5,3,1,2)$ & 362,834 & 362,834 & 362,834 \\
\hline & $x(1,3,1,3)$ & 0 & 0 & 0 \\
\hline & $x(2,3,1,3)$ & 44,837 & 44,837 & 0 \\
\hline & $x(3,3,1,3)$ & 0 & 0 & 0 \\
\hline & $x(4,3,1,3)$ & $6,498,045$ & $6,496,562$ & $6,541,399$ \\
\hline & $x(5,3,1,3)$ & 362,834 & 362,834 & 362,834 \\
\hline & $x(1,3,2,1)$ & 0 & 0 & 0 \\
\hline & $x(2,3,2,1)$ & 44,837 & 44,837 & 0 \\
\hline & $x(3,3,2,1)$ & 0 & 0 & 0 \\
\hline & $x(4,3,2,1)$ & $5,635,860$ & $5,633,603$ & $5,678,440$ \\
\hline & $x(5,3,2,1)$ & 362,834 & 362,834 & 362,834 \\
\hline
\end{tabular}




\begin{tabular}{|c|c|c|c|c|}
\hline $\begin{array}{l}\text { Planning } \\
\text { Horizon }\end{array}$ & $\begin{array}{l}\text { Investment } \\
\text { Amount (\$) }\end{array}$ & $\begin{array}{l}\text { Investment } \\
\text { Portfolio } 1\end{array}$ & $\begin{array}{l}\text { Investment } \\
\text { Portfolio } 2\end{array}$ & $\begin{array}{l}\text { Investment } \\
\text { Portfolio } 2\end{array}$ \\
\hline \multirow{25}{*}{ م } & $x(1,3,2,2)$ & 0 & 0 & 0 \\
\hline & $x(2,3,2,2)$ & 44,837 & 44,837 & 0 \\
\hline & $x(3,3,2,2)$ & 0 & 0 & 0 \\
\hline & $x(4,3,2,2)$ & $6,551,303$ & $6,548,714$ & $6,593,551$ \\
\hline & $x(5,3,2,2)$ & 362,834 & 362,834 & 362,834 \\
\hline & $x(1,3,2,3)$ & 0 & 0 & 0 \\
\hline & $x(2,3,2,3)$ & 44,837 & 44,837 & 0 \\
\hline & $x(3,3,2,3)$ & 0 & 0 & 0 \\
\hline & $x(4,3,2,3)$ & $7,586,930$ & $7,583,965$ & $7,628,802$ \\
\hline & $x(5,3,2,3)$ & 362,834 & 362,834 & 362,834 \\
\hline & $x(1,3,3,1)$ & 0 & 0 & 0 \\
\hline & $x(2,3,3,1)$ & 44,837 & 44,837 & 0 \\
\hline & $x(3,3,3,1)$ & 0 & 0 & 0 \\
\hline & $x(4,3,3,1)$ & $6,569,997$ & $6,566,612$ & $6,611,449$ \\
\hline & $x(5,3,3,1)$ & 362,834 & 362,834 & 362,834 \\
\hline & $x(1,3,3,2)$ & 0 & 0 & 0 \\
\hline & $x(2,3,3,2)$ & 44,837 & 44,837 & 0 \\
\hline & $x(3,3,3,2)$ & 0 & 0 & 0 \\
\hline & $x(4,3,3,2)$ & $7,622,813$ & $7,618,930$ & $7,663,767$ \\
\hline & $x(5,3,3,2)$ & 362,834 & 362,834 & 362,834 \\
\hline & $x(1,3,3,3)$ & 0 & 0 & 0 \\
\hline & $x(2,3,3,3)$ & 44,837 & 44,837 & 0 \\
\hline & $x(3,3,3,3)$ & 0 & 0 & 0 \\
\hline & $x(4,3,3,3)$ & $8,814,130$ & $8,809,682$ & $8,854,519$ \\
\hline & $x(5,3,3,3)$ & 362,834 & 362,834 & 362,834 \\
\hline
\end{tabular}




\begin{tabular}{|c|c|c|c|c|}
\hline \multicolumn{5}{|c|}{ Model 2 Investment Portfolios for b=\$6,000,000 } \\
\hline $\begin{array}{c}\text { Planning } \\
\text { Horizon }\end{array}$ & $\begin{array}{c}\text { Investment } \\
\text { Amount } \mathbf{\$})\end{array}$ & $\begin{array}{c}\text { Investment } \\
\text { Portfolio 1 }\end{array}$ & $\begin{array}{c}\text { Investment } \\
\text { Portfolio 2 }\end{array}$ & $\begin{array}{c}\text { Investment } \\
\text { Portfolio 3 }\end{array}$ \\
\hline \multirow{4}{*}{} & $x(1,1)$ & 580,853 & 525,534 & 525,534 \\
\cline { 2 - 5 } & $x(2,1)$ & 53,667 & 53,667 & 53,667 \\
\cline { 2 - 5 } & $x(3,1)$ & 0 & 0 & 0 \\
\cline { 2 - 5 } & $x(4,1)$ & $5,365,480$ & $5,420,799$ & $5,420,799$ \\
\cline { 2 - 5 } & $x(5,1)$ & 0 & 0 & 0 \\
\hline \multirow{4}{*}{} & $x(1,2,1)$ & 0 & 0 & 0 \\
\cline { 2 - 5 } & $x(2,2,1)$ & 28,137 & 28,137 & 28,137 \\
\cline { 2 - 5 } & $x(3,2,1)$ & 0 & 0 & 0 \\
\cline { 2 - 5 } & $x(4,2,1)$ & $6,104,017$ & $6,102,910$ & $6,102,910$ \\
\cline { 2 - 5 } & $x(5,2,1)$ & 0 & 0 & 0 \\
\cline { 2 - 5 } & $x(1,2,2)$ & 0 & 0 & 0 \\
\cline { 2 - 5 } & $x(2,2,2)$ & 28,137 & 28,137 & 28,137 \\
\cline { 2 - 5 } & $x(3,2,2)$ & 0 & 0 & 0 \\
\cline { 2 - 5 } & $x(4,2,2)$ & $7,066,617$ & $7,064,405$ & $7,064,405$ \\
\cline { 2 - 5 } & $x(5,2,2)$ & 0 & 0 & 0 \\
\cline { 2 - 5 } & $x(1,2,3)$ & 0 & 0 & 0 \\
\cline { 2 - 5 } & $x(2,2,3)$ & 28,137 & 28,137 & 28,137 \\
\cline { 2 - 5 } & $x(3,2,3)$ & 0 & 0 & 0 \\
\cline { 2 - 5 } & $x(4,2,3)$ & $8,152,438$ & $8,149,119$ & $8,149,119$ \\
\cline { 2 - 5 } & $x(5,2,3)$ & 0 & 0 & 0 \\
\hline
\end{tabular}




\begin{tabular}{|c|c|c|c|c|}
\hline $\begin{array}{c}\text { Planning } \\
\text { Horizon }\end{array}$ & $\begin{array}{l}\text { Investment } \\
\text { Amount (\$) }\end{array}$ & $\begin{array}{l}\text { Investment } \\
\text { Portfolio } 1\end{array}$ & $\begin{array}{l}\text { Investment } \\
\text { Portfolio } 2\end{array}$ & $\begin{array}{l}\text { Investment } \\
\text { Portfolio } 2\end{array}$ \\
\hline \multirow{20}{*}{ 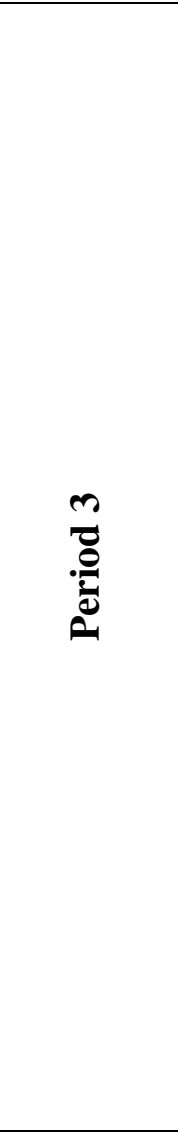 } & $x(1,3,1,1)$ & 0 & 0 & 0 \\
\hline & $x(2,3,1,1)$ & 44,837 & 44,837 & 0 \\
\hline & $x(3,3,1,1)$ & 0 & 0 & 0 \\
\hline & $x(4,3,1,1)$ & $5,847,407$ & $5,846,279$ & $5,891,116$ \\
\hline & $x(5,3,1,1)$ & 362,834 & 362,834 & 362,834 \\
\hline & $x(1,3,1,2)$ & 0 & 0 & 0 \\
\hline & $x(2,3,1,2)$ & 44,837 & 44,837 & 0 \\
\hline & $x(3,3,1,2)$ & 0 & 0 & 0 \\
\hline & $x(4,3,1,2)$ & $6,793,960$ & $6,792,666$ & $6,837,503$ \\
\hline & $x(5,3,1,2)$ & 362,834 & 362,834 & 362,834 \\
\hline & $x(1,3,1,3)$ & 0 & 0 & 0 \\
\hline & $x(2,3,1,3)$ & 44,837 & 44,837 & 0 \\
\hline & $x(3,3,1,3)$ & 0 & 0 & 0 \\
\hline & $x(4,3,1,3)$ & $7,864,845$ & $7,863,362$ & $7,908,199$ \\
\hline & $x(5,3,1,3)$ & 362,834 & 362,834 & 362,834 \\
\hline & $x(1,3,2,1)$ & 0 & 0 & 0 \\
\hline & $x(2,3,2,1)$ & 44,837 & 44,837 & 0 \\
\hline & $x(3,3,2,1)$ & 0 & 0 & 0 \\
\hline & $x(4,3,2,1)$ & $6,829,260$ & $6,827,003$ & $6,871,840$ \\
\hline & $x(5,3,2,1)$ & 362,834 & 362,834 & 362,834 \\
\hline
\end{tabular}




\begin{tabular}{|c|c|c|c|c|}
\hline $\begin{array}{c}\text { Planning } \\
\text { Horizon }\end{array}$ & $\begin{array}{l}\text { Investment } \\
\text { Amount (\$) }\end{array}$ & $\begin{array}{l}\text { Investment } \\
\text { Portfolio } 1\end{array}$ & $\begin{array}{l}\text { Investment } \\
\text { Portfolio } 2 \\
\end{array}$ & $\begin{array}{l}\text { Investment } \\
\text { Portfolio } 2 \\
\end{array}$ \\
\hline \multirow{25}{*}{ 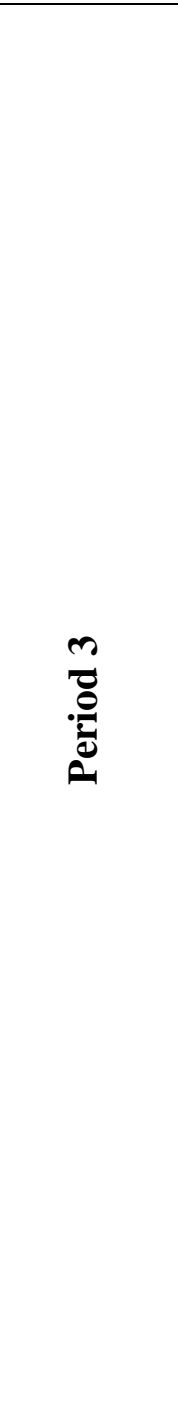 } & $x(1,3,2,2)$ & 0 & 0 & 0 \\
\hline & $x(2,3,2,2)$ & 44,837 & 44,837 & 0 \\
\hline & $x(3,3,2,2)$ & 0 & 0 & 0 \\
\hline & $x(4,3,2,2)$ & $7,920,203$ & 7,917,614 & $7,962,451$ \\
\hline & $x(5,3,2,2)$ & 362,834 & 362,834 & 362,834 \\
\hline & $x(1,3,2,3)$ & 0 & 0 & 0 \\
\hline & $x(2,3,2,3)$ & 44,837 & 44,837 & 0 \\
\hline & $x(3,3,2,3)$ & 0 & 0 & 0 \\
\hline & $x(4,3,2,3)$ & $9,154,730$ & $9,151,765$ & $9,196,602$ \\
\hline & $x(5,3,2,3)$ & 362,834 & 362,834 & 362,834 \\
\hline & $x(1,3,3,1)$ & 0 & 0 & 0 \\
\hline & $x(2,3,3,1)$ & 44,837 & 44,837 & 0 \\
\hline & $x(3,3,3,1)$ & 0 & 0 & 0 \\
\hline & $x(4,3,3,1)$ & $7,936,797$ & $7,933,412$ & $7,978,249$ \\
\hline & $x(5,3,3,1)$ & 362,834 & 362,834 & 362,834 \\
\hline & $x(1,3,3,2)$ & 0 & 0 & 0 \\
\hline & $x(2,3,3,2)$ & 44,837 & 44,837 & 0 \\
\hline & $x(3,3,3,2)$ & 0 & 0 & 0 \\
\hline & $x(4,3,3,2)$ & $9,190,613$ & $9,186,730$ & $9,231,567$ \\
\hline & $x(5,3,3,2)$ & 362,834 & 362,834 & 362,834 \\
\hline & $x(1,3,3,3)$ & 0 & 0 & 0 \\
\hline & $x(2,3,3,3)$ & 44,837 & 44,837 & 0 \\
\hline & $x(3,3,3,3)$ & 0 & 0 & 0 \\
\hline & $x(4,3,3,3)$ & $10,609,730$ & $10,605,280$ & $10,650,120$ \\
\hline & $x(5,3,3,3)$ & 362,834 & 362,834 & 362,834 \\
\hline
\end{tabular}




\begin{tabular}{|c|c|c|c|c|c|}
\hline \multicolumn{6}{|c|}{ Model 2 Investment Portfolios for $b=\$ 7,000,000$} \\
\hline $\begin{array}{l}\text { Planning } \\
\text { Horizon }\end{array}$ & $\begin{array}{l}\text { Investment } \\
\text { Amount (\$) }\end{array}$ & $\begin{array}{l}\text { Investment } \\
\text { Portfolio } 1\end{array}$ & $\begin{array}{c}\text { Investment } \\
\text { Portfolio } 2\end{array}$ & $\begin{array}{l}\text { Investment } \\
\text { Portfolio } 3\end{array}$ & $\begin{array}{l}\text { Investment } \\
\text { Portfolio } 4\end{array}$ \\
\hline \multirow{5}{*}{ 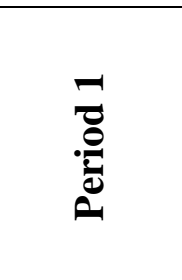 } & $x(1,1)$ & 580,853 & 525,534 & 525,534 & 525,534 \\
\hline & $x(2,1)$ & 53,667 & 53,667 & 53,667 & 53,667 \\
\hline & $x(3,1)$ & 0 & 0 & 0 & 0 \\
\hline & $x(4,1)$ & $6,105,891$ & $6,420,799$ & $6,420,799$ & $6,420,799$ \\
\hline & $x(5,1)$ & 259,589 & 0 & 0 & 0 \\
\hline \multirow{15}{*}{ 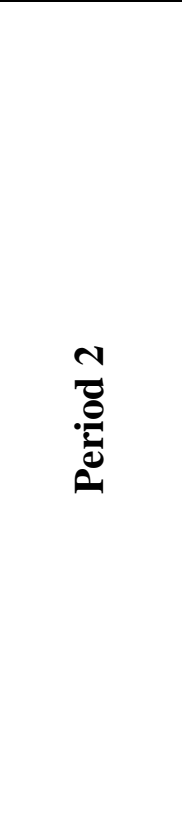 } & $x(1,2,1)$ & 0 & 0 & 0 & 0 \\
\hline & $x(2,2,1)$ & 28,137 & 28,137 & 28,137 & 28,137 \\
\hline & $x(3,2,1)$ & 0 & 0 & 0 & 0 \\
\hline & $x(4,2,1)$ & $7,131,804$ & $7,122,910$ & $7,122,910$ & $7,122,910$ \\
\hline & $x(5,2,1)$ & 0 & 0 & 0 & 0 \\
\hline & $x(1,2,2)$ & 0 & 0 & 0 & 0 \\
\hline & $x(2,2,2)$ & 28,137 & 28,137 & 28,137 & 28,137 \\
\hline & $x(3,2,2)$ & 0 & 0 & 0 & 0 \\
\hline & $x(4,2,2)$ & $8,231,426$ & $8,234,405$ & $8,234,405$ & $8,234,405$ \\
\hline & $x(5,2,2)$ & 0 & 0 & 0 & 0 \\
\hline & $x(1,2,3)$ & 0 & 0 & 0 & 0 \\
\hline & $x(2,2,3)$ & 28,137 & 28,137 & 28,137 & 28,137 \\
\hline & $x(3,2,3)$ & 0 & 0 & 0 & 0 \\
\hline & $x(4,2,3)$ & $9,183,520$ & $9,126,285$ & $9,489,119$ & $9,489,119$ \\
\hline & $x(5,2,3)$ & 277,768 & 362,834 & 0 & 0 \\
\hline
\end{tabular}




\begin{tabular}{|c|c|c|c|c|c|}
\hline $\begin{array}{l}\text { Planning } \\
\text { Horizon }\end{array}$ & $\begin{array}{l}\text { Investment } \\
\text { Amount (\$) }\end{array}$ & $\begin{array}{l}\text { Investment } \\
\text { Portfolio } 1\end{array}$ & $\begin{array}{l}\text { Investment } \\
\text { Portfolio } 2\end{array}$ & $\begin{array}{l}\text { Investment } \\
\text { Portfolio } 2\end{array}$ & $\begin{array}{l}\text { Investment } \\
\text { Portfolio } 2\end{array}$ \\
\hline \multirow{20}{*}{ 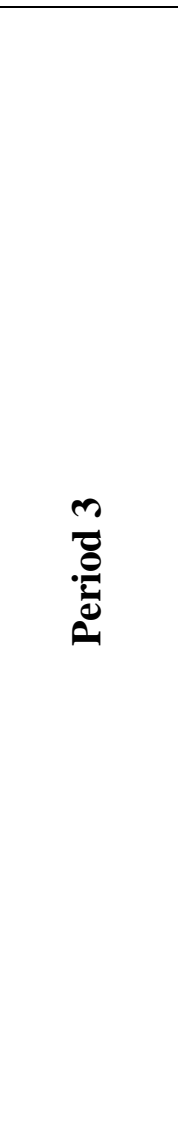 } & $x(1,3,1,1)$ & 0 & 0 & 0 & 0 \\
\hline & $x(2,3,1,1)$ & 44,837 & 44,837 & 44,837 & 0 \\
\hline & $x(3,3,1,1)$ & 0 & 0 & 0 & 0 \\
\hline & $x(4,3,1,1)$ & $7,155,340$ & $6,886,679$ & $6,886,679$ & $6,931,516$ \\
\hline & $x(5,3,1,1)$ & 103,245 & 362,834 & 362,834 & 362,834 \\
\hline & $x(1,3,1,2)$ & 0 & 0 & 0 & 0 \\
\hline & $x(2,3,1,2)$ & 44,837 & 44,837 & 44,837 & 0 \\
\hline & $x(3,3,1,2)$ & 0 & 0 & 0 & 0 \\
\hline & $x(4,3,1,2)$ & $8,256,061$ & $7,986,066$ & $7,986,066$ & $8,030,903$ \\
\hline & $x(5,3,1,2)$ & 103,245 & 362,834 & 362,834 & 362,834 \\
\hline & $x(1,3,1,3)$ & 0 & 0 & 0 & 0 \\
\hline & $x(2,3,1,3)$ & 44,837 & 44,837 & 44,837 & 0 \\
\hline & $x(3,3,1,3)$ & 0 & 0 & 0 & 0 \\
\hline & $x(4,3,1,3)$ & $9,501,670$ & $9,230,162$ & $9,230,162$ & $9,274,999$ \\
\hline & $x(5,3,1,3)$ & 103,245 & 362,834 & 362,834 & 362,834 \\
\hline & $x(1,3,2,1)$ & 0 & 0 & 0 & 0 \\
\hline & $x(2,3,2,1)$ & 44,837 & 44,837 & 44,837 & 0 \\
\hline & $x(3,3,2,1)$ & 0 & 0 & 0 & 0 \\
\hline & $x(4,3,2,1)$ & $8,276,954$ & $8,020,403$ & $8,020,403$ & $8,065,240$ \\
\hline & $x(5,3,2,1)$ & 103,245 & 362,834 & 362,834 & 362,834 \\
\hline
\end{tabular}




\begin{tabular}{|c|c|c|c|c|c|}
\hline $\begin{array}{c}\text { Planning } \\
\text { Horizon }\end{array}$ & $\begin{array}{l}\text { Investment } \\
\text { Amount (\$) }\end{array}$ & $\begin{array}{l}\text { Investment } \\
\text { Portfolio } 1\end{array}$ & $\begin{array}{l}\text { Investment } \\
\text { Portfolio } 2\end{array}$ & $\begin{array}{l}\text { Investment } \\
\text { Portfolio } 2\end{array}$ & $\begin{array}{l}\text { Investment } \\
\text { Portfolio } 2\end{array}$ \\
\hline \multirow{25}{*}{ 胥 } & $x(1,3,2,2)$ & 0 & 0 & 0 & 0 \\
\hline & $x(2,3,2,2)$ & 44,837 & 44,837 & 44,837 & 0 \\
\hline & $x(3,3,2,2)$ & 0 & 0 & 0 & 0 \\
\hline & $x(4,3,2,2)$ & $9,542,618$ & $9,286,514$ & $9,286,514$ & $9,331,351$ \\
\hline & $x(5,3,2,2)$ & 103,245 & 362,834 & 362,834 & 362,834 \\
\hline & $x(1,3,2,3)$ & 0 & 0 & 0 & 0 \\
\hline & $x(2,3,2,3)$ & 44,837 & 44,837 & 44,837 & 0 \\
\hline & $x(3,3,2,3)$ & 0 & 0 & 0 & 0 \\
\hline & $x(4,3,2,3)$ & $10,975,160$ & $10,719,560$ & $10,719,560$ & $10,764,400$ \\
\hline & $x(5,3,2,3)$ & 103,245 & 362,834 & 362,834 & 362,834 \\
\hline & $x(1,3,3,1)$ & 0 & 0 & 0 & 0 \\
\hline & $x(2,3,3,1)$ & 44,837 & 44,837 & 44,837 & 0 \\
\hline & $x(3,3,3,1)$ & 0 & 0 & 0 & 0 \\
\hline & $x(4,3,3,1)$ & $9,642,990$ & $9,673,931$ & $9,300,212$ & $9,345,049$ \\
\hline & $x(5,3,3,1)$ & 0 & 0 & 362,834 & 362,834 \\
\hline & $x(1,3,3,2)$ & 0 & 0 & 0 & 0 \\
\hline & $x(2,3,3,2)$ & 44,837 & 44,837 & 44,837 & 0 \\
\hline & $x(3,3,3,2)$ & 0 & 0 & 0 & 0 \\
\hline & $x(4,3,3,2)$ & $11,079,250$ & $11,110,110$ & $10,754,530$ & $10,799,370$ \\
\hline & $x(5,3,3,2)$ & 0 & 0 & 362,834 & 362,834 \\
\hline & $x(1,3,3,3)$ & 0 & 55,319 & 55,319 & 55,319 \\
\hline & $x(2,3,3,3)$ & 44,837 & 44,837 & 44,837 & 44,837 \\
\hline & $x(3,3,3,3)$ & 0 & 54,918 & 98,458 & 98,458 \\
\hline & $x(4,3,3,3)$ & $12,693,090$ & $12,435,420$ & $12,072,580$ & $12,072,580$ \\
\hline & $x(5,3,3,3)$ & 0 & 174,523 & 537,357 & 537,357 \\
\hline
\end{tabular}




\begin{tabular}{|c|c|c|c|c|c|}
\hline \multicolumn{6}{|c|}{ Model 2 Investment Portfolios for $b=\$ 7,350,000$} \\
\hline $\begin{array}{l}\text { Planning } \\
\text { Horizon }\end{array}$ & $\begin{array}{l}\text { Investment } \\
\text { Amount (\$) }\end{array}$ & $\begin{array}{l}\text { Investment } \\
\text { Portfolio } 1\end{array}$ & $\begin{array}{l}\text { Investment } \\
\text { Portfolio } 2\end{array}$ & $\begin{array}{l}\text { Investment } \\
\text { Portfolio } 3\end{array}$ & $\begin{array}{l}\text { Investment } \\
\text { Portfolio } 4\end{array}$ \\
\hline \multirow{5}{*}{ 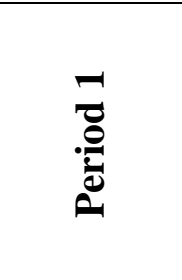 } & $x(1,1)$ & 0 & 0 & 0 & 0 \\
\hline & $x(2,1)$ & 0 & 0 & 0 & 0 \\
\hline & $x(3,1)$ & 89,914 & 89,914 & 96,700 & 96,700 \\
\hline & $x(4,1)$ & $6,722,729$ & $6,722,729$ & $6,890,466$ & $6,890,466$ \\
\hline & $x(5,1)$ & 537,357 & 537,357 & 362,834 & 362,834 \\
\hline \multirow{15}{*}{ 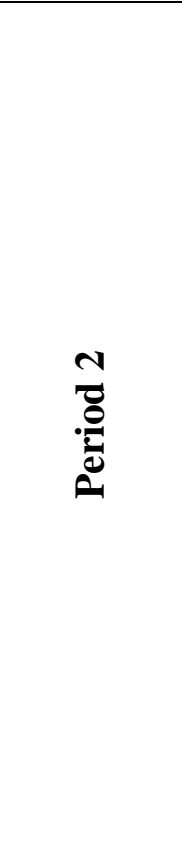 } & $x(1,2,1)$ & 580,853 & 525,534 & 525,534 & 525,534 \\
\hline & $x(2,2,1)$ & 28,137 & 28,137 & 28,137 & 28,137 \\
\hline & $x(3,2,1)$ & 89,914 & 89,914 & 96,700 & 96,700 \\
\hline & $x(4,2,1)$ & $6,722,504$ & $6,777,823$ & $6,758,880$ & $6,758,880$ \\
\hline & $x(5,2,1)$ & 0 & 0 & 0 & 0 \\
\hline & $x(1,2,2)$ & 580,853 & 525,534 & 525,534 & 525,534 \\
\hline & $x(2,2,2)$ & 28,137 & 28,137 & 28,137 & 28,137 \\
\hline & $x(3,2,2)$ & 89,914 & 89,914 & 96,700 & 96,700 \\
\hline & $x(4,2,2)$ & $7,784,649$ & $7,839,968$ & $7,828,733$ & $7,828,733$ \\
\hline & $x(5,2,2)$ & 0 & 0 & 0 & 0 \\
\hline & $x(1,2,3)$ & 0 & 0 & 0 & 0 \\
\hline & $x(2,2,3)$ & 0 & 0 & 0 & 0 \\
\hline & $x(3,2,3)$ & 218,076 & 218,076 & 218,076 & 218,076 \\
\hline & $x(4,2,3)$ & $9,445,956$ & $9,445,956$ & $9,283,283$ & $9,283,283$ \\
\hline & $x(5,2,3)$ & 0 & 0 & 174,523 & 174,523 \\
\hline
\end{tabular}




\begin{tabular}{|c|c|c|c|c|c|}
\hline $\begin{array}{l}\text { Planning } \\
\text { Horizon }\end{array}$ & $\begin{array}{l}\text { Investment } \\
\text { Amount (\$) }\end{array}$ & $\begin{array}{l}\text { Investment } \\
\text { Portfolio } 1\end{array}$ & $\begin{array}{c}\text { Investment } \\
\text { Portfolio } 2\end{array}$ & $\begin{array}{l}\text { Investment } \\
\text { Portfolio } 2\end{array}$ & $\begin{array}{c}\text { Investment } \\
\text { Portfolio } 2\end{array}$ \\
\hline \multirow{20}{*}{ 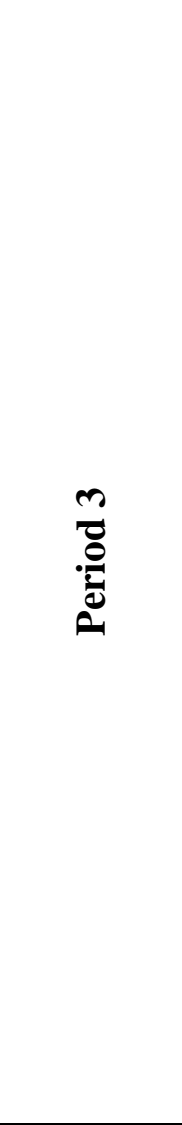 } & $x(1,3,1,1)$ & 0 & 0 & 0 & 0 \\
\hline & $x(2,3,1,1)$ & 44,837 & 44,837 & 44,837 & 0 \\
\hline & $x(3,3,1,1)$ & 89,914 & 89,914 & 96,700 & 96,700 \\
\hline & $x(4,3,1,1)$ & $7,355,271$ & $7,354,165$ & $7,328,057$ & $7,372,894$ \\
\hline & $x(5,3,1,1)$ & 0 & 0 & 0 & 0 \\
\hline & $x(1,3,1,2)$ & 0 & 0 & 0 & 0 \\
\hline & $x(2,3,1,2)$ & 44,837 & 44,837 & 44,837 & 0 \\
\hline & $x(3,3,1,2)$ & 89,914 & 89,914 & 96,700 & 96,700 \\
\hline & $x(4,3,1,2)$ & $8,493,342$ & $8,491,130$ & $8,462,180$ & $8,507,017$ \\
\hline & $x(5,3,1,2)$ & 0 & 0 & 0 & 0 \\
\hline & $x(1,3,1,3)$ & 0 & 0 & 0 & 0 \\
\hline & $x(2,3,1,3)$ & 44,837 & 44,837 & 44,837 & 0 \\
\hline & $x(3,3,1,3)$ & 89,914 & 89,914 & 96,700 & 96,700 \\
\hline & $x(4,3,1,3)$ & $9,779,732$ & $9,776,413$ & $9,744,243$ & $9,789,080$ \\
\hline & $x(5,3,1,3)$ & 0 & 0 & 0 & 0 \\
\hline & $x(1,3,2,1)$ & 0 & 0 & 0 & 0 \\
\hline & $x(2,3,2,1)$ & 44,837 & 44,837 & 44,837 & 0 \\
\hline & $x(3,3,2,1)$ & 89,914 & 89,914 & 96,700 & 96,700 \\
\hline & $x(4,3,2,1)$ & $8,438,659$ & $8,437,553$ & $8,419,307$ & $8,464,144$ \\
\hline & $x(5,3,2,1)$ & 0 & 0 & 0 & 0 \\
\hline
\end{tabular}




\begin{tabular}{|c|c|c|c|c|c|}
\hline $\begin{array}{l}\text { Planning } \\
\text { Horizon }\end{array}$ & $\begin{array}{l}\text { Investment } \\
\text { Amount (\$) }\end{array}$ & $\begin{array}{l}\text { Investment } \\
\text { Portfolio } 1\end{array}$ & $\begin{array}{l}\text { Investment } \\
\text { Portfolio } 2\end{array}$ & $\begin{array}{l}\text { Investment } \\
\text { Portfolio } 2\end{array}$ & $\begin{array}{l}\text { Investment } \\
\text { Portfolio } 2\end{array}$ \\
\hline \multirow{25}{*}{ 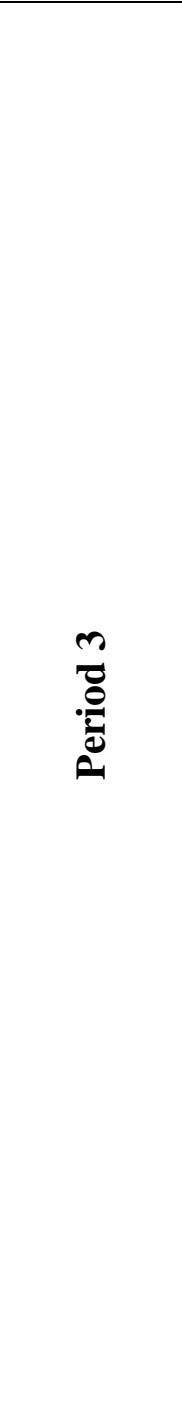 } & $x(1,3,2,2)$ & 0 & 0 & 0 & 0 \\
\hline & $x(2,3,2,2)$ & 44,837 & 44,837 & 44,837 & 0 \\
\hline & $x(3,3,2,2)$ & 89,914 & 89,914 & 96,700 & 96,700 \\
\hline & $x(4,3,2,2)$ & $9,736,052$ & $9,733,839$ & $9,713,909$ & $9,758,746$ \\
\hline & $x(5,3,2,2)$ & 0 & 0 & 0 & 0 \\
\hline & $x(1,3,2,3)$ & 0 & 0 & 0 & 0 \\
\hline & $x(2,3,2,3)$ & 44,837 & 44,837 & 44,837 & 0 \\
\hline & $x(3,3,2,3)$ & 89,914 & 89,914 & 96,700 & 96,700 \\
\hline & $x(4,3,2,3)$ & $11,203,010$ & $11,199,690$ & $11,177,850$ & $11,222,680$ \\
\hline & $x(5,3,2,3)$ & 0 & 0 & 0 & 0 \\
\hline & $x(1,3,3,1)$ & 525,534 & 525,534 & 525,534 & 525,534 \\
\hline & $x(2,3,3,1)$ & 44,837 & 44,837 & 44,837 & 0 \\
\hline & $x(3,3,3,1)$ & 89,914 & 89,914 & 96,700 & 96,700 \\
\hline & $x(4,3,3,1)$ & $8,974,590$ & $8,974,590$ & $8,985,127$ & $9,029,964$ \\
\hline & $x(5,3,3,1)$ & 0 & 0 & 0 & 0 \\
\hline & $x(1,3,3,2)$ & 525,534 & 525,534 & 525,534 & 525,534 \\
\hline & $x(2,3,3,2)$ & 44,837 & 44,837 & 44,837 & 0 \\
\hline & $x(3,3,3,2)$ & 89,914 & 89,914 & 96,700 & 96,700 \\
\hline & $x(4,3,3,2)$ & $10,391,480$ & $10,391,480$ & $10,395,070$ & $10,439,910$ \\
\hline & $x(5,3,3,2)$ & 0 & 0 & 0 & 0 \\
\hline & $x(1,3,3,3)$ & 580,853 & 580,853 & 580,853 & 580,853 \\
\hline & $x(2,3,3,3)$ & 44,837 & 44,837 & 44,837 & 44,837 \\
\hline & $x(3,3,3,3)$ & 218,076 & 218,076 & 218,076 & 218,076 \\
\hline & $x(4,3,3,3)$ & $11,813,820$ & $11,813,820$ & $11,808,750$ & $11,808,750$ \\
\hline & $x(5,3,3,3)$ & 0 & 0 & 0 & 0 \\
\hline
\end{tabular}




\begin{tabular}{|c|c|c|c|c|c|}
\hline \multicolumn{6}{|c|}{ Model 2 Investment Portfolios for $b=\$ 7,478,000$} \\
\hline $\begin{array}{l}\text { Planning } \\
\text { Horizon }\end{array}$ & $\begin{array}{l}\text { Investment } \\
\text { Amount (\$) }\end{array}$ & $\begin{array}{l}\text { Investment } \\
\text { Portfolio } 1\end{array}$ & $\begin{array}{l}\text { Investment } \\
\text { Portfolio } 2\end{array}$ & $\begin{array}{l}\text { Investment } \\
\text { Portfolio } 3\end{array}$ & $\begin{array}{l}\text { Investment } \\
\text { Portfolio } 4\end{array}$ \\
\hline \multirow{5}{*}{ تָ } & $x(1,1)$ & 0 & 0 & 0 & 0 \\
\hline & $x(2,1)$ & 0 & 0 & 0 & 0 \\
\hline & $x(3,1)$ & 217,914 & 217,914 & 218,076 & 218,076 \\
\hline & $x(4,1)$ & $6,722,729$ & $6,722,729$ & $6,726,727$ & $6,726,727$ \\
\hline & $x(5,1)$ & 537,357 & 537,357 & 533,197 & 533,197 \\
\hline \multirow{15}{*}{ مُ } & $x(1,2,1)$ & 580,853 & 525,534 & 525,534 & 525,534 \\
\hline & $x(2,2,1)$ & 28,137 & 28,137 & 28,137 & 28,137 \\
\hline & $x(3,2,1)$ & 217,914 & 217,914 & 218,076 & 218,076 \\
\hline & $x(4,2,1)$ & $6,594,504$ & $6,649,823$ & $6,649,371$ & $6,649,371$ \\
\hline & $x(5,2,1)$ & 0 & 0 & 0 & 0 \\
\hline & $x(1,2,2)$ & 580,853 & 525,534 & 525,534 & 525,534 \\
\hline & $x(2,2,2)$ & 28,137 & 28,137 & 28,137 & 28,137 \\
\hline & $x(3,2,2)$ & 217,914 & 217,914 & 218,076 & 218,076 \\
\hline & $x(4,2,2)$ & $7,656,649$ & $7,711,968$ & $7,711,700$ & $7,711,700$ \\
\hline & $x(5,2,2)$ & 0 & 0 & 0 & 0 \\
\hline & $x(1,2,3)$ & 0 & 0 & 0 & 0 \\
\hline & $x(2,2,3)$ & 0 & 0 & 0 & 0 \\
\hline & $x(3,2,3)$ & 218,076 & 218,076 & 218,076 & 218,076 \\
\hline & $x(4,2,3)$ & $9,445,956$ & $9,445,956$ & $9,442,078$ & $9,442,078$ \\
\hline & $x(5,2,3)$ & 0 & 0 & 4,160 & 4,160 \\
\hline
\end{tabular}




\begin{tabular}{|c|c|c|c|c|c|}
\hline $\begin{array}{c}\text { Planning } \\
\text { Horizon }\end{array}$ & $\begin{array}{l}\text { Investment } \\
\text { Amount (\$) }\end{array}$ & $\begin{array}{l}\text { Investment } \\
\text { Portfolio } 1\end{array}$ & $\begin{array}{c}\text { Investment } \\
\text { Portfolio } 2 \\
\end{array}$ & $\begin{array}{l}\text { Investment } \\
\text { Portfolio } 2 \\
\end{array}$ & $\begin{array}{l}\text { Investment } \\
\text { Portfolio } 2 \\
\end{array}$ \\
\hline \multirow{20}{*}{ r } & $x(1,3,1,1)$ & 0 & 0 & 0 & 0 \\
\hline & $x(2,3,1,1)$ & 44,837 & 44,837 & 44,837 & 44,837 \\
\hline & $x(3,3,1,1)$ & 217,914 & 217,914 & 218,076 & 218,076 \\
\hline & $x(4,3,1,1)$ & $7,096,711$ & $7,095,605$ & $7,094,982$ & $7,094,982$ \\
\hline & $x(5,3,1,1)$ & 0 & 0 & 0 & 0 \\
\hline & $x(1,3,1,2)$ & 0 & 0 & 0 & 0 \\
\hline & $x(2,3,1,2)$ & 44,837 & 44,837 & 44,837 & 44,837 \\
\hline & $x(3,3,1,2)$ & 217,914 & 217,914 & 218,076 & 218,076 \\
\hline & $x(4,3,1,2)$ & $8,215,582$ & $8,213,370$ & $8,212,679$ & $8,212,679$ \\
\hline & $x(5,3,1,2)$ & 0 & 0 & 0 & 0 \\
\hline & $x(1,3,1,3)$ & 0 & 0 & 0 & 0 \\
\hline & $x(2,3,1,3)$ & 44,837 & 44,837 & 44,837 & 44,837 \\
\hline & $x(3,3,1,3)$ & 217,914 & 217,914 & 218,076 & 218,076 \\
\hline & $x(4,3,1,3)$ & $9,480,212$ & $9,476,893$ & $9,476,126$ & $9,476,126$ \\
\hline & $x(5,3,1,3)$ & 0 & 0 & 0 & 0 \\
\hline & $x(1,3,2,1)$ & 0 & 0 & 0 & 0 \\
\hline & $x(2,3,2,1)$ & 44,837 & 44,837 & 44,837 & 44,837 \\
\hline & $x(3,3,2,1)$ & 217,914 & 217,914 & 218,076 & 218,076 \\
\hline & $x(4,3,2,1)$ & $8,180,099$ & $8,178,993$ & $8,178,558$ & $8,178,558$ \\
\hline & $x(5,3,2,1)$ & 0 & 0 & 0 & 0 \\
\hline
\end{tabular}




\begin{tabular}{|c|c|c|c|c|c|}
\hline $\begin{array}{l}\text { Planning } \\
\text { Horizon }\end{array}$ & $\begin{array}{l}\text { Investment } \\
\text { Amount (\$) }\end{array}$ & $\begin{array}{l}\text { Investment } \\
\text { Portfolio } 1\end{array}$ & $\begin{array}{l}\text { Investment } \\
\text { Portfolio } 2\end{array}$ & $\begin{array}{l}\text { Investment } \\
\text { Portfolio } 2\end{array}$ & $\begin{array}{l}\text { Investment } \\
\text { Portfolio } 2\end{array}$ \\
\hline \multirow{25}{*}{ 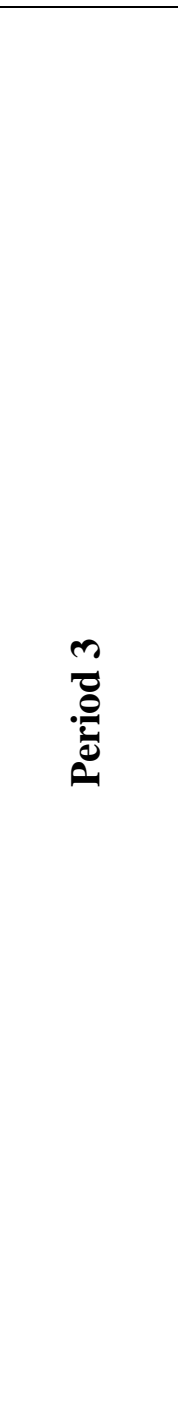 } & $x(1,3,2,2)$ & 0 & 0 & 0 & 0 \\
\hline & $x(2,3,2,2)$ & 44,837 & 44,837 & 44,837 & 44,837 \\
\hline & $x(3,3,2,2)$ & 217,914 & 217,914 & 218,076 & 218,076 \\
\hline & $x(4,3,2,2)$ & $9,458,292$ & $9,456,079$ & $9,455,604$ & $9,455,604$ \\
\hline & $x(5,3,2,2)$ & 0 & 0 & 0 & 0 \\
\hline & $x(1,3,2,3)$ & 0 & 0 & 0 & 0 \\
\hline & $x(2,3,2,3)$ & 44,837 & 44,837 & 44,837 & 44,837 \\
\hline & $x(3,3,2,3)$ & 217,914 & 217,914 & 218,076 & 218,076 \\
\hline & $x(4,3,2,3)$ & $10,903,490$ & $10,900,170$ & $10,899,650$ & $10,899,650$ \\
\hline & $x(5,3,2,3)$ & 0 & 0 & 0 & 0 \\
\hline & $x(1,3,3,1)$ & 525,534 & 525,534 & 525,534 & 525,534 \\
\hline & $x(2,3,3,1)$ & 44,837 & 44,837 & 44,837 & 44,837 \\
\hline & $x(3,3,3,1)$ & 217,914 & 217,914 & 218,076 & 218,076 \\
\hline & $x(4,3,3,1)$ & $8,846,590$ & $8,846,590$ & $8,846,841$ & $8,846,841$ \\
\hline & $x(5,3,3,1)$ & 0 & 0 & 0 & 0 \\
\hline & $x(1,3,3,2)$ & 525,534 & 525,534 & 525,534 & 525,534 \\
\hline & $x(2,3,3,2)$ & 44,837 & 44,837 & 44,837 & 44,837 \\
\hline & $x(3,3,3,2)$ & 217,914 & 217,914 & 218,076 & 218,076 \\
\hline & $x(4,3,3,2)$ & $10,263,480$ & $10,263,480$ & $10,263,570$ & $10,263,570$ \\
\hline & $x(5,3,3,2)$ & 0 & 0 & 0 & 0 \\
\hline & $x(1,3,3,3)$ & 580,853 & 580,853 & 580,853 & 580,853 \\
\hline & $x(2,3,3,3)$ & 44,837 & 44,837 & 44,837 & 44,837 \\
\hline & $x(3,3,3,3)$ & 218,076 & 218,076 & 218,076 & 218,076 \\
\hline & $x(4,3,3,3)$ & $11,813,820$ & $11,813,820$ & $11,813,690$ & $11,813,690$ \\
\hline & $x(5,3,3,3)$ & 0 & 0 & 0 & 0 \\
\hline
\end{tabular}




\section{G.2 DETAILS OF MODEL 3 RESULTS}

\begin{tabular}{|c|c|c|c|}
\hline \multicolumn{4}{|c|}{ Model 3 Investment Portfolios for $b=\$ 283,000$} \\
\hline $\begin{array}{c}\text { Planning } \\
\text { Horizon }\end{array}$ & $\begin{array}{l}\text { Investment } \\
\text { Amount (\$) }\end{array}$ & $\begin{array}{l}\text { Investment } \\
\text { Portfolio } 1\end{array}$ & $\begin{array}{l}\text { Investment } \\
\text { Portfolio } 2\end{array}$ \\
\hline \multirow{5}{*}{ 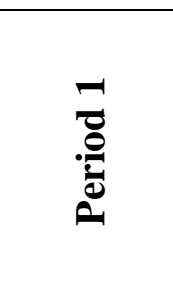 } & $x(1,1)$ & 155,417 & 155,417 \\
\hline & $x(2,1)$ & 0 & 0 \\
\hline & $x(3,1)$ & 0 & 0 \\
\hline & $x(4,1)$ & 0 & 0 \\
\hline & $x(5,1)$ & 127,583 & 127,583 \\
\hline \multirow{15}{*}{ 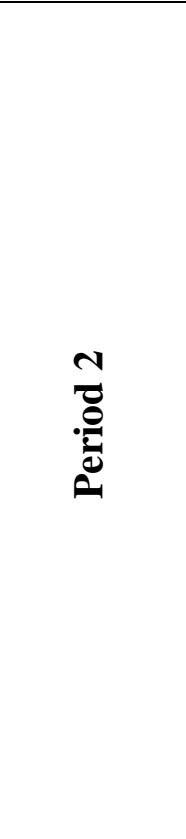 } & $x(1,2,1)$ & 60,345 & 60,345 \\
\hline & $x(2,2,1)$ & 0 & 0 \\
\hline & $x(3,2,1)$ & 0 & 0 \\
\hline & $x(4,2,1)$ & 0 & 0 \\
\hline & $x(5,2,1)$ & 235,251 & 235,251 \\
\hline & $x(1,2,2)$ & 306,638 & 306,638 \\
\hline & $x(2,2,2)$ & 28,137 & 28,137 \\
\hline & $x(3,2,2)$ & 0 & 0 \\
\hline & $x(4,2,2)$ & 0 & 0 \\
\hline & $x(5,2,2)$ & 0 & 0 \\
\hline & $x(1,2,3)$ & 345,098 & 345,098 \\
\hline & $x(2,2,3)$ & 28,137 & 28,137 \\
\hline & $x(3,2,3)$ & 0 & 0 \\
\hline & $x(4,2,3)$ & 0 & 0 \\
\hline & $x(5,2,3)$ & 0 & 0 \\
\hline
\end{tabular}




\begin{tabular}{|c|c|c|c|}
\hline Planning & $\begin{array}{c}\text { Investment } \\
\text { Amount (\$) }\end{array}$ & $\begin{array}{c}\text { Investment } \\
\text { Portfolio 1 }\end{array}$ & $\begin{array}{c}\text { Investment } \\
\text { Portfolio 2 }\end{array}$ \\
\hline \multirow{4}{*}{} & $x(1,3,1,1)$ & 309,772 & 309,772 \\
\cline { 2 - 4 } & $x(2,3,1,1)$ & 0 & 0 \\
\cline { 2 - 4 } & $x(3,3,1,1)$ & 0 & 0 \\
\cline { 2 - 4 } & $x(4,3,1,1)$ & 0 & 0 \\
\cline { 2 - 4 } & $x(5,3,1,1)$ & 0 & 0 \\
\cline { 2 - 4 } & $x(1,3,1,2)$ & 309,772 & 309,772 \\
\cline { 2 - 4 } & $x(2,3,1,2)$ & 33,784 & 0 \\
\cline { 2 - 4 } & $x(3,3,1,2)$ & 0 & 0 \\
\cline { 2 - 4 } & $x(4,3,1,2)$ & 0 & 33,784 \\
\cline { 2 - 4 } & $x(5,3,1,2)$ & 0 & 0 \\
\cline { 2 - 4 } & $x(1,3,1,3)$ & 309,772 & 309,772 \\
\cline { 2 - 4 } & $x(2,3,1,3)$ & 44,837 & 0 \\
\cline { 2 - 4 } & $x(3,3,1,3)$ & 0 & 0 \\
\cline { 2 - 4 } & $x(4,3,1,3)$ & 16,880 & 61,717 \\
\cline { 2 - 4 } & $x(5,3,1,3)$ & 0 & 0 \\
\cline { 2 - 4 } & $x(1,3,2,1)$ & 63,479 & 63,479 \\
\cline { 2 - 4 } & $x(2,3,2,1)$ & 44,837 & 0 \\
\cline { 2 - 4 } & $x(3,3,2,1)$ & 0 & 0 \\
\cline { 2 - 4 } & $x(4,3,2,1)$ & 4,318 & 49,155 \\
\cline { 2 - 4 } & $x(5,3,2,1)$ & 235,251 & 235,251 \\
\hline
\end{tabular}




\begin{tabular}{|c|c|c|c|}
\hline $\begin{array}{l}\text { Planning } \\
\text { Horizon }\end{array}$ & $\begin{array}{l}\text { Investment } \\
\text { Amount (\$) }\end{array}$ & $\begin{array}{l}\text { Investment } \\
\text { Portfolio } 1\end{array}$ & $\begin{array}{l}\text { Investment } \\
\text { Portfolio } 2\end{array}$ \\
\hline \multirow{25}{*}{ 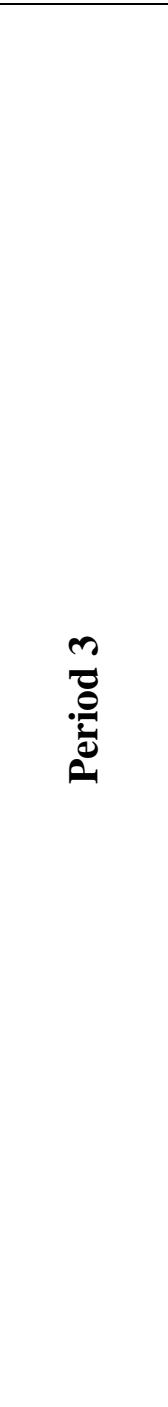 } & $x(1,3,2,2)$ & 63,479 & 63,479 \\
\hline & $x(2,3,2,2)$ & 44,837 & 0 \\
\hline & $x(3,3,2,2)$ & 0 & 0 \\
\hline & $x(4,3,2,2)$ & 87,397 & 132,234 \\
\hline & $x(5,3,2,2)$ & 235,251 & 235,251 \\
\hline & $x(1,3,2,3)$ & 63,479 & 63,479 \\
\hline & $x(2,3,2,3)$ & 44,837 & 0 \\
\hline & $x(3,3,2,3)$ & 0 & 0 \\
\hline & $x(4,3,2,3)$ & 178,860 & 223,697 \\
\hline & $x(5,3,2,3)$ & 235,251 & 235,251 \\
\hline & $x(1,3,3,1)$ & 25,019 & 25,019 \\
\hline & $x(2,3,3,1)$ & 44,837 & 0 \\
\hline & $x(3,3,3,1)$ & 0 & 0 \\
\hline & $x(4,3,3,1)$ & 82,776 & 127,613 \\
\hline & $x(5,3,3,1)$ & 235,251 & 235,251 \\
\hline & $x(1,3,3,2)$ & 25,019 & 25,019 \\
\hline & $x(2,3,3,2)$ & 44,837 & 0 \\
\hline & $x(3,3,3,2)$ & 0 & 0 \\
\hline & $x(4,3,3,2)$ & 172,394 & 217,231 \\
\hline & $x(5,3,3,2)$ & 235,251 & 235,251 \\
\hline & $x(1,3,3,3)$ & 25,019 & 25,019 \\
\hline & $x(2,3,3,3)$ & 44,837 & 0 \\
\hline & $x(3,3,3,3)$ & 0 & 0 \\
\hline & $x(4,3,3,3)$ & 271,164 & 316,001 \\
\hline & $x(5,3,3,3)$ & 235,251 & 235,251 \\
\hline
\end{tabular}




\begin{tabular}{|c|c|c|c|c|c|c|c|c|}
\hline \multicolumn{9}{|c|}{ Model 3 Investment Portfolios for $b=\$ 500,000$} \\
\hline $\begin{array}{c}\text { Investment } \\
\text { Amount } \\
(\$)\end{array}$ & $\begin{array}{l}\text { Investment } \\
\text { Portfolio } 1\end{array}$ & $\begin{array}{l}\text { Investment } \\
\text { Portfolio } 2\end{array}$ & $\begin{array}{l}\text { Investment } \\
\text { Portfolio } 3\end{array}$ & $\begin{array}{l}\text { Investment } \\
\text { Portfolio } 4\end{array}$ & $\begin{array}{l}\text { Investment } \\
\text { Portfolio } 5\end{array}$ & $\begin{array}{c}\text { Investment } \\
\text { Portfolio } 6\end{array}$ & $\begin{array}{l}\text { Investment } \\
\text { Portfolio } 7\end{array}$ & $\begin{array}{l}\text { Investment } \\
\text { Portfolio } 8\end{array}$ \\
\hline$x(1,1)$ & 391,198 & 391,198 & 383,197 & 383,197 & 446,333 & 446,333 & 446,333 & 446,333 \\
\hline$x(2,1)$ & 53,667 & 53,667 & 53,667 & 53,667 & 53,667 & 53,667 & 53,667 & 53,667 \\
\hline$x(3,1)$ & 0 & 0 & 0 & 0 & 0 & 0 & 0 & 0 \\
\hline$x(4,1)$ & 0 & 0 & 0 & 0 & 0 & 0 & 0 & 0 \\
\hline$x(5,1)$ & 55,136 & 55,136 & 63,136 & 63,136 & 0 & 0 & 0 & 0 \\
\hline$x(1,2,1)$ & 189,656 & 134,337 & 142,338 & 142,338 & 79,201 & 79,201 & 79,201 & 79,201 \\
\hline$x(2,2,1)$ & 28,137 & 28,137 & 28,137 & 28,137 & 28,137 & 28,137 & 28,137 & 28,137 \\
\hline$x(3,2,1)$ & 0 & 0 & 0 & 0 & 0 & 0 & 0 & 0 \\
\hline$x(4,2,1)$ & 302,222 & 357,541 & 349,620 & 349,620 & 412,125 & 412,125 & 412,125 & 412,125 \\
\hline$x(5,2,1)$ & 0 & 0 & 0 & 0 & 0 & 0 & 0 & 0 \\
\hline$x(1,2,2)$ & 189,656 & 189,656 & 197,657 & 142,338 & 79,201 & 79,201 & 79,201 & 79,201 \\
\hline$x(2,2,2)$ & 28,137 & 28,137 & 28,137 & 28,137 & 28,137 & 28,137 & 28,137 & 28,130 \\
\hline$x(3,2,2)$ & 0 & 0 & 0 & 0 & 0 & 0 & 0 & 0 \\
\hline$x(4,2,2)$ & 433,273 & 433,273 & 424,792 & 480,111 & 547,036 & 547,036 & 547,036 & 547,036 \\
\hline$x(5,2,2)$ & 0 & 0 & 0 & 0 & 0 & 0 & 0 & 0 \\
\hline$x(1,2,3)$ & 189,656 & 189,656 & 197,657 & 197,657 & 134,520 & 134,520 & 134,520 & 134,520 \\
\hline$x(2,2,3)$ & 28,137 & 28,137 & 28,137 & 28,137 & 28,137 & 28,137 & 28,137 & 28,137 \\
\hline$x(3,2,3)$ & 0 & 0 & 0 & 0 & 9,579 & 0 & 0 & 0 \\
\hline$x(4,2,3)$ & 92,566 & 92,566 & 223,381 & 223,381 & 220,797 & 210,429 & 639,847 & 639,847 \\
\hline$x(5,2,3)$ & 482,222 & 482,222 & 341,965 & 341,965 & 409,471 & 429,418 & 0 & 0 \\
\hline
\end{tabular}




\begin{tabular}{|c|c|c|c|c|c|c|c|c|}
\hline $\begin{array}{l}\text { Investment } \\
\text { Amount (\$) }\end{array}$ & $\begin{array}{l}\text { Investment } \\
\text { Portfolio } 1\end{array}$ & $\begin{array}{l}\text { Investment } \\
\text { Portfolio } 2\end{array}$ & $\begin{array}{l}\text { Investment } \\
\text { Portfolio } 3\end{array}$ & $\begin{array}{l}\text { Investment } \\
\text { Portfolio } 4\end{array}$ & $\begin{array}{l}\text { Investment } \\
\text { Portfolio } 5\end{array}$ & $\begin{array}{l}\text { Investment } \\
\text { Portfolio } 6\end{array}$ & $\begin{array}{l}\text { Investment } \\
\text { Portfolio } 7\end{array}$ & $\begin{array}{l}\text { Investment } \\
\text { Portfolio } 8\end{array}$ \\
\hline$x(1,3,1,1)$ & 0 & 0 & 0 & 0 & 0 & 0 & 0 & 0 \\
\hline$x(2,3,1,1)$ & 44,837 & 44,837 & 44,837 & 44,837 & 44,837 & 44,837 & 44,837 & 0 \\
\hline$x(3,3,1,1)$ & 0 & 0 & 0 & 0 & 0 & 0 & 0 & 0 \\
\hline$x(4,3,1,1)$ & 181,954 & 180,848 & 189,090 & 189,090 & 124,047 & 124,047 & 124,047 & 168,884 \\
\hline$x(5,3,1,1)$ & 307,699 & 307,699 & 299,698 & 299,698 & 362,834 & 362,834 & 362,834 & 362,834 \\
\hline$x(1,3,1,2)$ & 0 & 0 & 0 & 0 & 0 & 0 & 0 & 0 \\
\hline$x(2,3,1,2)$ & 44,837 & 44,837 & 44,837 & 44,837 & 44,837 & 44,837 & 44,837 & 0 \\
\hline$x(3,3,1,2)$ & 0 & 0 & 0 & 0 & 0 & 0 & 0 & 0 \\
\hline$x(4,3,1,2)$ & 290,479 & 288,267 & 296,681 & 296,681 & 230,281 & 230,281 & 230,281 & 275,118 \\
\hline$x(5,3,1,2)$ & 307,699 & 307,699 & 299,698 & 299,698 & 362,834 & 362,834 & 362,834 & 362,834 \\
\hline$x(1,3,1,3)$ & 0 & 0 & 0 & 0 & 0 & 0 & 0 & 0 \\
\hline$x(2,3,1,3)$ & 44,837 & 44,837 & 44,837 & 44,837 & 44,837 & 44,837 & 44,837 & 0 \\
\hline$x(3,3,1,3)$ & 0 & 0 & 0 & 0 & 0 & 0 & 0 & 0 \\
\hline$x(4,3,1,3)$ & 411,093 & 407,774 & 416,363 & 416,363 & 348,592 & 348,592 & 348,592 & 393,429 \\
\hline$x(5,3,1,3)$ & 307,699 & 307,699 & 299,698 & 299,698 & 362,834 & 362,834 & 362,834 & 362,834 \\
\hline$x(1,3,2,1)$ & 0 & 0 & 0 & 0 & 0 & 0 & 0 & 0 \\
\hline$x(2,3,2,1)$ & 44,837 & 44,837 & 44,837 & 44,837 & 44,837 & 44,837 & 44,837 & 0 \\
\hline$x(3,3,2,1)$ & 0 & 0 & 0 & 0 & 0 & 0 & 0 & 0 \\
\hline$x(4,3,2,1)$ & 315,626 & 315,626 & 323,297 & 322,191 & 261,656 & 261,656 & 261,656 & 306,493 \\
\hline$x(5,3,2,1)$ & 307,699 & 307,699 & 299,698 & 299,698 & 362,834 & 362,834 & 362,834 & 362,834 \\
\hline
\end{tabular}




\begin{tabular}{|c|c|c|c|c|c|c|c|c|}
\hline $\begin{array}{l}\text { Investment } \\
\text { Amount (\$) }\end{array}$ & $\begin{array}{l}\text { Investment } \\
\text { Portfolio } 1 \\
\end{array}$ & $\begin{array}{l}\text { Investment } \\
\text { Portfolio } 2 \\
\end{array}$ & $\begin{array}{l}\text { Investment } \\
\text { Portfolio } 3 \\
\end{array}$ & $\begin{array}{l}\text { Investment } \\
\text { Portfolio } 4 \\
\end{array}$ & $\begin{array}{l}\text { Investment } \\
\text { Portfolio } 5 \\
\end{array}$ & $\begin{array}{c}\text { Investment } \\
\text { Portfolio } 6 \\
\end{array}$ & $\begin{array}{l}\text { Investment } \\
\text { Portfolio } 7 \\
\end{array}$ & \begin{tabular}{|c|} 
Investment \\
Portfolio 8 \\
\end{tabular} \\
\hline$x(1,3,2,2)$ & 0 & 0 & 0 & 0 & 0 & 0 & 0 & 0 \\
\hline$x(2,3,2,2)$ & 44,837 & 44,837 & 44,837 & 44,837 & 44,837 & 44,837 & 44,837 & 0 \\
\hline$x(3,3,2,2)$ & 0 & 0 & 0 & 0 & 0 & 0 & 0 & 0 \\
\hline$x(4,3,2,2)$ & 443,809 & 443,809 & 451,568 & 449,356 & 388,126 & 388,126 & 388,126 & 432,963 \\
\hline$x(5,3,2,2)$ & 307,699 & 307,699 & 299,698 & 299,698 & 362,834 & 362,834 & 362,834 & 362,834 \\
\hline$x(1,3,2,3)$ & 0 & 0 & 0 & 0 & 55,319 & 55,319 & 55,319 & 55,319 \\
\hline$x(2,3,2,3)$ & 44,837 & 44,837 & 44,837 & 44,837 & 44,837 & 44,837 & 44,837 & 44,837 \\
\hline$x(3,3,2,3)$ & 0 & 0 & 0 & 0 & 0 & 0 & 0 & 0 \\
\hline$x(4,3,2,3)$ & 566,727 & 566,727 & 575,208 & 519,889 & 452,964 & 452,964 & 452,964 & 452,964 \\
\hline$x(5,3,2,3)$ & 327,673 & 327,673 & 319,029 & 371,029 & 383,922 & 383,922 & 383,922 & 383,922 \\
\hline$x(1,3,3,1)$ & 0 & 0 & 0 & 0 & 0 & 0 & 0 & 0 \\
\hline$x(2,3,3,1)$ & 44,837 & 44,837 & 44,837 & 44,837 & 44,837 & 44,837 & 44,837 & 44,837 \\
\hline$x(3,3,3,1)$ & 0 & 0 & 0 & 0 & 0 & 0 & 0 & 0 \\
\hline$x(4,3,3,1)$ & 782,135 & 782,135 & 776,619 & 776,619 & 779,203 & 789,571 & 360,153 & 360,153 \\
\hline$x(5,3,3,1)$ & 0 & 0 & 0 & 0 & 0 & 0 & 416,536 & 416,536 \\
\hline$x(1,3,3,2)$ & 0 & 0 & 0 & 0 & 0 & 0 & 0 & 0 \\
\hline$x(2,3,3,2)$ & 44,837 & 44,837 & 44,837 & 44,837 & 44,837 & 44,837 & 44,837 & 44,837 \\
\hline$x(3,3,3,2)$ & 0 & 0 & 0 & 0 & 0 & 20,387 & 28,975 & 28,975 \\
\hline$x(4,3,3,2)$ & 907,434 & 907,434 & 776,619 & 776,619 & 779,203 & 789,571 & 360,153 & 360,153 \\
\hline$x(5,3,3,2)$ & 0 & 0 & 132,256 & 132,256 & 127,886 & 107,939 & 537,357 & 537,357 \\
\hline$x(1,3,3,3)$ & 0 & 0 & 0 & 0 & 0 & 0 & 0 & 0 \\
\hline$x(2,3,3,3)$ & 44,837 & 44,837 & 44,837 & 44,837 & 44,837 & 44,837 & 44,837 & 44,837 \\
\hline$x(3,3,3,3)$ & 118,728 & 118,728 & 132,669 & 132,669 & 124,959 & 144,979 & 196,509 & 196,509 \\
\hline$x(4,3,3,3)$ & 907,434 & 907,434 & 776,619 & 776,619 & 779,203 & 789,571 & 360,153 & 360,153 \\
\hline$x(5,3,3,3)$ & 0 & 0 & 132,256 & 132,256 & 127,886 & 107,939 & 537,357 & 537,357 \\
\hline
\end{tabular}




\begin{tabular}{|c|c|c|c|c|c|c|c|c|c|c|c|}
\hline \multicolumn{12}{|c|}{ Model 3 Investment Portfolios for $b=\$ 750,000$} \\
\hline \begin{tabular}{|c|} 
Planning \\
Horizon \\
\end{tabular} & $\begin{array}{l}\text { Investment } \\
\text { Amount (\$) }\end{array}$ & \begin{tabular}{|l|} 
Investment \\
Portfolio 1
\end{tabular} & \begin{tabular}{|c|} 
Investment \\
Portfolio 2 \\
\end{tabular} & \begin{tabular}{|c|} 
Investment \\
Portfolio 3 \\
\end{tabular} & \begin{tabular}{|c|} 
Investment \\
Portfolio 4 \\
\end{tabular} & \begin{tabular}{|c|} 
Investment \\
Portfolio 5
\end{tabular} & \begin{tabular}{|l|} 
Investment \\
Portfolio 6
\end{tabular} & \begin{tabular}{|c|} 
Investment \\
Portfolio 7 \\
\end{tabular} & \begin{tabular}{|c|} 
Investment \\
Portfolio 8 \\
\end{tabular} & \begin{tabular}{|c|} 
Investment \\
Portfolio 9 \\
\end{tabular} & \begin{tabular}{|l|} 
Investment \\
Portfolio 10 \\
\end{tabular} \\
\hline \multirow{5}{*}{ 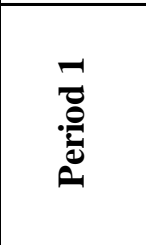 } & $x(1,1)$ & 47,230 & 15,820 & 15,820 & 15,820 & 0 & 0 & 0 & 0 & 0 & 0 \\
\hline & $x(2,1)$ & 53,667 & 53,667 & 53,667 & 53,667 & 53,667 & 53,667 & 53,667 & 53,667 & 53,667 & 53,667 \\
\hline & $x(3,1)$ & 84,404 & 83,652 & 83,652 & 83,652 & 82,703 & 82,813 & 72,191 & 72,191 & 70,028 & 68,302 \\
\hline & $x(4,1)$ & 218,420 & 263,105 & 263,105 & 263,105 & 313,006 & 315,625 & 369,355 & 369,355 & 315,892 & 265,197 \\
\hline & $x(5,1)$ & 346,279 & 333,755 & 333,755 & 333,755 & 300,624 & 297,895 & 254,787 & 254,787 & 310,413 & 362,834 \\
\hline \multirow{15}{*}{ 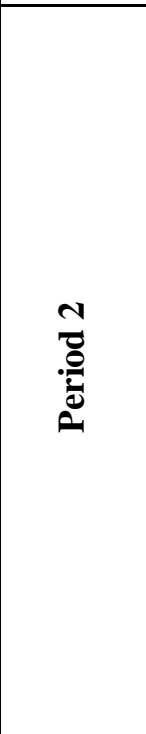 } & $x(1,2,1)$ & 533,623 & 565,033 & 509,714 & 509,714 & 525,534 & 525,534 & 525,534 & 525,534 & 525,534 & 525,534 \\
\hline & $x(2,2,1)$ & 28,137 & 28,137 & 28,137 & 28,137 & 28,137 & 28,137 & 28,137 & 28,137 & 28,137 & 28,137 \\
\hline & $x(3,2,1)$ & 84,404 & 83,652 & 83,652 & 83,652 & 82,703 & 82,813 & 72,191 & 72,191 & 70,028 & 68,302 \\
\hline & $x(4,2,1)$ & 44,613 & 13,718 & 69,037 & 69,037 & 53,824 & 53,520 & 73,683 & 73,683 & 79,721 & 84,781 \\
\hline & $x(5,2,1)$ & 0 & 0 & 0 & 0 & 0 & 0 & 0 & 0 & 0 & 0 \\
\hline & $x(1,2,2)$ & 521,611 & 509,714 & 509,714 & 509,714 & 478,672 & 481,550 & 525,534 & 525,534 & 525,534 & 525,534 \\
\hline & $x(2,2,2)$ & 28,137 & 28,137 & 28,137 & 28,137 & 28,137 & 28,137 & 28,137 & 28,137 & 28,137 & 28,137 \\
\hline & $x(3,2,2)$ & 84,404 & 83,652 & 83,652 & 83,652 & 82,703 & 82,813 & 105,334 & 105,334 & 111,305 & 116,405 \\
\hline & $x(4,2,2)$ & 0 & 0 & 0 & 0 & 0 & 0 & 16,290 & 16,290 & 82,491 & 144,480 \\
\hline & $x(5,2,2)$ & 191,078 & 203,602 & 203,602 & 203,602 & 236,733 & 233,672 & 164,165 & 164,165 & 93,412 & 27,295 \\
\hline & $x(1,2,3)$ & 521,611 & 509,714 & 509,714 & 509,714 & 486,707 & 483,973 & 0 & 0 & 0 & 0 \\
\hline & $x(2,2,3)$ & 28,137 & 28,137 & 28,137 & 28,137 & 22,311 & 22,496 & 0 & 0 & 0 & 0 \\
\hline & $x(3,2,3)$ & 218,076 & 218,076 & 218,076 & 218,076 & 218,076 & 218,076 & 218,076 & 218,076 & 218,076 & 218,076 \\
\hline & $x(4,2,3)$ & 0 & 0 & 0 & 0 & 0 & 0 & 482,767 & 482,767 & 534,617 & 593,801 \\
\hline & $x(5,2,3)$ & 191,078 & 203,602 & 203,602 & 203,602 & 236,733 & 239,462 & 282,570 & 282,570 & 226,944 & 163,783 \\
\hline
\end{tabular}




\begin{tabular}{|c|c|c|c|c|c|c|c|c|c|c|c|}
\hline $\begin{array}{r}\text { Planning } \\
\text { Horizon }\end{array}$ & $\begin{array}{l}\text { Investment } \\
\text { Amount (\$) }\end{array}$ & \begin{tabular}{|l} 
Investment \\
Portfolio 1 \\
\end{tabular} & \begin{tabular}{|c|} 
Investment \\
Portfolio 2 \\
\end{tabular} & \begin{tabular}{|l} 
Investment \\
Portfolio 3 \\
\end{tabular} & \begin{tabular}{|c|} 
Investment \\
Portfolio 4 \\
\end{tabular} & \begin{tabular}{|l} 
Investment \\
Portfolio 5
\end{tabular} & \begin{tabular}{|c|} 
Investment \\
Portfolio 6 \\
\end{tabular} & \begin{tabular}{|l} 
Investment \\
Portfolio 7 \\
\end{tabular} & \begin{tabular}{|l} 
Investment \\
Portfolio 8 \\
\end{tabular} & \begin{tabular}{|c|} 
Investment \\
Portfolio 8 \\
\end{tabular} & \begin{tabular}{|c|} 
Investment \\
Portfolio 8 \\
\end{tabular} \\
\hline \multirow{20}{*}{ 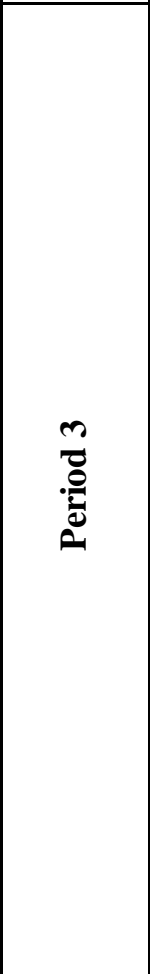 } & $x(1,3,1,1)$ & 0 & 0 & 0 & 0 & 0 & 0 & 0 & 0 & 0 & 0 \\
\hline & $x(2,3,1,1)$ & 44,837 & 44,837 & 44,837 & 44,837 & 44,837 & 44,837 & 44,837 & 0 & 0 & 0 \\
\hline & $x(3,3,1,1)$ & 84,404 & 83,652 & 83,652 & 83,652 & 82,703 & 82,813 & 72,191 & 72,191 & 70,028 & 68,302 \\
\hline & $x(4,3,1,1)$ & 483,658 & 473,040 & 471,933 & 471,933 & 440,687 & 437,538 & 425,618 & 470,455 & 534,403 & 593,712 \\
\hline & $x(5,3,1,1)$ & 16,555 & 29,079 & 29,079 & 29,079 & 62,210 & 64,939 & 108,047 & 108,047 & 52,421 & 0 \\
\hline & \begin{tabular}{|l|}
$x(1,3,1,2)$ \\
\end{tabular} & 0 & 0 & 0 & 0 & 0 & 0 & 0 & 0 & 17,428 & 31,862 \\
\hline & $x(2,3,1,2)$ & 44,837 & 44,837 & 44,837 & 44,837 & 44,837 & 44,837 & 44,837 & 44,837 & 44,837 & 44,837 \\
\hline & \begin{tabular}{|l|}
$x(3,3,1,2)$ \\
\end{tabular} & 84,404 & 83,652 & 83,652 & 83,652 & 82,703 & 82,813 & 72,191 & 72,191 & 70,028 & 68,302 \\
\hline & \begin{tabular}{|l|}
$x(4,3,1,2)$ \\
\end{tabular} & 612,016 & 602,104 & 599,891 & 599,891 & 569,052 & 565,858 & 556,962 & 556,962 & 604,388 & 650,022 \\
\hline & $x(5,3,1,2)$ & 16,555 & 29,079 & 29,079 & 29,079 & 62,210 & 64,939 & 108,047 & 108,047 & 52,421 & 0 \\
\hline & \begin{tabular}{|l|}
$x(1,3,1,3)$ \\
\end{tabular} & 0 & 0 & 0 & 55,319 & 55,319 & 55,319 & 55,319 & 55,319 & 55,319 & 55,319 \\
\hline & \begin{tabular}{|l|}
$x(2,3,1,3)$ \\
\end{tabular} & 44,837 & 44,837 & 44,837 & 44,837 & 44,837 & 44,837 & 44,837 & 44,837 & 44,837 & 44,837 \\
\hline & $x(3,3,1,3)$ & 84,404 & 83,652 & 83,652 & 83,652 & 82,703 & 82,813 & 72,191 & 72,191 & 70,028 & 68,302 \\
\hline & \begin{tabular}{|l|}
$x(4,3,1,3)$ \\
\end{tabular} & 736,967 & 723,176 & 667,857 & 667,857 & 633,170 & 630,855 & 556,962 & 556,962 & 604,388 & 650,022 \\
\hline & $x(5,3,1,3)$ & 33,779 & 50,896 & 102,896 & 47,577 & 84,976 & 86,774 & 198,308 & 198,308 & 161,135 & 124,009 \\
\hline & $x(1,3,2,1)$ & 0 & 0 & 0 & 0 & 46,862 & 43,984 & 0 & 0 & 0 & 0 \\
\hline & $x(2,3,2,1)$ & 44,837 & 44,837 & 44,837 & 44,837 & 44,837 & 44,837 & 44,837 & 44,837 & 44,837 & 44,837 \\
\hline & \begin{tabular}{|l|}
$x(3,3,2,1)$ \\
\end{tabular} & 84,404 & 83,652 & 83,652 & 83,652 & 82,703 & 82,813 & 105,334 & 105,334 & 111,305 & 116,405 \\
\hline & \begin{tabular}{|l|}
$x(4,3,2,1)$ \\
\end{tabular} & 642,848 & 644,376 & 644,376 & 644,376 & 600,967 & 603,513 & 614,355 & 614,355 & 601,618 & 590,323 \\
\hline & $x(5,3,2,1)$ & 0 & 0 & 0 & 0 & 0 & 0 & 0 & 0 & 0 & 0 \\
\hline
\end{tabular}




\begin{tabular}{|c|c|c|c|c|c|c|c|c|c|c|c|}
\hline \begin{tabular}{r|} 
Planning \\
Horizon
\end{tabular} & \begin{tabular}{|l|} 
Investment \\
Amount (\$)
\end{tabular} & \begin{tabular}{|l} 
Investment \\
Portfolio 1
\end{tabular} & \begin{tabular}{|c|} 
Investment \\
Portfolio 2 \\
\end{tabular} & \begin{tabular}{|l} 
Investment \\
Portfolio 3 \\
\end{tabular} & \begin{tabular}{|c|} 
Investment \\
Portfolio 4 \\
\end{tabular} & $\begin{array}{l}\text { Investment } \\
\text { Portfolio } 5\end{array}$ & \begin{tabular}{|c|} 
Investment \\
Portfolio 6 \\
\end{tabular} & \begin{tabular}{|l} 
Investment \\
Portfolio 7 \\
\end{tabular} & \begin{tabular}{|c|} 
Investment \\
Portfolio 8 \\
\end{tabular} & $\begin{array}{c}\text { Investment } \\
\text { Portfolio } 8 \\
\end{array}$ & \begin{tabular}{|l} 
Investment \\
Portfolio 8 \\
\end{tabular} \\
\hline \multirow{25}{*}{ 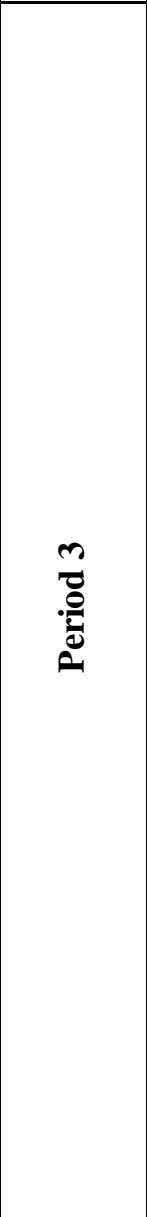 } & $x(1,3,2,2)$ & 0 & 45,443 & 45,443 & 45,443 & 96,833 & 99,303 & 55,319 & 55,319 & 55,319 & 55,319 \\
\hline & $x(2,3,2,2)$ & 44,837 & 44,837 & 44,837 & 44,837 & 44,837 & 44,837 & 44,837 & 44,837 & 44,837 & 44,837 \\
\hline & \begin{tabular}{|l|}
$x(3,3,2,2)$ \\
\end{tabular} & 84,404 & 83,652 & 83,652 & 83,652 & 82,703 & 82,813 & 105,334 & 105,334 & 111,305 & 116,405 \\
\hline & $x(4,3,2,2)$ & 781,580 & 736,895 & 736,895 & 736,895 & 686,994 & 684,375 & 614,355 & 614,355 & 601,618 & 590,323 \\
\hline & $x(5,3,2,2)$ & 0 & 0 & 0 & 0 & 0 & 0 & 83,833 & 83,833 & 86,687 & 89,374 \\
\hline & \begin{tabular}{|l|}
$x(1,3,2,3)$ \\
\end{tabular} & 12,012 & 55,319 & 55,319 & 55,319 & 102,181 & 99,303 & 55,319 & 55,319 & 55,319 & 55,319 \\
\hline & \begin{tabular}{|l|}
$x(2,3,2,3)$ \\
\end{tabular} & 44,837 & 44,837 & 44,837 & 44,837 & 44,837 & 44,837 & 44,837 & 44,837 & 44,837 & 44,837 \\
\hline & $x(3,3,2,3)$ & 218,076 & 218,076 & 218,076 & 218,076 & 218,076 & 218,076 & 218,076 & 218,076 & 218,076 & 218,076 \\
\hline & $x(4,3,2,3)$ & 781,580 & 736,895 & 736,895 & 736,895 & 686,994 & 684,375 & 614,355 & 614,355 & 601,618 & 590,323 \\
\hline & $x(5,3,2,3)$ & 0 & 0 & 0 & 0 & 0 & 5,790 & 118,405 & 118,405 & 133,532 & 147,229 \\
\hline & $x(1,3,3,1)$ & 0 & 0 & 0 & 0 & 38,827 & 41,561 & 525,534 & 525,534 & 525,534 & 525,534 \\
\hline & \begin{tabular}{|l|}
$x(2,3,3,1)$ \\
\end{tabular} & 44,837 & 44,837 & 44,837 & 44,837 & 44,837 & 44,837 & 44,837 & 10,375 & 0 & 0 \\
\hline & \begin{tabular}{|l|}
$x(3,3,3,1)$ \\
\end{tabular} & 84,404 & 83,652 & 83,652 & 83,652 & 82,703 & 82,813 & 105,334 & 105,334 & 111,305 & 116,405 \\
\hline & \begin{tabular}{|l|}
$x(4,3,3,1)$ \\
\end{tabular} & 642,848 & 644,376 & 644,376 & 644,376 & 611,357 & 608,727 & 113,416 & 147,878 & 146,761 & 135,710 \\
\hline & $x(5,3,3,1)$ & 0 & 0 & 0 & 0 & 0 & 0 & 0 & 0 & 0 & 0 \\
\hline & $x(1,3,3,2)$ & 0 & 45,443 & 45,443 & 45,443 & 94,146 & 96,880 & 580,853 & 580,853 & 580,853 & 580,853 \\
\hline & $x(2,3,3,2)$ & 44,837 & 44,837 & 44,837 & 44,837 & 44,837 & 44,837 & 44,837 & 44,837 & 44,837 & 44,837 \\
\hline & \begin{tabular}{|l|}
$x(3,3,3,2)$ \\
\end{tabular} & 84,404 & 83,652 & 83,652 & 83,652 & 82,703 & 82,813 & 116,226 & 116,226 & 111,305 & 116,405 \\
\hline & $x(4,3,3,2)$ & 781,580 & 736,895 & 736,895 & 736,895 & 686,994 & 684,375 & 147,878 & 147,878 & 149,492 & 141,002 \\
\hline & \begin{tabular}{|l|}
$x(5,3,3,2)$ \\
\end{tabular} & 0 & 0 & 0 & 0 & 0 & 0 & 0 & 0 & 0 & 0 \\
\hline & $x(1,3,3,3)$ & 12,012 & 55,319 & 55,319 & 55,319 & 94,146 & 96,880 & 580,853 & 580,853 & 580,853 & 580,853 \\
\hline & $x(2,3,3,3)$ & 44,837 & 44,837 & 44,837 & 44,837 & 44,837 & 44,837 & 44,837 & 44,837 & 44,837 & 44,837 \\
\hline & $x(3,3,3,3)$ & 218,076 & 218,076 & 218,076 & 218,076 & 218,076 & 218,076 & 218,076 & 218,076 & 218,076 & 218,076 \\
\hline & $x(4,3,3,3)$ & 781,580 & 736,895 & 736,895 & 736,895 & 686,994 & 684,375 & 147,878 & 147,878 & 149,492 & 141,002 \\
\hline & $x(5,3,3,3)$ & 0 & 0 & 0 & 0 & 0 & 0 & 0 & 0 & 0 & 10,740 \\
\hline
\end{tabular}




\begin{tabular}{|c|c|c|c|c|c|}
\hline \multicolumn{6}{|c|}{ Model 3 Investment Portfolios for $b=\$ 953,000$} \\
\hline $\begin{array}{l}\text { Planning } \\
\text { Horizon }\end{array}$ & $\begin{array}{l}\text { Investment } \\
\text { Amount (\$) }\end{array}$ & $\begin{array}{l}\text { Investment } \\
\text { Portfolio } 1\end{array}$ & $\begin{array}{l}\text { Investment } \\
\text { Portfolio } 2\end{array}$ & $\begin{array}{l}\text { Investment } \\
\text { Portfolio } 3\end{array}$ & $\begin{array}{l}\text { Investment } \\
\text { Portfolio } 4\end{array}$ \\
\hline \multirow{5}{*}{ ح" } & $x(1,1)$ & 0 & 0 & 0 & 0 \\
\hline & $x(2,1)$ & 0 & 0 & 0 & 0 \\
\hline & $x(3,1)$ & 218,076 & 218,076 & 218,076 & 218,076 \\
\hline & $x(4,1)$ & 197,567 & 197,567 & 206,469 & 206,469 \\
\hline & $x(5,1)$ & 537,357 & 537,357 & 528,455 & 528,455 \\
\hline \multirow{15}{*}{ 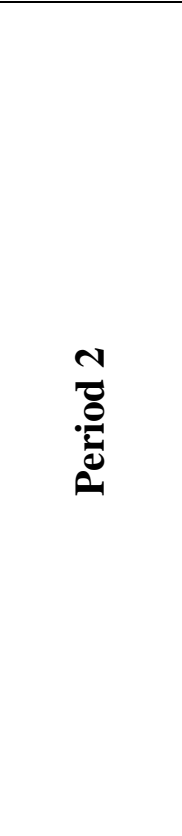 } & $x(1,2,1)$ & 519,530 & 519,530 & 519,263 & 519,263 \\
\hline & $x(2,2,1)$ & 28,137 & 28,137 & 28,137 & 28,137 \\
\hline & $x(3,2,1)$ & 218,076 & 218,076 & 218,076 & 218,076 \\
\hline & $x(4,2,1)$ & 0 & 0 & 0 & 0 \\
\hline & $x(5,2,1)$ & 0 & 0 & 0 & 0 \\
\hline & $x(1,2,2)$ & 580,853 & 525,534 & 525,534 & 525,534 \\
\hline & $x(2,2,2)$ & 28,137 & 28,137 & 28,137 & 28,137 \\
\hline & $x(3,2,2)$ & 218,076 & 218,076 & 218,076 & 218,076 \\
\hline & $x(4,2,2)$ & 22,048 & 77,367 & 77,545 & 77,545 \\
\hline & $x(5,2,2)$ & 0 & 0 & 0 & 0 \\
\hline & $x(1,2,3)$ & 49,317 & 49,317 & 25,460 & 25,460 \\
\hline & $x(2,2,3)$ & 0 & 0 & 0 & 0 \\
\hline & $x(3,2,3)$ & 218,076 & 218,076 & 218,076 & 218,076 \\
\hline & $x(4,2,3)$ & 652,923 & 652,923 & 668,946 & 668,946 \\
\hline & $x(5,2,3)$ & 0 & 0 & 8,902 & 8,902 \\
\hline
\end{tabular}




\begin{tabular}{|c|c|c|c|c|c|}
\hline $\begin{array}{l}\text { Planning } \\
\text { Horizon }\end{array}$ & $\begin{array}{l}\text { Investment } \\
\text { Amount (\$) }\end{array}$ & $\begin{array}{l}\text { Investment } \\
\text { Portfolio } 1\end{array}$ & $\begin{array}{l}\text { Investment } \\
\text { Portfolio } 2\end{array}$ & $\begin{array}{l}\text { Investment } \\
\text { Portfolio } 3\end{array}$ & $\begin{array}{l}\text { Investment } \\
\text { Portfolio } 4\end{array}$ \\
\hline \multirow{20}{*}{ 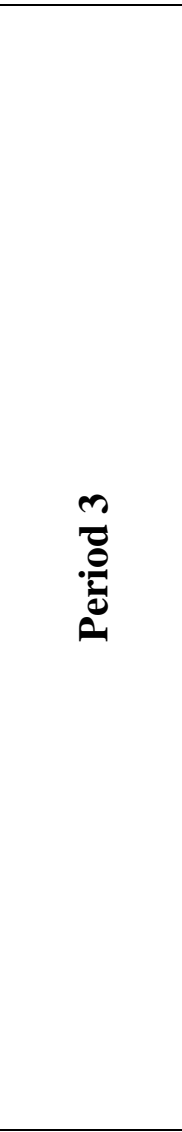 } & $x(1,3,1,1)$ & 6,004 & 6,004 & 6,271 & 6,271 \\
\hline & $x(2,3,1,1)$ & 44,837 & 44,837 & 44,837 & 0 \\
\hline & $x(3,3,1,1)$ & 218,076 & 218,076 & 218,076 & 218,076 \\
\hline & $x(4,3,1,1)$ & 300,376 & 300,376 & 299,831 & 344,668 \\
\hline & $x(5,3,1,1)$ & 0 & 0 & 0 & 0 \\
\hline & $x(1,3,1,2)$ & 6,004 & 6,004 & 6,271 & 6,271 \\
\hline & $x(2,3,1,2)$ & 44,837 & 44,837 & 44,837 & 0 \\
\hline & $x(3,3,1,2)$ & 218,076 & 218,076 & 218,076 & 218,076 \\
\hline & $x(4,3,1,2)$ & 419,647 & 419,647 & 419,056 & 463,893 \\
\hline & $x(5,3,1,2)$ & 0 & 0 & 0 & 0 \\
\hline & $x(1,3,1,3)$ & 6,004 & 6,004 & 6,271 & 6,271 \\
\hline & $x(2,3,1,3)$ & 44,837 & 44,837 & 44,837 & 0 \\
\hline & $x(3,3,1,3)$ & 218,076 & 218,076 & 218,076 & 218,076 \\
\hline & $x(4,3,1,3)$ & 551,559 & 551,559 & 550,918 & 595,755 \\
\hline & $x(5,3,1,3)$ & 0 & 0 & 0 & 0 \\
\hline & $x(1,3,2,1)$ & 0 & 0 & 0 & 0 \\
\hline & $x(2,3,2,1)$ & 44,837 & 44,837 & 44,837 & 0 \\
\hline & $x(3,3,2,1)$ & 218,076 & 218,076 & 218,076 & 218,076 \\
\hline & $x(4,3,2,1)$ & 392,644 & 391,538 & 391,719 & 436,556 \\
\hline & $x(5,3,2,1)$ & 0 & 0 & 0 & 0 \\
\hline
\end{tabular}




\begin{tabular}{|c|c|c|c|c|c|}
\hline $\begin{array}{l}\text { Planning } \\
\text { Horizon }\end{array}$ & $\begin{array}{l}\text { Investment } \\
\text { Amount (\$) }\end{array}$ & $\begin{array}{l}\text { Investment } \\
\text { Portfolio } 1\end{array}$ & $\begin{array}{l}\text { Investment } \\
\text { Portfolio } 2\end{array}$ & $\begin{array}{c}\text { Investment } \\
\text { Portfolio } 3\end{array}$ & $\begin{array}{l}\text { Investment } \\
\text { Portfolio } 4\end{array}$ \\
\hline \multirow{25}{*}{$\begin{array}{l}n \\
0 \\
0 \\
0\end{array}$} & $x(1,3,2,2)$ & 0 & 0 & 0 & 0 \\
\hline & $x(2,3,2,2)$ & 44,837 & 44,837 & 44,837 & 0 \\
\hline & $x(3,3,2,2)$ & 218,076 & 218,076 & 218,076 & 218,076 \\
\hline & $x(4,3,2,2)$ & 525,647 & 523,434 & 523,643 & 568,480 \\
\hline & $x(5,3,2,2)$ & 0 & 0 & 0 & 0 \\
\hline & $x(1,3,2,3)$ & 0 & 0 & 0 & 0 \\
\hline & $x(2,3,2,3)$ & 44,837 & 44,837 & 44,837 & 0 \\
\hline & $x(3,3,2,3)$ & 218,076 & 218,076 & 218,076 & 218,076 \\
\hline & $x(4,3,2,3)$ & 672,959 & 669,640 & 669,878 & 714,715 \\
\hline & $x(5,3,2,3)$ & 0 & 0 & 0 & 0 \\
\hline & $x(1,3,3,1)$ & 476,218 & 476,218 & 500,074 & 500,074 \\
\hline & $x(2,3,3,1)$ & 22,977 & 22,977 & 0 & 0 \\
\hline & $x(3,3,3,1)$ & 218,076 & 218,076 & 218,076 & 218,076 \\
\hline & $x(4,3,3,1)$ & 0 & 0 & 0 & 0 \\
\hline & $x(5,3,3,1)$ & 0 & 0 & 0 & 0 \\
\hline & $x(1,3,3,2)$ & 476,218 & 476,218 & 500,074 & 500,074 \\
\hline & $x(2,3,3,2)$ & 44,837 & 44,837 & 44,837 & 0 \\
\hline & $x(3,3,3,2)$ & 218,076 & 218,076 & 218,076 & 218,076 \\
\hline & $x(4,3,3,2)$ & 84,462 & 84,462 & 60,723 & 105,560 \\
\hline & $x(5,3,3,2)$ & 0 & 0 & 0 & 0 \\
\hline & $x(1,3,3,3)$ & 531,537 & 531,537 & 555,393 & 555,393 \\
\hline & $x(2,3,3,3)$ & 44,837 & 44,837 & 44,837 & 44,837 \\
\hline & $x(3,3,3,3)$ & 218,076 & 218,076 & 218,076 & 218,076 \\
\hline & $x(4,3,3,3)$ & 149,510 & 149,510 & 124,586 & 124,586 \\
\hline & $x(5,3,3,3)$ & 0 & 0 & 0 & 0 \\
\hline
\end{tabular}




\section{G.3 DETAILS OF MODEL 4 RESULTS}

\begin{tabular}{|c|c|c|c|c|c|c|c|c|c|c|c|}
\hline \multicolumn{12}{|c|}{ Model 4 Investment Portfolios for $b=\$ 500,000$} \\
\hline Planning & Investment & Investment & Investment & Investment & Investment & Investment & Investment & Investment & Investment & Investment & Inves tment \\
\hline Horizon & Amount (\$) & Portfolio 1 & Portfolio 2 & Portfolio 3 & Portfolio 4 & Portfolio 5 & Portfolio 6 & Portfolio 7 & Portfolio 8 & Portfolio 9 & Portfolio 10 \\
\hline \multirow{5}{*}{ 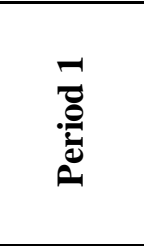 } & $x(1,1)$ & 0 & 0 & 0 & 0 & 30,045 & 367,023 & 446,333 & 446,333 & 446,333 & 446,333 \\
\hline & $x(2,1)$ & 53,667 & 53,667 & 53,667 & 53,667 & 53,667 & 53,667 & 53,667 & 53,667 & 53,667 & 53,667 \\
\hline & $x(3,1)$ & 446,333 & 446,333 & 446,333 & 446,333 & 416,288 & 79,310 & 0 & 0 & 0 & 0 \\
\hline & $x(4,1)$ & 0 & 0 & 0 & 0 & 0 & 0 & 0 & 0 & 0 & 0 \\
\hline & $x(5,1)$ & 0 & 0 & 0 & 0 & 0 & 0 & 0 & 0 & 0 & 0 \\
\hline \multirow{15}{*}{ 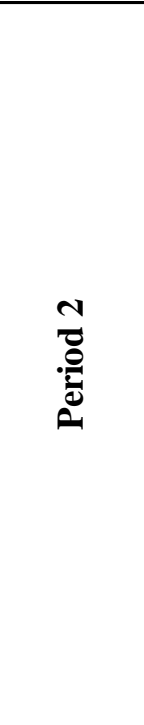 } & $x(1,2,1)$ & 495,790 & 495,790 & 495,790 & 495,790 & 495,489 & 158,511 & 79,201 & 79,201 & 79,201 & 79,201 \\
\hline & $x(2,2,1)$ & 28,137 & 28,137 & 28,137 & 28,137 & 28,137 & 28,137 & 28,137 & 28,137 & 28,137 & 28,137 \\
\hline & $x(3,2,1)$ & 0 & 0 & 0 & 0 & 0 & 0 & 0 & 0 & 0 & 0 \\
\hline & $x(4,2,1)$ & 0 & 0 & 0 & 0 & 0 & 333,608 & 412,125 & 412,125 & 412,125 & 412,125 \\
\hline & $x(5,2,1)$ & 0 & 0 & 0 & 0 & 0 & 0 & 0 & 0 & 0 & 0 \\
\hline & $x(1,2,2)$ & 525,534 & 525,534 & 525,534 & 525,534 & 495,489 & 158,511 & 79,201 & 79,201 & 79,201 & 79,201 \\
\hline & $x(2,2,2)$ & 28,137 & 28,137 & 28,137 & 28,137 & 28,137 & 28,137 & 28,137 & 28,137 & 28,137 & 28,137 \\
\hline & $x(3,2,2)$ & 96,239 & 96,239 & 96,239 & 0 & 0 & 0 & 0 & 0 & 0 & 0 \\
\hline & $x(4,2,2)$ & 0 & 0 & 0 & 96,239 & 126,585 & 466,933 & 547,036 & 547,036 & 547,036 & 547,036 \\
\hline & $x(5,2,2)$ & 0 & 0 & 0 & 0 & 0 & 0 & 0 & 0 & 0 & 0 \\
\hline & $x(1,2,3)$ & 580,853 & 525,534 & 525,534 & 525,534 & 495,489 & 158,511 & 79,201 & 134,520 & 134,520 & 134,520 \\
\hline & $x(2,2,3)$ & 28,137 & 28,137 & 28,137 & 28,137 & 28,137 & 28,137 & 28,137 & 28,137 & 28,137 & 28,137 \\
\hline & $x(3,2,3)$ & 263,355 & 276,121 & 232,391 & 232,391 & 299,036 & 292,503 & 264,540 & 55,363 & 55,363 & 29,871 \\
\hline & $x(4,2,3)$ & 0 & 0 & 284,242 & 284,242 & 229,615 & 370,939 & 430,626 & 584,484 & 584,484 & 609,976 \\
\hline & $x(5,2,3)$ & 197,959 & 240,512 & 0 & 0 & 0 & 0 & 0 & 0 & 0 & 0 \\
\hline
\end{tabular}




\begin{tabular}{|c|c|c|c|c|c|c|c|c|c|c|c|}
\hline $\begin{array}{r}\text { Planning } \\
\text { Horizon }\end{array}$ & $\begin{array}{l}\text { Investment } \\
\text { Amount (\$) }\end{array}$ & \begin{tabular}{|l} 
Investment \\
Portfolio 1 \\
\end{tabular} & \begin{tabular}{|c|} 
Investment \\
Portfolio 2 \\
\end{tabular} & \begin{tabular}{|l} 
Investment \\
Portfolio 3 \\
\end{tabular} & \begin{tabular}{|c|} 
Investment \\
Portfolio 4 \\
\end{tabular} & $\begin{array}{l}\text { Investment } \\
\text { Portfolio } 5 \\
\end{array}$ & \begin{tabular}{|c|} 
Investment \\
Portfolio 6 \\
\end{tabular} & \begin{tabular}{|l} 
Investment \\
Portfolio 7 \\
\end{tabular} & \begin{tabular}{|c|} 
Investment \\
Portfolio 8 \\
\end{tabular} & \begin{tabular}{|l} 
Investment \\
Portfolio 8 \\
\end{tabular} & \begin{tabular}{|l} 
Investment \\
Portfolio 8 \\
\end{tabular} \\
\hline \multirow{20}{*}{ 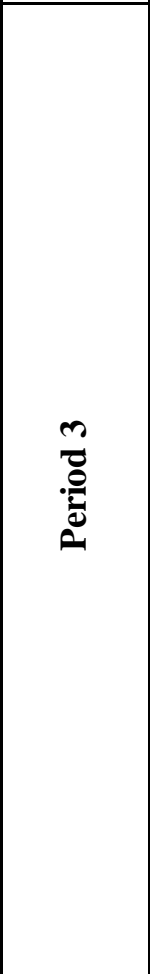 } & $x(1,3,1,1)$ & 29,744 & 29,744 & 29,744 & 29,744 & 0 & 0 & 0 & 0 & 0 & 0 \\
\hline & $x(2,3,1,1)$ & 44,837 & 44,837 & 44,837 & 44,837 & 44,837 & 44,837 & 44,837 & 44,837 & 0 & 0 \\
\hline & $x(3,3,1,1)$ & 107,187 & 107,187 & 0 & 0 & 0 & 0 & 0 & 0 & 0 & 0 \\
\hline & $x(4,3,1,1)$ & 0 & 0 & 107,187 & 107,187 & 136,619 & 126,442 & 124,047 & 124,047 & 168,884 & 168,884 \\
\hline & $x(5,3,1,1)$ & 362,834 & 362,834 & 362,834 & 362,834 & 362,834 & 362,834 & 362,834 & 362,834 & 362,834 & 362,834 \\
\hline & \begin{tabular}{|l|}
$x(1,3,1,2)$ \\
\end{tabular} & 29,744 & 29,744 & 29,744 & 29,744 & 0 & 0 & 0 & 0 & 0 & 0 \\
\hline & $x(2,3,1,2)$ & 44,837 & 44,837 & 44,837 & 44,837 & 44,837 & 44,837 & 44,837 & 44,837 & 0 & 0 \\
\hline & $x(3,3,1,2)$ & 222,422 & 222,422 & 0 & 0 & 0 & 0 & 0 & 0 & 0 & 0 \\
\hline & \begin{tabular}{|l|}
$x(4,3,1,2)$ \\
\end{tabular} & 0 & 0 & 222,422 & 222,422 & 251,803 & 234,381 & 230,281 & 230,281 & 275,118 & 275,118 \\
\hline & $x(5,3,1,2)$ & 362,834 & 362,834 & 362,834 & 362,834 & 362,834 & 362,834 & 362,834 & 362,834 & 362,834 & 362,834 \\
\hline & $x(1,3,1,3)$ & 29,744 & 29,744 & 29,744 & 29,744 & 0 & 0 & 0 & 0 & 0 & 0 \\
\hline & \begin{tabular}{|l|}
$x(2,3,1,3)$ \\
\end{tabular} & 44,837 & 44,837 & 44,837 & 44,837 & 44,837 & 44,837 & 44,837 & 44,837 & 0 & 0 \\
\hline & $x(3,3,1,3)$ & 349,824 & 349,824 & 0 & 0 & 0 & 0 & 0 & 0 & 0 & 0 \\
\hline & \begin{tabular}{|l|}
$x(4,3,1,3)$ \\
\end{tabular} & 0 & 0 & 349,824 & 349,824 & 379,147 & 354,413 & 348,592 & 348,592 & 393,429 & 393,429 \\
\hline & \begin{tabular}{|l|}
$x(5,3,1,3)$ \\
\end{tabular} & 362,834 & 362,834 & 362,834 & 362,834 & 362,834 & 362,834 & 362,834 & 362,834 & 362,834 & 362,834 \\
\hline & $x(1,3,2,1)$ & 0 & 0 & 0 & 0 & 0 & 0 & 0 & 0 & 0 & 0 \\
\hline & $x(2,3,2,1)$ & 44,837 & 44,837 & 44,837 & 44,837 & 44,837 & 44,837 & 44,837 & 44,837 & 0 & 0 \\
\hline & \begin{tabular}{|l|}
$x(3,3,2,1)$ \\
\end{tabular} & 268,917 & 268,917 & 0 & 0 & 0 & 0 & 0 & 0 & 0 & 0 \\
\hline & \begin{tabular}{|l|}
$x(4,3,2,1)$ \\
\end{tabular} & 0 & 0 & 268,917 & 266,030 & 265,735 & 262,433 & 261,656 & 261,656 & 306,493 & 306,493 \\
\hline & $x(5,3,2,1)$ & 362,834 & 362,834 & 362,834 & 362,834 & 362,834 & 362,834 & 362,834 & 362,834 & 362,834 & 362,834 \\
\hline
\end{tabular}




\begin{tabular}{|c|c|c|c|c|c|c|c|c|c|c|c|}
\hline $\begin{array}{c}\text { Planning } \\
\text { Horizon } \\
\end{array}$ & \begin{tabular}{|l|} 
Investment \\
Amount (\$) \\
\end{tabular} & \begin{tabular}{|c|} 
Investment \\
Portfolio 1 \\
\end{tabular} & \begin{tabular}{|c|} 
Investment \\
Portfolio 2 \\
\end{tabular} & \begin{tabular}{|c|} 
Investment \\
Portfolio 3 \\
\end{tabular} & \begin{tabular}{|c|} 
Investment \\
Portfolio 4 \\
\end{tabular} & \begin{tabular}{|c|} 
Investment \\
Portfolio 5 \\
\end{tabular} & \begin{tabular}{|c|} 
Investment \\
Portfolio 6 \\
\end{tabular} & \begin{tabular}{|c|} 
Investment \\
Portfolio 7 \\
\end{tabular} & \begin{tabular}{|c|} 
Investment \\
Portfolio 8 \\
\end{tabular} & \begin{tabular}{|c|} 
Investment \\
Portfolio 8 \\
\end{tabular} & \begin{tabular}{|c|} 
Investment \\
Portfolio 8 \\
\end{tabular} \\
\hline \multirow{25}{*}{ 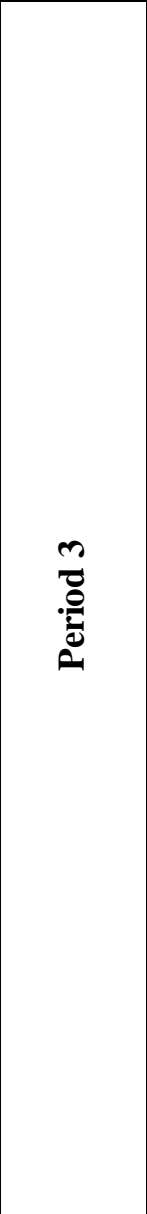 } & $x(1,3,2,2)$ & 0 & 0 & 0 & 0 & 0 & 0 & 0 & 0 & 0 & 0 \\
\hline & $x(2,3,2,2)$ & 44,837 & 44,837 & 44,837 & 44,837 & 44,837 & 44,837 & 44,837 & 44,837 & 0 & 0 \\
\hline & $x(3,3,2,2)$ & 403,644 & 403,644 & 0 & 0 & 0 & 0 & 0 & 0 & 0 & 0 \\
\hline & $x(4,3,2,2)$ & 0 & 0 & 403,644 & 400,757 & 399,907 & 390,370 & 388,126 & 388,126 & 432,963 & 432,963 \\
\hline & $x(5,3,2,2)$ & 362,834 & 362,834 & 362,834 & 362,834 & 362,834 & 362,834 & 362,834 & 362,834 & 362,834 & 362,834 \\
\hline & $x(1,3,2,3)$ & 0 & 0 & 0 & 0 & 0 & 0 & 0 & 55,319 & 55,319 & 55,319 \\
\hline & \begin{tabular}{|l|}
$x(2,3,2,3)$ \\
\end{tabular} & 44,837 & 44,837 & 44,837 & 44,837 & 44,837 & 44,837 & 44,837 & 44,837 & 44,837 & 44,837 \\
\hline & \begin{tabular}{|l|}
$x(3,3,2,3)$ \\
\end{tabular} & 457,428 & 457,428 & 0 & 0 & 0 & 0 & 76,407 & 0 & 0 & 0 \\
\hline & \begin{tabular}{|l|}
$x(4,3,2,3)$ \\
\end{tabular} & 156,261 & 156,261 & 613,689 & 550,171 & 548,771 & 533,068 & 452,964 & 452,964 & 452,964 & 452,964 \\
\hline & $x(5,3,2,3)$ & 362,834 & 362,834 & 362,834 & 362,834 & 362,834 & 362,834 & 362,834 & 383,922 & 383,922 & 383,922 \\
\hline & $x(1,3,3,1)$ & 0 & 0 & 0 & 0 & 0 & 0 & 0 & 0 & 0 & 0 \\
\hline & \begin{tabular}{|l|}
$x(2,3,3,1)$ \\
\end{tabular} & 44,837 & 44,837 & 44,837 & 44,837 & 44,837 & 44,837 & 44,837 & 44,837 & 44,837 & 44,837 \\
\hline & $x(3,3,3,1)$ & 290,312 & 277,546 & 0 & 0 & 0 & 0 & 0 & 0 & 0 & 0 \\
\hline & $x(4,3,3,1)$ & 617,424 & 673,296 & 701,803 & 701,803 & 684,814 & 471,648 & 420,685 & 415,516 & 415,516 & 390,024 \\
\hline & $x(5,3,3,1)$ & 164,875 & 122,322 & 362,834 & 362,834 & 362,834 & 362,834 & 362,834 & 362,834 & 362,834 & 387,561 \\
\hline & $x(1,3,3,2)$ & 0 & 0 & 0 & 0 & 0 & 0 & 0 & 0 & 0 & 0 \\
\hline & $x(2,3,3,2)$ & 44,837 & 44,837 & 44,837 & 44,837 & 44,837 & 44,837 & 44,837 & 44,837 & 44,837 & 44,837 \\
\hline & \begin{tabular}{|l|}
$x(3,3,3,2)$ \\
\end{tabular} & 290,312 & 277,546 & 183,831 & 183,831 & 108,910 & 0 & 0 & 0 & 0 & 0 \\
\hline & \begin{tabular}{|l|}
$x(4,3,3,2)$ \\
\end{tabular} & 806,418 & 859,056 & 715,759 & 715,759 & 770,385 & 629,061 & 569,374 & 415,516 & 415,516 & 390,024 \\
\hline & $x(5,3,3,2)$ & 164,875 & 122,322 & 362,834 & 362,834 & 362,834 & 362,834 & 362,834 & 512,630 & 512,630 & 537,357 \\
\hline & $x(1,3,3,3)$ & 0 & 55,319 & 55,319 & 55,319 & 55,319 & 0 & 0 & 0 & 0 & 0 \\
\hline & $x(2,3,3,3)$ & 44,837 & 44,837 & 44,837 & 44,837 & 44,837 & 44,837 & 44,837 & 44,837 & 44,837 & 44,837 \\
\hline & $x(3,3,3,3)$ & 290,312 & 277,546 & 321,276 & 321,276 & 284,676 & 360,381 & 333,089 & 177,686 & 177,686 & 186,353 \\
\hline & $x(4,3,3,3)$ & $1,000,000$ & $1,000,000$ & 715,759 & 715,759 & 770,385 & 629,061 & 569,374 & 415,516 & 415,516 & 390,024 \\
\hline & $x(5,3,3,3)$ & 339,398 & 296,845 & 537,357 & 537,357 & 537,357 & 362,834 & 362,834 & 537,357 & 537,357 & 537,357 \\
\hline
\end{tabular}




\section{BIBLIOGRAPHY}

Anthony, R. N., Dearden J. and Bedford, N. M., "Management Control Systems," Prentice-Hall, Irwin, IL, 1984.

Arny, M., "The Economics of LEED for Existing Buildings - For Individual Buildings," Leonardo Academy, Inc., April, 2008 (http://www.leonardoacademy.org/download/ Economics\%20of\%20LEED-EB\%2020090222.pdf, Accessed on May 07, 2009).

Aschenbrennerová, H., "Small and Medium Sized Industrial Company Performance Measurement and Management Concept," Proc. of the 4th Conference on Performance Measurement and Management Control, Nice, France, September 26-28, 2007.

Athena Institute, "Applying Life Cycle Costing (LCC) to Roofing Investments: A Guide to Using Green Roofs for Healthy Cities GreenSave Calculator," April, 2007 (http://commons.bcit.ca/greenroof/download/calculator_guide.pdf, Accessed on May 04, 2009).

Atkinson, G. "Measuring Corporate Sustainability," Journal of Environmental Planning and Management, Vol. 43, Issue 2, pp. 235-252, 2000.

AT\&T Inc. (http://www.att.com/gen/landing-pages?pid=3309, Accessed on May 4, 2008).

Baxter International Inc. (http://www.baxter.com, Accessed on May 4, 2008).

Beale, E. M. L., “On Minimizing a Convex Function Subject to Linear Inequalities,” Journal of the Royal Statistical Society, Series B 17, pp. 173-184, 1955.

Berkshire, M., "Green Roof Fact Sheet,” (http://www.revisionarch.com/Library.php, Accessed on May 04, 2009).

Birge, J. R., “Introduction to Stochastic Programming," Springer-Verlag, New York, 1997.

Bittker, B.,I., and Lokken, L., "Fundamentals of International Taxation," Warren, Gorham and Lamont, Boston, MA, 1991. 
Black and Veatch Corporation, "Survey: Electric Service Reliability Top Concern," 2006 (http://www.bv.com/wcm/press_release/11062006_7701.aspx, Accessed on January 16, 2008).

Boodram, K., Hamilton, S., Kheidr, J., McKinnon, A., and Walker, K., "An Extensive Green Roof for the ES2 Building," December, 2004 (http://www.watgreen. uwaterloo.ca/projects/library/f04greenroof2.pdf, Accessed on May 04, 2009).

Boston Metropolitan Area Planning Council (MAPC) "Massachusetts Low Impact Development Toolkit - Fact Sheet \#4: Green Roofs," 2005 (http://www.mapc.org /regionalplanning/LID/PDFs/greenroof.pdf, Accessed on June 18, 2009).

Branco, M. C. and Rodrigues, L. L., "Positioning Stakeholder Theory within the Debate on Corporate Social Responsibility," EJBO Electronic Journal of Business Ethics and Organization Studies, Vol. 12, Issue 1, 2007.

Bristol-Myers Squibb Company (http://www.bms.com/sr/data, Accessed on May 4, 2008).

British Telecom (http://www.bt.com, Accessed on May 4, 2008).

Building Owners and Managers Association (BOMA) International, "Experience Exchange Report," 2007.

Bukowitz, W. R. and Petrash, G. P., "Visualizing, Measuring and Managing Knowledge," Research and Technology Management, Vol. 40, Issue 4, pp. 24-31, 1997.

Cheng, E.W.L., and Li H., "Analytic Network Process Applied to Project Selection,” Journal of Construction Engineering and Management, 131(4), 459-466, 2005.

Clarkson, M. B. E., "A Stakeholder Framework for Analyzing and Evaluating Corporate Social Performance," Academy Management Review, Vol. 20, Issue 1, pp. 92-117, 1995.

Dantzig, G. B., "Linear Programming Under Uncertainty," Management Science, Vol. 1, pp. 197-206, 1955.

Dikmen, I., Birgonul, M.T., and Ozorhon, B., 2007, "Project Appraisal and Selection Using the Analytic Network Process," Canadian Journal of Civil Engineering, 34(7), 786-792, 2007.

Dinsdale, S., Pearen, B., and Wilson, C., "Feasibility Study for Green Roof Application on Queen's University Campus,” April, 2006 (http://www.queensu.ca/pps/reports/ greenroof.pdf, Accessed on May 04, 2009).

Dyllick, T. and Hockerts, K., "Beyond the Business Case for Corporate Sustainability," Business Strategy and the Environment, Vol. 11, pp. 130-141, 2002. 
Dow Jones Sustainability Indexes (http://www.sustainability-index.com, Accessed on May 4, 2008).

Eccles, R. G., "The Performance Measurement Manifesto," Harvard Business Review, pp. 131137, 1991.

Elkington, J., "Cannibals with Forks: The Triple Bottom Line of $21^{\text {st }}$ Century Business," Capstone Publishing, Oxford, UK, 1997.

Energy Information Administration (http://www.eia.doe.gov/, Accessed on August 16, 2009).

Epstein, M. J., Roy, M. J., "Sustainability in Action: Identifying and Measuring the Key Performance Drivers," Long Range Planning, Vol. 34, pp. 585-604, 2001.

Expert Choice Software for Decision-Making (http://www.expertchoice.com/, Accessed on January 16, 2008).

Figge, F., Hahn, T., Schaltegger, S. and Wagner, M., “The Sustainability Balanced Scorecard Linking Sustainability Management to Business Strategy," Business Strategy and the Environment, Vol. 11, pp. 269-184, 2002.

Ford Motor Company (http://www.ford.com, Accessed on May 4, 2008).

Freeman, R. E., “Strategic Management: A Stakeholder Approach,” Pitman, Boston, MA, 1984.

Gass, S.I., "Model World: The Great Debate - MAUT versus AHP," Interfaces, 35(4), 308-312, 2005.

Gershman, Brickner \& Bratton, Inc., "Municipal Yard Waste Composting Reference Manual," October, 1991.

Ghoshal, S. and Bartlett, C. A., "The Individualized Corporation: A Fundamentally New Approach to Management," HarperBusiness, New York, 1999.

Goodwin, P., and Wright, G., "Decision Analysis for Management Judgment", $3{ }^{\text {rd }}$ Edition, John Wiley \& Sons, Ltd, West Sussex, UK, 2004.

Gordon, T. J., "The Delphi Method," AC/UNU Millennium Project, Futures Research Methodology, 1994.

Green Roofs for Healthy Cities (www.greenroofs.org, Accessed on May 04, 2009).

Helmer, O. and Rescher, N., "On the Epistemology of the Inexact Sciences," Management Science, Vol. 6, Issue 1, 1959. 
Hopwood, A. G., “Accounting and Human Behaviour,” Prentice-Hall, New Jersey, 1973.

http://fueleconomy.gov/ (Accessed on May 15, 2009).

http://www.nadaguides.com/ (Accessed on May 15, 2009).

http://www.twp.cranberry.pa.us/ (Accessed on September 28, 2009).

ILOG, Cplex 9.0 Documentation - IloCplex User Manual (http://www.ilog.com, Accessed on June 04, 2008).

Interface Inc., (http://www.interfaceinc.com, Accessed on May 4, 2008).

Ittner, C. D. and Larcker, D. F., "Innovations in Performance Measurement: Trends and Research Implications," Journal of Management Accounting Research, Vol. 10, pp. 20538, 1998.

Kaplan, R. S., and Norton, D. P. "The balanced scorecard - Measures that drive performance," Harvard Business Review, Vol. 70, Issue 1, pp. 71 -79, 1992.

Kosareo, L. and Ries, R., "Comparative Environmental Life Cycle Assessment of Green Roofs," Building and Environment, Vol. 42, No. 7, 2007, pp. 2606-2613.

Kula, R., "Green Roofs and Maximizing Credits under the LEED - Green Building System," The Green Roof Infrastructure Monitor, 2005.

Langer, M. E. and Schön A., "Enhancing Corporate Sustainability: A Framework Based Evaluation Tool for Sustainable Development," research paper series of the Research Focus - Managing Sustainability, Vienna University of Economics and Business Administration, April, 2003.

Lavelle, M., "The 10 Biggest Carbon Dioxide Polluters," U.S. News, November 14, 2007.

Lee, J.W., and Kim S.H., "Using Analytic Network Process and Goal Programming for Interdependent Information System Project Selection," Computers and Operations Research, 27(4), 367-382, 2000.

Lev, B., "Intangibles: Management, Measurement, and Reporting," Brookings Institution Press, Washington D.C., 2001.

Linstone, H. A. and Turoff, M., "The Delphi Method: Techniques and Applications," Addison Wesley Publishing Company, Inc., MA, 1975. 
Liu, K., and Baskaran, B., "Thermal Performance of Green Roofs Through Field Evaluation", Proceedings of the First North American Green Roof Infrastructure Conference, Chicago, IL, May 29-30, 2003, pp. 1-10.

Lo, S. F. and Sheu, H. J., "Is Corporate Sustainability a Value-Increasing Strategy for Business," Corporate Governance, Vol. 15, Issue 2, March, 2007.

Macalister, T., "Protests Increase Over Shell Pipeline," Guardian, December 14, 2005 (http://www.guardian.co.uk, Accessed on May 4, 2008).

Madsen, H. and Ulhøi, J.P., "Integrating Environmental and Stakeholder Management," Business Strategy and the Environment, Vol. 10, pp. 77-78, 2001.

Maciariello, J. A. and Kirby, C. J., "Management Control Systems," Prentice-Hall, New Jersey, 1994.

McGhie, T., "Pipeline Protests Hit Shell," This Is Money - Associated Newspapers, July 3, 2005 (http://www.thisismoney.co.uk, Accessed on May 4, 2008).

Meade, L.M., and Presley, A., "R\&D Project Selection Using the Analytic Network Process," IEEE Transaction on Engineering Management, 49(1), 59-66, 2002.

Mehalik, M.M., Wozniak, G.A., Mazza, D., Reaves, R., Hockenberry, S.G., Gould, C., Hartman, P.G., Colosi, L., Grupp, D.R., and Casadei, C., "Sustainable Pittsburgh - Cranberry Township Sustainability Assessment," July, 2008 (http://www. cranberrytownship.org/Document View.asp?DID=671, Accessed on May 04, 2009).

Merchant, K. A., "Control in Business Organizations,” Pitman, Marshfield, MA, 1985.

Michael Baker Corporation, "Cranberry Area Transit Study," August, 2005 (http://www.spcregion.org/CATS/downloads/final_report.pdf, Accessed on June 08, 2009).

Mirvis, P.H., "The Triple Bottom Line: Catching a Wave," The Voice of Corporate Citizenship, 2007, (http://www.bcccc.net/index.cfm?fuseaction=page.viewPage\&Page ID=1506, Accessed on January 16, 2008).

Mohanty, R.P., Agarwal, R., Choudhury, A.K., and Tiwari, M.K., "A Fuzzy ANP-based Approach to R\&D Project Selection: A Case Study," International Journal of Production Research, 43(24), 5199-5216, 2005.

Nordhaus, W., "The Challenge of Global Warming: Economic Models and Environmental Policy,” July, 2007, (http://nordhaus.econ.yale.edu/dice_mss_072407_all.pdf, Accessed on March 1, 2008). 
Norman, W. and MacDonald, C., "Getting to the Bottom of "Triple Bottom Line"," Business Ethics Quarterly, Vol. 14, Issue 2, pp. 243-262, 2004.

North Carolina Division of Pollution Prevention and Environmental Assistance, "Waste Reduction Fact Sheet - Yard Waste Management," July, 1996 (http://www.p2pays.org/ref/01/00122.htm, Accessed on April 15, 2009).

Olson, D.L., Moshkovich, H.M., Schellenberger, R., and Mechitov, A.I., "Consistency and Accuracy in Decision Aids: Experiments with Four Multiattribute Systems," Decision Sciences, 26(6), 723-748, 1995.

Paladino \& Company, Inc., "Green Roof Feasibility Review - King County Office Project," March, $2004 \quad$ (http://your.kingcounty.gov/solidwaste/greenbuilding/documents /KCGreenRoofStudy_ Final.pdf, Accessed on May 04, 2009).

Parker, L. D., "Divisional Performance Measurement: Beyond an Exclusive Profit Test," Accounting and Business Research, Vol. 9, Issue 36, pp. 309-319, 1979.

Pennsylvania Department of Environmental Protection (DEP), "Compost Site Feasibility and Design,” $\quad 2005 \quad$ August, $\quad 2$ http://www.dep.state.pa.us/dep/DEPUTATE /AIRWASTE/WM/recycle/Tech_Rpts/Lebanon_328_329.pdf, Accessed on April 15, 2009).

Pennsylvania Department of Environmental Protection (DEP), "Development of a MultiMunicipal Yard Waste Composting Facility - Luzerne County," January, 2002 (http://www.dep.state.pa.us/dep/deputate/airwaste/wm/recycle/tech_rpts/Fairview.pdf, Accessed on April 15, 2009).

Pennsylvania Department of Environmental Protection (DEP), "Guidelines for Yard Waste Composting Facilities,” January, 2009 (http://www.depweb.state.pa.us/landrecwaste/cwp/ view.asp? $a=1338 \& q=469423$, Accessed on April 15, 2009).

Pennsylvania Department of Environmental Protection (DEP), "Municipal Yard Waste Composting Facility - Operator's Reference Guide and Handbook," January, 1999 (http://www.dep.state.pa.us/dep/deputate/airwaste/wm/recycle/Tech_Rpts/Cumberland.p df, Accessed on April 15, 2009).

Pennsylvania Department of Environmental Protection (DEP), "Yard Waste Facility in Pittsburgh," October, $1999 \quad$ (http://www.depweb.state.pa.us/landrecwaste/ lib/landrecwaste/ composting/Pittsburgh.pdf, Accessed on April 15, 2009).

Perrini, F. and Tencati A., "Sustainability and Stakeholder Management: The Need for New Corporate Performance Evaluation and Reporting Systems," Business Strategy and the Environment, Vol. 15, pp. 296-308, 2006. 
Plinke, E., "Share Performance and Sustainability: Does Environmental and Social Performance Have any Influence on Share Performance?, Bank Sarasin \& Co. Ltd - Sarasin Sustainable Investment Publications, 2002, (http://www.sarasin.ch/internet/ iech/en/studiesi_performance_iech.pdf, Accessed on January 16, 2008).

Savitz, A.W., Besly, M. and Booth, K., "2002 Sustainability Survey Report," PriceWaterhouseCoopers LLP, 2002, (http://www.pwc.com/fas/pdfs/sustainability\%20 survey\%20report.pdf, Accessed on January 16, 2008).

Saaty, T. L., Decision Making for Leaders: The Analytic Hierarchy Process for Decisions in a Complex World, $3^{\text {rd }}$ Edition, RWS Publications, Pittsburgh, Pennsylvania, 1995.

Saaty, T. L., Decision Making with Dependence and Feedback: The Analytic Network Process, $2^{\text {nd }}$ Edition, RWS Publications, Pittsburgh, Pennsylvania, 2001.

Saaty, T. L., "How to Make a Decision: The Analytic Hierarchy Process," Interfaces, Vol. 24, Issue 6, pp. 19-43, 1994.

Saaty, T., L., "The Analytic Hierarchy Process: Planning, Setting Priorities, Resource Allocation," McGraw-Hill International Book Co., New York, 1980.

Saaty, T. L., "Theory and Applications of the Analytic Network Process," RWS Publications, Pittsburgh, 2005.

Sakhalinsk, Y., "Sakhalin Indigenous People Blockade Oil Development," Environment News Service, June 30, 2005 (http://www.ens-newswire.com/ens/jun2005/2005-06-30-02.asp, Accessed on June 4, 2008).

Schoenfeld, H. M. and Holzer, H. P., "Managerial Accounting and Analysis in Multinational Enterprises," Walter de Gruyter, Berlin, 1986.

Shell Group (http://www.shell.com, Accessed on May 4, 2008).

Sherman, C.R., "When are Alternative Fuel Vehicles a Cost-Effective Option for Local Governments," 2007.

Stern, N., "The Economics of Climate Change: The Stern Review," Cambridge University Press, Cambridge, UK, 2007.

Super Decisions Software for Decision-Making (http://www.superdecisions.com/, Accessed on January 16, 2008).

The Cooperative Bank, "The Partnership Report 2001," 2001, (http://www.cooperativebank.co.uk/partnership2001/pr/index.html, Accessed on March 1, 2008). 
The Dow Chemical Company (http://www.dow.com, Accessed on May 4, 2008).

Thor, C. G., "Using A Family of Measures to Assess Organizational Performance," National Productivity Review, Vol. 14, Issue 3, pp. 111-131, 1995.

Tobin, J., "A general equilibrium approach to monetary theory," Journal of Money Credit and Banking, Vol. 1, Issue 1, pp. 15-29, 1969.

Unilever (http://www.unilever.com, Accessed on May 4, 2008).

United States Census Bureau (www.census.gov).

United States Department of Energy, "Workforce Trends in the Electric Utility Industry: A Report to the United States Congress Pursuant to Section 1101 of the Energy Policy Act of 2005," 2006, (http://www.oe.energy.gov/DocumentsandMedia/Workforce_Trends _Report_090706_FINAL.pdf, Accessed on January 16, 2008).

United States Department of Treasury, Internal Revenue Services (IRS) (www.irs.gov).

United States Environmental Protection Agency, "EPA's Green Power Partnership - Partnership Requirements," (http://www.epa.gov/grnpower/documents/gpp_partnership_ reqs.pdf, Accessed on June 10, 2009).

Unites States Green Building Council (http://www.usgbc.org, Accessed on May 04, 2009).

Verschoor, C. C., "Is BP an Acronym for "Big Polluter"?," Strategic Finance - Ethics Column, September, 2007.

Weston Solutions, Inc. (www.greengridroofs.com, Accessed on May 04, 2009).

White, J.,A., Case, K.,E., Pratt, D.,B. and Agee, M.,H., "Principles of Engineering Economic Analysis," John Wiley and Sons, Inc., New York, NY, $4^{\text {th }}$ Edition, 1998.

Wills, R., "Municipalities Strive to Keep Yard Debris out of Landfills," Pittsburgh TribuneReview, September 11, 2008.

Wilson, M., "Corporate Sustainability: What Is It and Where Does It Come From?," Ivey Business Journal, March/April, 2003.

Wang, L. and Lin, L., "A Methodological Framework for the Triple Bottom Line Accounting and Management of Industry Enterprises," International Journal of Production Research, Vol. 45, Issue 5, pp. 1063-1088, 2007.

World Commission on Environment and Development, "Our Common Future," Oxford University Press, Oxford, UK, 1987. 